Argonne

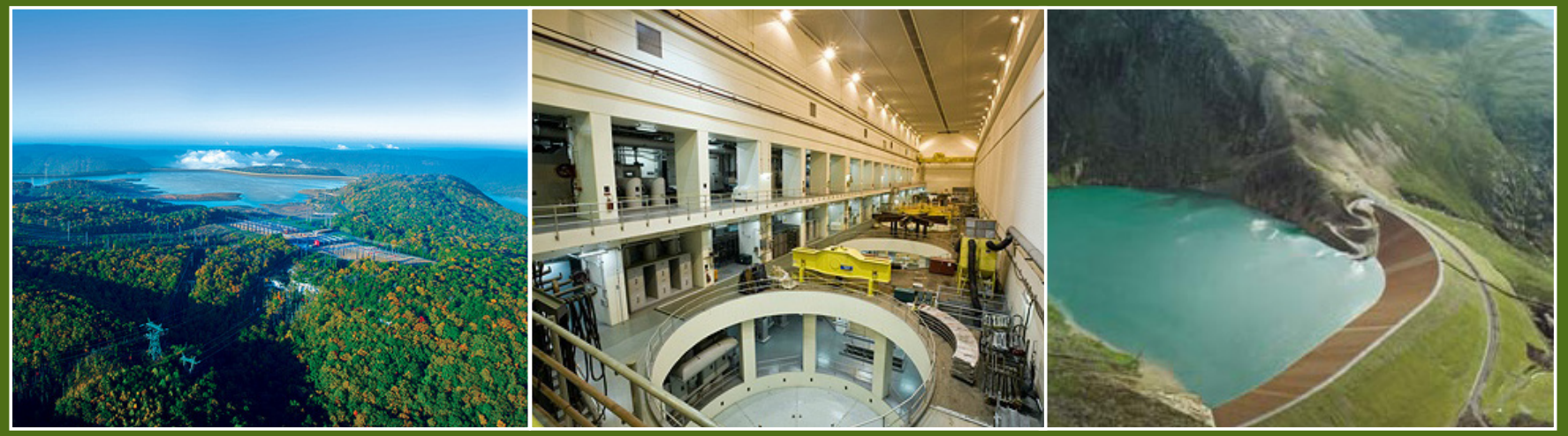

\title{
Testing Dynamic Simulation Models for Different Types of Advanced Pumped Storage Hydro Units
}

Decision and Information Sciences 


\begin{abstract}
About Argonne National Laboratory
Argonne is a U.S. Department of Energy laboratory managed by UChicago Argonne, LLC under contract DE-AC02-06CH11357. The Laboratory's main facility is outside Chicago, at 9700 South Cass Avenue, Argonne, Illinois 60439. For information about Argonne and its pioneering science and technology programs, see www.anl.gov.
\end{abstract}

\title{
Availability of This Report
}

This report is available, at no cost, at http://www.osti.gov/bridge. It is also available on paper to the U.S. Department of Energy and its contractors, for a processing fee, from:

U.S. Department of Energy

Office of Scientific and Technical Information

P.O. Box 62

Oak Ridge, TN 37831-0062

phone (865) 576-8401

fax (865) 576-5728

reports@adonis.osti.gov

\section{Disclaimer}

This report was prepared as an account of work sponsored by an agency of the United States Government. Neither the United States Government nor any agency thereof, nor UChicago Argonne, LLC, nor any of their employees or officers, makes any warranty, express or implied, or assumes any legal liability or responsibility for the accuracy, completeness, or usefulness of any information, apparatus, product, or process disclosed, or represents that its use would not infringe privately owned rights. Reference herein to any specific commercial product, process, or service by trade name, trademark, manufacturer, or otherwise, does not necessarily constitute or imply its endorsement, recommendation, or favoring by the United States Government or any agency thereof. The views and opinions of document authors expressed herein do not necessarily state or reflect those of the United States Government or any agency thereof, Argonne National Laboratory, or UChicago Argonne, LLC.

This report is being disseminated by the Department of Energy. As such, this document was prepared in compliance with Section 515 of the Treasury and General Government Appropriations Act for Fiscal Year 2001 (Public Law 106-554) and Information Quality Guidelines issued by the Department of Energy. Although this report does not constitute "influential" information, as that term is defined in DOE's Information Quality Guidelines or the Office of Management and Budget's Information Quality Bulletin for Peer Review, the study was reviewed both internally and externally prior to publication. For purposes of external review, the study benefited from the advice and comments of an advisory working group consisting of more than 30 experts from the industry, government, and research institutions. 


\section{Testing Dynamic Simulation Models for Different Types of Advanced Pumped Storage Hydro Units}

prepared for

U.S. Department of Energy - Wind and Water Power Technologies Office

prepared by

Vladimir Koritarov

Decision and Information Sciences, Argonne National Laboratory

James Feltes, Yuriy Kazachkov and Bo Gong

Siemens PTI

Peter Donalek

MWH Americas

Vahan Gevorgian

National Renewable Energy Laboratory

August 2013 
This page intentionally left blank. 


\section{Preface}

This report is one of several reports developed during the U.S. Department of Energy (DOE) study on the Modeling and Analysis of Value of Advanced Pumped Storage Hydropower in the United States. The study was led by Argonne National Laboratory in collaboration with Siemens PTI, Energy Exemplar, MWH Americas, and the National Renewable Energy Laboratory. Funding for the study was provided by DOE's Office of Energy Efficiency and Renewable Energy (EERE) through a program managed by the EERE's Wind and Water Power Technologies Office (WWPTO).

The scope of work for the study has two main components: (1) development of vendorneutral dynamic simulation models for advanced pumped storage hydro (PSH) technologies, and (2) production cost and revenue analyses to assess the value of PSH in the power system. Throughout the study, the project team was supported and guided by an Advisory Working Group (AWG) consisting of more than thirty experts from a diverse group of organizations including the hydropower industry and equipment manufacturers, electric power utilities and regional electricity market operators, hydro engineering and consulting companies, national laboratories, universities and research institutions, hydropower industry associations, and government and regulatory agencies.

The development of vendor-neutral models was carried out by the Advanced Technology Modeling Task Force Group (TFG) and was led by experts from Siemens PTI with the participation of experts from other project team members. First, the Advanced Technology Modeling TFG reviewed and prepared a summary of the existing dynamic models of hydro and PSH plants that are currently in use in the United States. This is published in the report Review of Existing Hydroelectric Turbine-Governor Simulation Models. The review served to determine the needs for improving existing models and developing new ones.

While it was found that the existing dynamic models for conventional hydro and PSH plants allow for accurate representation and modeling of these technologies, it was concluded that there is a need for the development of dynamic models for two PSH technologies for which there were no existing models available in the United States at the time of the study. Those two technologies are (1) adjustable speed PSH plants employing doubly fed induction machines (DFIM) and (2) ternary PSH units. The Advanced Technology Modeling TFG developed vendor-neutral models of these two PSH technologies, which are published in two reports: (1) Modeling Adjustable Speed Pumped Storage Hydro Units Employing Doubly-Fed Induction Machines and (2) Modeling Ternary Pumped Storage Units.

Extensive testing of newly developed models was performed using the Siemens PTI's standard test cases for the Power System Simulator for Engineering (PSS $\left.{ }^{\circledR} E\right)$ model as well as the Western Electricity Coordinating Council's (WECC's) modeling cases for Western Interconnection that were provided in $\mathrm{PSS}^{\circledR} \mathrm{E}$ format. The results of model testing are presented in the report Testing Dynamic Simulation Models for Different Types of Advanced Pumped Storage Hydro Units. 
In addition to review by the project team members and the DOE, all of these reports have been reviewed by members of the AWG, and their comments and suggestions have been incorporated into the final versions of the reports. Parts of these reports will also be included in the final report for the entire study to illustrate the model development component of the work. 


\section{Acknowledgments}

The authors would like to acknowledge the support and guidance provided to the project team by the staff and contractors of the U.S. Department of Energy Office of Energy Efficiency and Renewable Energy's (DOE/EERE's) Wind and Water Power Technologies Office (WWPTO), including Michael Reed, Rajesh Dham, Charlton Clark, Rob Hovsapian, Patrick O'Connor, Richard Gilker, and others. The authors are also grateful to the members of the Advisory Working Group for their excellent collaboration and efforts in advising the project team and guiding the study. The Advisory Working Group included a broad spectrum of global pumped storage hydropower specialists:

\begin{tabular}{|l|l|}
\hline $\begin{array}{l}\text { Rajesh Dham, Charlton Clark, Rob } \\
\text { Govsapian, Patrick O'Connor, Richard }\end{array}$ & $\begin{array}{l}\text { DOE/EERE - Wind and Water Power Technologies } \\
\text { Office (WWPTO) }\end{array}$ \\
\hline Rachna Handa & $\begin{array}{l}\text { DOE - Office of Electricity Delivery and Energy } \\
\text { Reliability (OE) }\end{array}$ \\
\hline Rahim Amerkhail & Federal Energy Regulatory Commission (FERC) \\
\hline Michael Manwaring, Douglas Divine & National Hydropower Association (NHA) \\
\hline Mark Jones, Elliot Mainzer & Bonneville Power Administration (BPA) \\
\hline Xiaobo Wang & California Independent System Operator (CAISO) \\
\hline Zheng Zhou & Midwest Independent System Operator (MISO) \\
\hline Matt Hunsaker & Western Electricity Coordinating Council (WECC) \\
\hline Tuan Bui & California Department of Water Resources (CDWR) \\
\hline David Harpman & Bureau of Reclamation (Reclamation) \\
\hline Kyle L. Jones & U.S. Army Corps of Engineers (USACE) \\
\hline Scott Flake, Greg Brownell & Sacramento Municipal Utility District (SMUD) \\
\hline Paul Jacobson, Stan Rosinski & Electric Power Research Institute (EPRI) \\
\hline Alan Soneda & Pacific Gas and Electric Co. (PG\&E) \\
\hline Osamu Nagura & Hitachi Mitsubishi Hydro \\
\hline Teruyuki Ishizuki & Toshiba Corp. \\
\hline Rick Miller. Rick Jones & HDR Engineering Inc. (HDR|DTA) \\
\hline Jiri Koutnik, Maximilian Manderla & Voith Hydro \\
\hline Christophe Nicolet & Power Vision Engineering (PVE) \\
\hline Peter McLaren & Center for Advanced Power System (CAPS) \\
\hline Landis Kannberg & Pacific Northwest National Laboratory (PNNL) \\
\hline Klaus Engels & E.ON Wasserkraft GmbH \\
\hline Kim Johnson & Riverbank Power \\
\hline Steve Aubert, Le Tang & ABB Switzerland Ltd. \\
\hline Ali Nourai & DNV KEMA \\
\hline & \\
\hline
\end{tabular}


This page intentionally left blank. 


\section{Contents}

Preface. . i

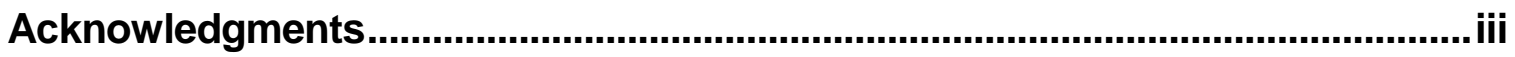

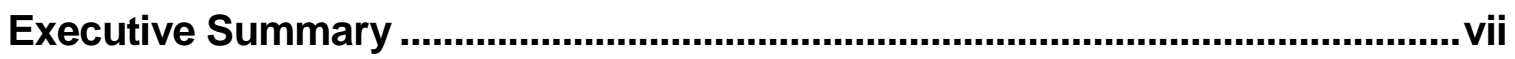

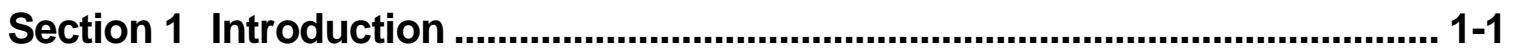

Section 2 Adjustable Speed Pumped Storage Hydro Turbine Employing a Doubly Fed Induction Machine ................................... 2-1

2.1 Description of the Test System .....................................................................

2.2 Testing the System with All Conventional Units ......................................2-4

2.3 Testing the Adjustable Speed Pumped Storage Hydro Turbine Modeled as a Single Unit and Penstock ................................................2-9

2.4 Testing the Pumped Storage Hydro Turbine with Several Units Sharing the Same Penstock.

Section 3 Adjustable Speed Pumped Storage Hydro Pump Employing a Doubly Fed Induction Machine................................................... 3-1

3.1 Initialization of the Pump Model......................................................................

3.2 Testing the Pumped Storage Hydro Pump ………………………………….....

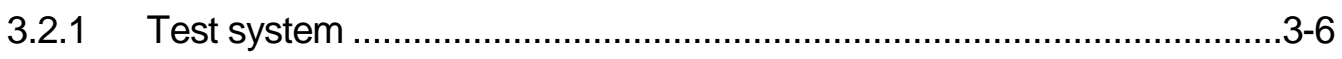

3.2.2 Test of the pumped storage hydro unit in pump mode.............................3-7

Section 4 Ternary Pumped Storage Hydro Unit................................................ 4-1

4.1 Tests of the Ternary Model in the Turbine Mode .............................................4-6

4.2 Tests of the Ternary Model in the Pump Mode .................................................4-9

4.3 Test in the Mixed Mode .......................................................................... $4-12$

Section 5 Testing the Fast Frequency Control Ability of the AS PSH............ 5-1

Section 6 Testing the Models for the Western Interconnection ...................... 6-1

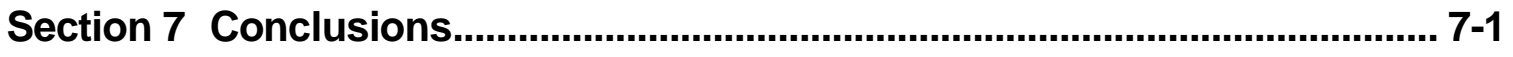

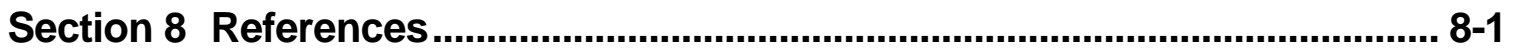

Appendix A PSS ${ }^{\circledR}$ E Load Flow Raw Data Files ............................................

A.1 $P S S^{\oplus} E$ Raw Data File for the Test System with the Single PSH Turbine............ A-2

A.2 PSS ${ }^{\oplus}$ E Raw Data File for the Test System with the Single PSH Pump............... A-4 
A.3 PSS ${ }^{\circledR} E$ Raw Data File for the Test System with Four PSH Turbines.................. A-6

\section{Appendix B PSS ${ }^{\circledR}$ E Dynamic Data Documentation .......................................... B-1}

B.1 Dynamic Data for the System with All Conventional Units ................................ B-2

B.2 Dynamic Data for the PSH Turbine .........................................................

B.3 Dynamic Data for four PSH Turbines Sharing the Same Penstock ..................... B-6

B.4 Dynamic Data for the System with the PSH Pump ....................................... B-11

B.5 Dynamic Data for the System with the Ternary Turbine ................................. B-13

B.6 Dynamic Data for the System with the Ternary Pump ................................... B-15

B.7 Dynamic Data for the System with the Ternary Unit Operating in the Hydraulic Short-Circuit Mode................................................................. B-17

B.8 Dynamic Data for Castaic PSH Plant in WECC for Conventional Units ............. B-19

B.9 Dynamic Data for Helms PSH Plant in WECC for Conventional Units .............. B-20

B.10 Dynamic Data for Cabin Creek PSH Plant in WECC for Conventional

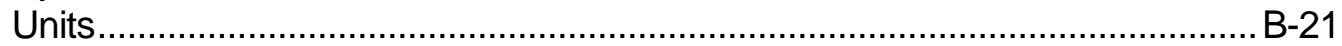

B.11 Dynamic Data for San Luis PSH Plant in WECC for Conventional Units .......... B-22

B.12 Dynamic Data for E.G. Hyatt Conventional Units...................................... B-23

B.13 Dynamic Data for Mt. Elbert Conventional Units ........................................ B-24

B.14 Dynamic Data for Castaic AS PSH Turbine ................................................. B-25

B.15 Dynamic Data for Helms AS PSH Turbine ................................................ B-26

B.16 Dynamic Data for Cabin Creek AS PSH Turbine ........................................ B-27

B.17 Dynamic Data for San Luis AS PSH Turbine .............................................. B-28

B.18 Dynamic Data for Hyatt AS PSH Turbine ............................................... B-29

B.19 Dynamic Data for Mt. Elbert AS PSH Turbine ............................................... B-30 


\section{Executive Summary}

A major task of the U.S. Department of Energy (DOE)-sponsored project "Modeling and Analysis of Value of Advanced Pumped Storage Hydropower in the U.S." was to develop new dynamic simulation models to represent advanced pumped storage hydro (PSH) technologies. This report describes the testing that was performed to demonstrate the performance of these simulation models and illustrates how these models can now be used in analyses required for investigations into applications of these technologies.

The following new dynamic simulation models have been developed:

1. A model of an adjustable speed pumped storage hydro (AS PSH) unit employing a doubly fed induction machine and operating as a turbine.

2. A model of an AS PSH unit operating as a pump.

3. A combined model of a ternary PSH unit that can be used for simulation of any of three modes of operation of this type of unit, namely:

- As a conventional hydro turbine

- As a conventional hydro pump

- As a ternary unit operating in the hydraulic short-circuit mode.

Earlier reports described the performance of these technologies, the approach to their modeling, and details of the models' designs. The purpose of this report is to describe the testing of the newly developed models. Tests were performed using three test systems.

A small 12-bus sample test system was used to make sure that models showed adequate performance responding to different disturbances such as under-frequency and overfrequency events caused by loss of generation or load, and three-phase and single-line-toground faults in the vicinity of the plant under study. This test system allowed for variation in the level of penetration of the advanced technology. The following types of pumped storage hydro units were tested:

- Conventional turbines, to have a basis for comparison

- Conventional pumps, to have a basis for comparison

- $\quad$ AS PSH turbine

- Up to four AS PSH turbines sharing a common penstock

- $\quad$ AS PSH pump

- Up to four AS PSH pumps sharing a common penstock 
- Ternary unit in the pump mode of operation

- Ternary unit in the turbine mode of operation

- Ternary unit in the hydraulic short-circuit mode of operation.

Simulations were performed to test transient stability response and voltage control/reactive power control capabilities, and to demonstrate fast frequency regulation for events involving loss of generation or other events that result in an imbalance between system load and generation. These tests ensured that the newly developed models can be used to simulate the PSH unit's response to different disturbances and to demonstrate the potential for fast frequency control of the AS PSH units.

A second series of tests was performed using another small sample test system to demonstrate the potential benefits of the faster frequency control capability of the AS PSH technology.

The use of the models as part of a large U.S. system was demonstrated through tests performed using the Western Interconnection (WI) power system that has about $190 \mathrm{GW}$ of generation capacity. Power system data for modeling of the WI were obtained from the Western Electricity Coordinating Council (WECC). Six existing pumped storage hydro plants, totaling about 3,200 MW of installed capacity, were simulated using the newly developed models as well as their original conventional PSH models. The response of these units (and of the system with these units) was simulated for a wide variety of typical disturbances, including the response to changes in the power generated by renewable energy sources. These tests ensured that the newly developed models could be used for practical analyses of real systems.

Thus, the tests demonstrated that the new models performed well and can be used for the typical dynamic simulation analyses required by planning and interconnection studies. The tests also demonstrated the new capabilities available in these models (e.g., the use of an adjustable speed pumped storage plant to provide regulation services in pump mode). The tests showed the improved capabilities of the equipment such as the faster response to system events.

These new models fill a major need in the transmission system interconnection activity with regard to system dynamic performance studies for new pumped storage plants with adjustable speed or ternary pumped storage units. These models will be very useful in studies investigating how these technologies can be implemented to help address concerns related to the increasing integration of wind and solar photovoltaic renewable resources. 


\section{Section

\section{Introduction}

In the framework of the U.S. Department of Energy (DOE)-sponsored project "Modeling and Analysis of Value of Advanced Pumped Storage Hydropower in the U.S.," new dynamic simulation models were developed to represent advanced pumped storage hydro (PSH) technologies. The models developed include:

- Adjustable speed PSH unit employing a doubly fed induction machine (DFIM)

o In generator/turbine mode of operation

o In motor/pump mode of operation

- $\quad$ Ternary PSH unit
o In turbine mode of operation
o In pump mode of operation
o In mixed (hydraulic short-circuit) mode of operation.

Previous reports [1-3] described these technologies and gave a detailed description of the models.

This report contains additional information on the models and their characteristics. However, the primary purpose of this report is to show the results of the testing of the new models to demonstrate their performance and illustrate how these models can now be used in analyses required for investigations into applications of these technologies.

Several test systems were developed to illustrate different characteristics and control capabilities of the models.

- A 12-bus system with three machines in which the PSH is the dominant machine. Thus, the capabilities of the PSH unit are clearly shown, albeit in an exaggerated manner from a system impact standpoint.

- A 23-bus system with six machines. In this case, the PSH unit still represents a large portion of the system generation, but the case can be used to demonstrate the faster frequency control of the adjustable speed pumped storage hydro (AS PSH) technology.

- The full WI (Western Interconnection) system. This is a large system model containing nearly 20,000 buses that represents the western portion of the North 
American power grid, approximately the western third of the United States from the Rocky Mountains west to the Pacific Ocean and the Western provinces of Canada. The present conventional PSH units in WI are modeled in this case. A revised WI model was created in which these existing installations are modeled using the new models, thus showing the response using the new technologies in real PSH locations and also allowing for a comparison of the response with the advanced technologies to that with conventional technologies.

These test systems were used to demonstrate that the new models were robust and showed the expected performance for different disturbances. In some cases, it is shown that the advanced technologies have advantages (e.g., the ability to respond faster to frequency events compared to conventional units).

Simulations using the WI system demonstrate that the new models can be used for planning and interconnection studies for practical systems and can be tuned to local conditions. In general, throughout the course of testing described in this report, we have performed many and various simulations, creating various frequency events, applying different types of faults, and in general putting the models through all of the usual activities that would be encountered in studies using a tool such as PSS ${ }^{\circledR} \mathrm{E}$. Thus, the tests documented below have confirmed and demonstrated the expected capabilities of the advanced PSH technology, such as riding through faults, voltage control, and participation in frequency control. 


\section{Section \\ 2}

\section{Adjustable Speed Pumped Storage Hydro Turbine Employing a Doubly Fed Induction Machine}

The block diagram of the model for the DFIM-based turbine is provided in Figure 2-1. A detailed explanation of the technology and a detailed description of the model were given in a previous report, Modeling Adjustable Speed Pumped Storage Hydro Units Employing Doubly-Fed Induction Machines [2]. A brief summary is given below.

The converter module in Figure 2-1 is responsible for controlling active power and voltage. It uses two inputs. One is the active current command (Ipcmd) from the active power controller, and the other is the magnetizing voltage command (Eqcmd) from the reactive power controller. The converter module determines the total complex current injected/absorbed by the converter to/from the grid.

The power command is combined with the command from the frequency controller to create the power set point Pset. The power error is processed through the proportional-integral (PI) controller whose output is the power order Pord. The rotating speed of the machine rotor calculated by the rotor dynamics module is used as the third input to the PI controller, which is used to keep the machine speed from going outside the allowable range, as determined by the capabilities of the converter.

The hydro governor module covers governor, turbine, and penstock dynamics. Different from the conventional hydro unit, the mechanical power of the DFIM-based turbine can be adjusted by either a change in turbine speed or by a change in gate position, or a combination of both. The speed and gate optimizers select the proper coordination of speed and gate position to maximize efficiency. The optimal power/gate/speed relationships are represented through simplified functional characteristics, which should be built based on information provided by the manufacturer. This module allows taking into consideration the hydraulic coupling effect of up to four units sharing a common penstock.

While all of the simulations in this report have been performed using the $\mathrm{PSS}^{\circledR} \mathrm{E}$ program, the models have been documented in sufficient detail that they could be developed in other software packages and similar results would be expected. 


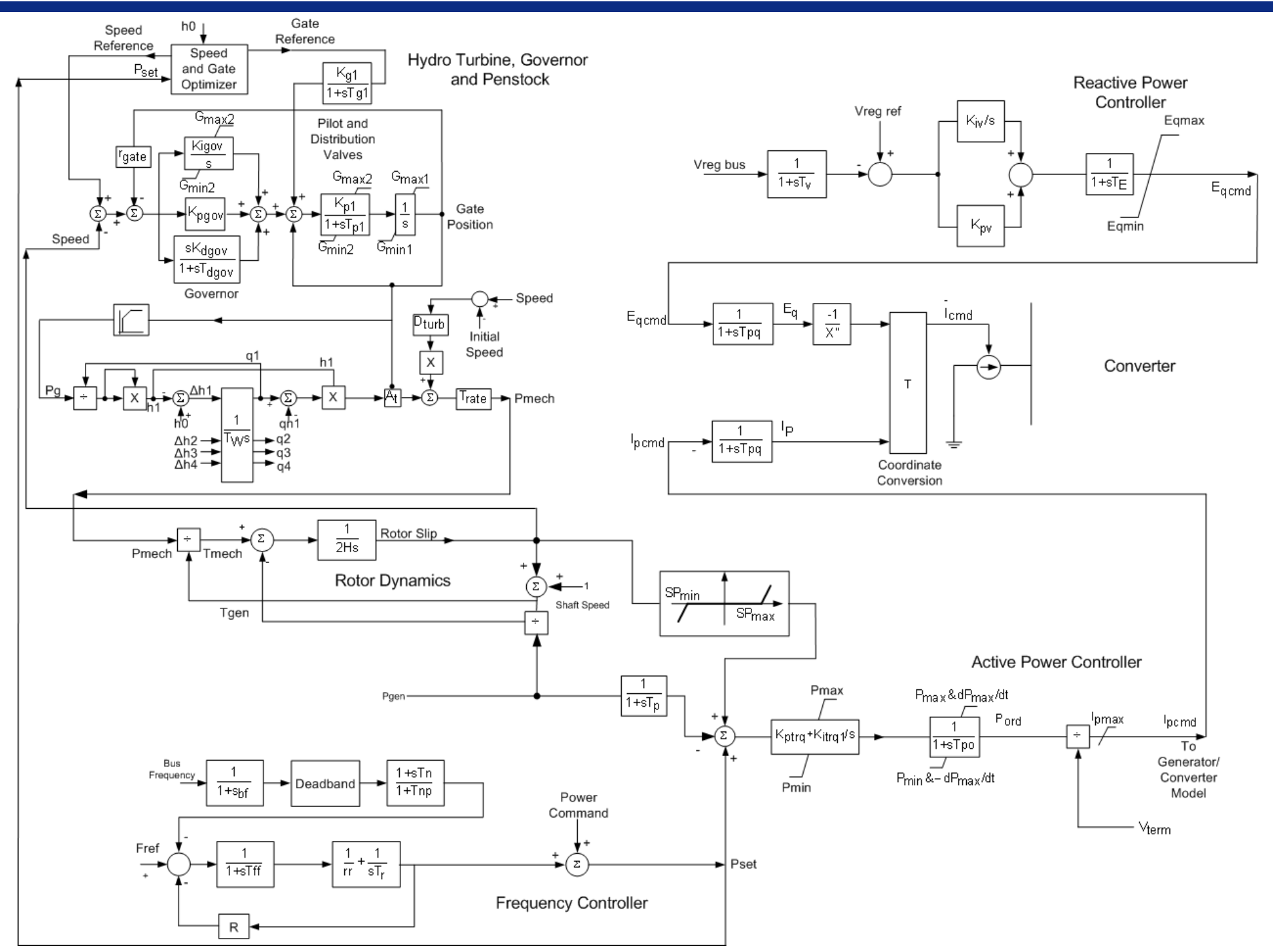

Figure 2-1 Block Diagram of the DFIM-Based Turbine Model 


\subsection{Description of the Test System}

A small test was developed to highlight the capability of the AS PSH unit. The test system shown in Figure 2-2 includes 10 buses of $24 \mathrm{kV}, 34.5 \mathrm{kV}$, and $230 \mathrm{kV}$. There are three generating units. The PSH turbine under study is represented by the 1,176-MVA machine connected to bus 19, the 24-kV bus located at the top left of Figure 2-2. A 200-MVA gas turbine unit is connected to bus 20 , the $24-\mathrm{kV}$ bus located at the bottom left of Figure 2-2. A small conventional hydro unit of 28.9 MVA is connected to the 24-kV bus 15 shown at the right of the figure. There are two loads of 1,000 and $100 \mathrm{MW}$ connected to the 230-kV bus 11 in the center of the system.

It is easily seen that the PSH unit represents the dominant share of the total generating capacity: $84 \%$. While not realistic of actual systems, in which PSH units are likely just one component of a larger mix of thermal and hydro units, the dominance in the test case was done with the intention of better seeing the impact of the PSH unit.

Parameters of the test system are shown in Figure 2-2. The data on the buses indicate the bus numbers, names, and base voltages in $\mathrm{kV}$. Branch parameters are resistance and reactance on the top of the branch and line charging below the branch. Transformer data includes resistance, reactance, and the transformer taps.

Figure 2-3 depicts the base case power flows and bus voltages.

The load flow raw data file in $P S S^{\circledR} E$ format is provided in Appendix A, Section A-1.

This system is designed to provide flexibility for testing the response to different events including over-frequency events that can be created by shedding one of the loads, underfrequency events that can be created by dropping one of the generating units, and fault events that can be simulated by applying a fault to one of the buses.

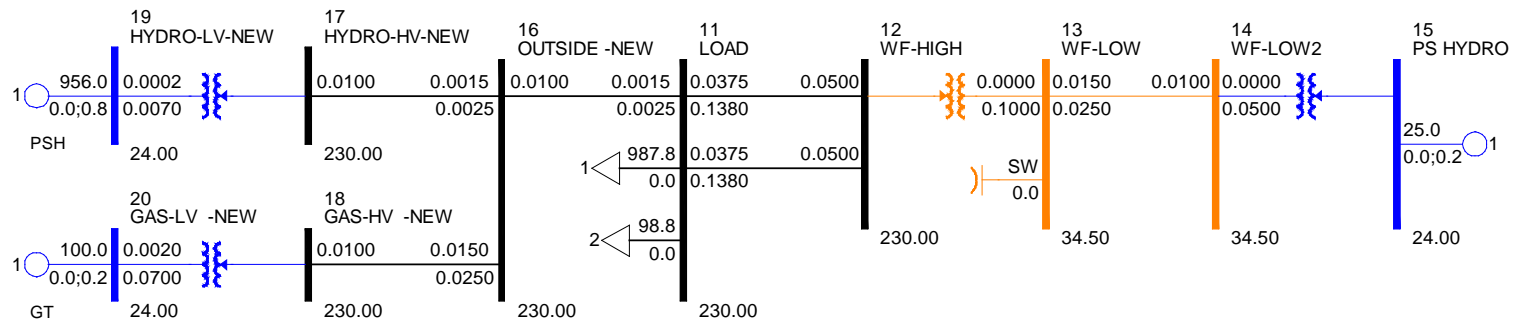

Figure 2-2 One-Line Diagram of the Test System Showing Parameters 


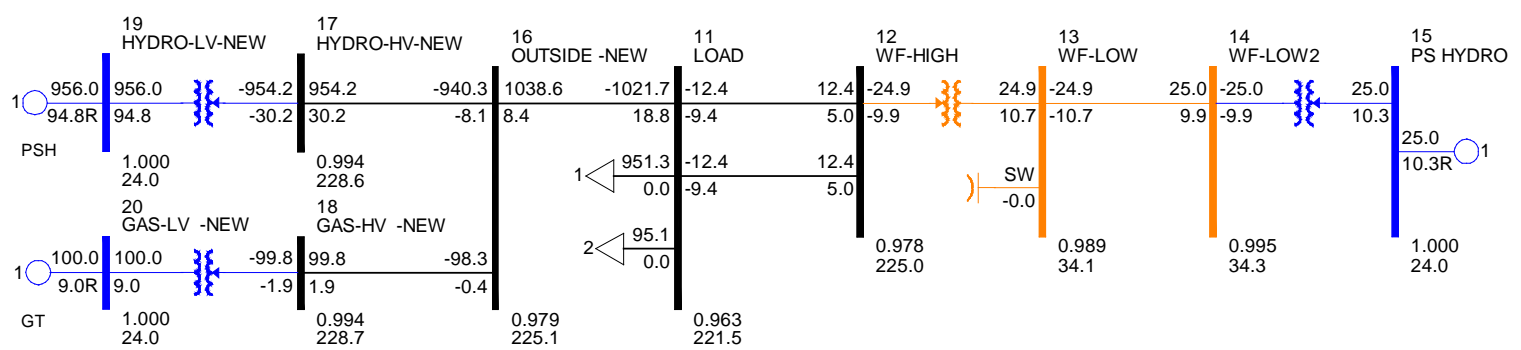

Figure 2-3 One-Line Diagram of the Test System Showing Base Case Power Flows and Voltages

\subsection{Testing the System with All Conventional Units}

To give a baseline for comparison, all machines were first modeled as conventional units.

The documentation of the conventional dynamic models is provided in Appendix $B$, Section B-1.

The two hydro units on buses 15 and 19 have the same set of models and parameters for the salient pole generators (model GENSAE), the excitation system (model IEEEX1), and the turbine-governor (model HYGOV). The gas turbine on bus 20 is represented only by a machine model; that is, no explicit excitation system or governor models, and thus is modeled as on manual excitation control and with, for example, a large deadband in the governor controls. This further emphasizes the controls on the hydro unit.

\section{Over-Frequency Test}

In the first test, the 100-MW load was tripped to demonstrate the response to an event resulting in an increase in frequency.

Figure 2-4 shows the resulting frequency increase. Frequency reaches a peak of $61.044 \mathrm{~Hz}$ (about $+1.74 \%$ ) about 4 seconds after the load is tripped (note that the disturbances are generally applied at time equals 1 second to clearly show the initial steady state condition). Frequency is controlled by governor action and settles at $60.13 \mathrm{~Hz}(+0.21 \%)$, as determined by governor droop characteristics. Note that the hydro governor action is relatively slow and the steady state frequency is reached after about 20 seconds. 


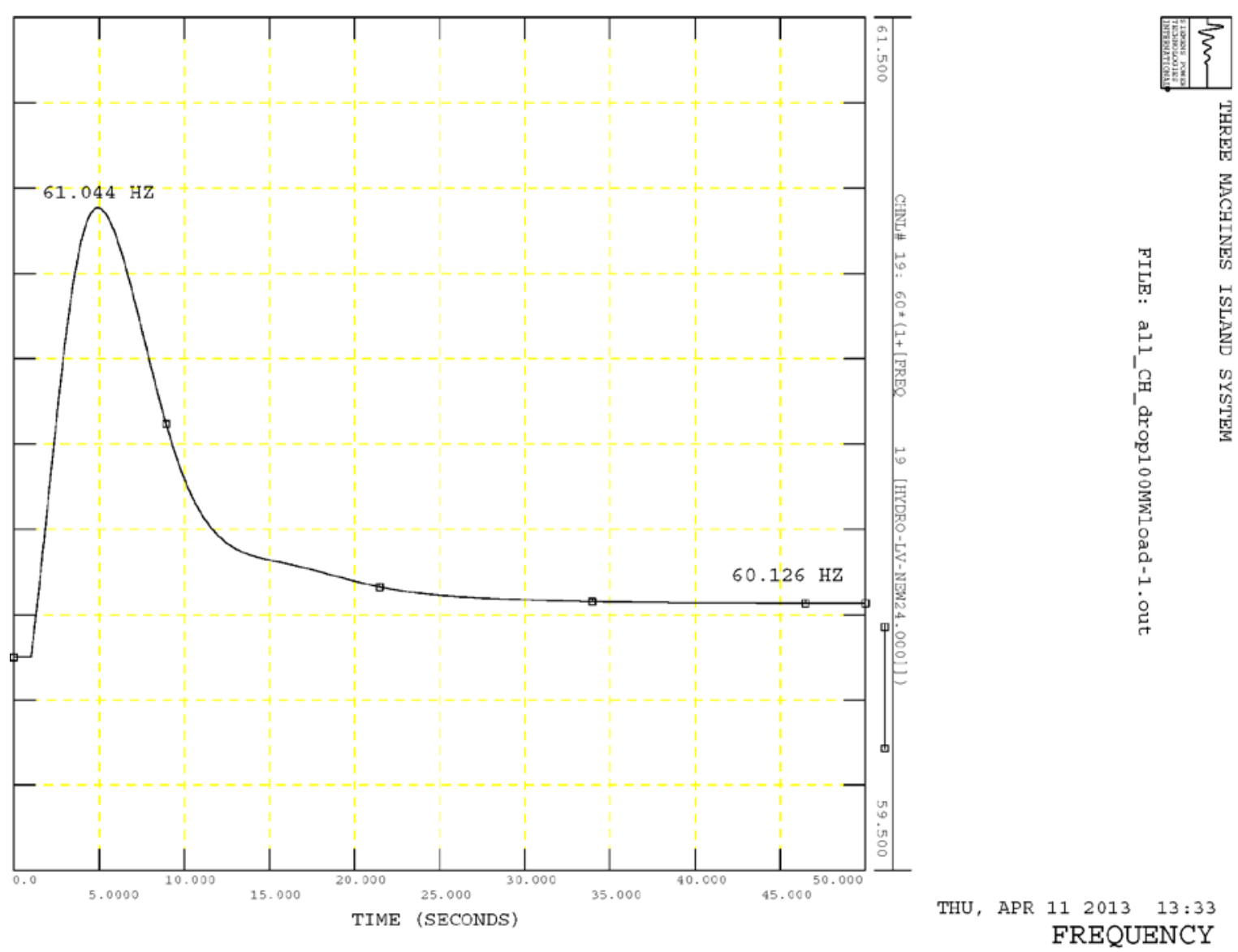

Figure 2-4 System Frequency in Response to an Over-Frequency Event with All Conventional Units

The mechanical power and electrical power of the large hydro unit on bus 19 are shown in Figure 2-5. The mechanical power initially goes up, the wrong direction, as is characteristic of hydro units. As the governor responds and begins to close the gates, the mechanical power is reduced to control the overspeed and shows a well damped response. The electrical power reduces instantaneously to match the unit's share of the total electrical load demand. The gas turbine unit does not have an explicit governor model; hence, mechanical power is kept constant (Figure 2-6). However, the electrical power of the gas turbine reduces instantaneously to match the unit's share of the total electrical load demand, but is restored to its original value as the hydro units respond and decrease their mechanical and electrical power.

Figure 2-7 shows the response of the rotor speed of all three conventional units. Note that in this small system all of the units have very similar speed responses. As we will see below, this is not the case for the PSH unit employing the DFIM. 


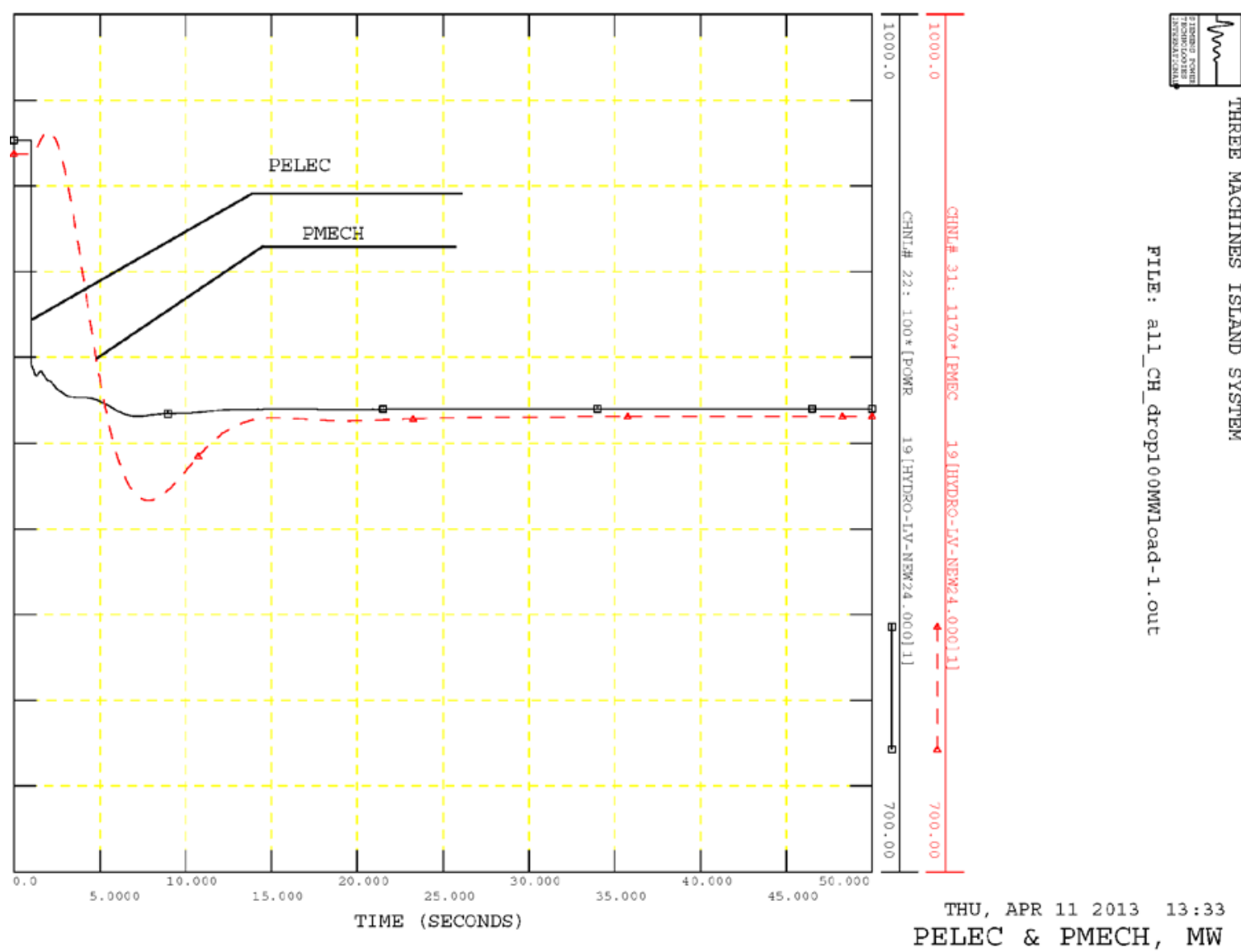

Figure 2-5 Electrical Power and Mechanical Power of the Large Hydro Unit in Response to an Over-Frequency Event with All Conventional Units 


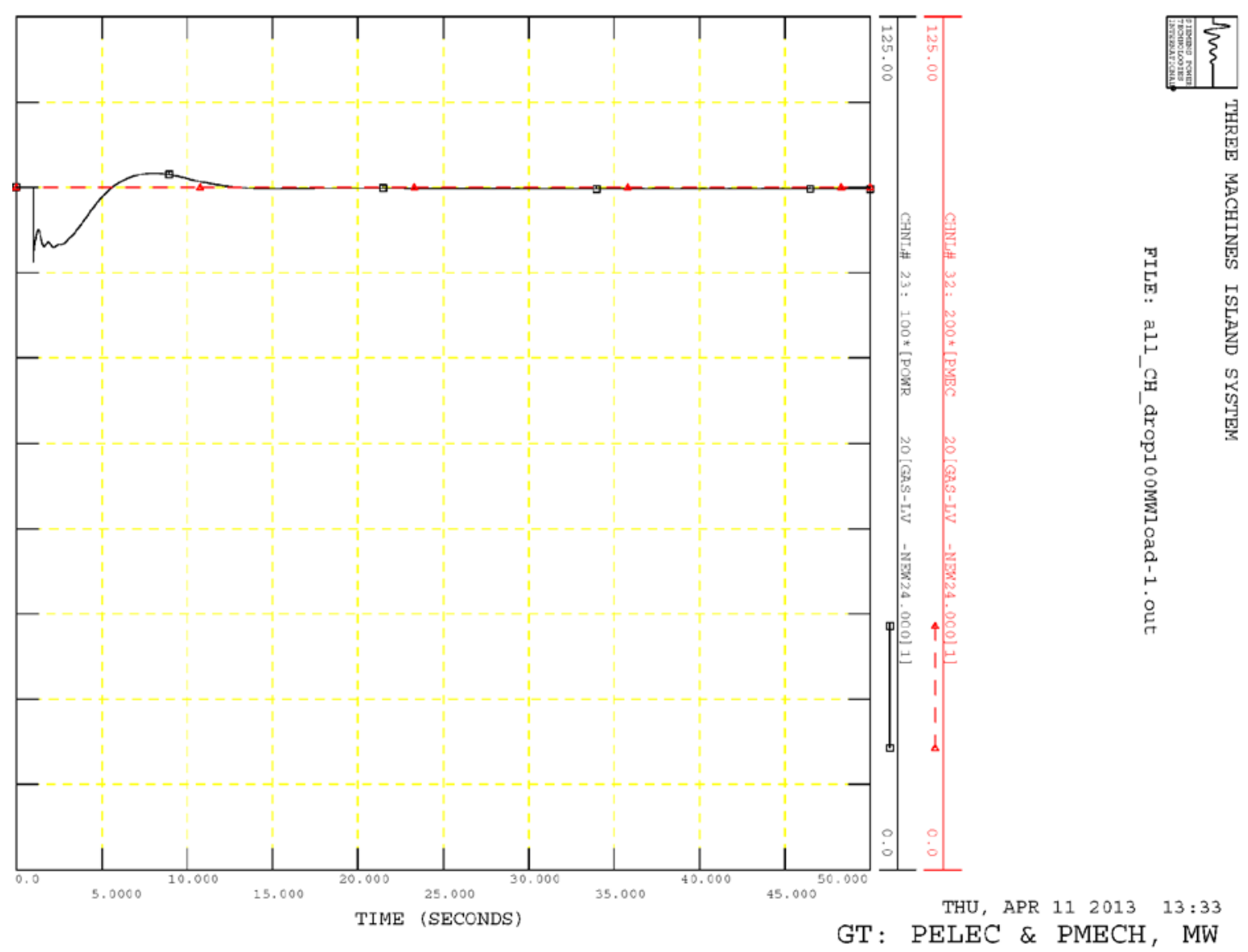

Figure 2-6 Electrical Power and Mechanical Power of the Gas Turbine Unit in Response to an Over-Frequency Event with All Conventional Units 


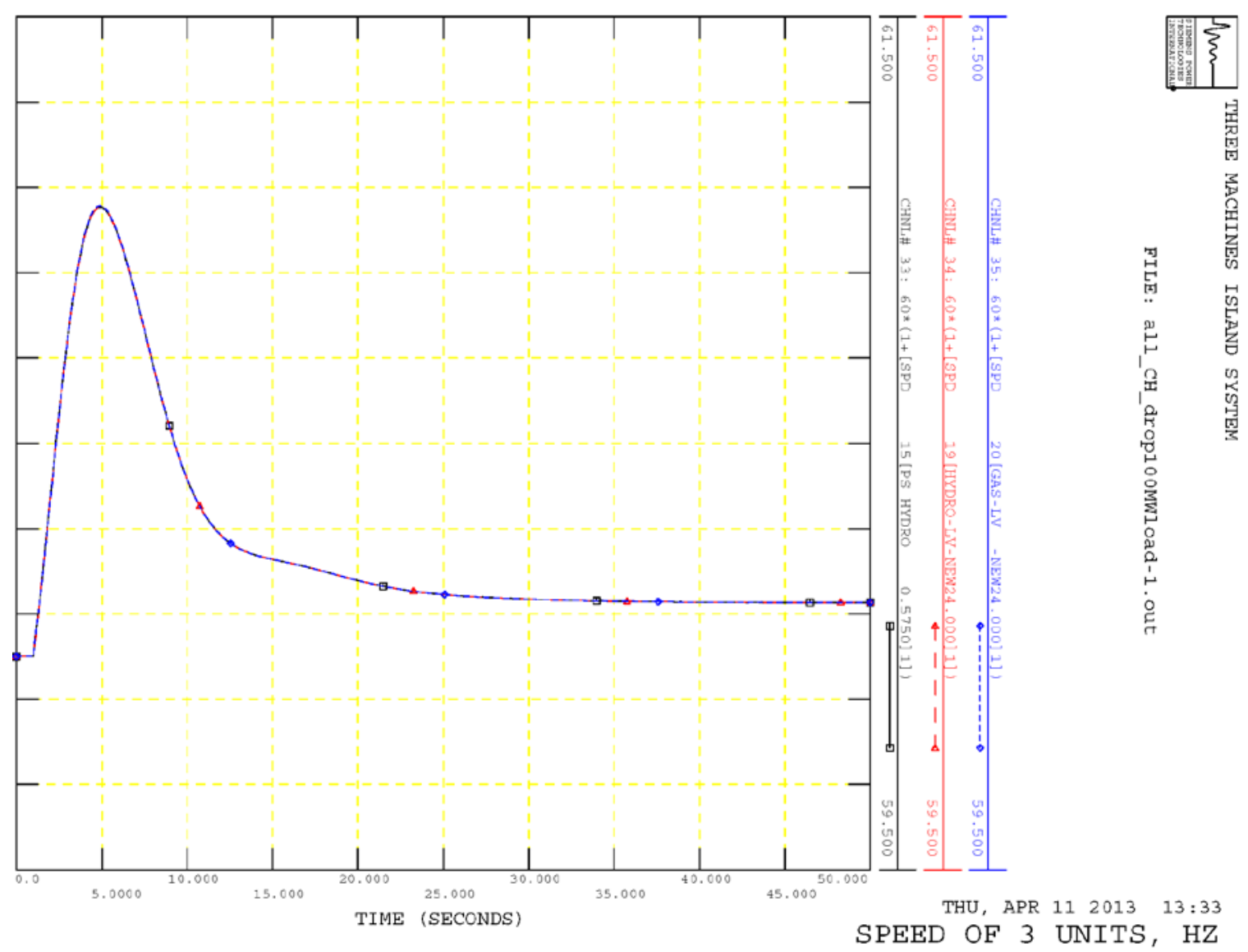

Figure 2-7 Rotor Speeds of All Three Generating Units in $\mathrm{Hz}$ in Response to an Over-Frequency Event with All Conventional Units

\section{Under-Frequency Test}

To create an under-frequency condition, the 100-MW gas turbine unit on bus 20 was tripped. The resulting system frequency and the electrical and mechanical power of the large hydro unit are shown in Figure 2-8. The frequency drops to a minimum of about $58.8 \mathrm{~Hz}$ and recovers to a steady state frequency of about $59.9 \mathrm{~Hz}$ after about 20 seconds (not $60 \mathrm{~Hz}$, due to governor droop). 


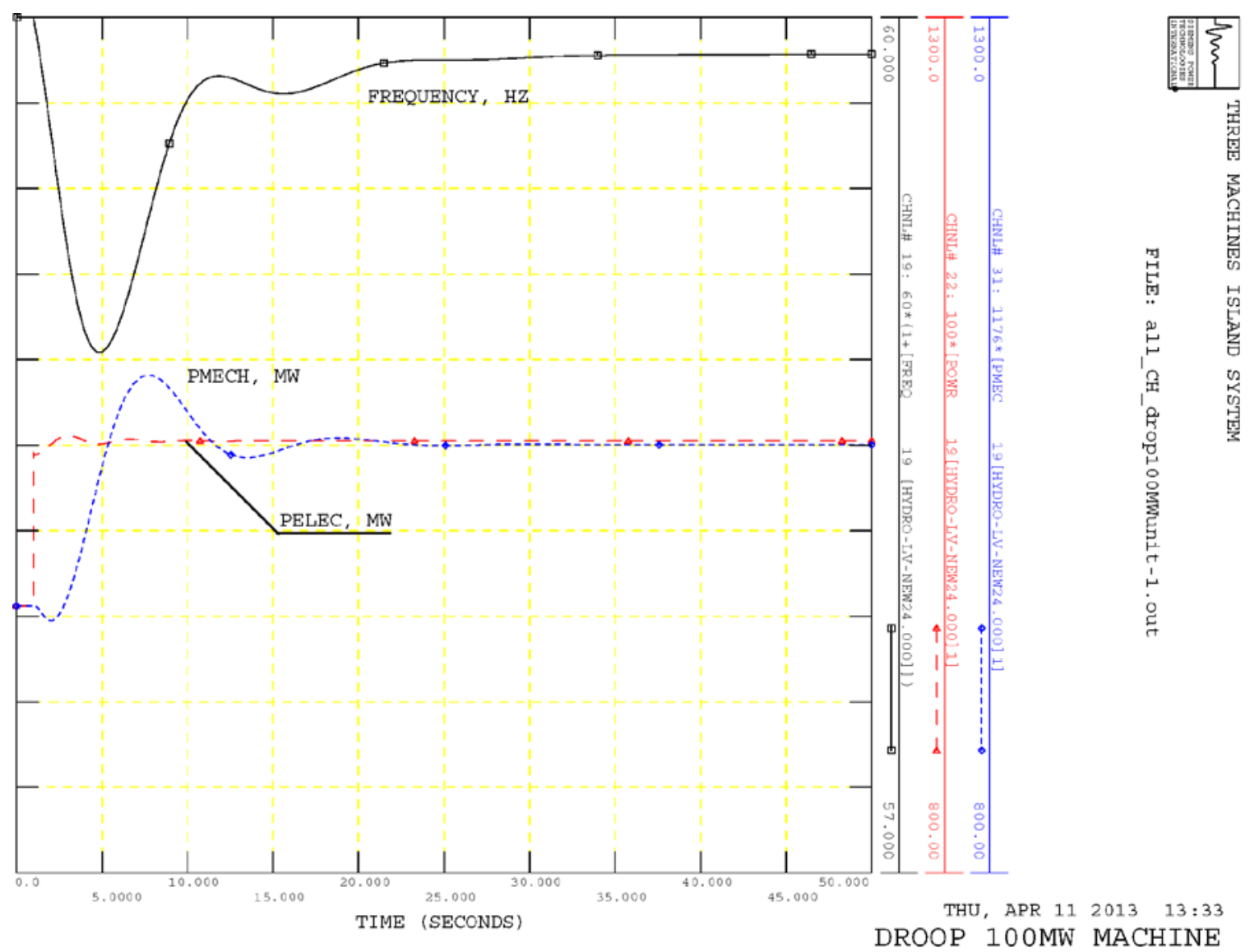

Figure 2-8 System Frequency and Electrical Power and Mechanical Power of the Large Hydro Unit in Response to an Under-Frequency Event with All Conventional Units

\subsection{Testing the Adjustable Speed Pumped Storage Hydro Turbine Modeled as a Single Unit and Penstock}

The next set of simulations was performed to show the response with an adjustable speed pumped storage plant. The set of conventional models for the large hydro unit on bus 19 were replaced by the adjustable speed pumped storage turbine model described above. The dynamic data for this model is shown in Appendix B, Section B-2. Note that the dynamic model for the adjustable speed pumped storage unit includes voltage and speed controls, and thus includes the roles of the generator, excitation system, and governor models of the conventional units. The dynamic data for the other units (small hydro unit and gas turbine unit) remains the same.

The report describing the model [2], which was published earlier in this project, discussed the issue of the characteristics of the rotor speed and gate optimizers. The characteristics shown in Figure 2-9 and Figure 2-10 were used for testing the pumped storage hydro turbine. They represent the family of characteristics that relate power, speed, gate, and head. Using these characteristics, the optimizer finds the steady state operating point that maximizes efficiency at a given power output while observing any operational constraints. Both the rotor speed and 
gate references were represented as linear functions of the power command and a static head.

Figure 2-9 shows the characteristics of the rotor speed optimizer. The "optimal" rotor speed is shown on the $y$-axis for different electrical power levels (80 to 100\%) on the $x$-axis. Note that the speed range is typically limited to on the order of $+10 \%$ of rated to $-10 \%$ of rated, although that may vary as a function of the design. The multiple characteristics shown are for different static heads.

Figure 2-10 shows the characteristics of the gate optimizer. The "optimal" gate position is shown on the $y$-axis for different electrical power levels (80 to 100\%) on the $x$-axis. The multiple characteristics shown are for different static heads.

Note that these two characteristics are very interdependent and must be adjusted for the specific characteristics of the turbine and hydraulic system. They are defined by a table, an example of which is given in Appendix B, Section B-2.

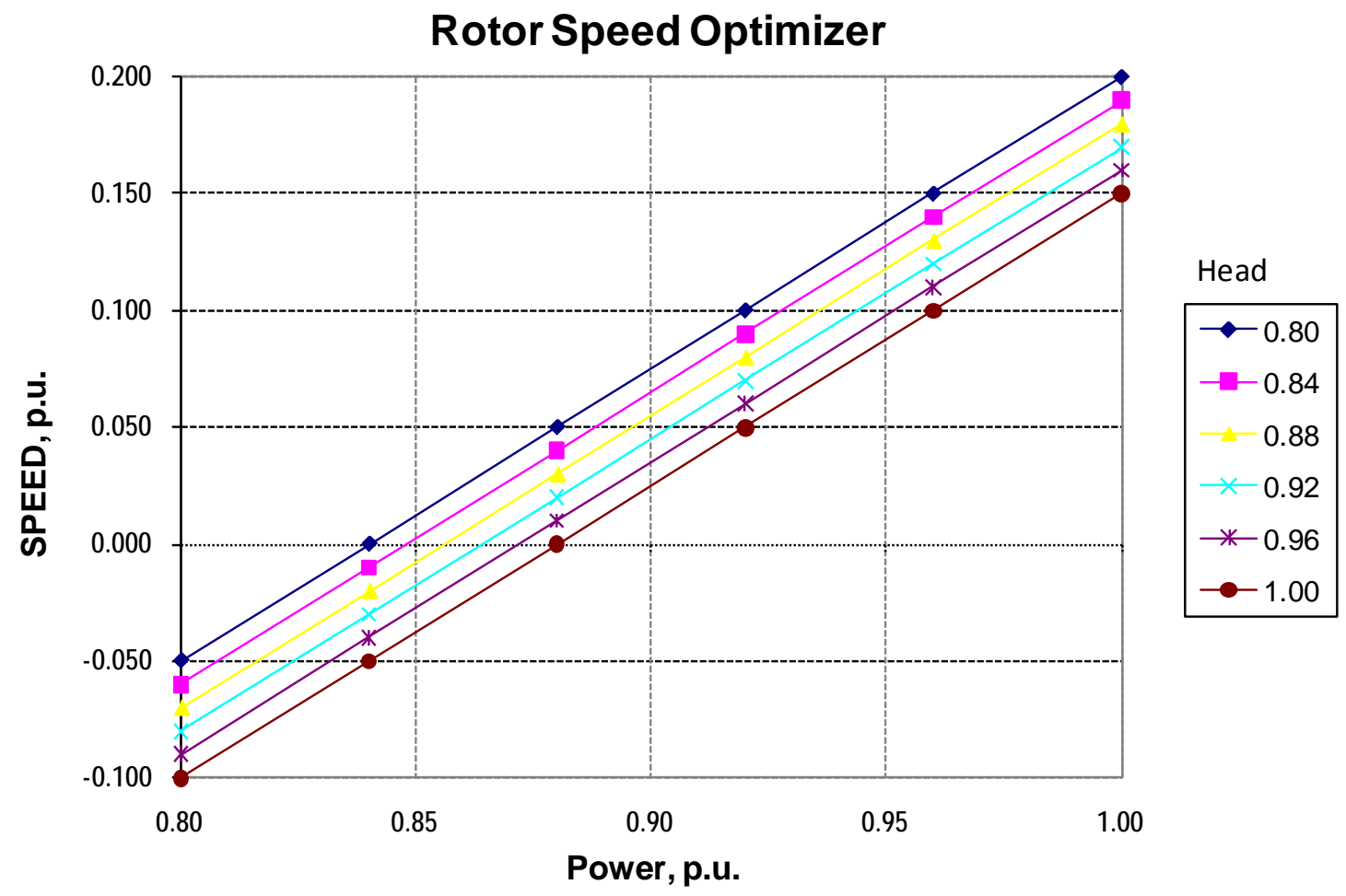

Figure 2-9 Characteristics of the Rotor Speed Optimizer 


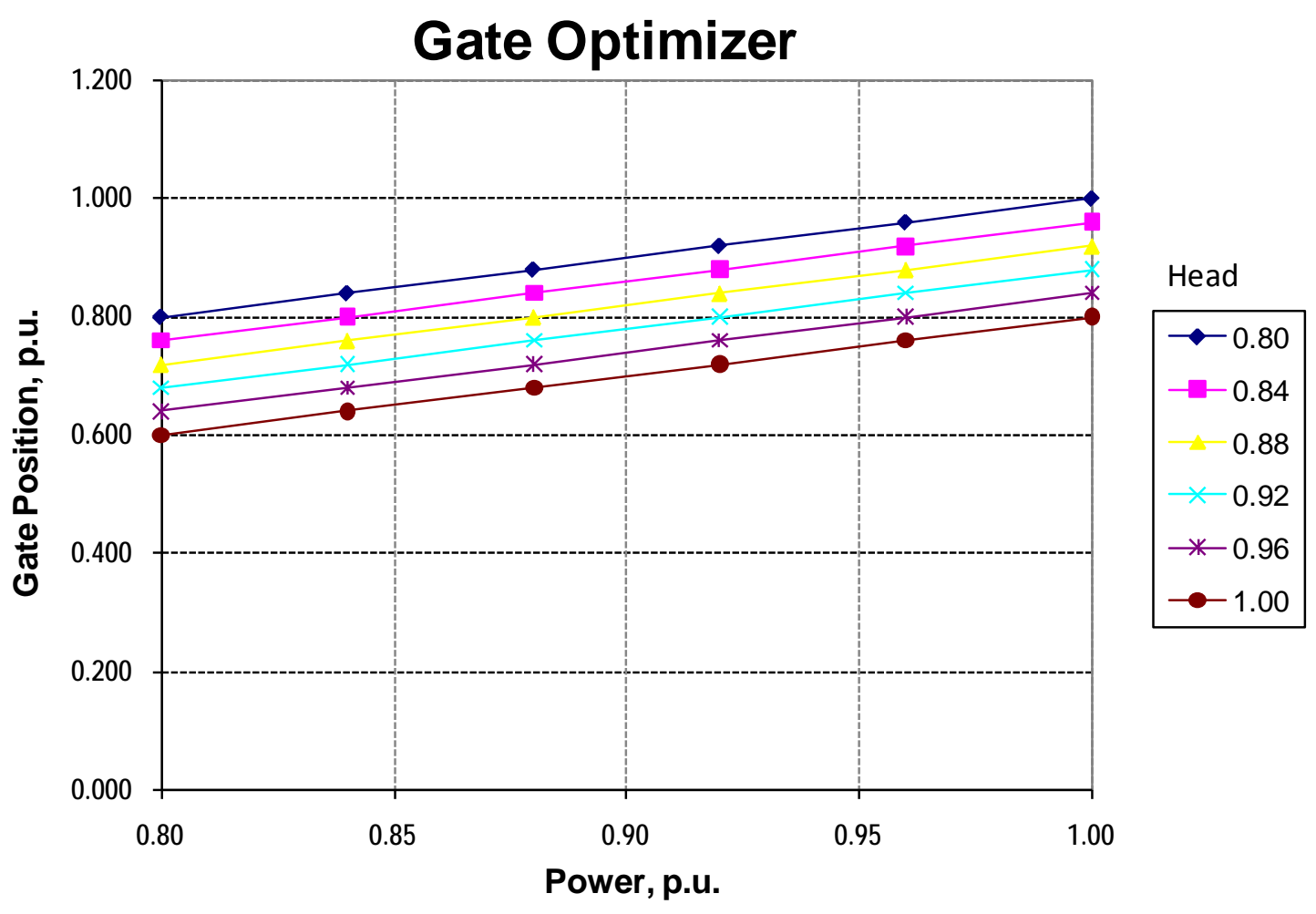

Figure 2-10 Characteristics of the Gate Optimizer

\section{Over-Frequency Test}

The same 100-MW load trip as described above was simulated to create an over-frequency condition, with the large hydro unit represented as an adjustable speed unit. Figure 2-11 through Figure 2-15 show a comparison of frequency, electrical power, mechanical power, rotor speed, and load voltage, respectively, with the conventional hydro unit and the adjustable speed pumped storage hydro unit.

Figure 2-11 compares the resulting system frequency with a conventional unit (black curve) and the adjustable speed unit (red curve). Note that the over-frequency is controlled quicker with the adjustable speed unit. The maximum over-frequency reached is less than that with the adjustable speed unit and the final frequency is reached faster.

Figure 2-12 compares the electrical power of the hydro unit with a conventional unit (black curve) and the adjustable speed unit (red curve). Note that the electrical power of the PSH turbine does not drop instantaneously, as it did for the conventional unit. There still must be an instantaneous match between the electrical power produced and the electrical power consumed by the load. However, the control of the electrical power by the power converter of the DFIM-based PSH unit changes the power response considerably. In this case, this adversely affected the initial rate of frequency rise seen in Figure 2-11. However, as explained above, due to the controllability of the active power by the converter, the peak of frequency is lower and the frequency decay is faster than with a conventional unit. The PSH 
power electronics and turbine controls provide significantly different capabilities for frequency control versus conventional units. Tuning of these controllers depends on system needs in terms of initial frequency decay rate, frequency nadir, and frequency recovery rate.

It should also be noted that in this test system, where the PSH unit represents the majority of the generation, the change in system inertia is very significant when the $\mathrm{PSH}$ machine is connected to the system through power electronics rather than being directly connected as a conventional machine. The AS PSH unit does not contribute to the total system inertia, as its machine speed is not synchronously connected to system frequency. This significantly impacts the initial system response to the generation/load imbalance in these simulations, as well as the potential rate of change in frequency possible through control action to recover from the event. This impact would not be as pronounced for the usual situation in which the AS PSH unit is part of a much larger power system.

Figure 2-13 compares the mechanical powers of the conventional and adjustable speed pumped storage hydro turbine units. The mechanical power of the adjustable speed can be adjusted through adjustment of both speed and gate position. Note that the mechanical powers of the adjustable speed unit in Figure 2-13 is adjusted rather quickly in the model and such fast adjustment may be limited by mechanical or hydraulic constraints. The parameters used in the model are not based on a specific installation (no such data was available), and hence may not represent the limitations seen in an actual installation.

Figure 2-14 compares the rotor speeds of the conventional and adjustable speed pumped storage hydro turbine units. Initial and final values of the PSH unit rotor speed are determined by the references provided by the speed optimizer for the respective values of power. Note that the adjustable speed pumped storage unit does not start (or finish) at synchronous speed, but at the speed determined by the optimizer.

Figure 2-15 compares the terminal voltage and reactive power of the conventional and adjustable speed pumped storage hydro turbine units. 


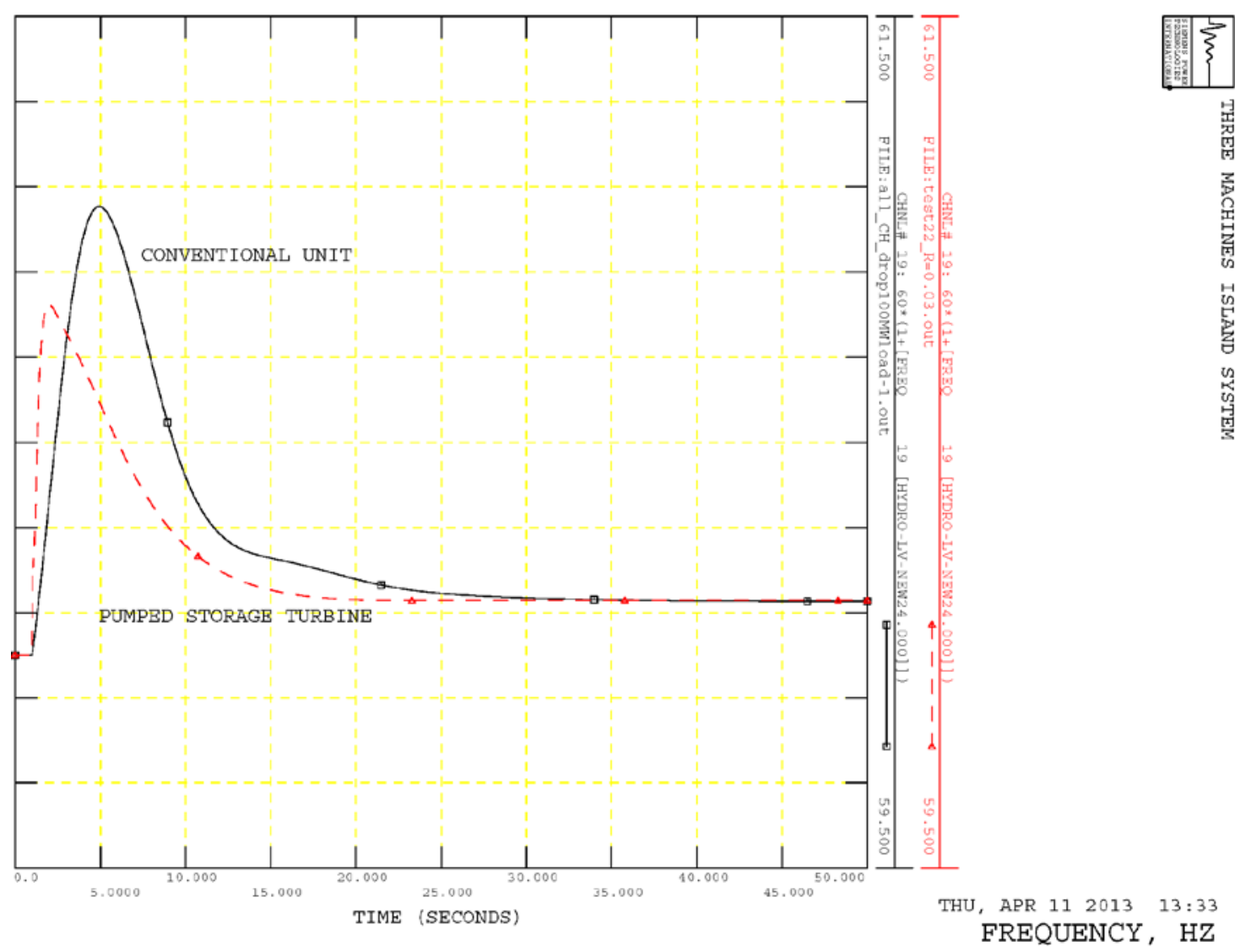

Figure 2-11 Comparison of System Frequency with the Conventional and Adjustable Speed PSH Units in Response to the 100-MW Load Drop 


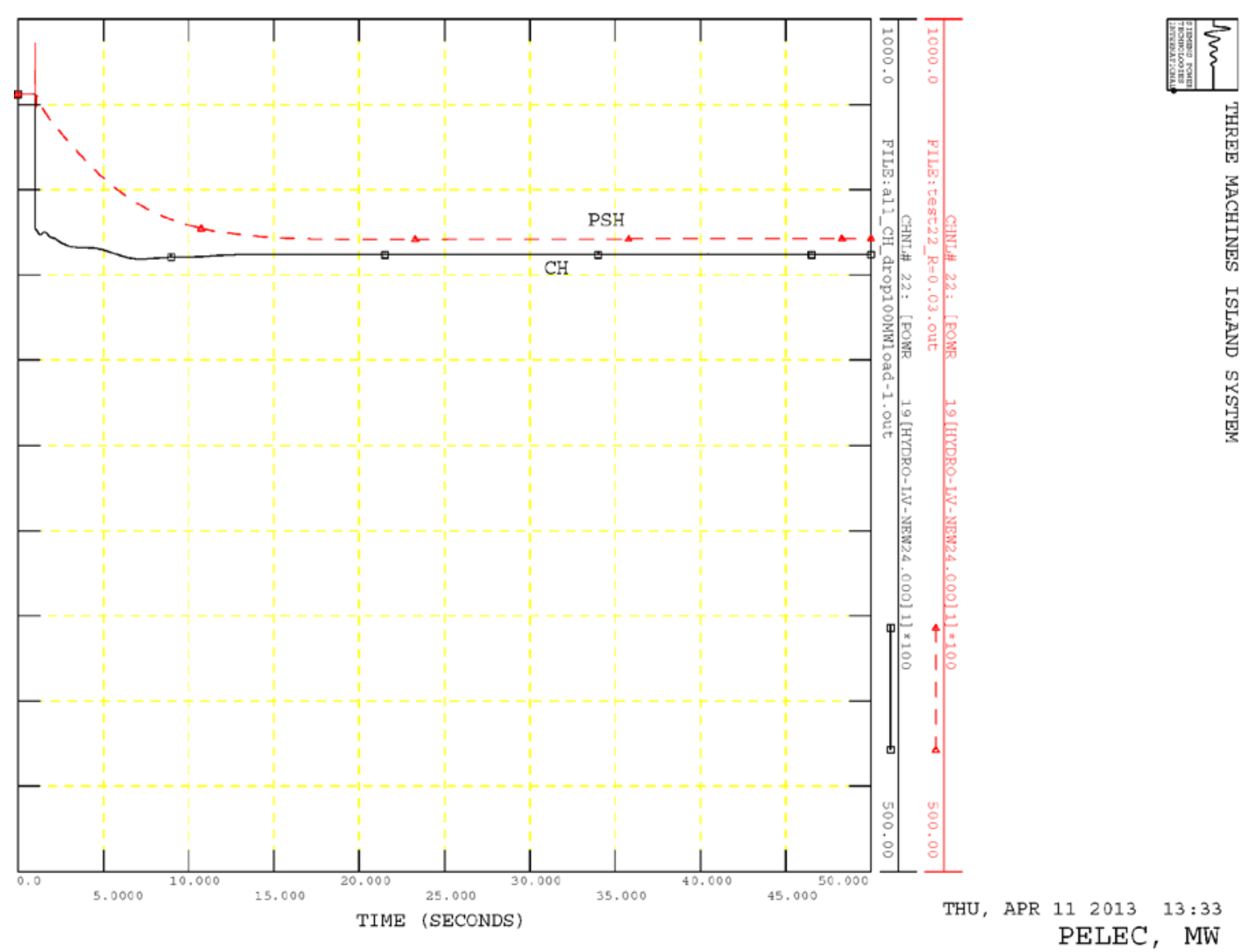

Figure 2-12 Comparison of Hydro Unit Electrical Power with the Conventional and Adjustable Speed PSH Units in Response to the 100-MW Load Drop 


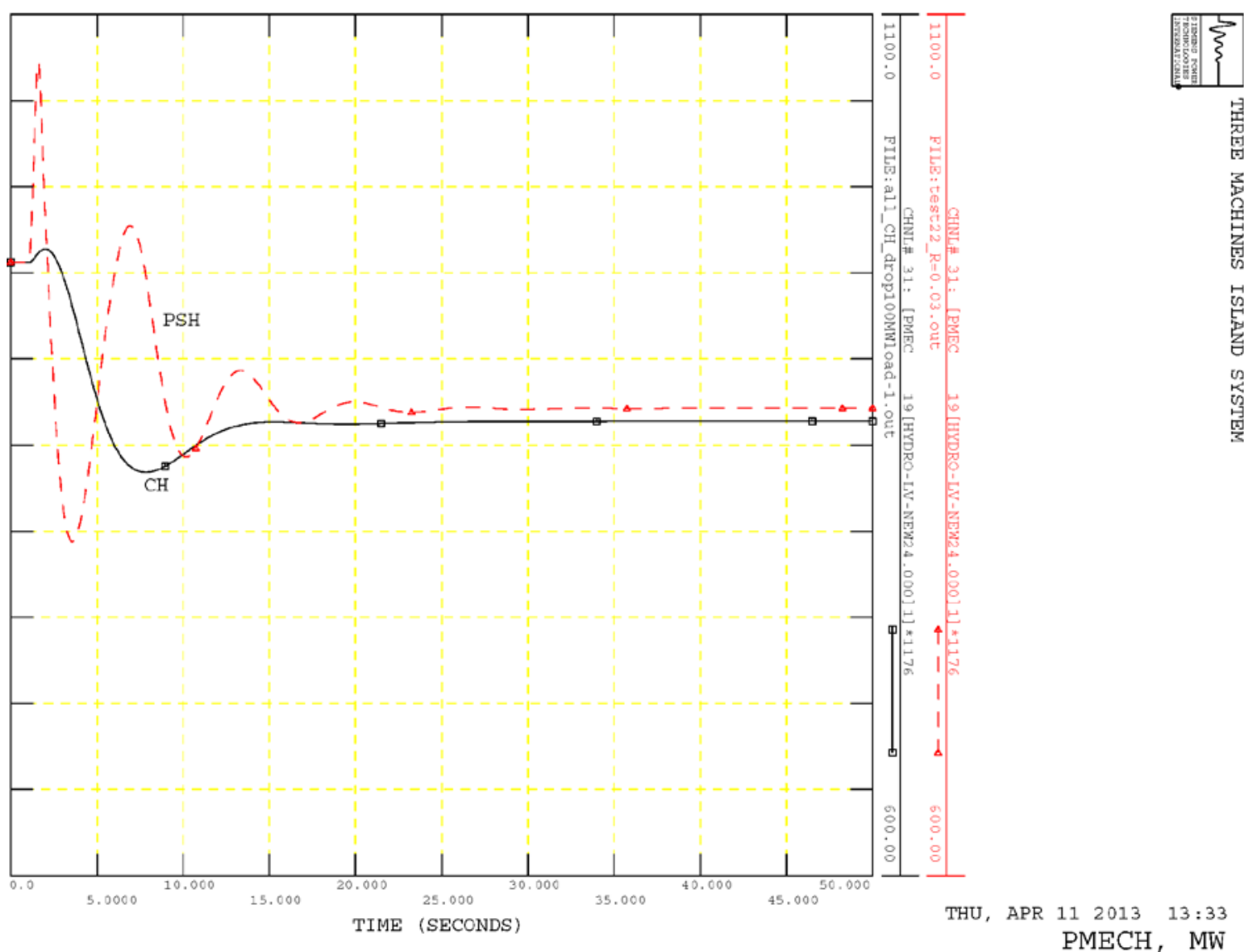

Figure 2-13 Comparison of Hydro Unit Mechanical Power with the Conventional and Adjustable Speed PSH Units in Response to the 100-MW Load Drop 


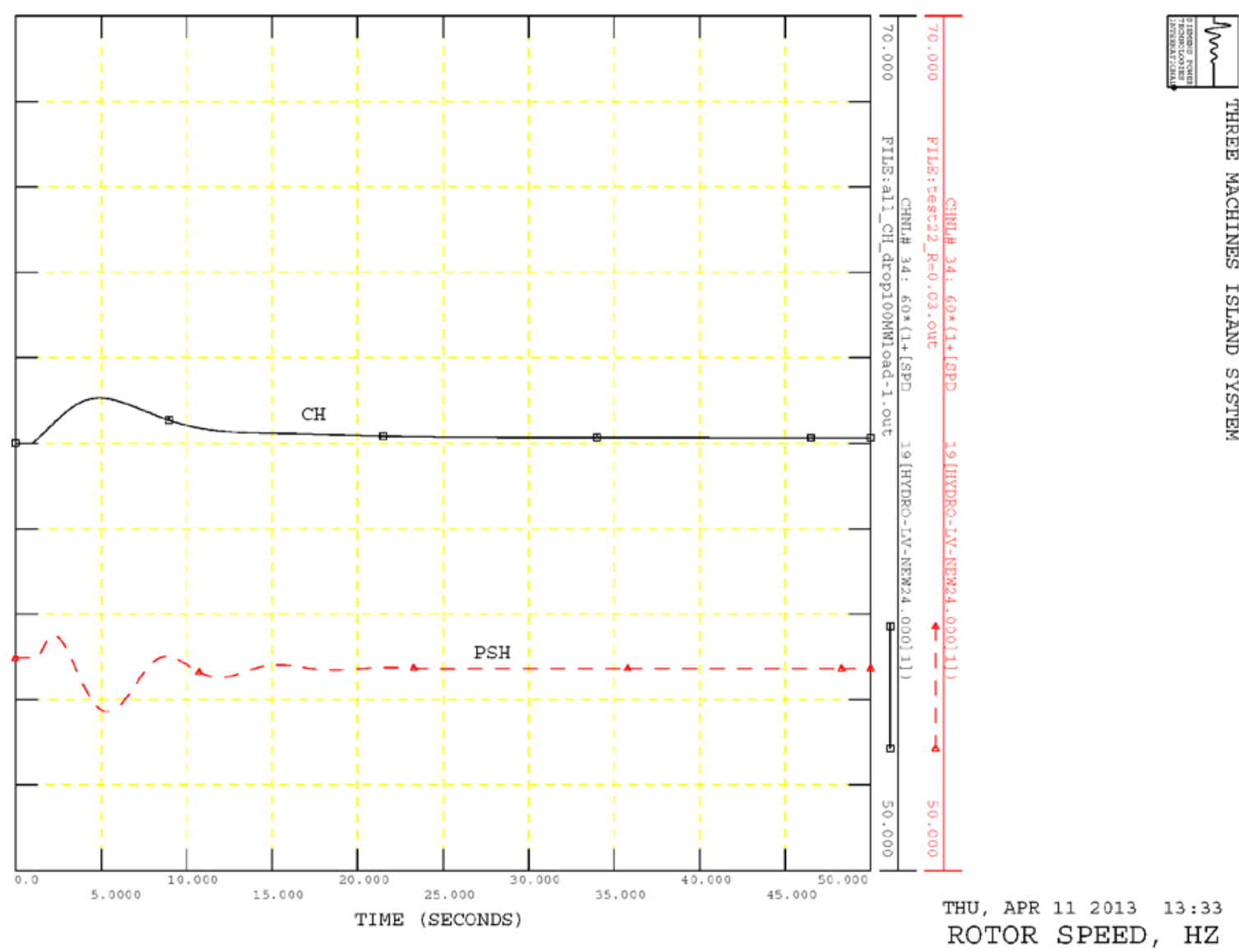

Figure 2-14 Comparison of Hydro Unit Rotor Speed with the Conventional and Adjustable Speed PSH Units in Response to the 100-MW Load Drop 


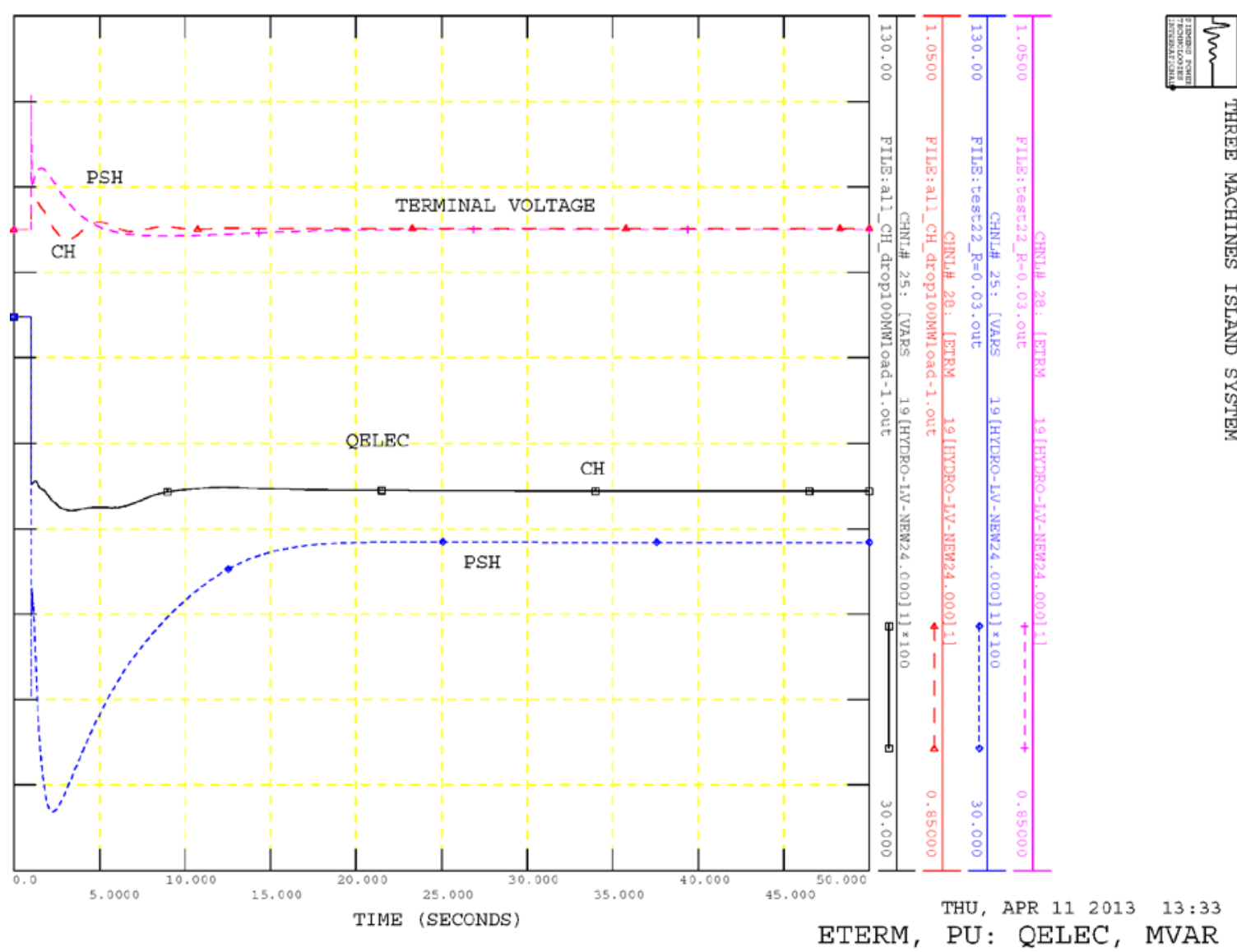

Figure 2-15 Comparison of Terminal Voltage and Reactive Power with the Conventional and Adjustable Speed PSH Units in Response to the 100-MW Load Drop 


\section{Under-Frequency Test}

As the next test, the trip of the 100-MW gas turbine unit was simulated, again in a similar manner to that described above for the conventional unit. Figure 2-16 through Figure 2-20 show a comparison of frequency, electrical power, mechanical power, rotor speed, and load voltage, respectively, with the conventional hydro unit and the AS PSH unit.

Figure 2-16 compares the resulting system frequency with a conventional unit (black curve) and the adjustable speed unit (red curve). Note that the under-frequency is controlled quicker with the adjustable speed unit. The maximum under-frequency reached is less than that with the adjustable speed unit and the final frequency is reached faster.

Figure 2-17 compares the electrical power of the hydro unit with a conventional unit and the adjustable speed unit. As noted above for the over-frequency test, the electrical power of the PSH turbine does not change instantaneously, as it did for the conventional unit. There still must be an instantaneous match between the electrical power produced and the electrical power consumed by the load. However, the control of the electrical power by the power electronics of the PSH unit considerably changes this characteristic. In this case, this adversely affected the initial rate of frequency decay seen in Figure 2-16. However, as explained above, due to the controllability of the active power by the converter, the peak of frequency is lower and the frequency decay is faster than with a conventional unit. The PSH power electronics and turbine controls provide significantly different capabilities for frequency control versus conventional units. Tuning of these controllers depends on system needs in terms of initial frequency decay rate, frequency nadir, and frequency recovery rate.

Figure 2-18 compares the mechanical power of the conventional and adjustable speed pumped storage hydro turbine units. The mechanical power of the adjustable speed unit can be adjusted through adjustment of both speed and gate position. As noted above for the over-frequency test, the mechanical power of the adjustable speed unit in Figure 2-18 is adjusted rather quickly in the model and such fast adjustment may be limited by mechanical or hydraulic constraints. The parameters used in the model are not based on a specific installation (no such data was available), and hence may not represent the limitations seen in an actual installation.

Figure 2-19 compares the rotor speeds of the conventional and adjustable speed pumped storage hydro turbine units. Initial and final values of the PSH unit rotor speed are determined by the references provided by the speed optimizer for the respective values of power. Note that the adjustable speed pumped storage unit does not start (or finish) at synchronous speed, but at the speed determined by the optimizer.

Figure 2-20 compares the terminal voltage and reactive power with the conventional and adjustable speed pumped storage hydro turbine units. 


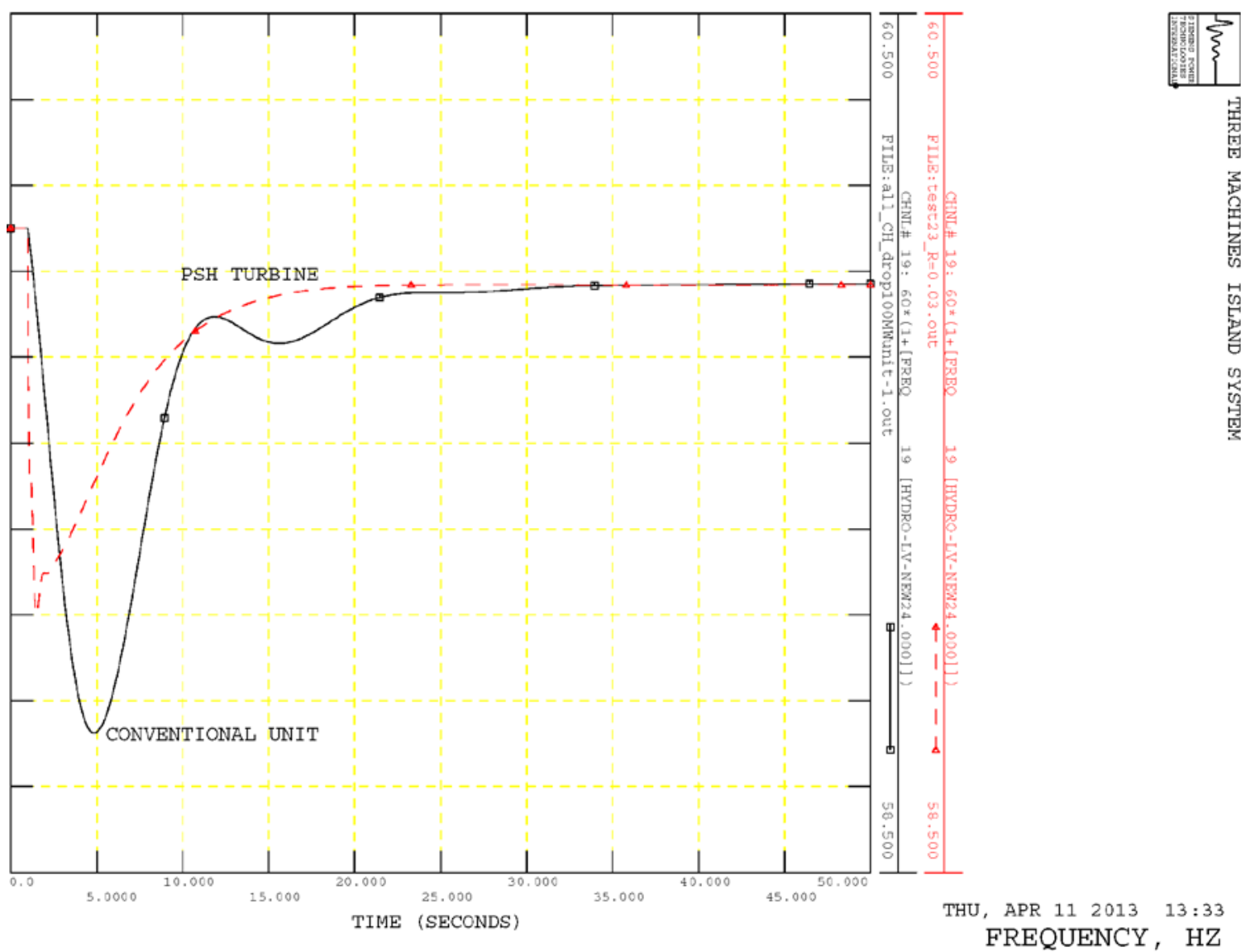

Figure 2-16 Comparison of System Frequency with the Conventional and Adjustable Speed PSH Units in Response to the Trip of the 100-MW Gas Turbine 


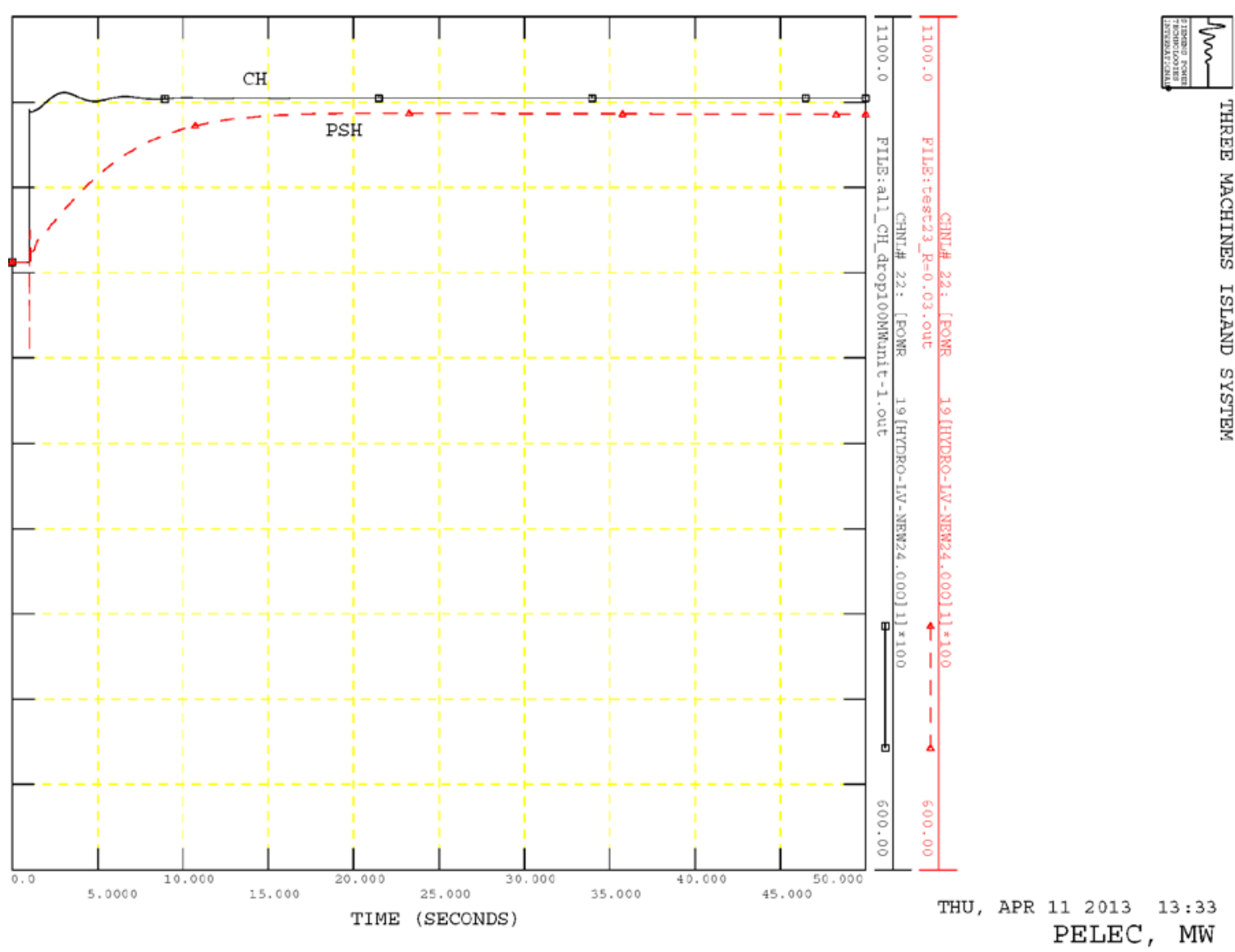

Figure 2-17 Comparison of Hydro Unit Electrical Power with the Conventional and Adjustable Speed PSH Units in Response to the Trip of the 100-MW Gas Turbine 


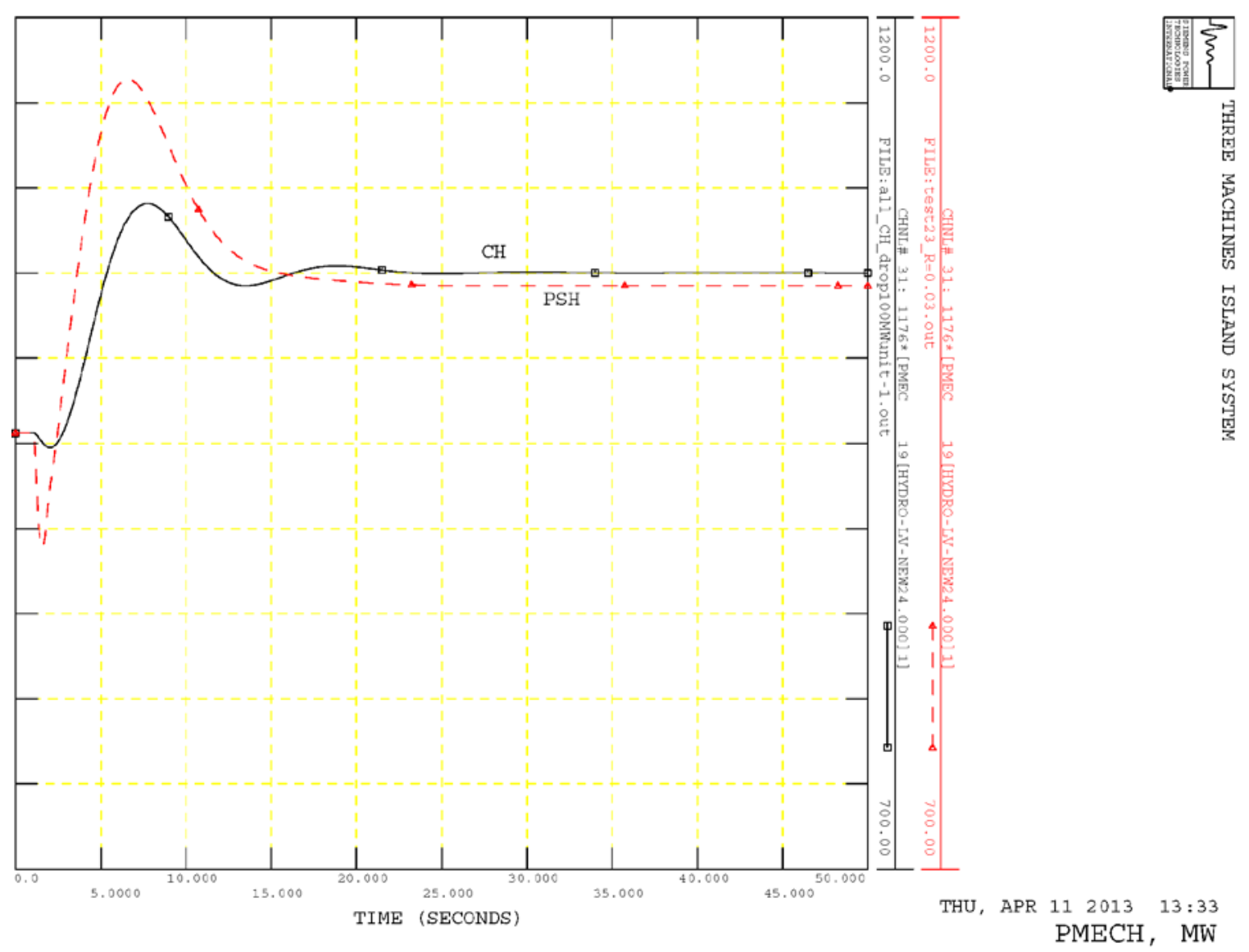

Figure 2-18 Comparison of Hydro Unit Mechanical Power with the Conventional and Adjustable Speed PSH Units in Response to the Trip of the 100-MW Gas Turbine 


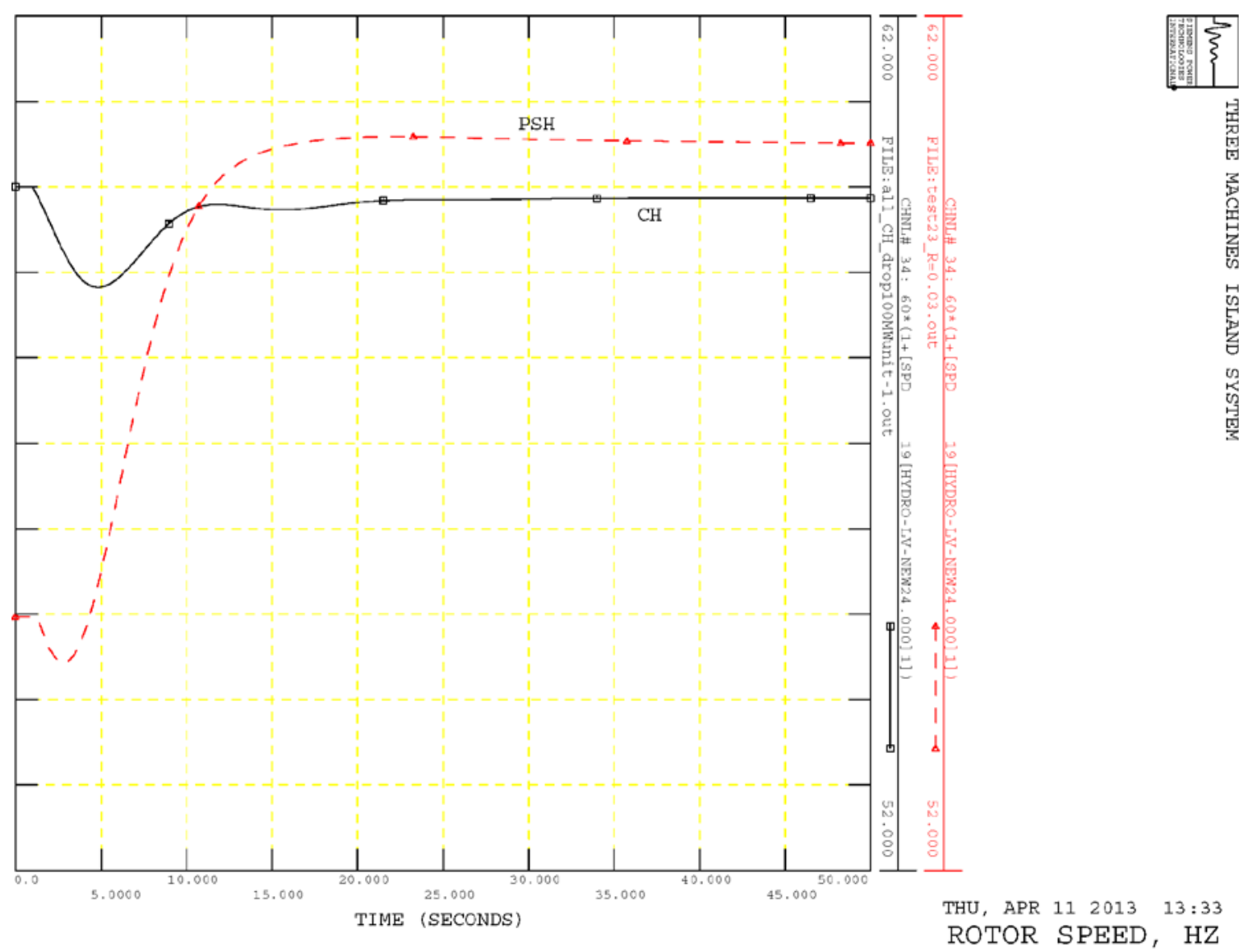

Figure 2-19 Comparison of the Hydro Unit Rotor Speed with the Conventional and Adjustable Speed PSH Units in Response to the Trip of the 100-MW Gas Turbine 


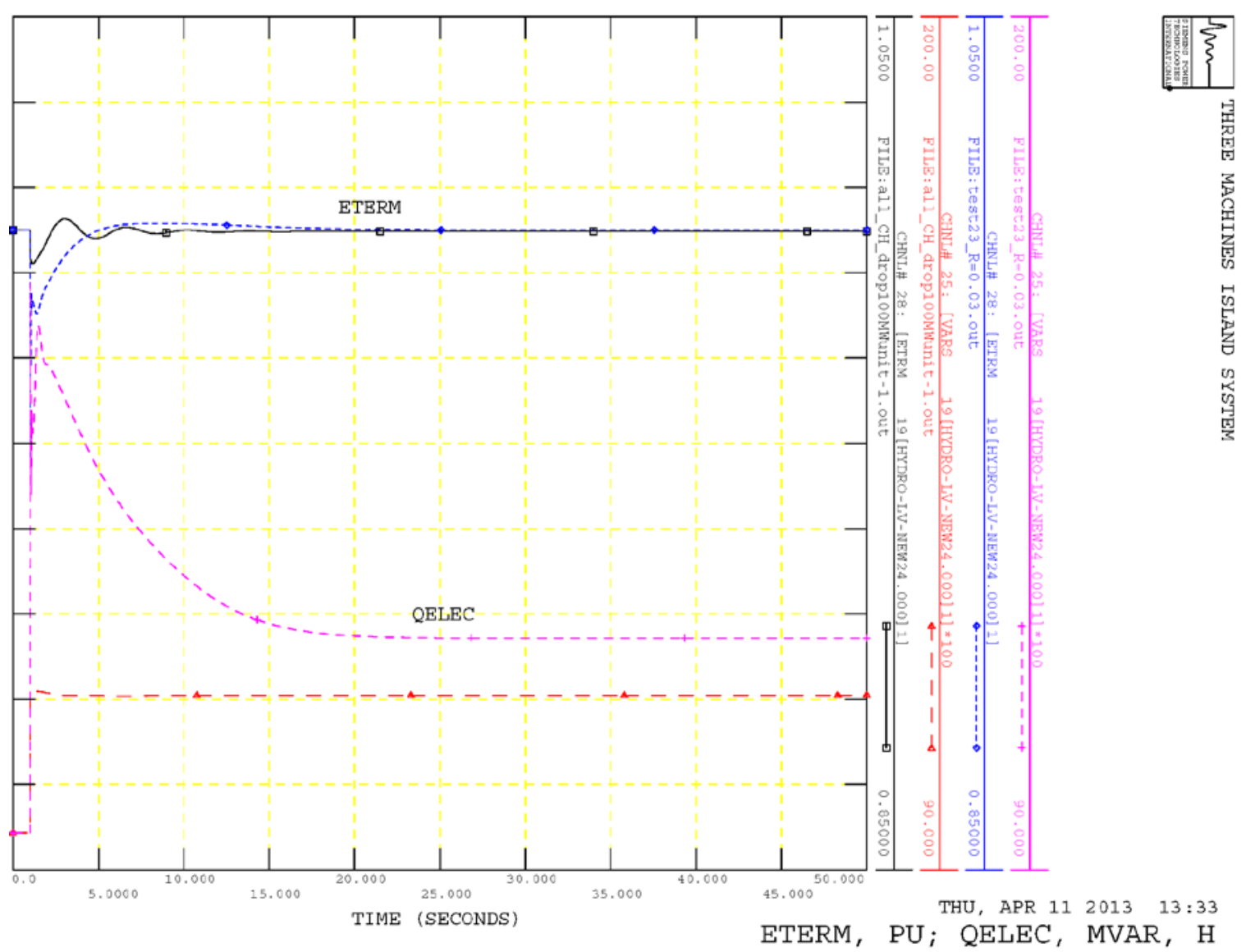

Figure 2-20 Comparison of the Terminal Voltage and Reactive Power with the Conventional and Adjustable Speed PSH Units as a Response to the 100-MW Unit Drop

\section{Impact of Under/Over-Speed Control}

There is an under/over speed control in Figure 2-1, which shows the block diagram of the AS $\mathrm{PSH}$ unit. The purpose of this control function is to prevent the rotor speed from increasing above SPmax or reducing below SPmin. To do this, it uses the deadband function shown in Figure 2-21.

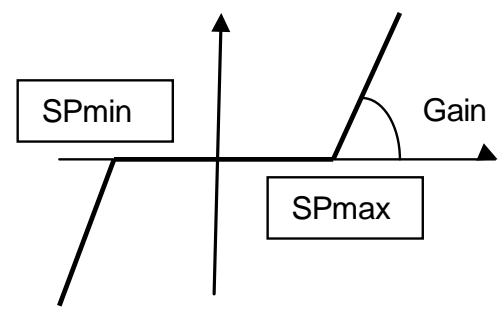

Figure 2-21 Deadband Function for the Under/Over-Speed Controller 
To test this feature, the gate position was reduced (closed) linearly as shown below in Figure 2-22. This change in gate position resulted in a reduction of mechanical power and rotor speed. Figure 2-22 shows the PSH unit's electrical power and speed. Note that electrical power is initially held constant and does not change as the gate changes. When the rotor speed crosses the threshold of "speed=SP $\mathrm{Sin}_{\mathrm{m}}=-0.1$ " (shown as a line in Figure 2-22), the controls start to reduce the power in order to keep the rotor speed close to this lower limit.

The accuracy of holding the rotor speed at SPmin or SPmax depends on the gain determined by the slope of the deadband function, as illustrated in Figure 2-23. In other words, once the deadband is exceeded and the speed is outside the desired range, proportional control is applied to keep the deviation small. The actual settings of these parameters would need to be adjusted to match equipment control capabilities and the control strategies of the manufacturer.

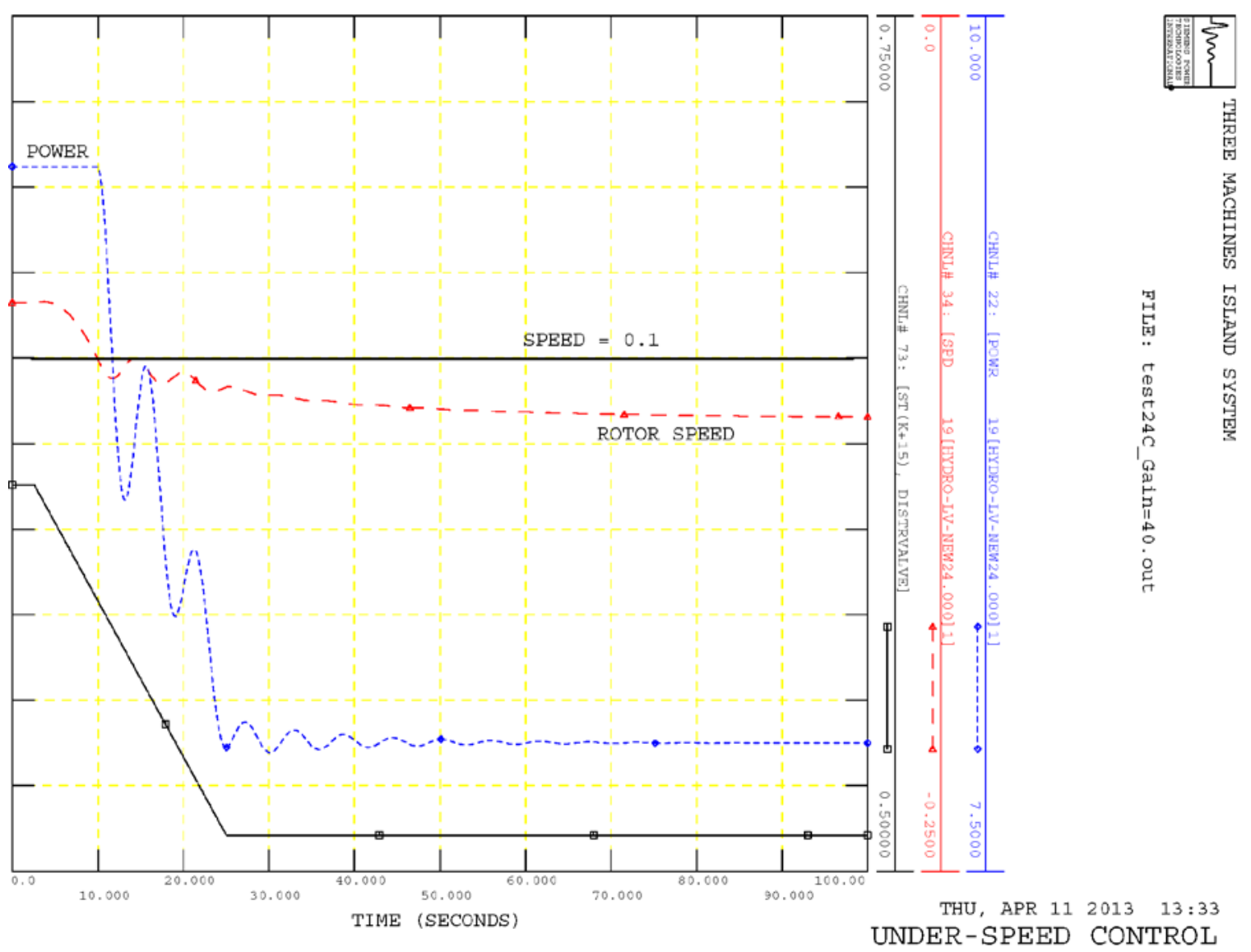

Figure 2-22 Under-Speed Control in Response to a Forced Reduction of the Gate Position (Closing of the Gate) 


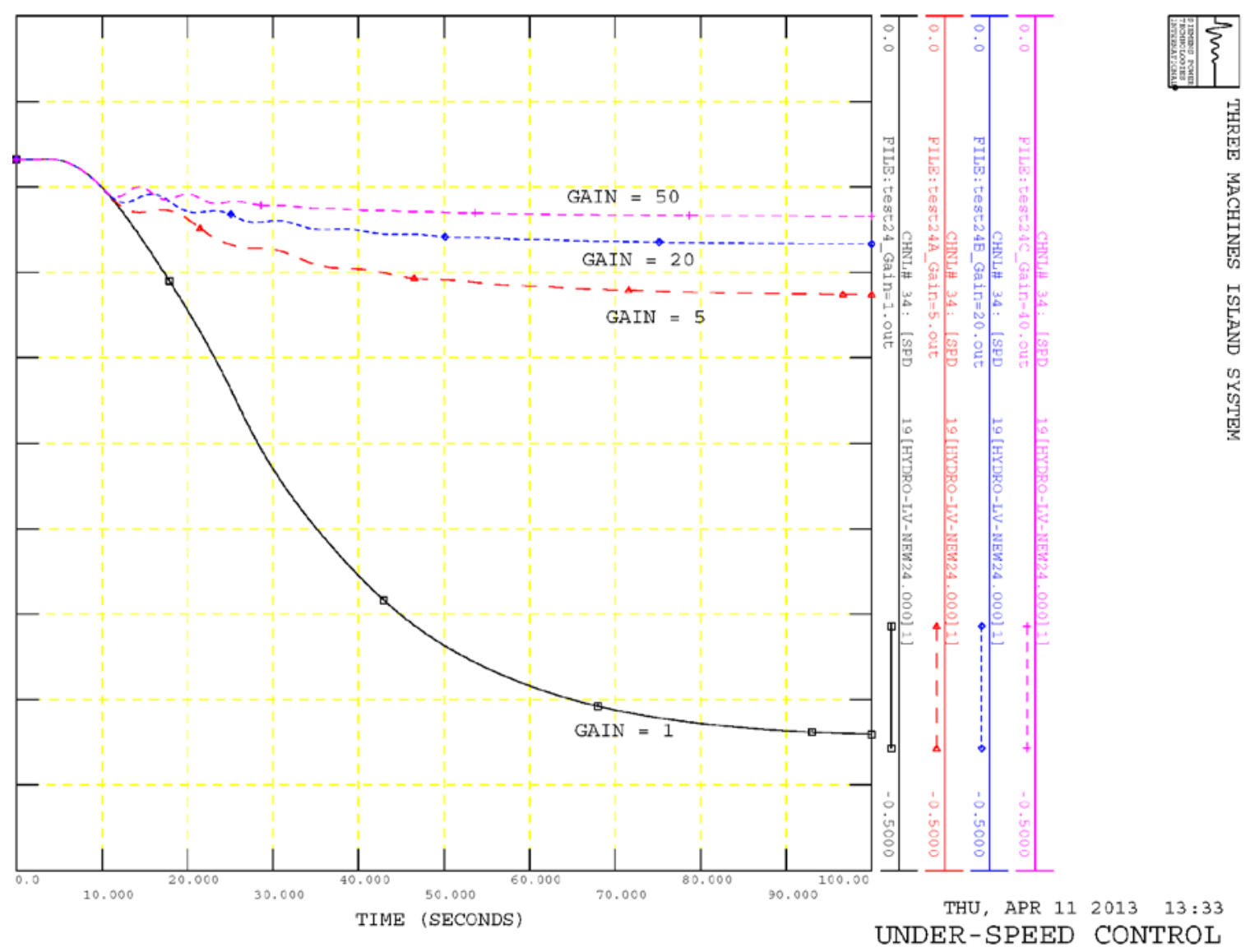

Figure 2-23 Under-Speed Control for Different Deadband Function Gains

\subsection{Testing the Pumped Storage Hydro Turbine with Several Units Sharing the Same Penstock}

The PSH model allows modeling the effects of units sharing a common penstock. This is a relatively common design consideration for plants with multiple units and a long penstock. In such installations, the major portion of the penstock is designed to handle the full flow of all the units and the penstock is bifurcated near the powerhouse into sections supplying flow to the individual units. Thus, there is a hydraulic coupling between the units as a change in the flow though a unit results in a change in the dynamic head at the bifurcation point, and thus impacts the flow through the other units. Note that this level of detail is only necessary when the units are not all at the same initial condition and responding in unison (in which case, these interdependencies all cancel out).

To test this portion of the model, the test system described above was modified to represent the large hydro unit as four individual units, each connected to bus 19, as shown in Figure 2-24. All four turbine units on bus 19 are dispatched with the same power of $239 \mathrm{MW}$, thus giving the same total power of $956 \mathrm{MW}$ as the single PSH unit in Figure 2-2. Note that in an actual implementation, each of these units would likely have its own step-up transformer to the high voltage side bus, but the purpose of the test systems is to test the models and show 
that they perform as expected, so system changes were minimized to highlight specific model characteristics.

The raw data file showing the power flow data in $\mathrm{PSS}^{\circledR} \mathrm{E}$ format is given in Appendix $\mathrm{A}$, Section A-3. The dynamic model documentation related to the four PSH turbines sharing a common penstock is given in Appendix $B$, Section B-3.

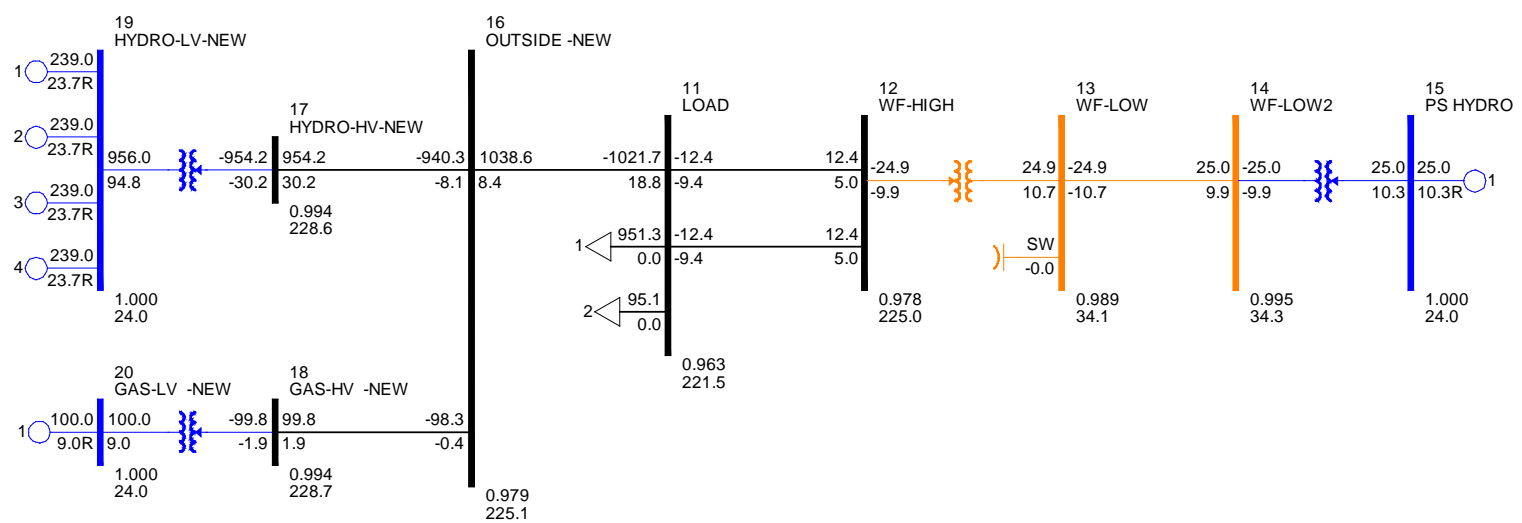

Figure 2-24 Test System with Four PSH Turbine Units Sharing a Common Penstock

When units are sharing a common penstock, it is necessary to determine a matrix representing the water time constant, rather than defining it as a simple parameter. The matrix formulation accounts for the impact of the flows through the individual sections, as well as the joint flows through common sections. In our test, the units were modeled as symmetrical; that is, each of the individual sections are the same and the common section splits into these four individual portions at a common location. Thus, the information for each of the units sharing the same penstock is the same. This simplifies the modeling and makes it much easier to explain, but the model is designed to handle non-symmetric penstock configurations.

There can be up to four units modeled sharing a common penstock. For example, for four units sharing a common penstock, the dynamic data includes the following data which define the four units; in this case, the four units on bus 19, but it could be, in a more general case, four units on different buses.

\begin{tabular}{|c|c|c|c|c|c|c|}
\hline $\operatorname{ICON}(M+2)$ & UNIT & $1 \mathrm{BUS}$ & $=$ & 19 & $\operatorname{ICON}(M+3)$ & $I D=1$ \\
\hline $\operatorname{ICON}(M+4)$ & UNIT & 2 BUS & $=$ & 19 & $\operatorname{ICON}(M+5)$ & $I D=2$ \\
\hline $\operatorname{ICON}(M+6)$ & UNIT & 3 BUS & - & 19 & $\operatorname{ICON}(M+7)$ & $\mathrm{ID}=$ \\
\hline $\operatorname{CON}(M+8)$ & UNIT & 4 BUS & & 19 & $\operatorname{ICON}(M+9)$ & ID $=$ \\
\hline
\end{tabular}

For a system of four units, sixteen parameters are required to identify a 4-by-4 matrix of water time constants. Since we are modeling a symmetric configuration, the matrix is symmetric and the information is thus the same for all four units. When calculating the derivatives of the water flow for each unit, the model uses the respective rows and columns of the matrix. For 
further discussion of the theory on modeling units sharing a common penstock, please see the references $[4,6$, and 7$]$.

This portion of the model was tested in several stages. First, a diagonal matrix for the water time constant Tw was used, with the diagonal elements of the matrix being exactly the same as in the above described test with the single turbine, that is:

$$
\mathrm{Tw}=\left|\begin{array}{cccc}
1.72 & 0 & 0 & 0 \\
0 & 1.72 & 0 & 0 \\
0 & 0 & 1.72 & 0 \\
0 & 0 & 0 & 1.72
\end{array}\right|
$$

Since the diagonal terms are all equal and there are no off-diagonal terms, the units all share the full penstock and the response of the four units should be equal to that of the lumped unit.

The test performed was the same, the drop of the 100-MW load. Figure 2-25 compares the mechanical powers of the PSH turbines with the red curve representing the mechanical power of the lumped unit from the previously described test and the pink, brown, and green curves representing the mechanical powers of three of the four units sharing the common penstock. All of the responses are the same (mechanical power is given in per unit on machine base; that is, each of the individual units represents $1 / 4$ of the lumped unit, and hence both the power and base are $1 / 4$ of the lumped unit, so the mechanical power is the same per unit for either the lumped or individual units). Figure 2-25 additionally shows that the system frequency is also exactly the same with the four units or the lumped equivalent unit. 


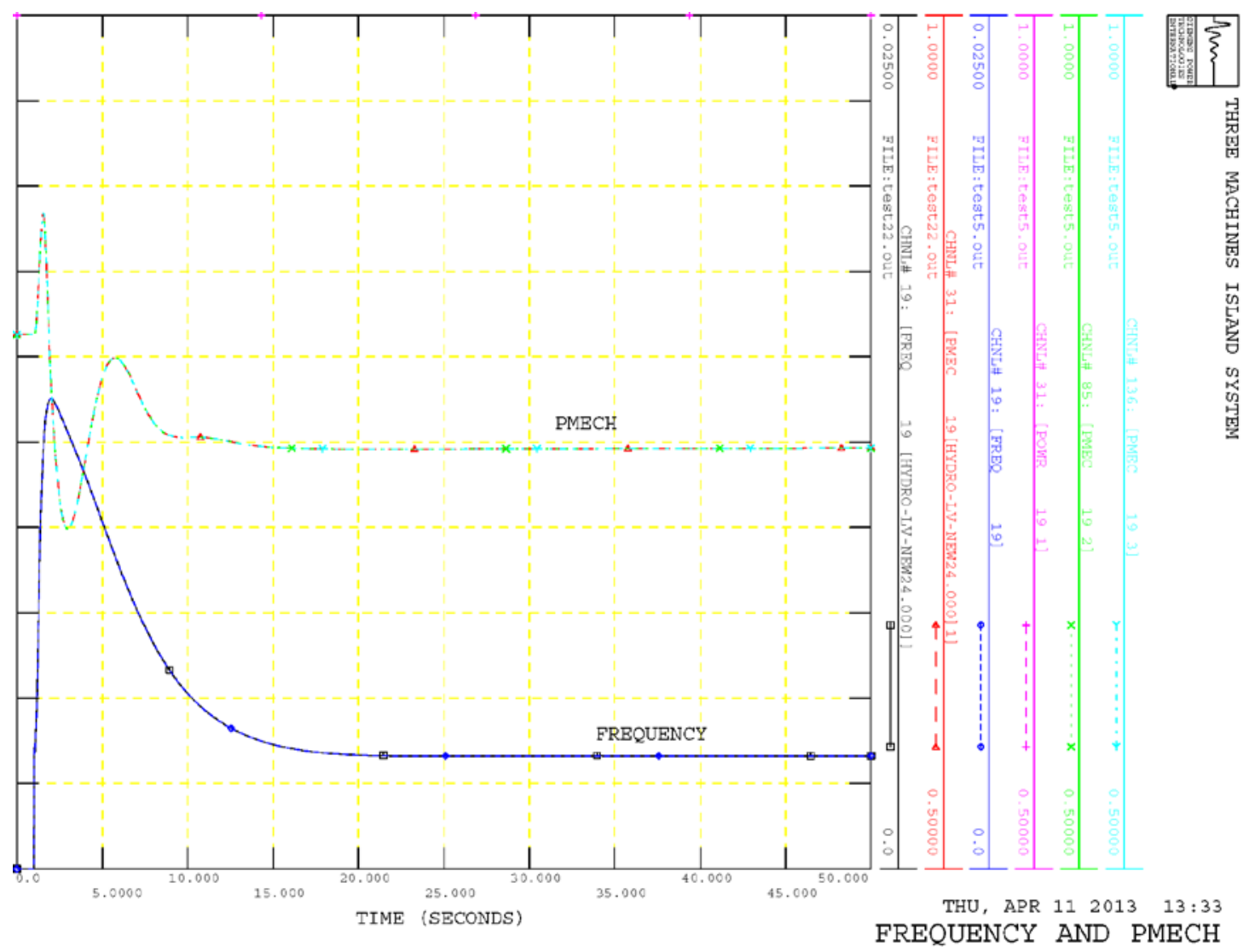

Figure 2-25 Comparison of Mechanical Power and Frequency after Disconnecting the 100-MW Load with a Single Unit and Four Units Sharing a Common Penstock

While the above test is useful to show the equivalence of the modeling methodology, it does not fully test this portion of the model. To further test the model with four PSH turbines sharing a common penstock, the hydraulic system of an existing hydroelectric project that has units sharing a common penstock was used. The plant is modeled as a common penstock shared by four units, with a bifurcation into four individual penstocks, each feeding one unit. In this case, the dimensions of the four individual penstock sections are identical (or at least very similar). Thus, the diagonal terms of the matrix are the Tw of the common penstock plus the Tw of the individual penstock portion. The off-diagonal terms are the Tw of the common penstock. For this plant, the Tw of the common penstock is 0.52 seconds and the four identical individual penstocks sections going to the four units have a Tw of 0.32 seconds. This results in the following Tw matrix:

$$
T w=\left|\begin{array}{llll}
0.84 & 0.52 & 0.52 & 0.52 \\
0.52 & 0.84 & 0.52 & 0.52 \\
0.52 & 0.52 & 0.84 & 0.52 \\
0.52 & 0.52 & 0.52 & 0.84
\end{array}\right|
$$

This matrix is a part of the dynamic input data for each unit sharing the common penstock. 
If the four units are all at the same initial loading and have similar controls, then each unit (or an equivalent plant model) will respond with an equivalent time constant of $0.84+3 \times 0.52=$ $2.4 \mathrm{sec}$.

Figure 2-26 shows the system frequency and the mechanical power of one of the four units after the 100-MW load is dropped. Figure 2-27 shows the water flows of all four units for the same disturbance.

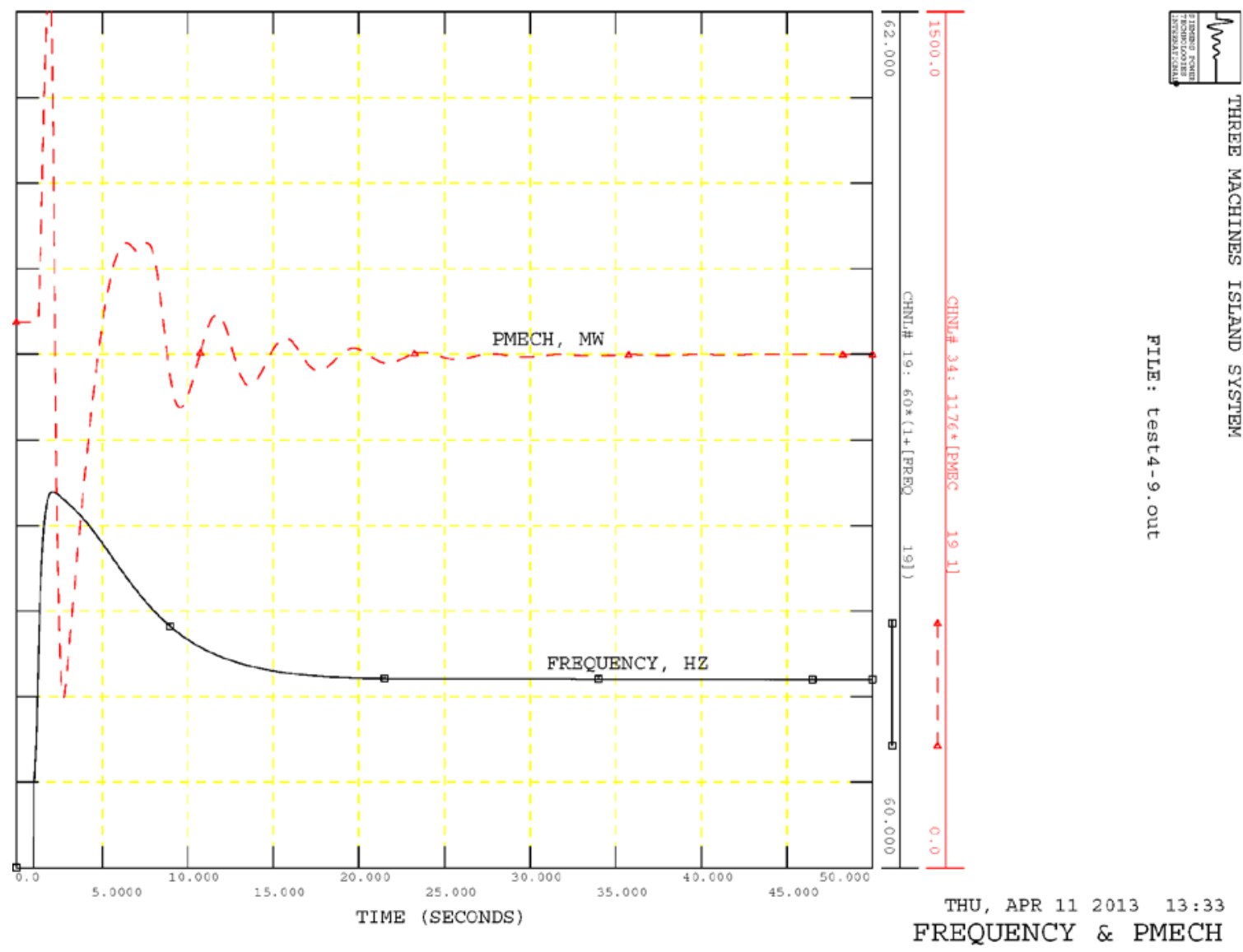

Figure 2-26 System Frequency and Mechanical Power of One of the Four Units Sharing a Common Penstock for Drop of the 100-MW Load 


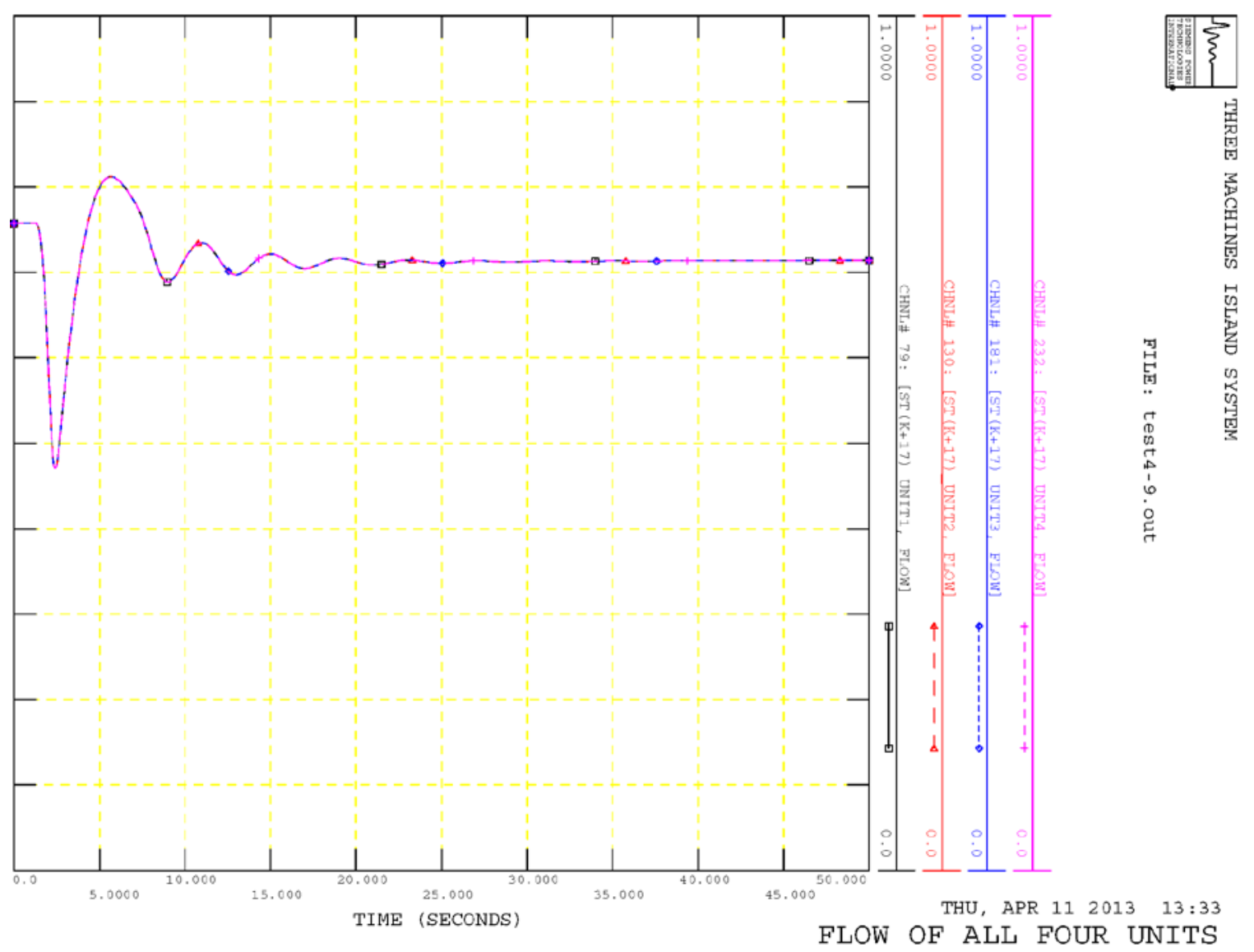

Figure 2-27 Water Flow of Each of Four Units Sharing a Common Penstock for Drop of the 100-MW Load

As shown above, if the hydraulic system for all units is the same, the responses of all units will be identical (assuming they start at the same initial condition and do not have different governor parameters).

However, in the general case, the hydraulic system need not be symmetric. The next test case models a plant with four units that share a common penstock, but with a bifurcation into four individual penstocks (each feeding one unit) that are of different dimensions. The diagonal terms of the matrix are the Tw of the common penstock plus the Tw of the individual penstock portions, and thus are also not identical. The off-diagonal terms are the Tw of the common penstock (which are all the same, since we assume that the bifurcation occurs at a common point for all four turbines). For this test, the Tw of the common penstock is assumed to be 0.52 seconds, as used previously, and the four individual penstocks sections going to the four units have a Tw of $0.28,0.32,0.36$, and 0.40 seconds respectively. Since the flows to the four units are the same, one could consider this as representing the individual penstocks as having similar cross sectional areas, but different lengths. This results in the following Tw matrix: 


$$
T w=\left|\begin{array}{llll}
0.80 & 0.52 & 0.52 & 0.52 \\
0.52 & 0.84 & 0.52 & 0.52 \\
0.52 & 0.52 & 0.88 & 0.52 \\
0.52 & 0.52 & 0.52 & 0.90
\end{array}\right|
$$

Figure 2-28 and Figure 2-29 show the electrical powers and mechanical powers of each of four units sharing the common penstock for this non-symmetric penstock system. Note that there is very little difference seen in the response of the four units. However, the difference would be more pronounced in cases where, for example, the units are not all at the same initial loading.

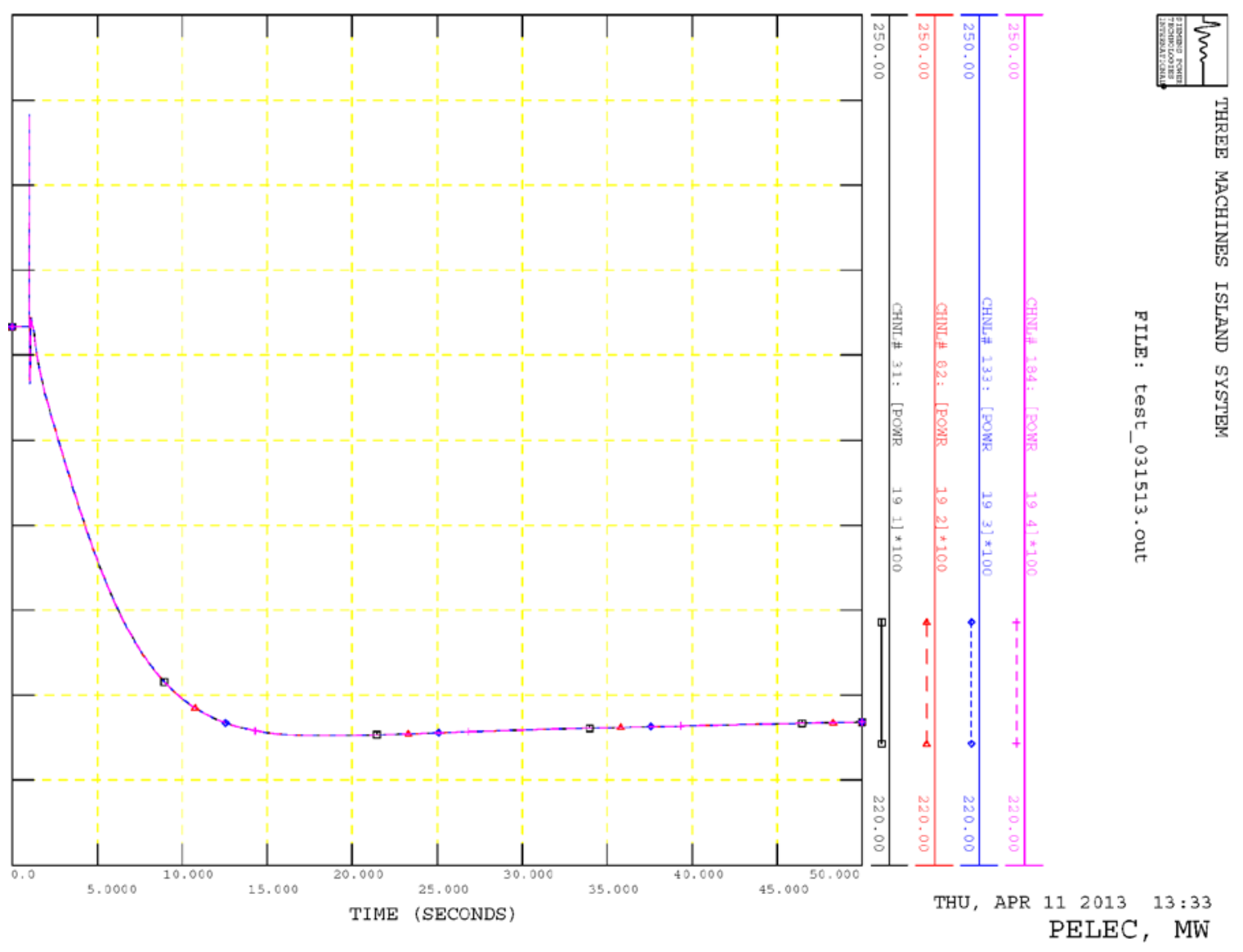

Figure 2-28 Active Powers of the Four Units Sharing a Common Penstock with a Non-Symmetrical Penstock Configuration for Drop of the 100-MW Load 


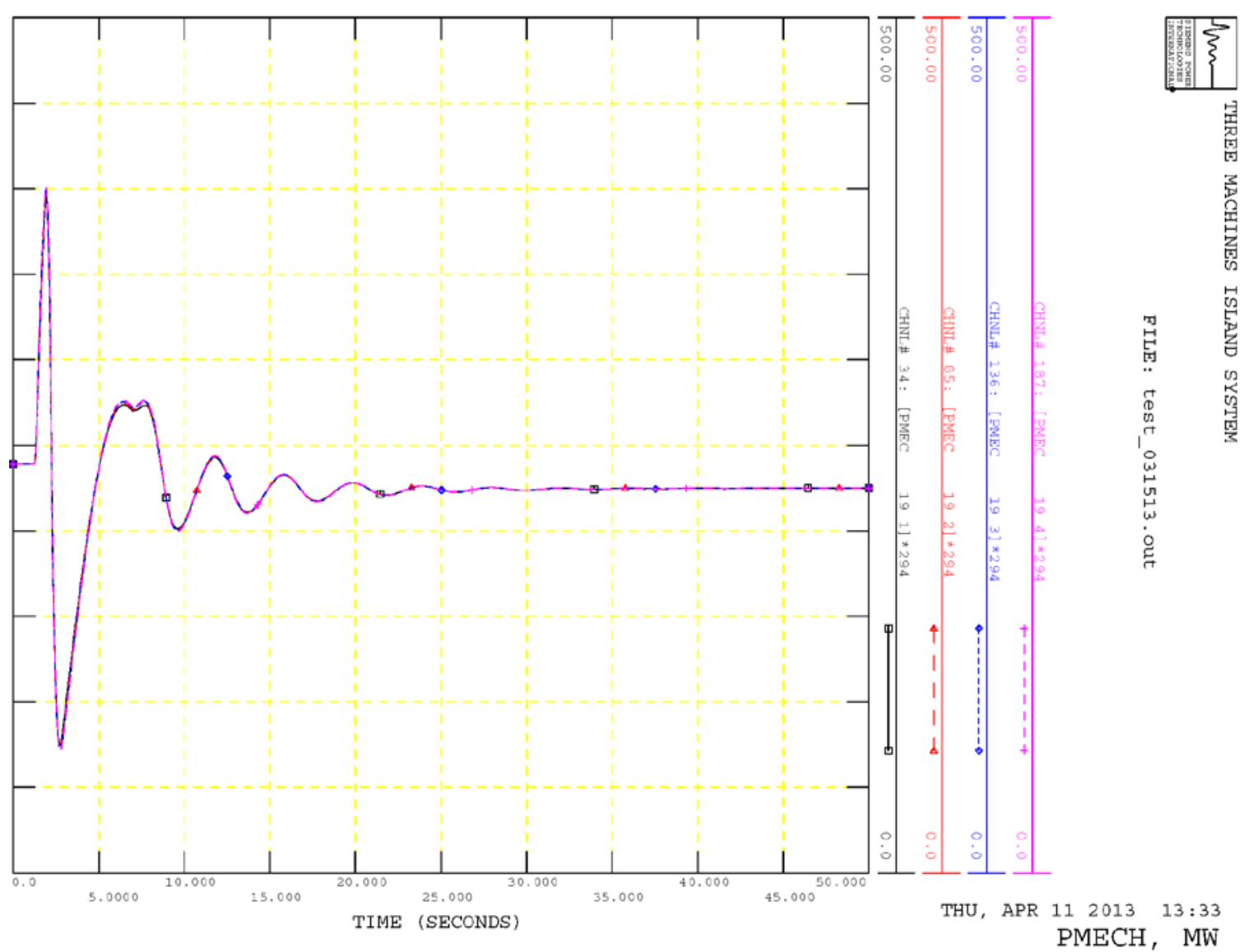

Figure 2-29 Mechanical Powers of the Four Units Sharing a Common Penstock with a Non-Symmetrical Penstock Configuration for Drop of the 100-MW Load

The next test illustrates the impact of the flow of an individual unit on the flows of the other units sharing the common penstock with it; that is, the cross coupling of the flows modeled by the matrix of water time constants. The test simulated the reduction in the power output of unit 1 in a step-wise manner (simulated by a step-wise reduction in the active power controller limit Ipmax). The dynamics of the model results in a reduction of the gate position of unit 1 to bring the unit's electrical and mechanical power back into equilibrium. It can be seen in Figure 2-30 that the power output of the other three units increases. This is explained by the change in water flows of all four units shown in Figure 2-31. The reduction in the gate position of unit 1 causes a reduction in the flow through unit 1 . The reduction in the power output of unit 1 also results in a decrease in system frequency due to the resulting generation/load imbalance. This then results in an increase in the power (though an increase in gate position and flow) of the other three units. The test illustrates both the coupling of the hydraulic systems as well as the ability of individual unit flows to move in different directions due to the event being simulated.

The algorithm of the model is designed in such a way as to automatically handle the situation when one or more of four units sharing the same penstock is initially off-line. However, the model does not allow tripping of one of the units sharing the same penstock in the course of 
the simulation (the simulation program does not call the governor model for an off-line unit, and hence the flow to that unit would not be calculated for each time step. Trip of the unit would not cause the water flow to go instantaneously to zero. Isolation of the a unit from the system (for example, simulating trip of its main breaker) can be simulated as the unit would remain on-line (albeit not connected to the system), and the closing of the gate and reduction in flow to stop the unit's over-speed would be calculated.

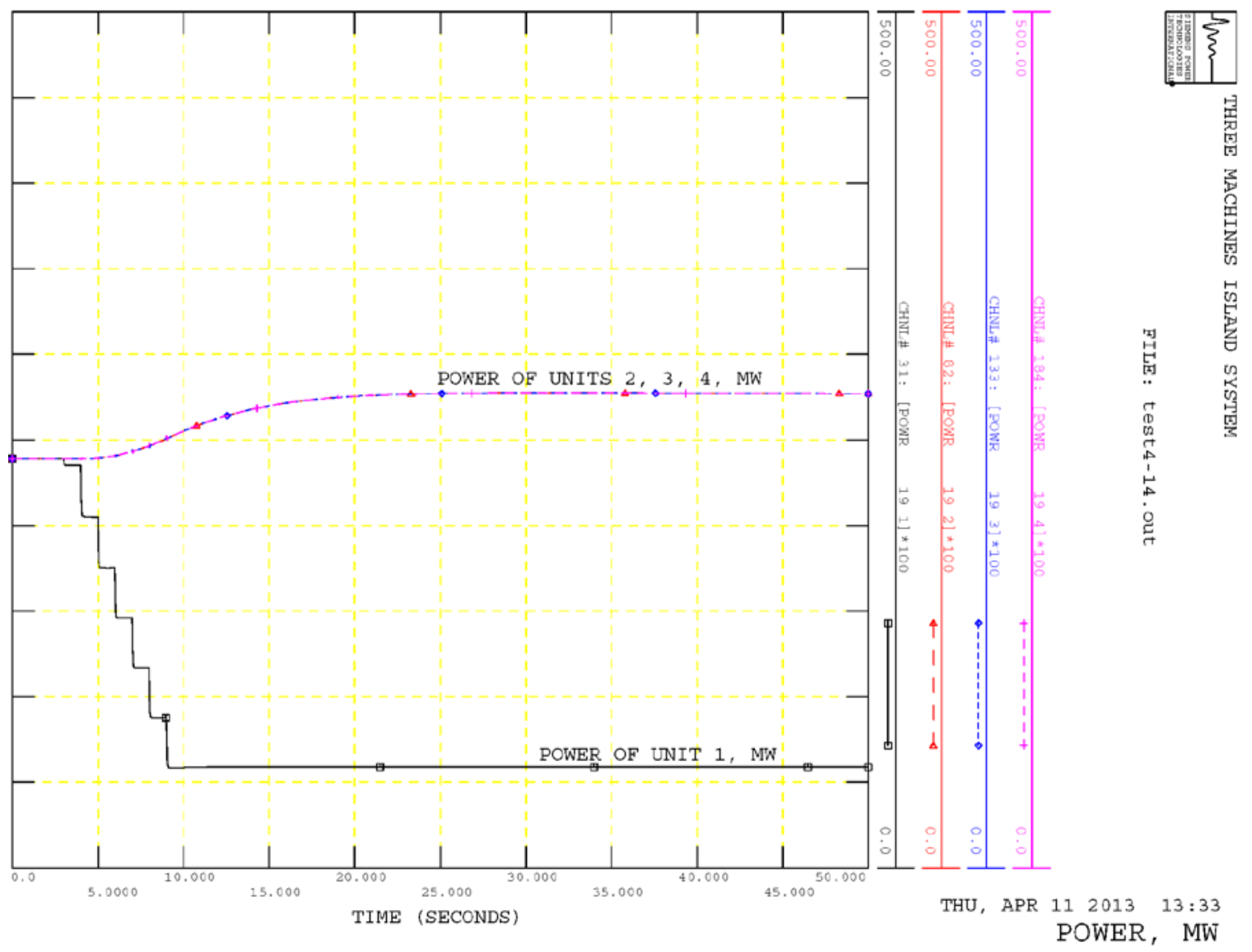

Figure 2-30 Response of the Power of Units 2, 3, and 4 to a Step Reduction in the Power of Unit 1 with Four Units Sharing a Common Penstock 


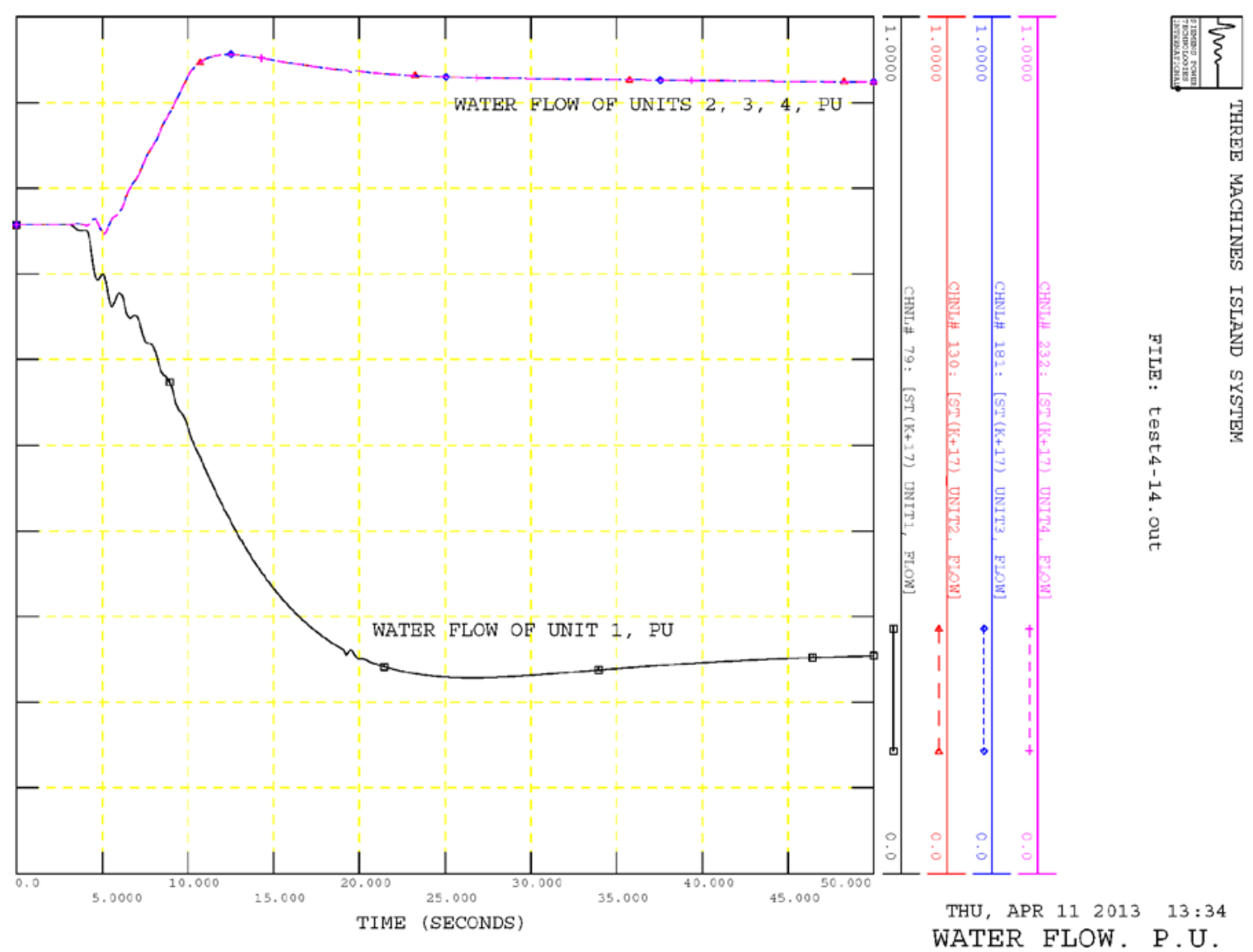

Figure 2-31 Response of Water Flows to a Step Reduction in the Power of Unit 1 with Four Units Sharing a Common Penstock 


\section{Section \\ 3}

\section{Adjustable Speed Pumped Storage Hydro Pump Employing a Doubly Fed Induction Machine}

The block diagram of the model for the DFIM-based pump is provided in Figure 3-1. As in the generating mode, the converter module is responsible for controlling active power and voltage. However, the AS PSH unit has two significant advantages over a conventional PSH unit. Whereas a conventional PSH unit does not participate in frequency control when pumping, the AS DFIM unit is able to participate in frequency control in both generating and pumping modes. The AS PSH unit also has the ability to improve the efficiency of pumping by optimizing the rotor speed and gate position.

The power command is combined with the command from the frequency controller to create the power set point Pset. It is used as an input for the speed optimizer whose output is the speed reference. The speed error processed through the "slow" speed PI controller makes up an additional input to the "fast" PI power controller. Hence, finally, frequency will be controlled and the rotor speed will be adjusted.

The pump module represents the hydro pump, gate, and penstock dynamics. The total power command Pset is also used by the gate optimizer to determine the desired gate position. The speed and gate optimizers select the proper coordination of speed and gate position to maximize efficiency. The optimal power/gate/speed relationships are represented through a simplified functional characteristic that should be built based on the information provided by the manufacturer. This module allows taking into consideration the hydraulic coupling effect for up to 4 pump units sharing a common penstock.

For the pump model, the static head in the turbine model must be replaced by the pump head, which is a function of the water flow. An example of this function obtained from an existing plant is shown in Figure 3-2 for a unit rotating at rated speed. 


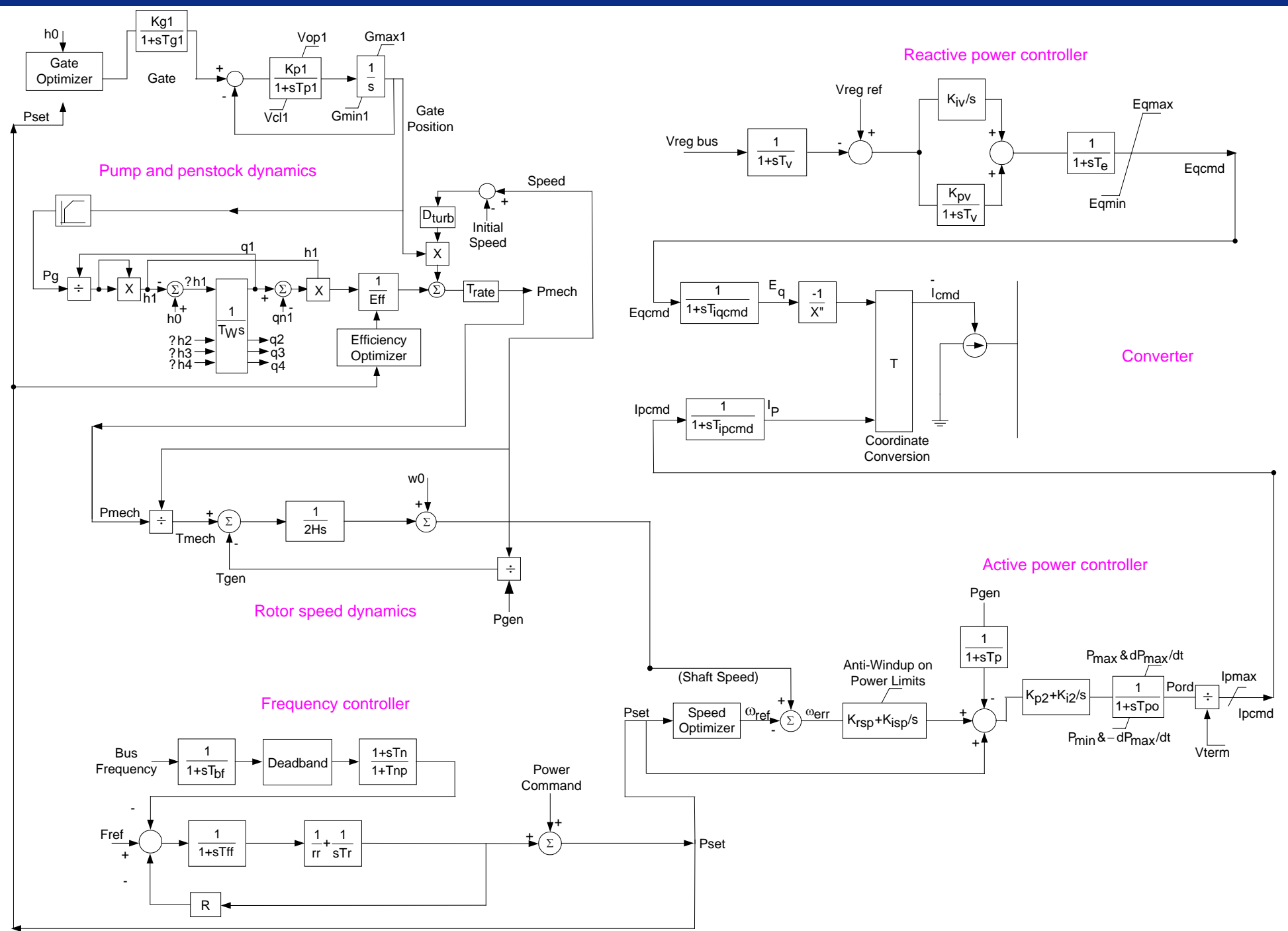

Figure 3-1 Block Diagram of the DFIM-Based Pump Model 


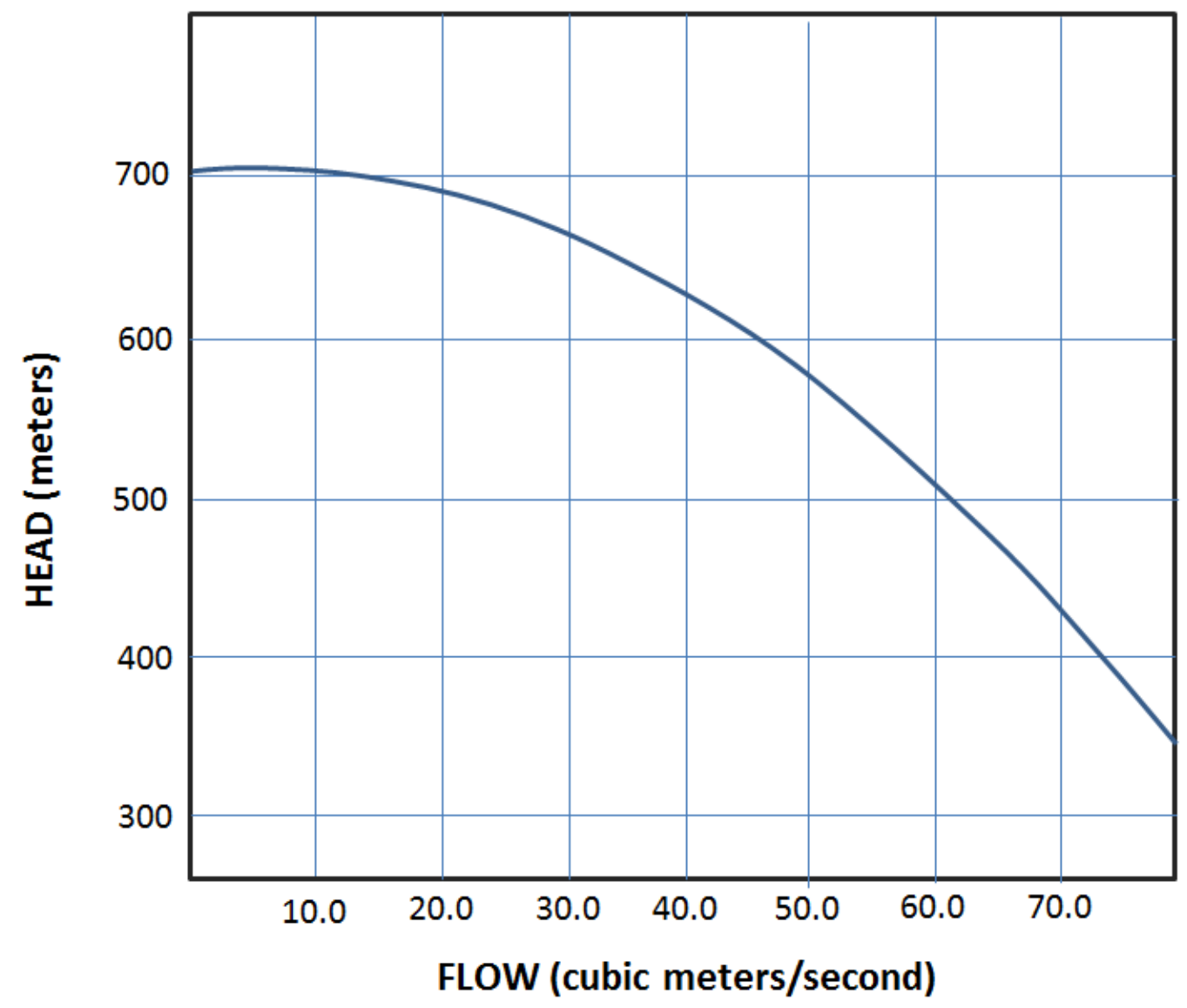

Figure 3-2 Pump Head Versus Water Flow

A quadratic approximation was suggested for this pump head-flow function. However, if speed deviations during transient conditions are noticeable, the pump head should be adjusted. The model allows adjustment of the pump head, per affinity law, proportionally to the square of speed.

Mechanical power is calculated as the product of flow and head divided by efficiency. Thus, the characteristic of the efficiency optimizer is an input to the model.

\subsection{Initialization of the Pump Model}

The non-linear nature of the pump flow-head characteristic causes significant initialization problems and makes success of initialization sensitive to the parameters of the model.

The sign convention being used for the pump model is that mechanical power Pmech $<0$, water flow $\mathrm{q}<0$, and head $\mathrm{hp}>0$.

Following recommendations given in reference [4], the model employs the following approximation for the water flow-pump head characteristic of Figure 3-2: 


$$
h p=\left(A_{o}+A_{1} \times q+A_{2} \times q^{2}\right) \times(1+d w)^{2}
$$

where $A_{o}=1.174, A_{1}=-0.0666, A_{2}=-0.354$

and $d w$ is the initial rotor speed deviation.

From the block diagram in Figure 3-1:

$$
\mathrm{P}_{\text {mech }} / \mathrm{T}_{\text {rate }}=\mathrm{hp} \times \mathrm{q} / \mathrm{Eff}
$$

The mechanical power of the pump is known from the initial steady state mode of operation. During the model initialization, the initial water flow q must be found based on the initial mechanical power Pmech. After substituting the pump head from (3.2) into (3.1), a cubic equation is obtained, as follows:

$$
P_{\text {mech }} / T_{\text {rate }}=\left(A_{0} \times q+A_{1} \times q^{2}+A_{2} \times q^{3}\right) \times(1+d w)^{2} / E f f
$$

Curves in Figure 3-3 represent solutions of this equation for several combinations of the rotor speed deviation dw and efficiency Eff.

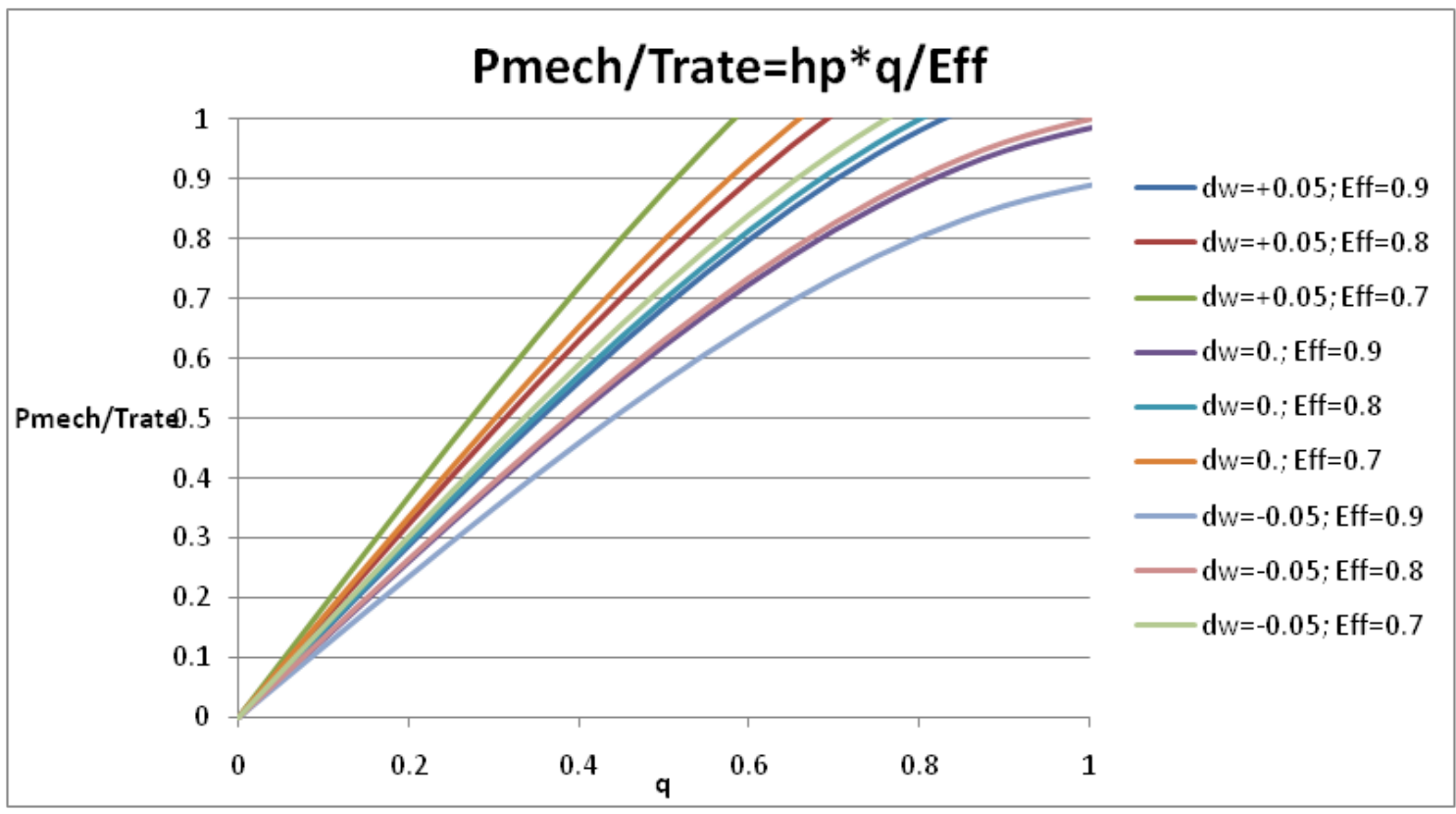

Figure 3-3 Solution for the Pump Model Initialization

From these curves, we know the values of Pmech/Trate at which the model can be successfully initialized.

Initial values for the rotor speed deviation dw and efficiency Eff are provided at initialization by the respective optimizers. A careful analysis of available publications was carried out, and it was found that reference [5] provided the most relevant information. 
Based on this analysis, the suggested characteristics of the rotor speed optimizer are shown in Figure 3-4 and the characteristics of the efficiency optimizer are shown in Figure 3-5.

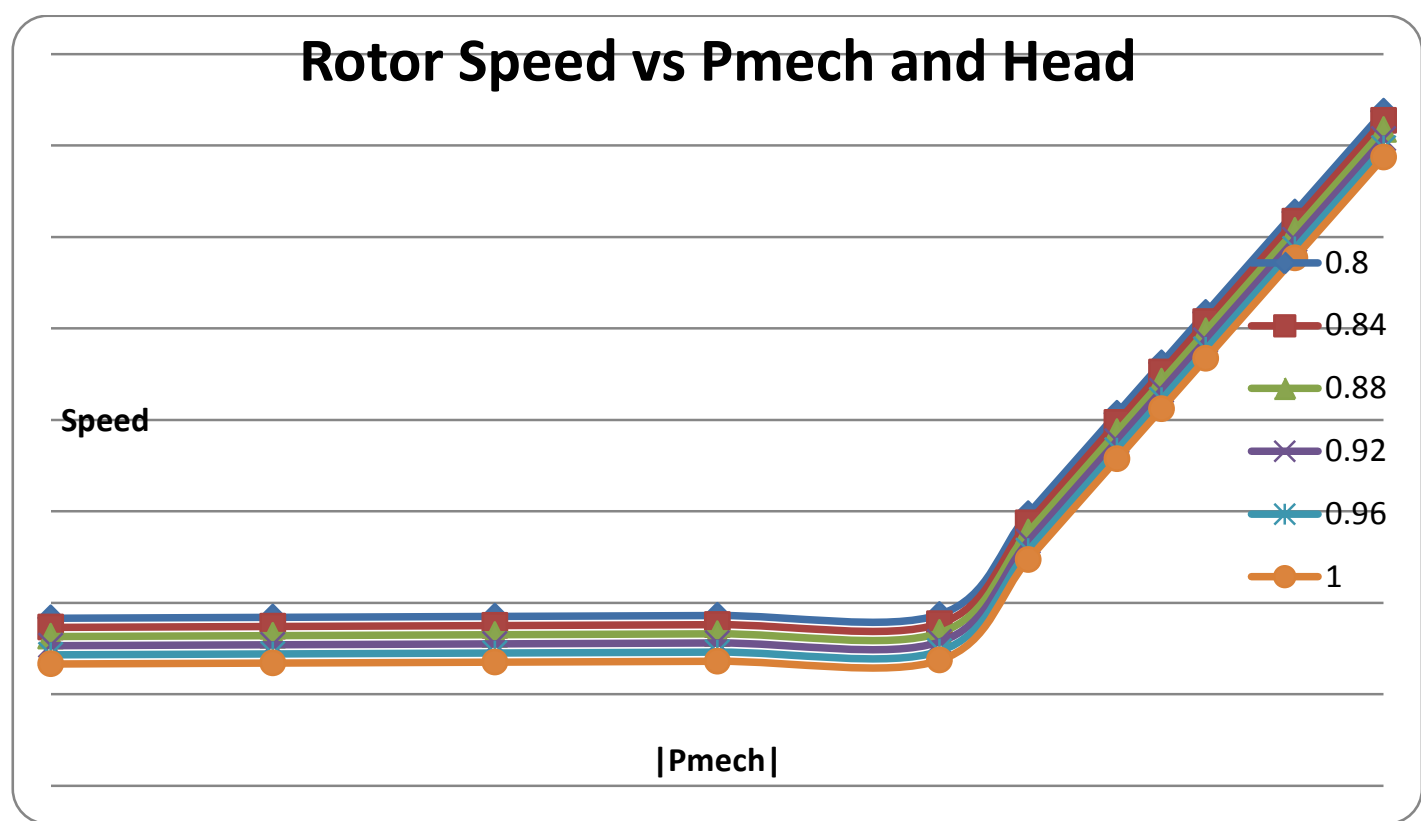

Figure 3-4 Pump Rotor Speed Optimizer Characteristics

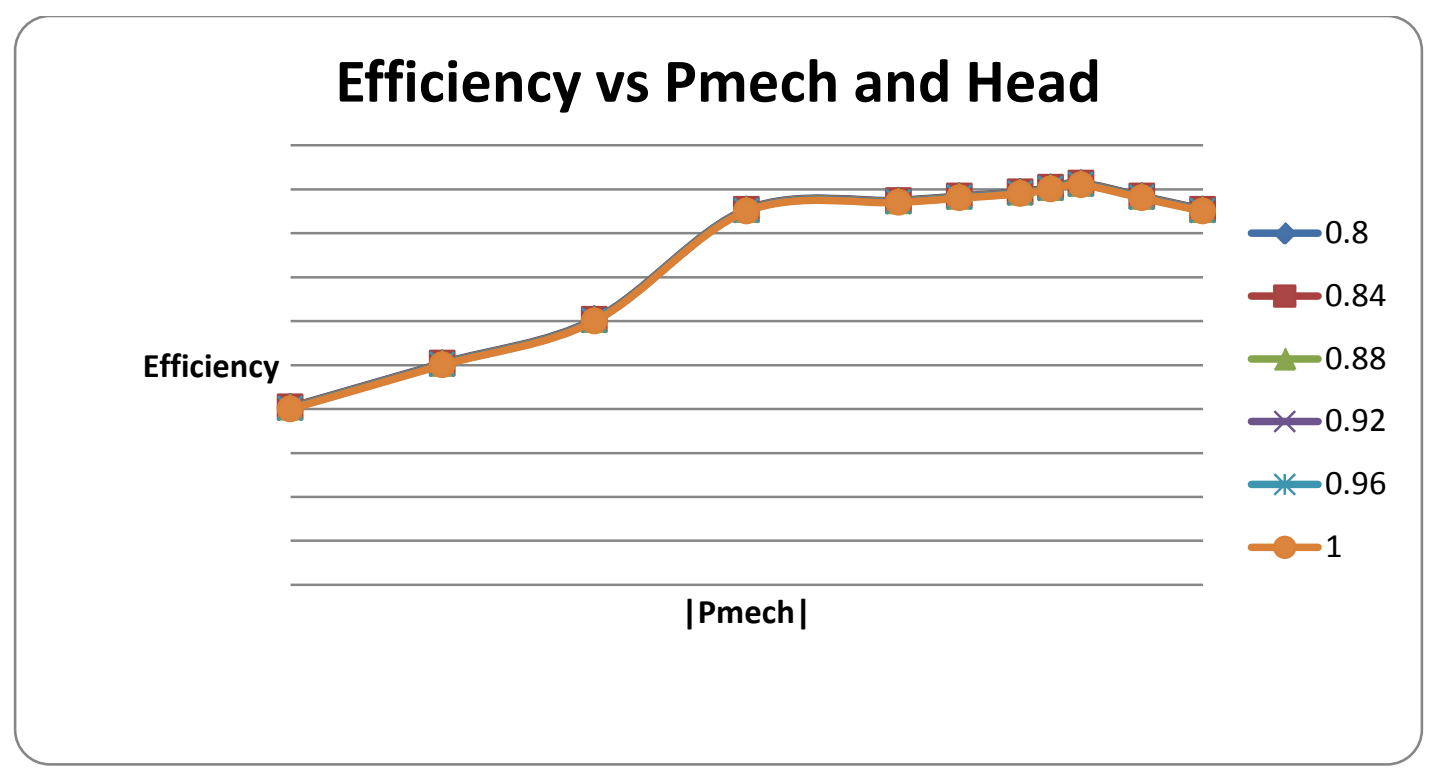

Figure 3-5 Pump Efficiency Optimizer Characteristics

With these characteristics and the suggested pump head- flow relationship hp(q) approximation, the model can be initialized for the practical range of initial Pmech. This is illustrated by the range of initial conditions shown in Table 3-1. 
Table 3-1 Initialization of the Pump Model

\begin{tabular}{cc}
\hline Pmech/Trate, p.u. & q, p.u. \\
\hline-0.9481 & -1.0565 \\
-0.9340 & -1.0316 \\
-0.8997 & -0.9781 \\
-0.8650 & -0.9354 \\
-0.8304 & -0.8979 \\
-0.7950 & -0.8601 \\
-0.7613 & -0.6913 \\
-0.7266 & -0.6554 \\
-0.6921 & -0.6213 \\
-0.6575 & -0.5159 \\
-0.6228 & -0.4902 \\
-0.5883 & -0.4651 \\
\hline
\end{tabular}

However, we note that the definitions of the characteristics of the rotor speed optimizer and the efficiency optimizer and the pump head-flow relationship must be coordinated and consistent to ensure that an operating point is possible. If the user would like to use another approximation for $\mathrm{hp}(\mathrm{q})$ or different characteristics of the speed and/or efficiency optimizers, then the solvability of the model initialization should be carefully checked by building curves similar to ones shown in Figure 3-3.

\subsection{Testing the Pumped Storage Hydro Pump}

\subsubsection{Test system}

The test system shown in Figure 3-6 includes 10 buses of 24, 34.5, and $230 \mathrm{kV}$ and is a modification of the system used to test the turbine model. There are two generating units and a pump unit. The pumped storage hydro unit (in pumping mode) under study is represented by the 1,276-MVA motor on bus 19 of $24 \mathrm{kV}$ and dispatched at $-500 \mathrm{MW}$. A gas turbine unit of 2,400 MVA is connected to bus 20 of $24 \mathrm{kV}$. A conventional hydro unit of 28.9 MVA is connected to the $24-k V$ bus 15 . There are two loads of approximately 1,000 and $100 \mathrm{MW}$ connected to the $230-\mathrm{kV}$ bus 11.

Parameters of the test system are shown in Figure 3-6. Figure 3-7 shows the base case power flows. The load flow raw data file in $\mathrm{PSS}^{\circledR} \mathrm{E}$ format is given in Appendix $A$, Section $A-2$.

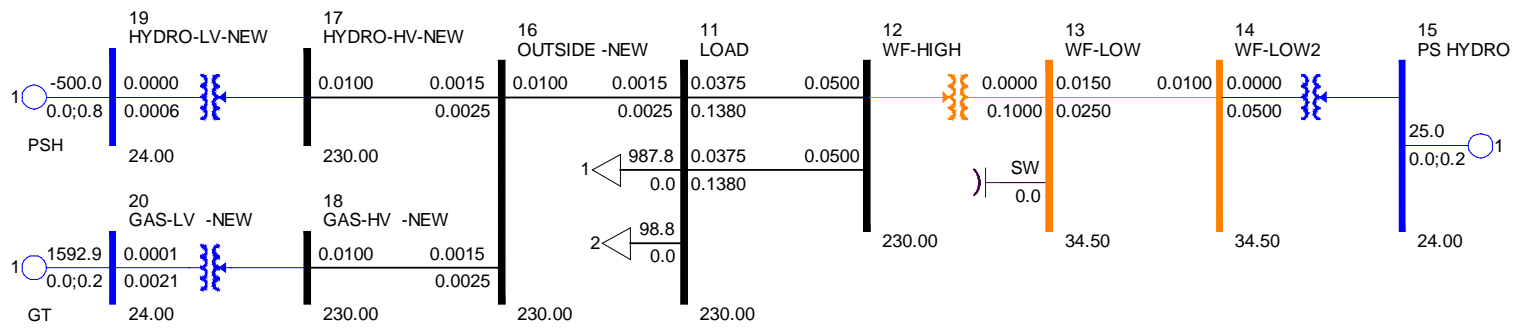

Figure 3-6 One-Line Diagram of the Test System Showing Parameters 


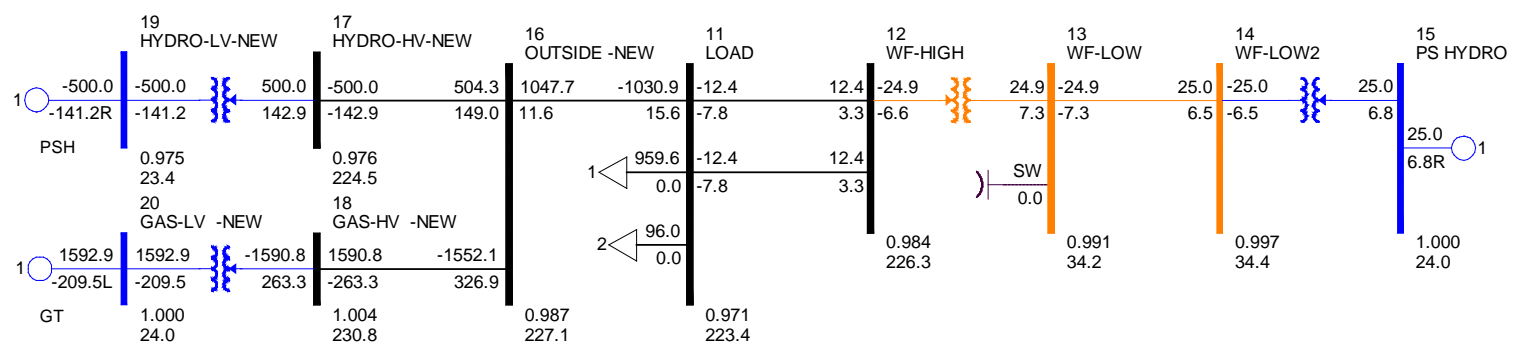

Figure 3-7 One-Line Diagram of the Test System Showing Power Flows

The documentation of the parameters for the dynamic model is provided in Appendix B, Section B-4.

The conventional hydro unit on bus 15 uses the same set of models and parameters as before, namely, GENSAE for the machine, IEEEX1 for the excitation system, and HYGOV for the turbine-governor. Only the machine model is used for the gas turbine on bus 20 . The gas turbine on bus 20 is represented only by a machine model; that is, no explicit excitation system or governor models, and thus modeled as on manual excitation control and with, for example, a large deadband in the governor controls. This further emphasizes the controls on the PSH unit.

\subsubsection{Test of the pumped storage hydro unit in pump mode}

The figures below show the response to trip of the 100-MW load.

The response of system frequency is shown in Figure 3-8. The frequency peak is $60.62 \mathrm{~Hz}$, and frequency is controlled by the pump controls, which in this case are dominant, as the pump is much larger than the small conventional hydro unit and the gas turbine is modeled as not responsive to frequency (to accentuate the PSH control action).

Figure 3-9 shows the response of the mechanical power (red curve) and active power (black curve of the pump. Both are increased (more power drawn from the system) to compensate for the loss of the load.

The rotor-speed response (black) and the speed reference (red) are shown in Figure 3-10. The speed is controlled to settle at the speed reference. Note that optimization of the controls was not an objective of this testing, so control performance is not necessarily indicative of actual operation.

Figure 3-11 shows the gate reference and the gate position, which closely follows the reference value. The gate is opened (increase in gate position) to increase the water flow and the power drawn by the pump/turbine.

The tests demonstrate that the AS PSH unit can regulate frequency while operating in a pumping mode, which is an advantage over conventional PSH units. 


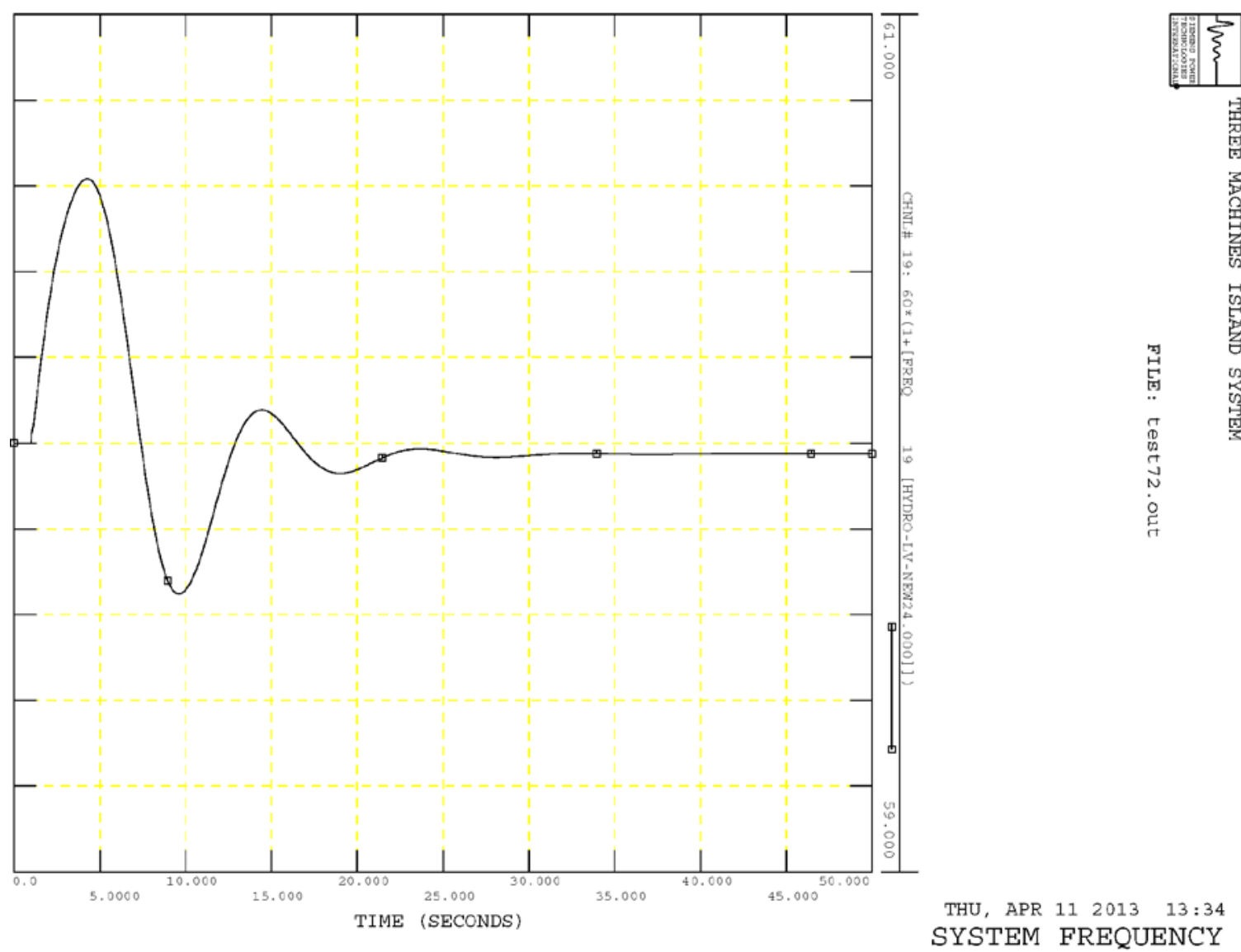

Figure 3-8 Response of System Frequency to the Drop of the 100-MW Load 


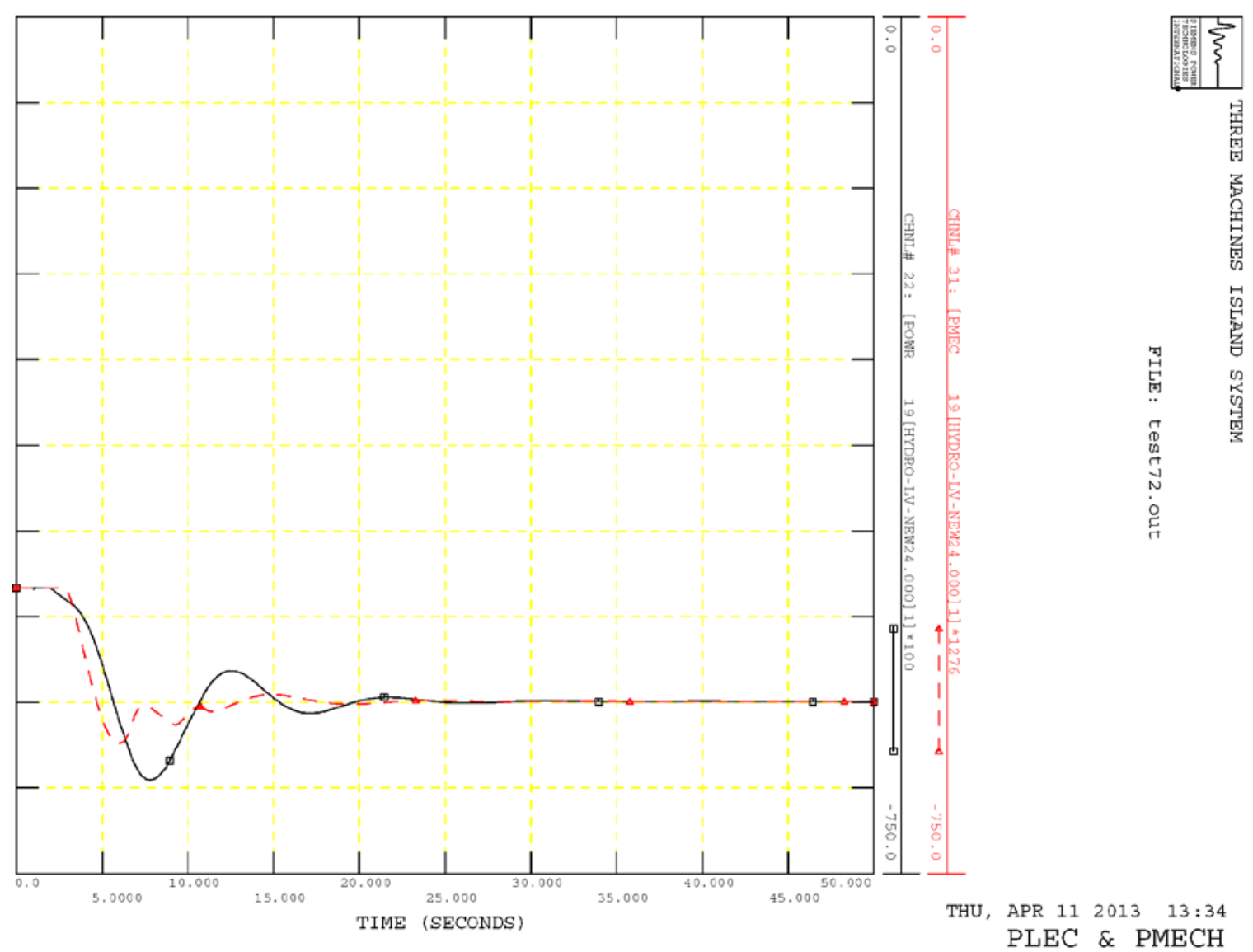

Figure 3-9 Response of Mechanical Power and Electrical Power of the Adjustable Speed PSH Pump to the Drop of the 100-MW Load 


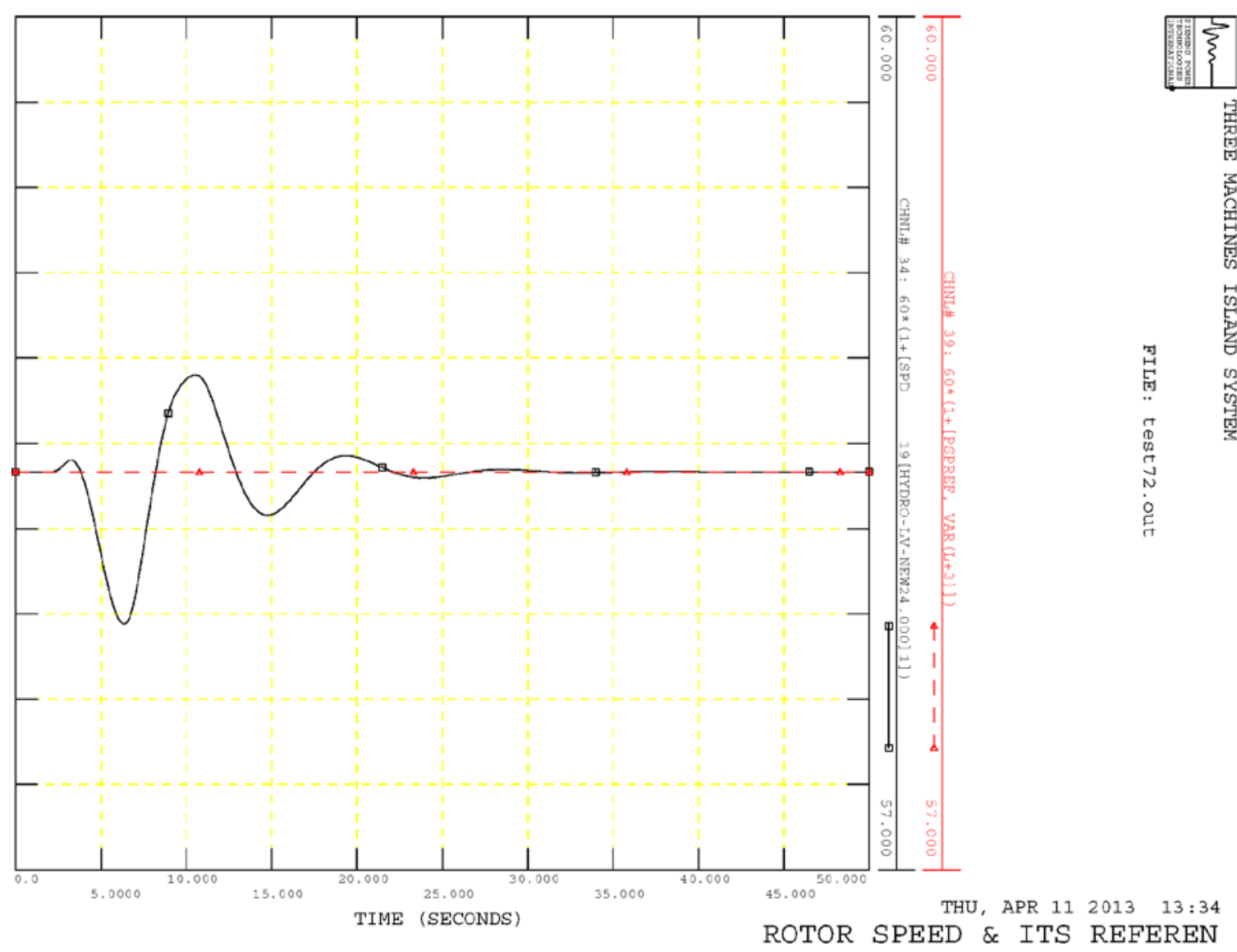

Figure 3-10 Response of Rotor Speed and Rotor Speed Reference of the Adjustable Speed PSH Pump to the Drop of the 100-MW Load 


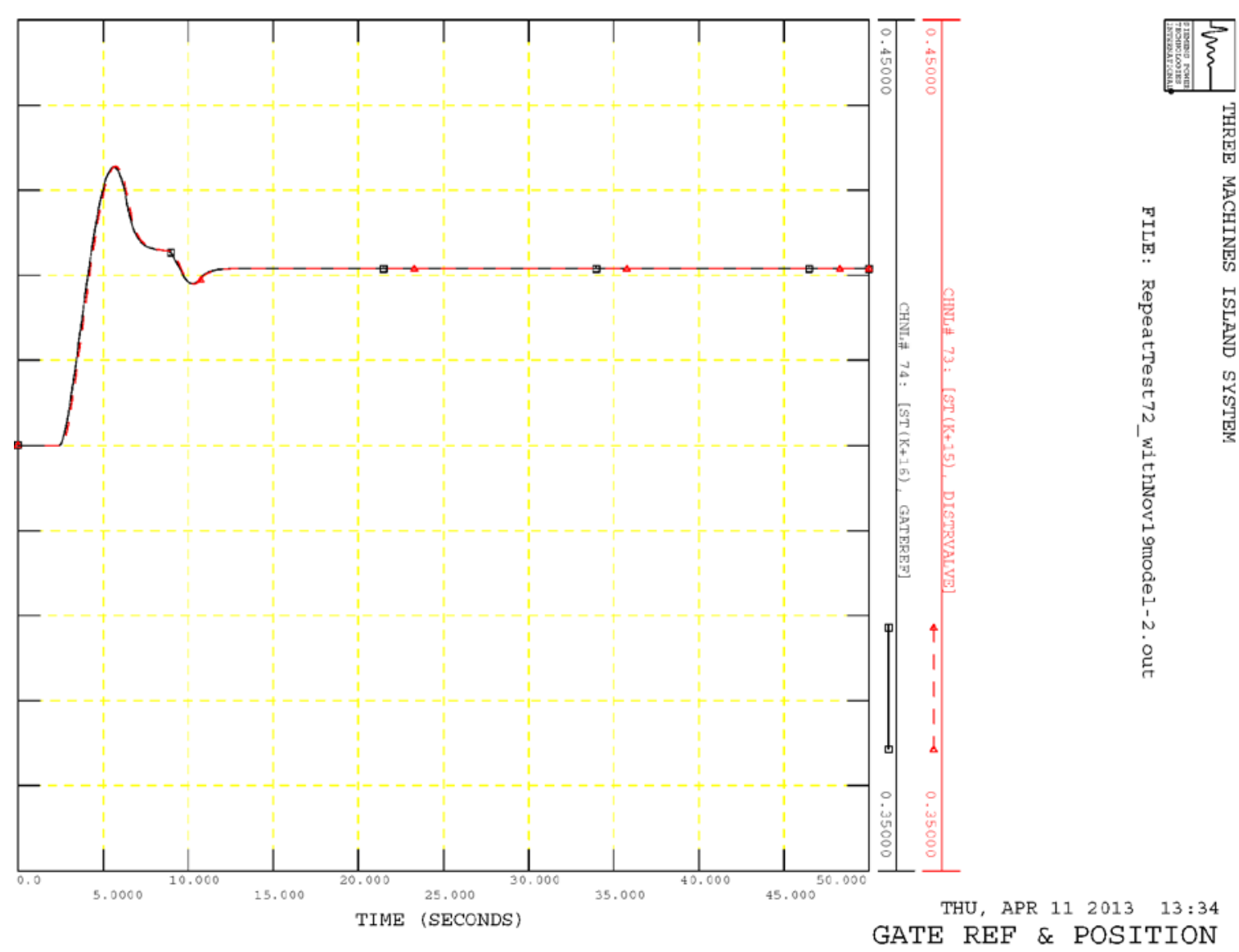

Figure 3-11 Response of Gate Reference and Gate Position of the Adjustable Speed PSH Pump to the Drop of the 100-MW Load 
This page intentionally left blank. 


\section{Section \\ 4}

\section{Ternary Pumped Storage Hydro Unit}

The model for the ternary unit incorporates all three potential modes of operation (turbine operation only, pump operation only, or both turbine and pump operation, i.e., hydraulic shortcircuit [3].

In the generating mode, with only the turbine in operation, the model of the ternary unit is similar to that of a conventional hydro unit. Conventional models are used for the salient pole machine and the excitation system. The machine will participate in the usual governor speed control, similarly to the other generators on the system. The block diagram for the conventional turbine is shown in Figure 4-1. Note that in Figure 4-1 the block diagram of the model is supplemented with a block diagram that illustrates calculation of the rotor speed deviation with the governor model's output mechanical power Pmech as an input (this portion of the figure is actually part of the generator model). The sign convention for the ternary PSH model in generating mode is that active power Pgen is positive.

In pumping mode, with only the pump in operation, the model of the ternary unit is again similar to that of a conventional hydro pump unit. Conventional models are used for the salient pole machine and the excitation system. The unit will not participate in governor speed control. The block diagram for the pump is shown in Figure 4-2. As noted above for Figure $4-1$, the block diagram of the model is supplemented with a block diagram that illustrates calculation of the rotor speed deviation with the governor model's output mechanical power Pmech as an input (this portion of the figure is actually part of the generator model). The sign convention for the ternary PSH model in pumping mode is that active power Pgen is negative.

The third mode is the hydraulic short-circuit operation when both the turbine and the pump are working together. In this mode, the unit can participate in governor speed control. Again, conventional models are used for the salient pole machine and the excitation system. The block diagram for the ternary unit with both turbine and pump in operation is shown in Figure 4-3. The block diagram of the model is again supplemented with a block diagram that illustrates calculation of the rotor speed deviation with the governor model's output mechanical power Pmech as an input (this portion of the figure is actually part of the generator model). The total mechanical power is the summation of the power produced by the turbine (positive quantity) and absorbed by the pump (negative quantity).

The total power for the hydraulic short-circuit mode of operation is always negative, i.e. the pumping power is always greater than the turbine power. At initialization of the dynamic 
model, the net electric power Pgen will be split between the turbine and the pump, based on the distribution coefficient $\mathrm{Kd}$ :

$$
\begin{aligned}
& \text { Pgen_pump }=\mathrm{Kd} \times \text { Pgen } \\
& \text { Pgen_turbine }=(1-\mathrm{Kd}) \times \text { Pgen }
\end{aligned}
$$

Note that since the net power must be negative (the magnitude of the pump power is greater than the magnitude of the turbine power), Pgen_pump must be $<0$, and Pgen_turbine must be $>0$, it is necessary that $\mathrm{Kd}$ be $>1$. The user should be careful to ensure that the distribution coefficient $\mathrm{Kd}$ results in powers for both the pump and turbine that are within their respective capabilities. 


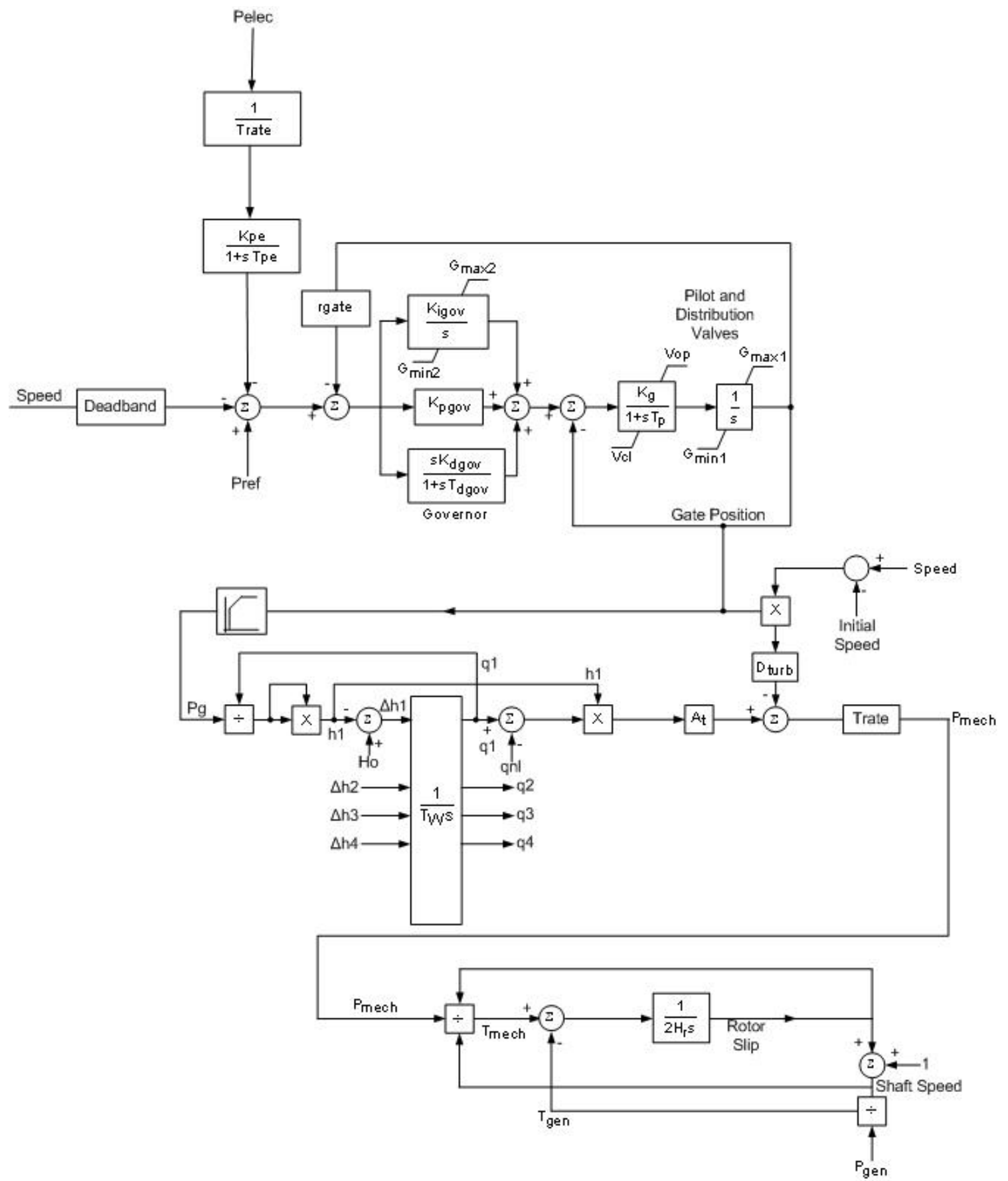

Figure 4-1 Ternary Unit Turbine Model 


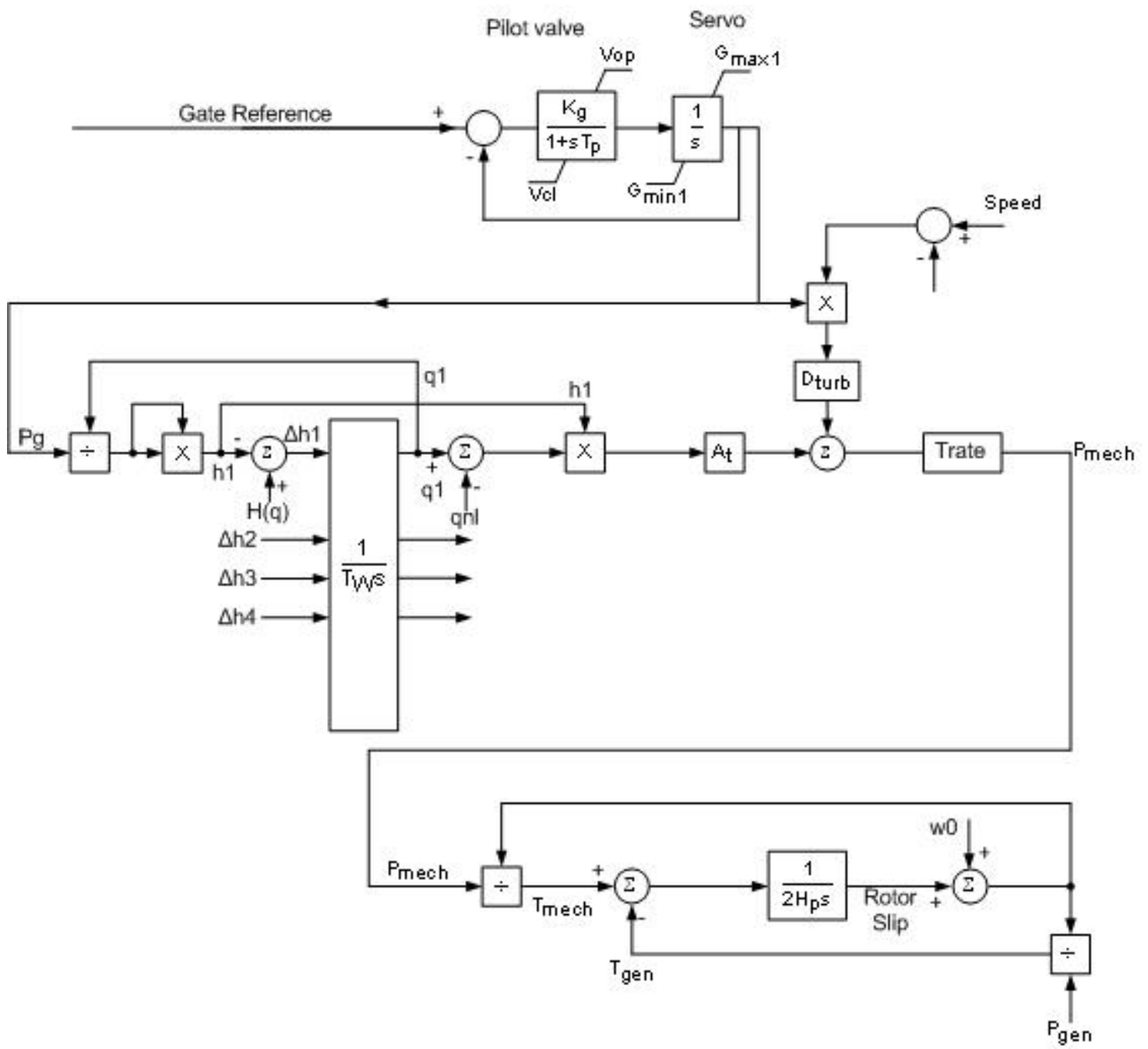

Figure 4-2 Ternary Unit Pump Model 


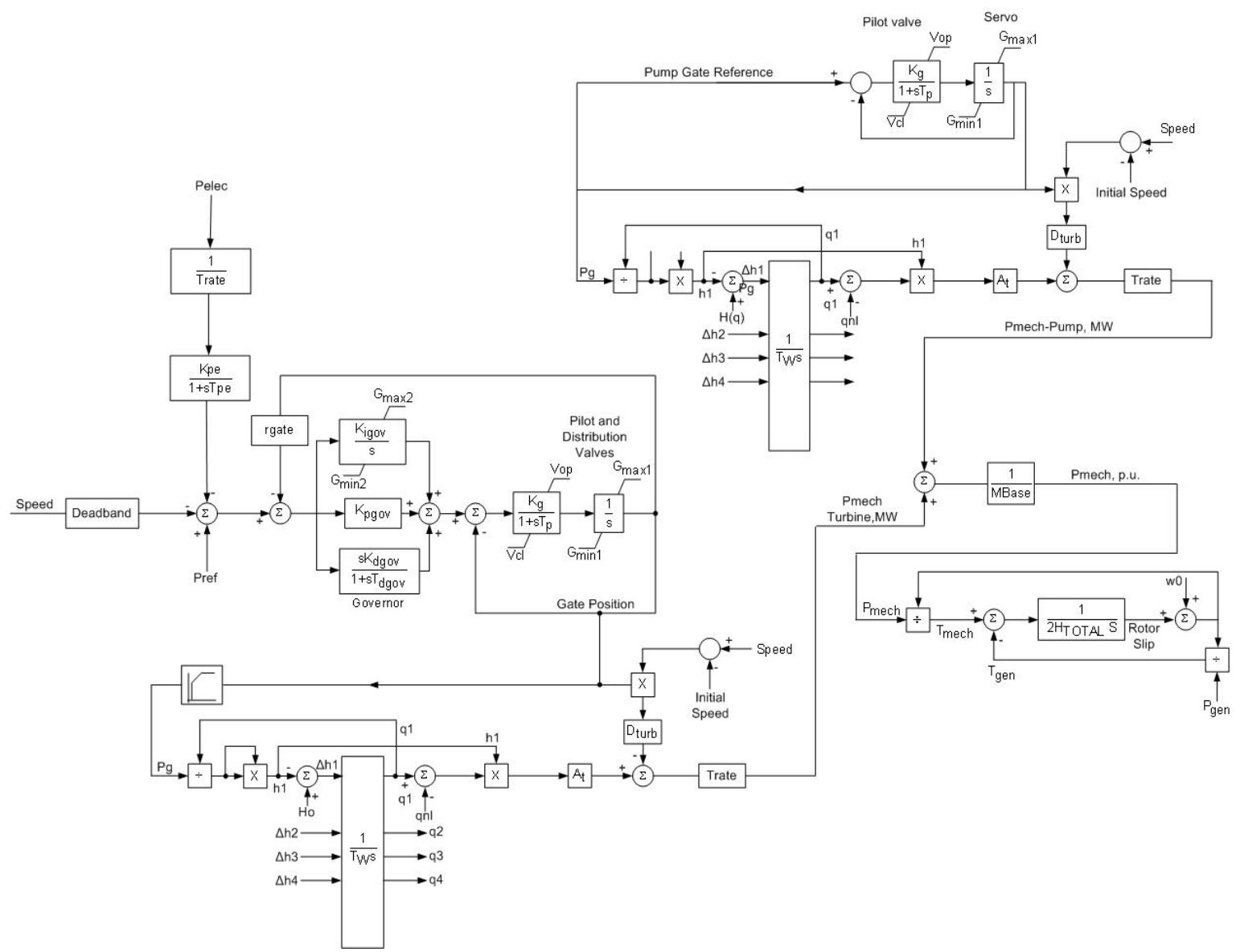

Figure 4-3 Ternary Unit Model with Both Pump and Turbine in Operation (Hydraulic Short-Circuit) 


\subsection{Tests of the Ternary Model in the Turbine Mode}

The test system shown in Figure 4-4 is the same as that used for testing the AS PSH turbine (Figure 2-2). The 1,176-MVA machine connected to bus 19 is modeled as a ternary unit in these tests.

The load flow raw data file in $P S S^{\circledR} E$ format is provided in Appendix A, Section A-1. The only difference between the load flow data file used for modeling the ternary unit and the AS PSH unit is the machine impedance (Zsorce). The documentation of the dynamic models is provided in Appendix B, Section B-5.

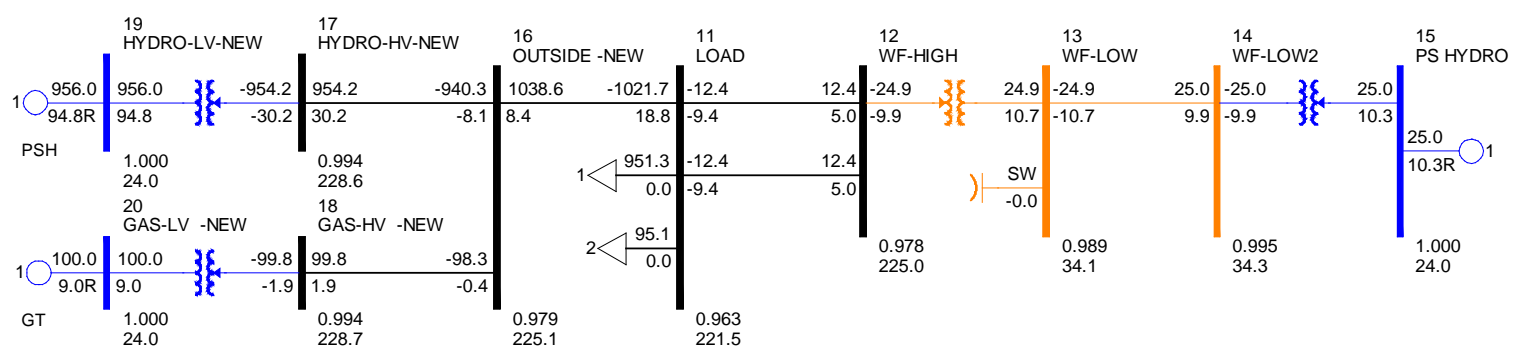

Figure 4-4 One-line Diagram of the Test System for the Ternary Unit in Turbine Mode Showing Parameters

The ability of the governor model to participate in frequency control was tested by simulating events that cause deviation in system frequency. Figure 4-5 shows the response of turbine mechanical power and system frequency to the over-frequency caused by trip of the 100-MW load. In this test system, the ternary unit is the dominant unit controlling system frequency, and it can be seen that frequency is controlled by closing the ternary unit's turbine gates and reducing mechanical power in a smoothly controlled manner. Figure 4-6 shows the response of turbine mechanical power and system frequency to the under-frequency caused by trip of the 100-MW gas turbine unit. Again, it can be seen that frequency is controlled in a smoothly controlled manner.

Figure 4-7 shows the response of the terminal voltage and relative machine rotor angle to a fault on the $230-k V$ bus 16 . Note that while the governor model does not have a very significant impact on the response to system faults such as the one shown here, the test indicates that the model works as expected. 


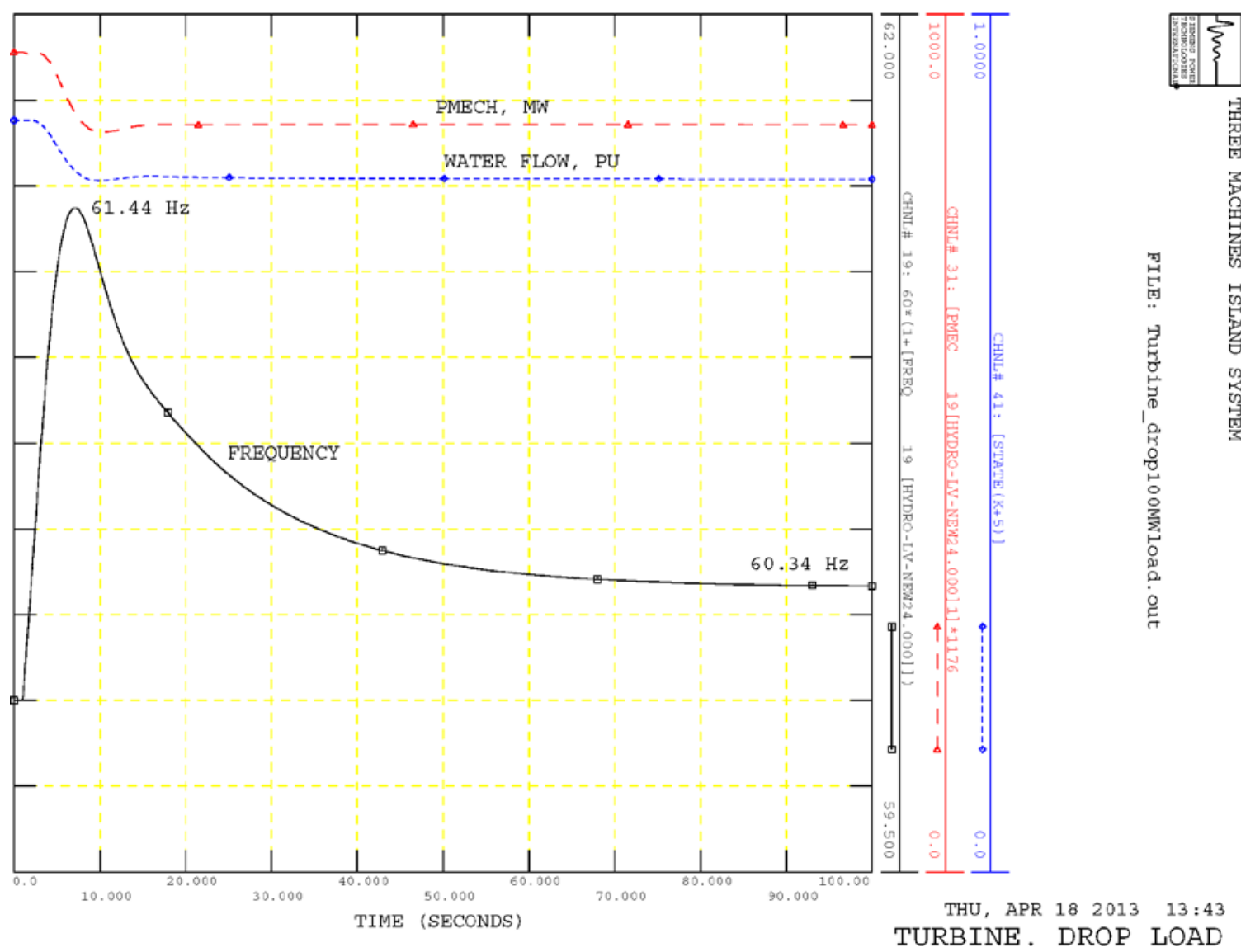

Figure 4-5 Response of System Frequency, Mechanical Power and Water Flow of the Ternary Turbine Responding to an Over-Frequency Event (Trip of the 100-MW Load) 


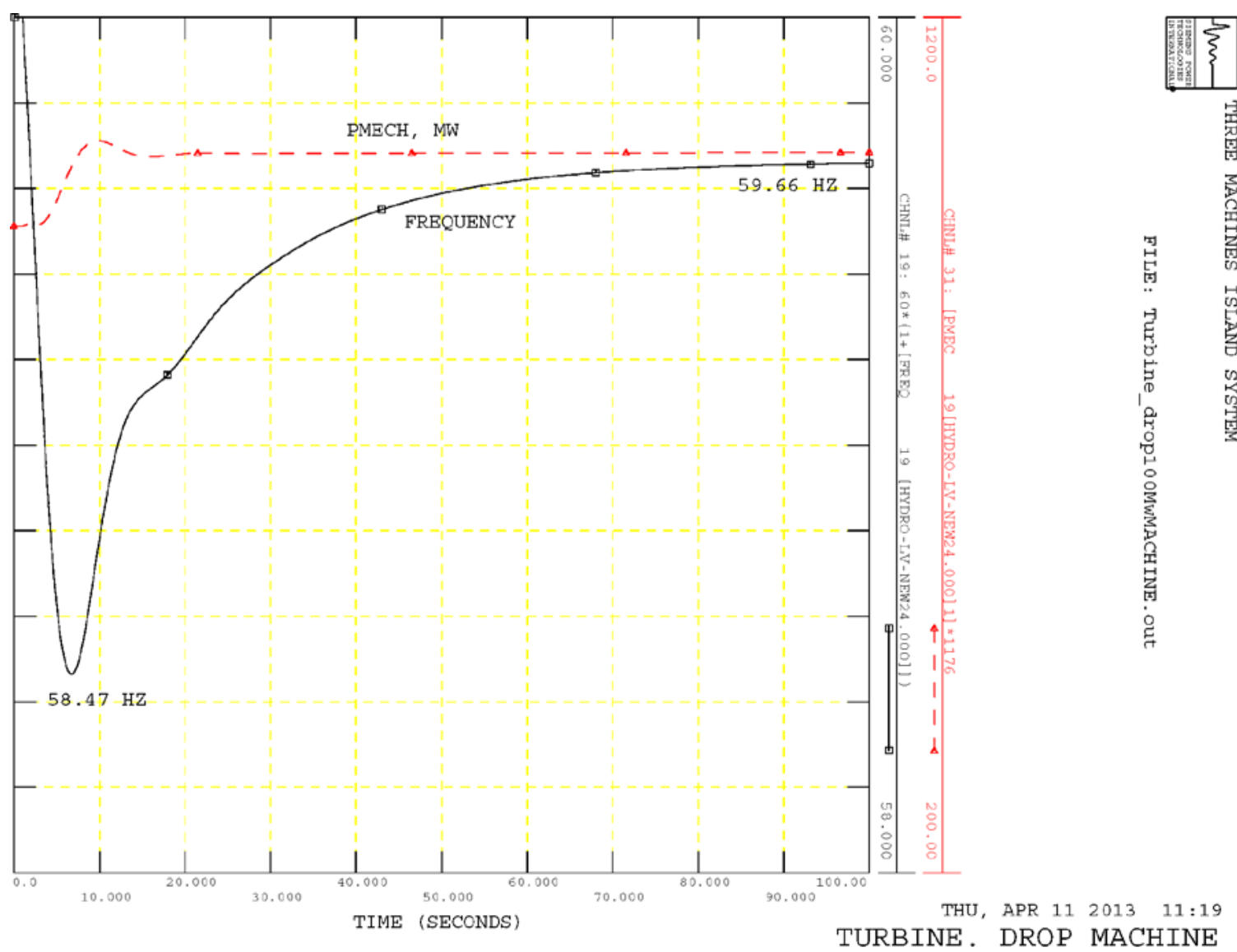

Figure 4-6 Response of System Frequency and Mechanical Power of the Ternary Turbine to an Under-Frequency Event (Trip of the 100 MW Gas Turbine Unit) 


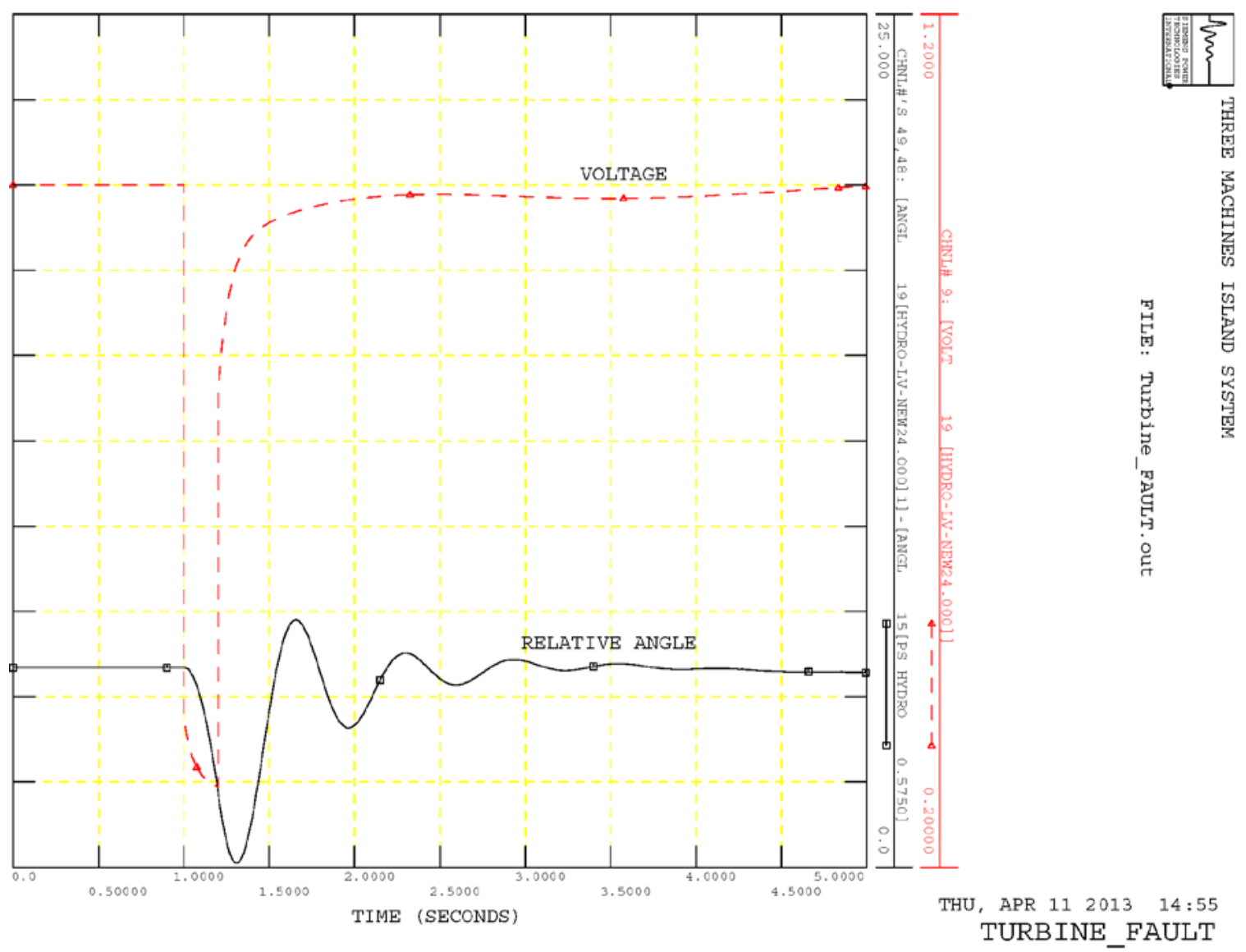

Figure 4-7 Response of Terminal Voltage and Relative Rotor Angle of the Ternary Unit in Turbine Mode to a Fault on Bus 16

\subsection{Tests of the Ternary Model in the Pump Mode}

The test system shown in Figure 4-8 is the same as was used for testing the AS PSH pump (Figure 3-6). The 1,276-MVA machine connected to bus 19 is modeled as a ternary unit in these tests.

The load flow raw data file in $\mathrm{PSS}^{\circledR} \mathrm{E}$ format is provided in Appendix A, Section A-1. The only difference between the load flow data file used for modeling the ternary unit and the AS PSH unit is the machine impedance (Zsorce). The documentation of the dynamic models is provided in Appendix B, Section-B-6.

The ternary unit does not participate in frequency control when in pump mode. Thus, the testing of the model was performed differently. Figure 4-9 shows the response to a ramp downward in the pump gate reference and the resulting reduction in mechanical power.

Figure 4-10 shows the response of the ternary unit to the trip of the 100-MW load. While the pump is not capable of participating in frequency control, it does respond to the overfrequency, due to the impact of machine speed on turbine mechanical power. 


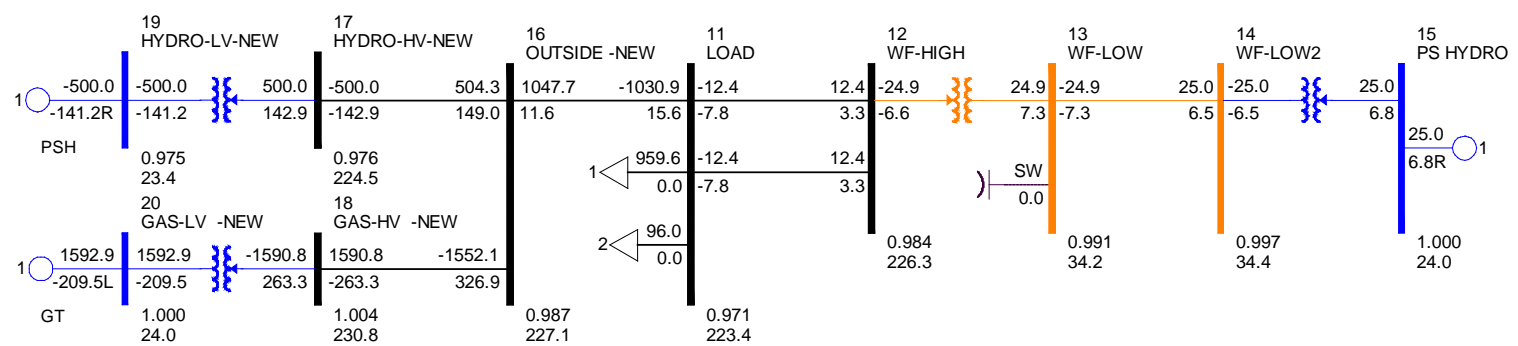

Figure 4-8 One-Line Diagram of the Test System for the Ternary in Pump Mode Showing Parameters

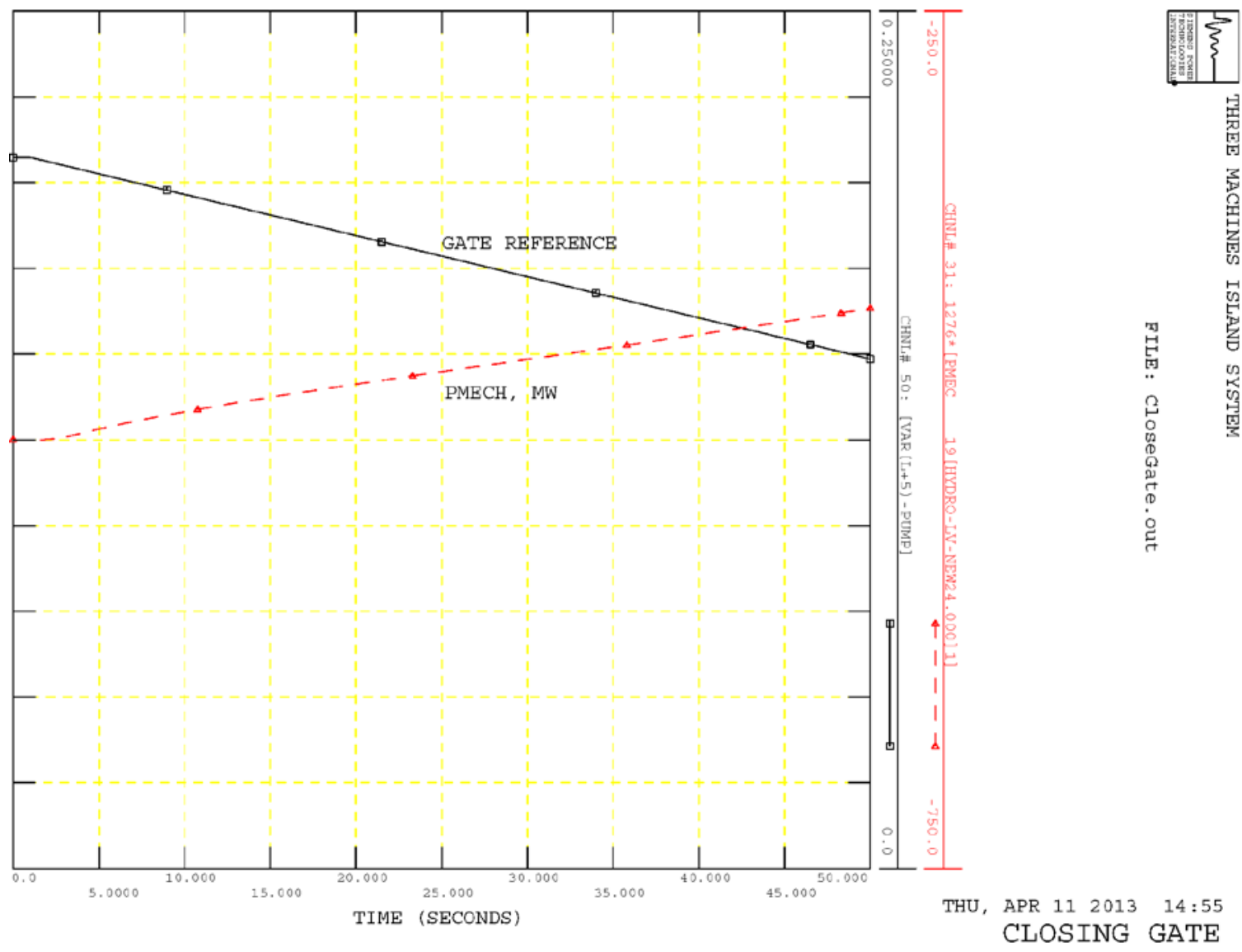

Figure 4-9 Response to Ramp Down in Gate Reference 


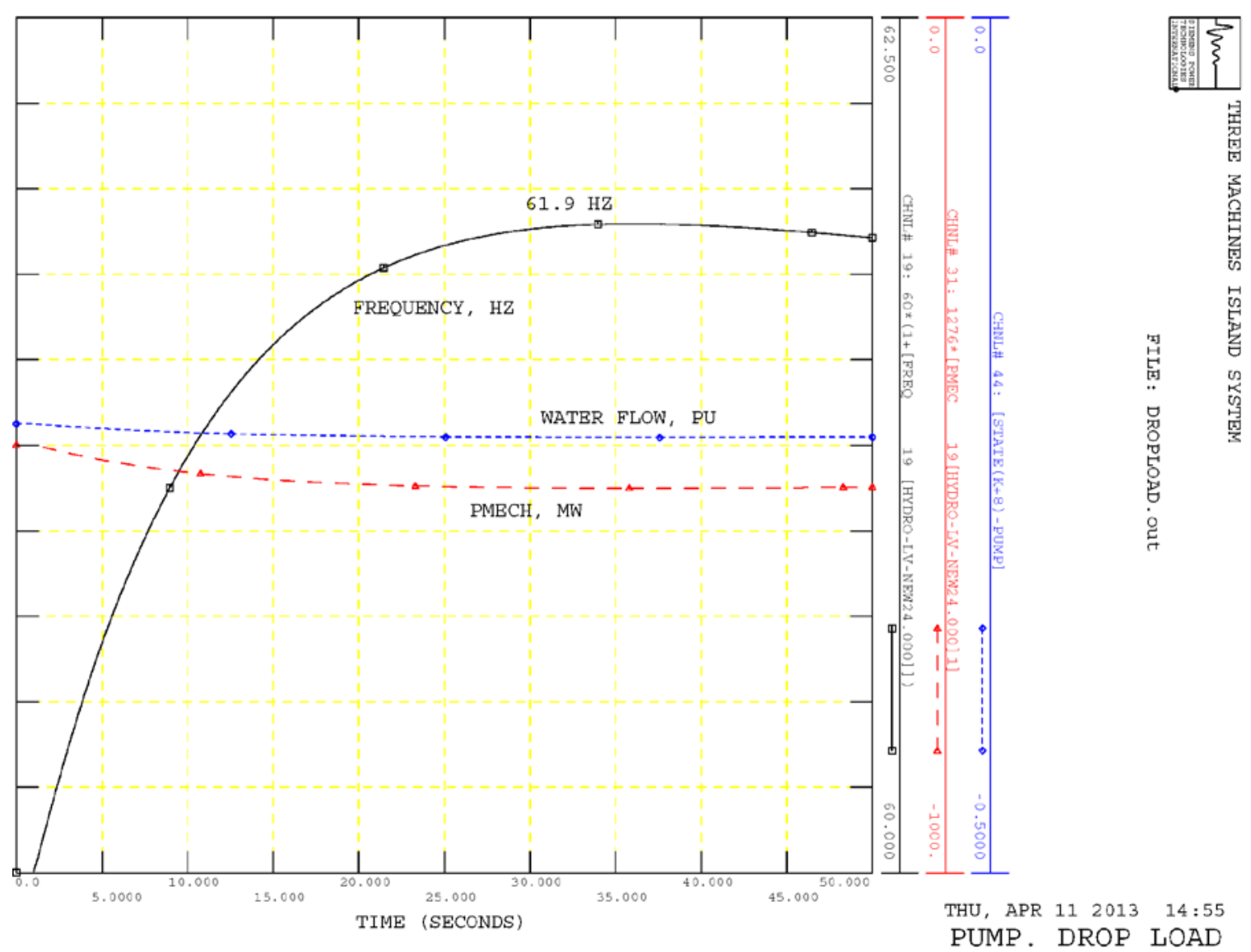

Figure 4-10 Response of Frequency, Mechanical Power, and Water Flow of the Ternary Unit in Pump Mode to Trip of the 100-MW Load 


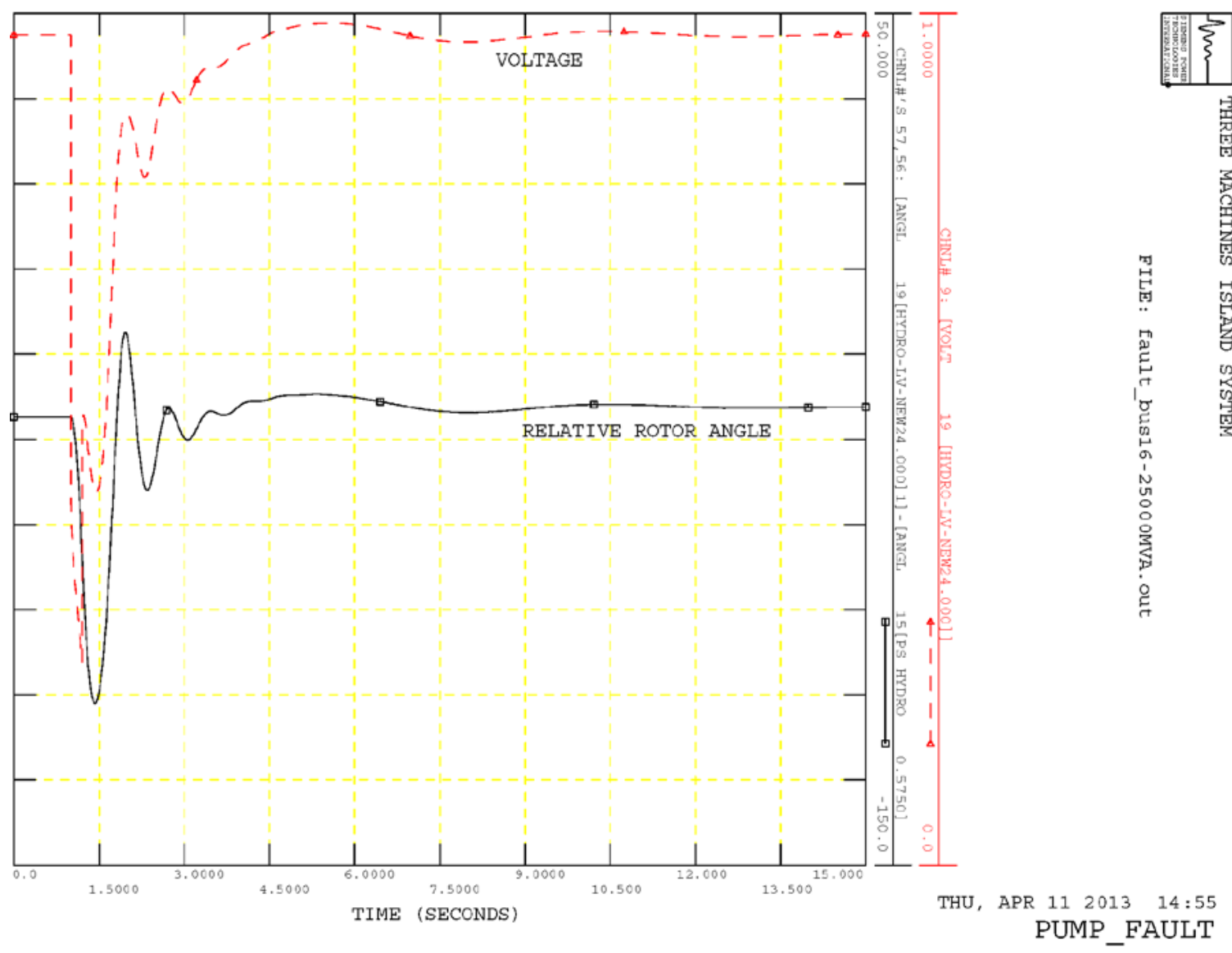

Figure 4-11 Response of Voltage and Relative Rotor Angle of the Ternary Unit in Pump Mode to a Fault on Bus 16

\subsection{Test in the Mixed Mode}

The same test system was used as one shown in Figure 4-8 with the ternary unit in pump mode. The net output of the machine is the same, $-500 \mathrm{MW}$. However, for the hydraulic short-circuit mode of operation, the unit's net power is the difference between $500 \mathrm{MW}$ provided by the turbine and -1,000 MW consumed by the pump, as shown in Figure 4-12.

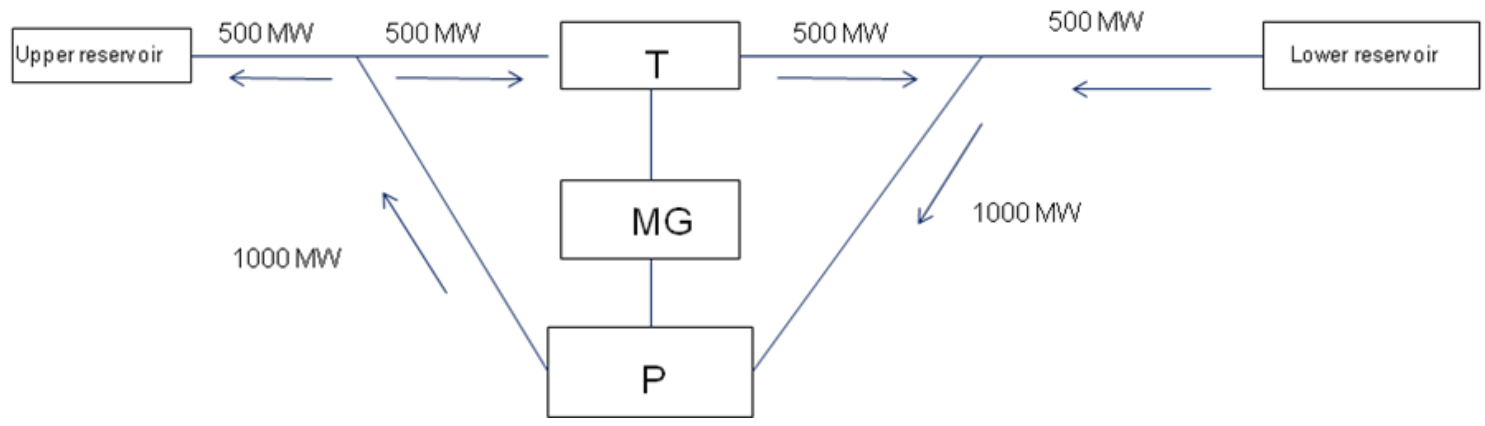

Figure 4-12 Initial Power Diagram of the Ternary Unit in the Hydraulic Short-Circuit Mode of Operation 
The documentation of the dynamic models is provided in Appendix B, Section B-7.

Results of testing provided in Figure 4-13 and Figure 4-14 clearly illustrate the main advantage of the ternary unit, namely, the capability of the unit operating in the hydraulic short-circuit mode to control the rotor speed and contribute to the control of system frequency. Figure 4-13 shows the response of turbine mechanical power and system frequency to the over-frequency caused by trip of the 100-MW load. The ternary unit contributes to frequency control by closing the ternary unit's turbine gates and reducing mechanical power in a smoothly controlled manner. Figure 4-14 shows the response to the under-frequency caused by the trip of the 25-MW hydro unit. Again, it can be seen that the ternary unit contributes to frequency control in a smoothly controlled manner.

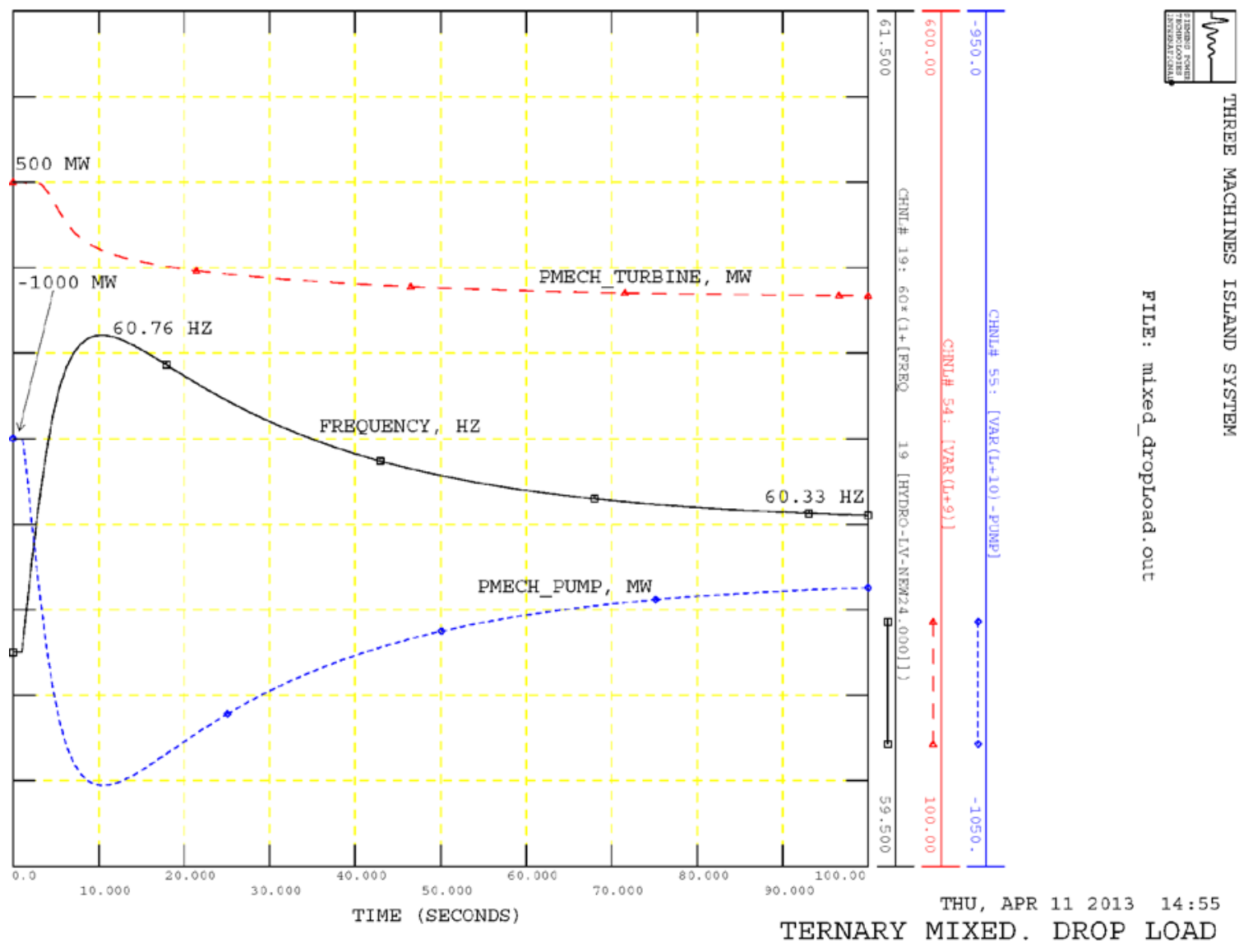

Figure 4-13 Response of Frequency and Mechanical Power of the Turbine and the Mechanical Power of the Pump of the Ternary Unit to the Trip of the 100-MW Load 


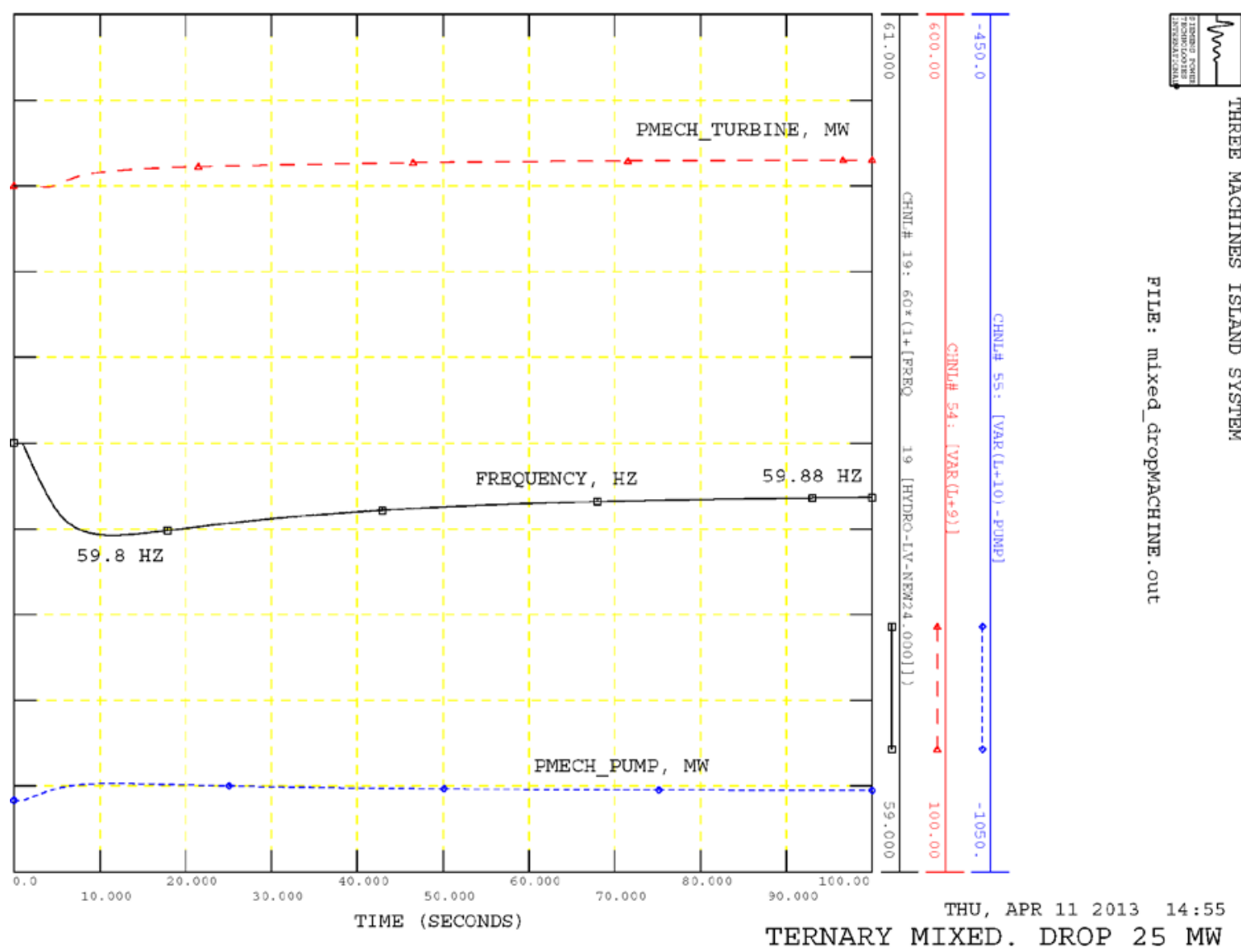

Figure 4-14 Response of Frequency and Mechanical Power of the Turbine and the Mechanical Power of the Pump of the Ternary Unit to the Trip of the 25-MW Hydro Unit 


\section{Section \\ 5}

\section{Testing the Fast Frequency Control Ability of the AS PSH}

The ability of a PSH unit to significantly impact the control of system frequency is limited by the relative size of the PSH unit to the size of the total system. Even a large PSH unit has a limited ability to make an impact on the very large interconnections in the United States. A series of tests were performed to demonstrate the impact on a smaller system, or alternately the impact when a portion of the system becomes isolated from the larger grid. The 23-bus system supplied with PSS ${ }^{\circledR} E$ as an example system was used for these tests and is shown in Figure 5-1.

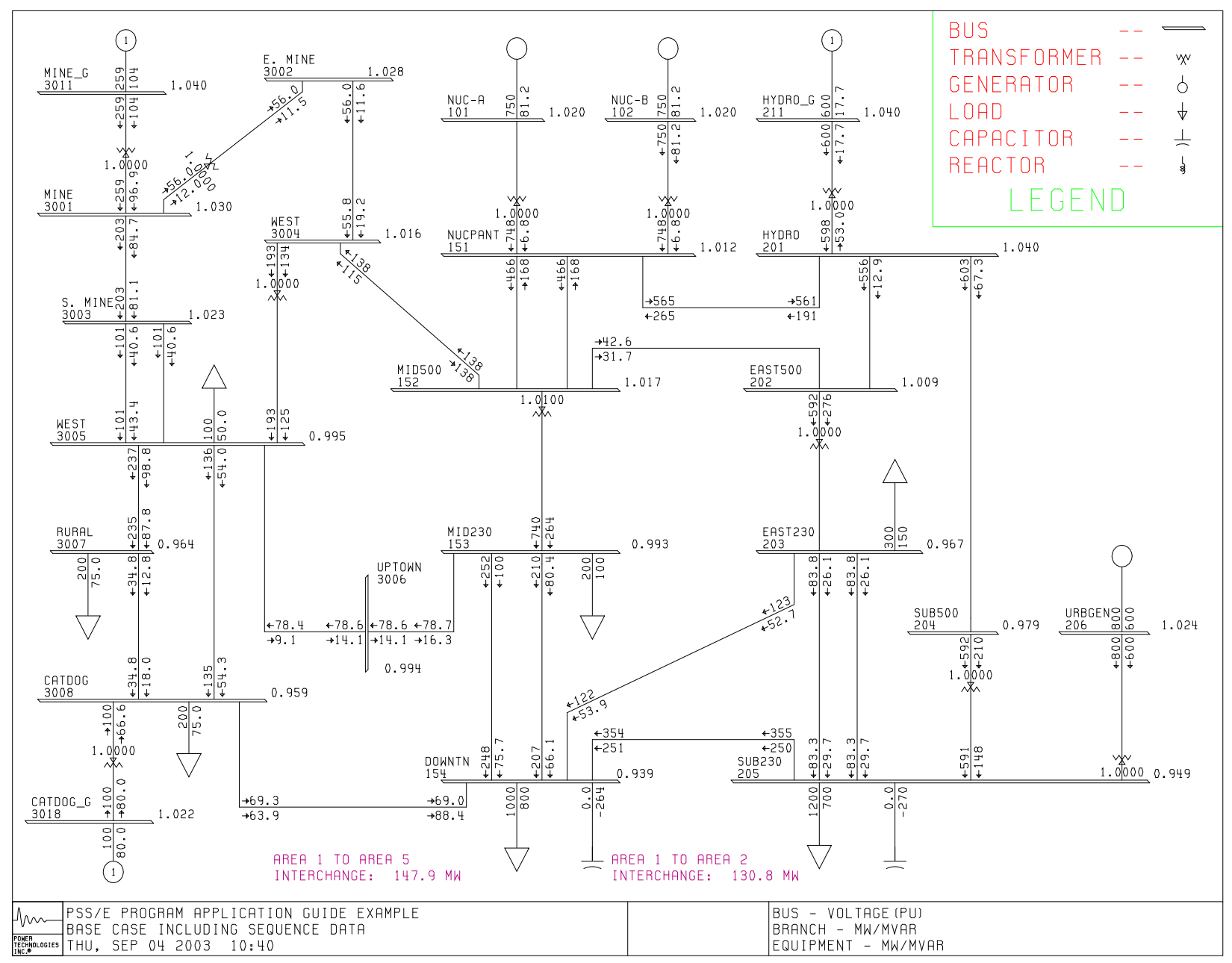

Figure 5-1 Test System 
This system comprises three areas: 1 (Center), 2 (East), and 5 (West). Area 5 is connected to area 1 by one $500-k V$ and two $230-k V$ lines. All together, they supply area 5 with $152 \mathrm{MW}$ of power. Three loads in area 5 connected to buses 3005, 3007, and 3008 demand $100 \mathrm{MW}, 200 \mathrm{MW}$, and $200 \mathrm{MW}$, respectively. Two local plants generate $358 \mathrm{MW}$ : the 1,000-MVA machine on bus 3011 is dispatched at $258 \mathrm{MW}$ and the 130-MVA machine on bus 3018 is dispatched at $100 \mathrm{MW}$.

Both plants in area 5 are assumed to be hydro plants. For the dynamic simulation, they are represented by the same set of models: the generator (GENSAL), excitation system (SCRX), and turbine-governor (HYGOV) models, as shown in Figure 5-2.

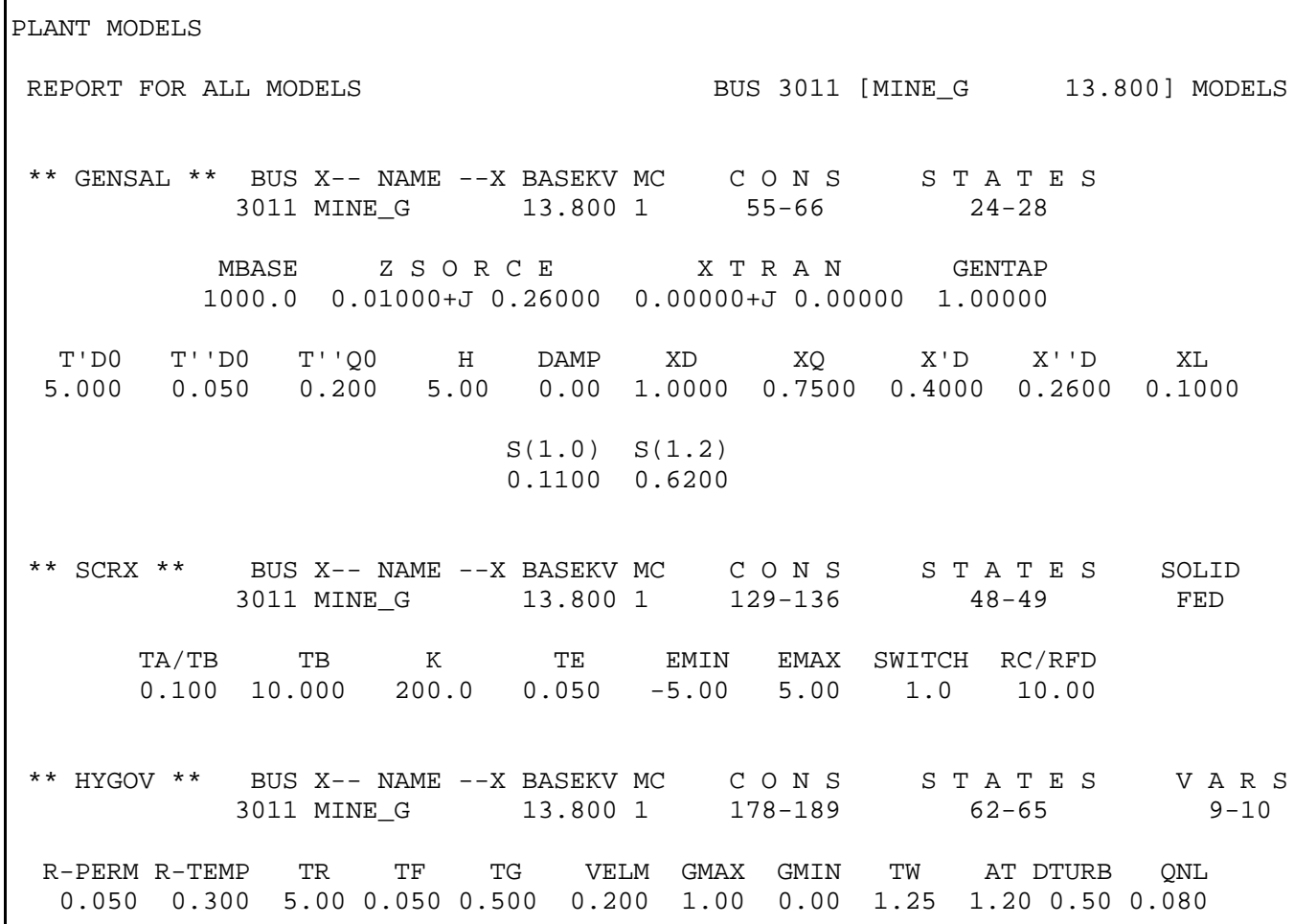

Figure 5-2 Dynamic Data for the Conventional Hydro Plants 
Trip of the three tie lines from area 1 to area 5 results in a deficit of $152 \mathrm{MW}$ in area 5 and a significant drop in frequency. A frequency nadir of $58.26 \mathrm{~Hz}$ was reached at time equal to 4.6 $\mathrm{sec}$, as shown in Figure 5-3. Frequency recovers and settles to $59.68 \mathrm{~Hz}$ in accordance with the permanent droop of the hydro governors.

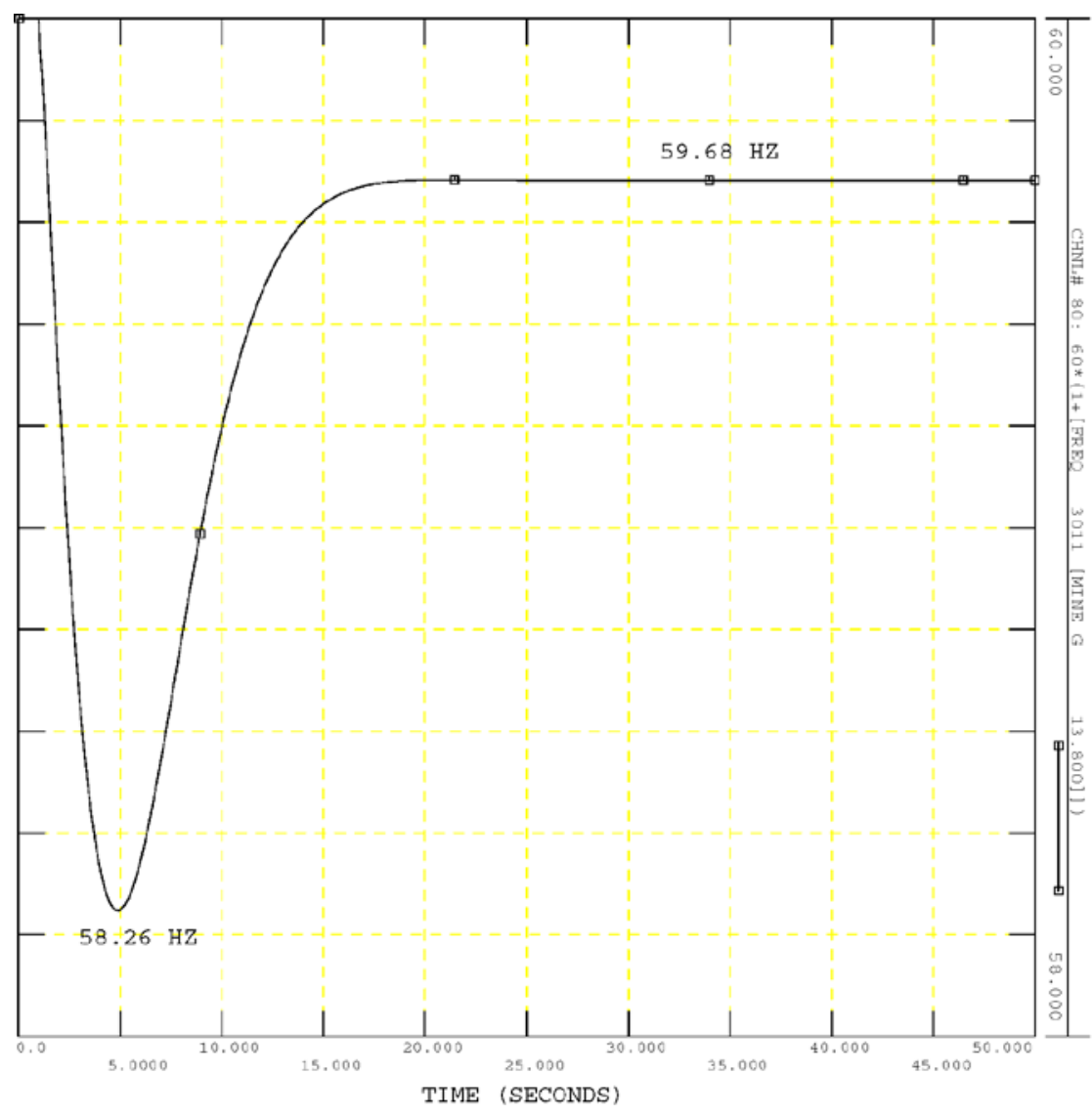

Figure 5-3 System Frequency with Conventional Units following Separation of Area 5

In reality, the local system would likely be equipped with under-frequency load shedding protection. An under-frequency load shedding model was added for the load on bus 3007. It had three stages of protection: at $59.3 \mathrm{~Hz}, 59.0 \mathrm{~Hz}$, and $58.7 \mathrm{~Hz}$. After the system frequency crosses any of these levels, $33.3 \%$ of the original load on this bus would be shed.

Plots in Figure 5-4 compare the response of system frequency for simulations of the loss of the tie lines without (black) and with load shedding (red). The blue trace shows the MW consumption of the load on bus 3007. Two stages of load shedding are clearly seen. As a result of load shedding, the nadir of the system frequency turned out to be $0.4 \mathrm{~Hz}$ greater. 


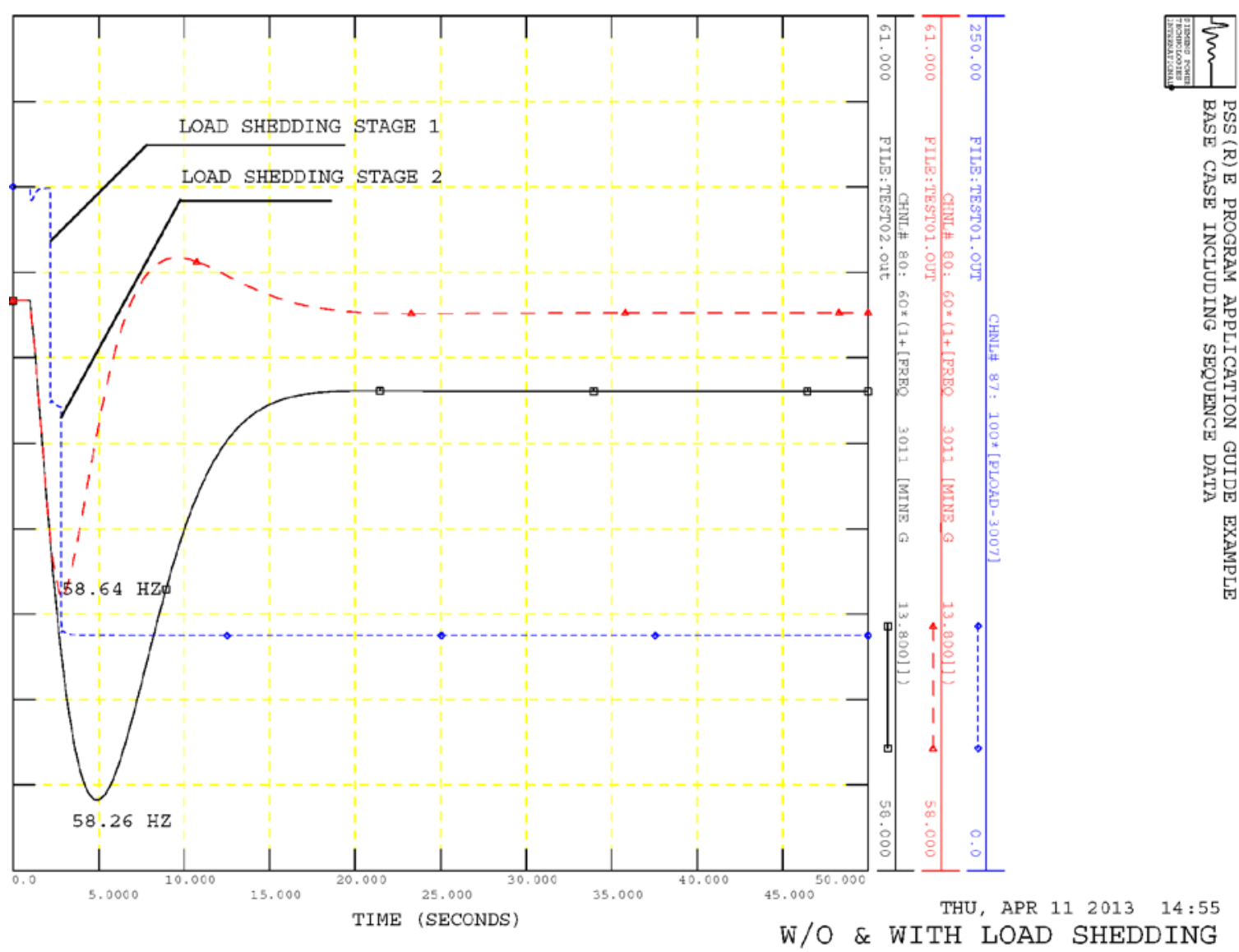

Figure 5-4 System Frequency with Conventional Units following Separation of Area 5 Showing the Impact of Under-Frequency Load Shedding

The set of models for the hydro unit on bus 3011 was replaced by the new model of the AS PSH turbine. The data conversion from the conventional unit models to the AS PSH turbine model retained key parameters such as rotor inertia, water time constant, and permanent droop. Parameters of the AS PSH turbine shown in Figure 5-5 were found in the process of tuning different controllers in order to get the most favorable response. 


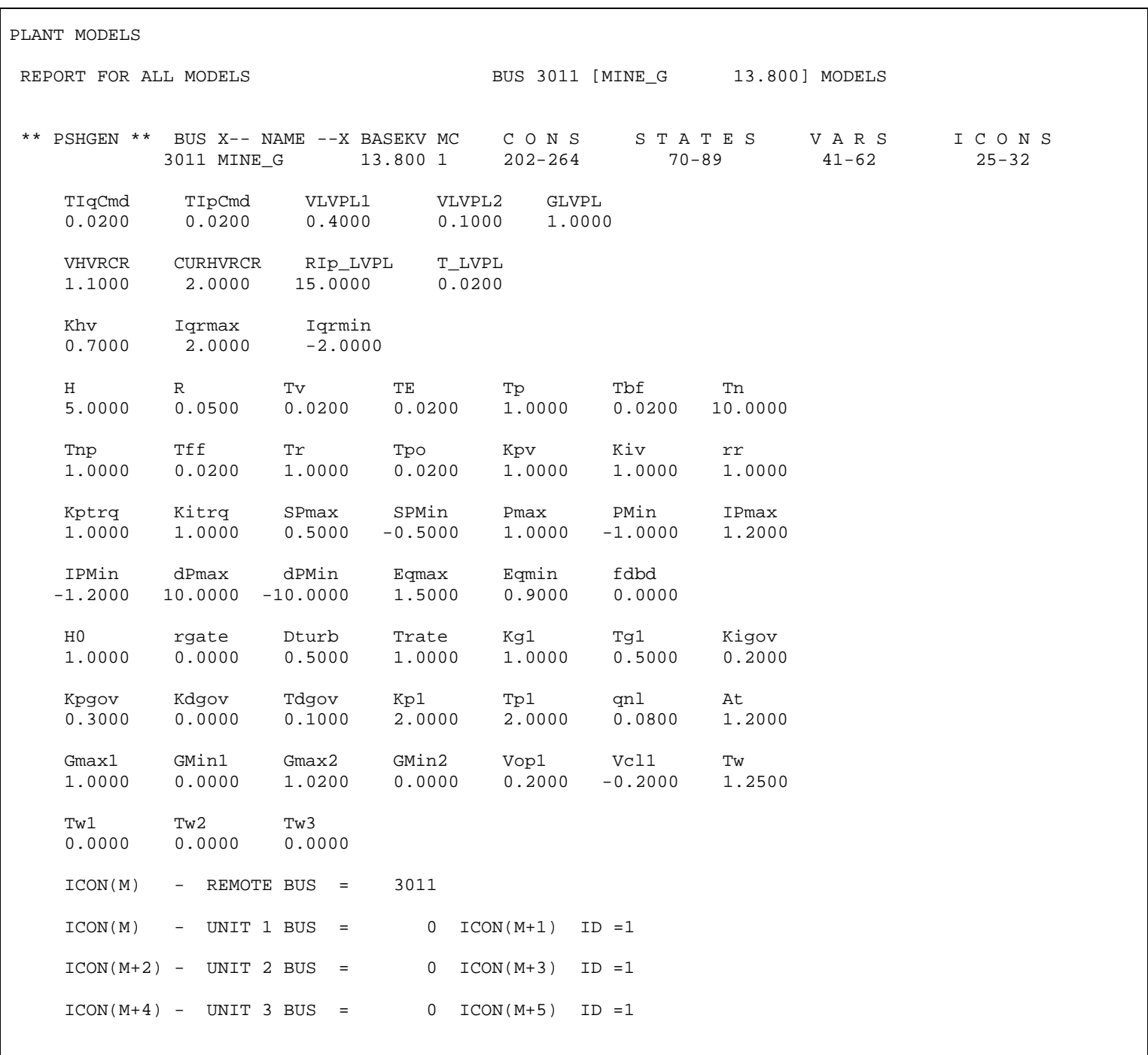

Figure 5-5 Model Parameters Used to Represent the AS PSH Unit

The trip of the three tie lines with the AS PSH turbine on bus 3011 did not cause a drop in the system frequency below the first load shedding threshold of $59.3 \mathrm{~Hz}$. Figure 5-6 compares the response of system frequency for the conventional and AS PSH turbine, both with no load shedding protection. The plots shown in Figure 5-7 depict the active power (black) and mechanical power (red) of the AS PSH turbine. 


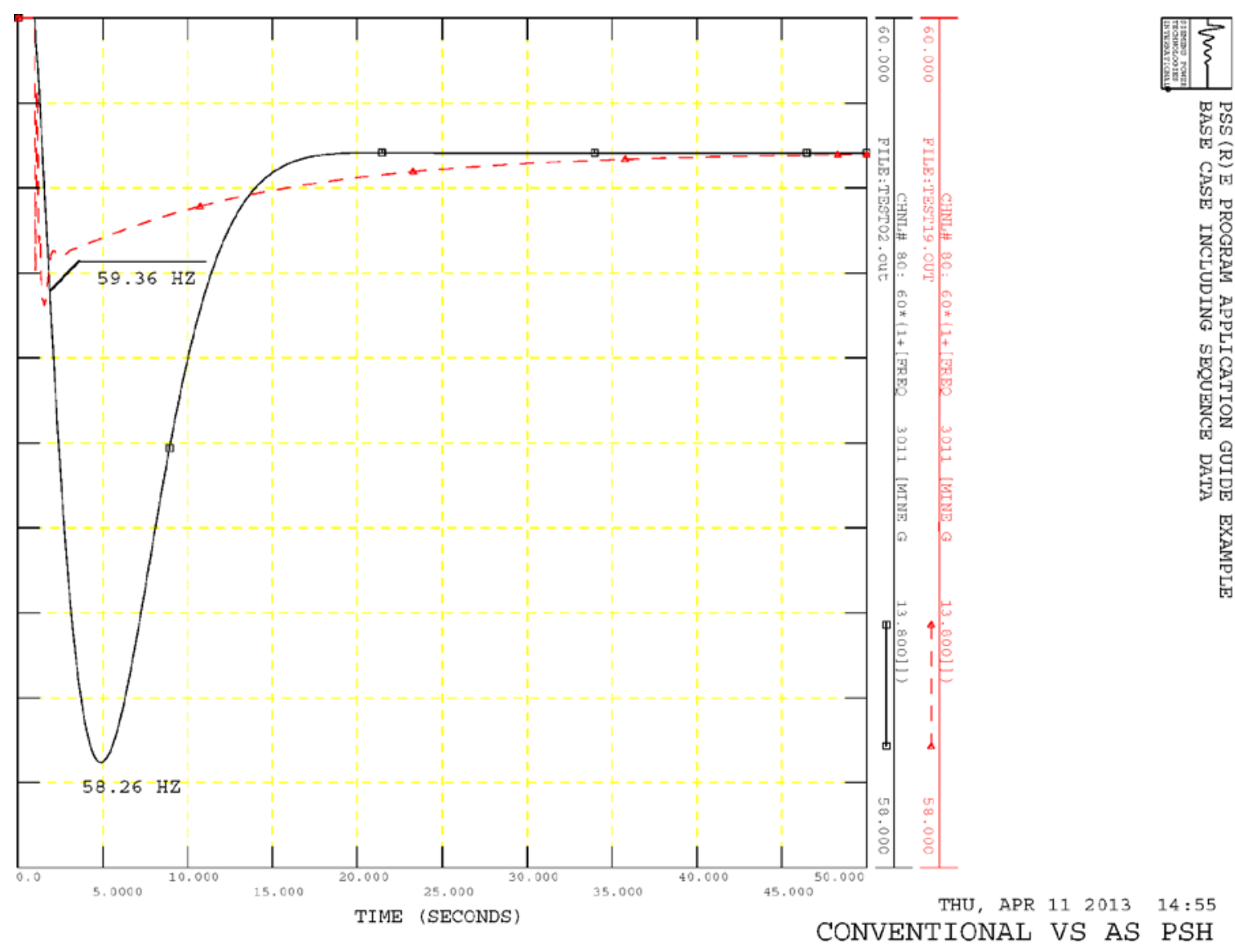

Figure 5-6 Comparison of System Frequency with Conventional Unit versus AS PSH following Separation of Area 5 


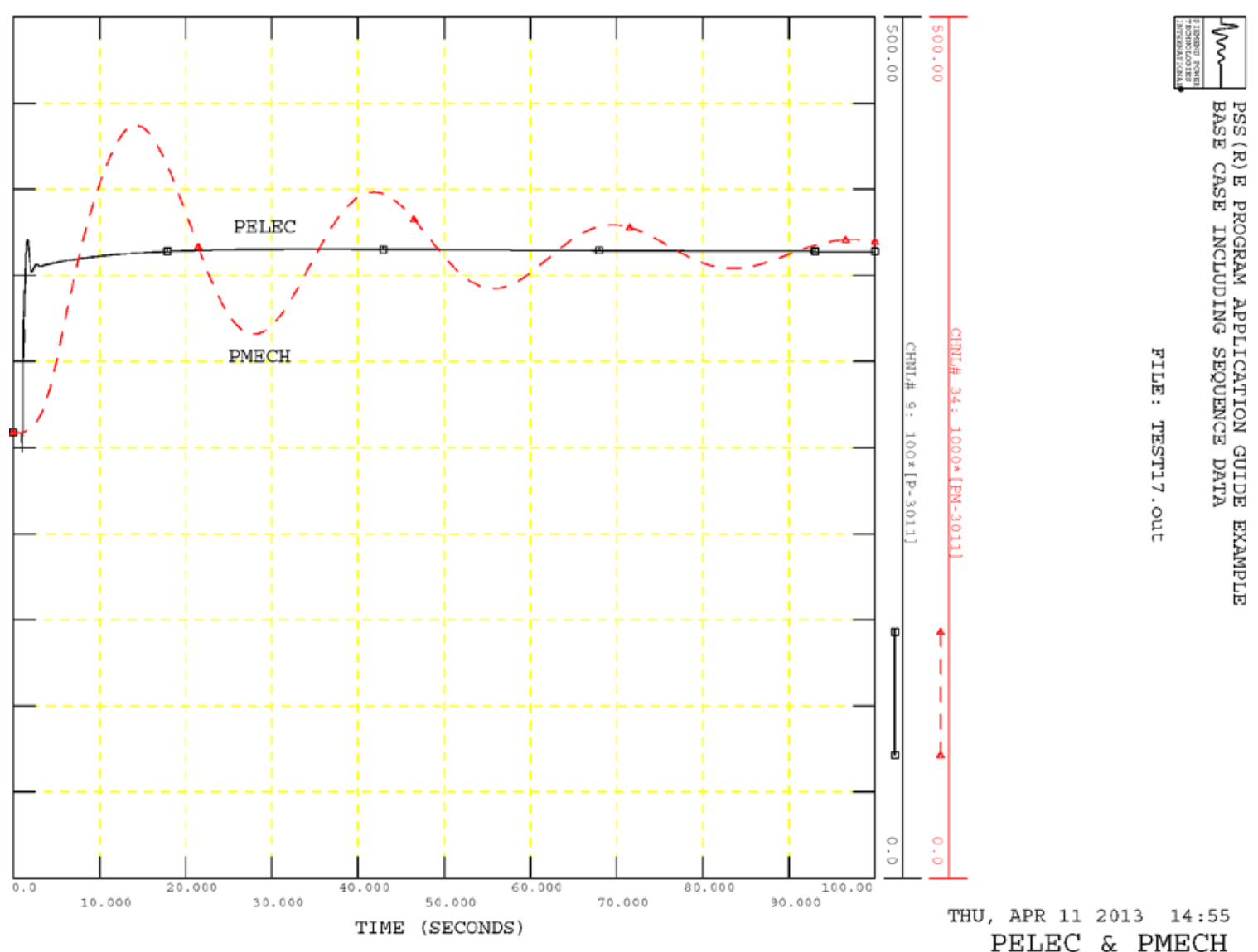

Figure 5-7 Comparison of Electrical Power and Mechanical Power of the Conventional Unit versus AS PSH following Separation of Area 5

In all of the above calculations, the size of the unit on bus 3011 was assumed to be 1,000 MVA. Reduction of the size, i.e., a reduction of the share of the AS PSH unit in the total generation, naturally reduces its benefit. For example, a change from 1,000 MVA to 500 MVA for the same disturbance does not completely prevent load shedding but limits it to only the first stage.

It is well-known that a conventional PSH unit in the pumping mode of operation does not participate in system frequency control but operates with a constant value of gate position as set by its operator. The AS PSH pump, due to availability of the power converter, can control the rotor speed and contribute to the control of system frequency.

In the test system in Figure 5-1, the machine on bus 3011 was set as a 500-MVA motor with 200 MW of power consumption. The 200-MW load on bus 3008 was removed. This results in different power flows in area 5, as shown in Figure 5-8. The total flow on the ties between areas 5 and 1 is about the same as in the original system in Figure 5-1. 


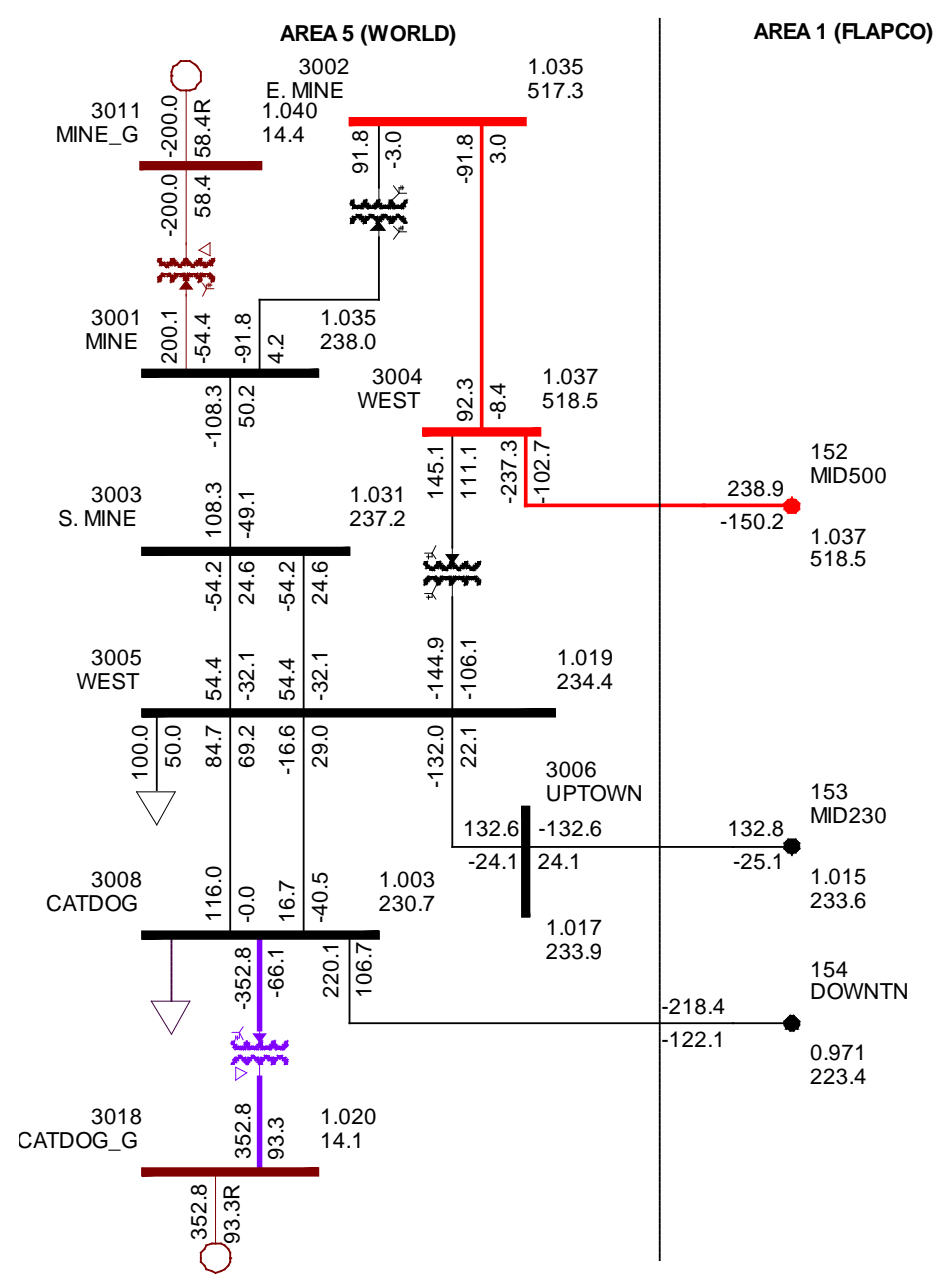

Figure 5-8 Area 5 with the Pump on Bus 3011

For studying the system with a conventional pump unit, the model of the ternary unit operating as a pure pump was used. The dynamic data for the hydro unit is shown in Figure 5-9.

The model developed in the course of this project and described above was used for the AS PSH pump. Its dynamic data documentation is shown in Figure 5-10. 


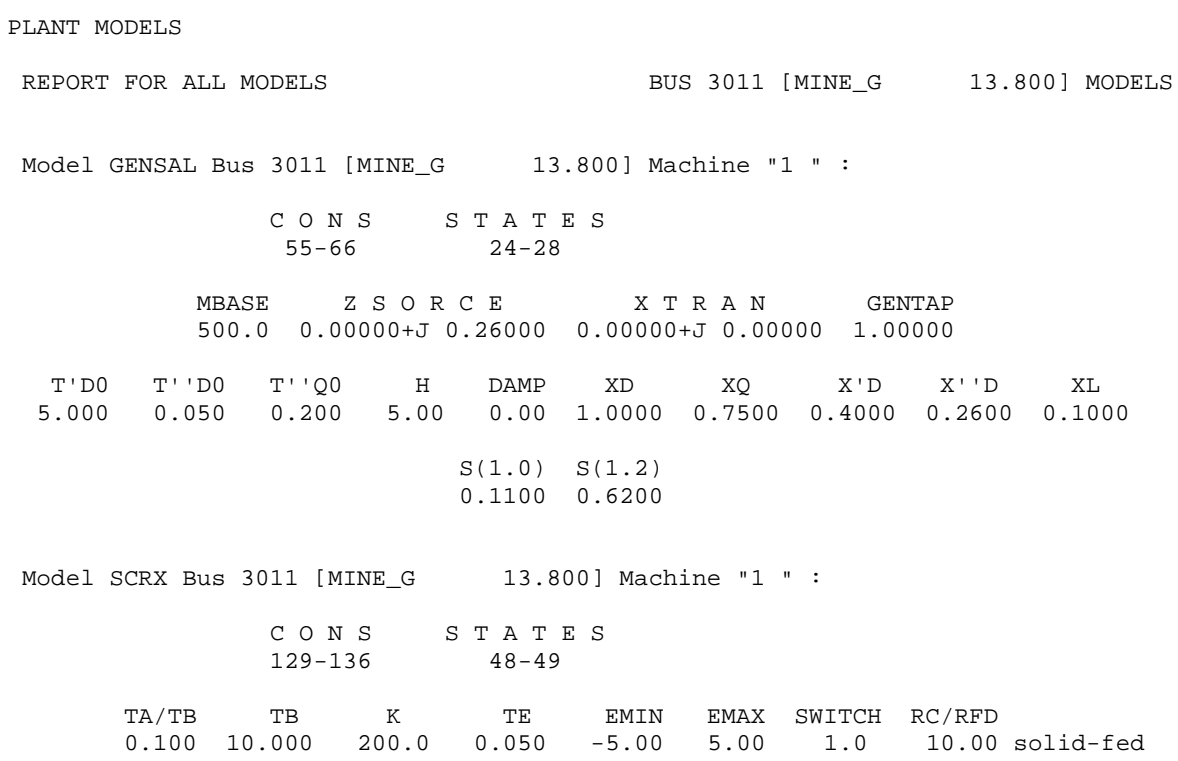

Figure 5-9 Dynamic Data for the Conventional Pump Model 


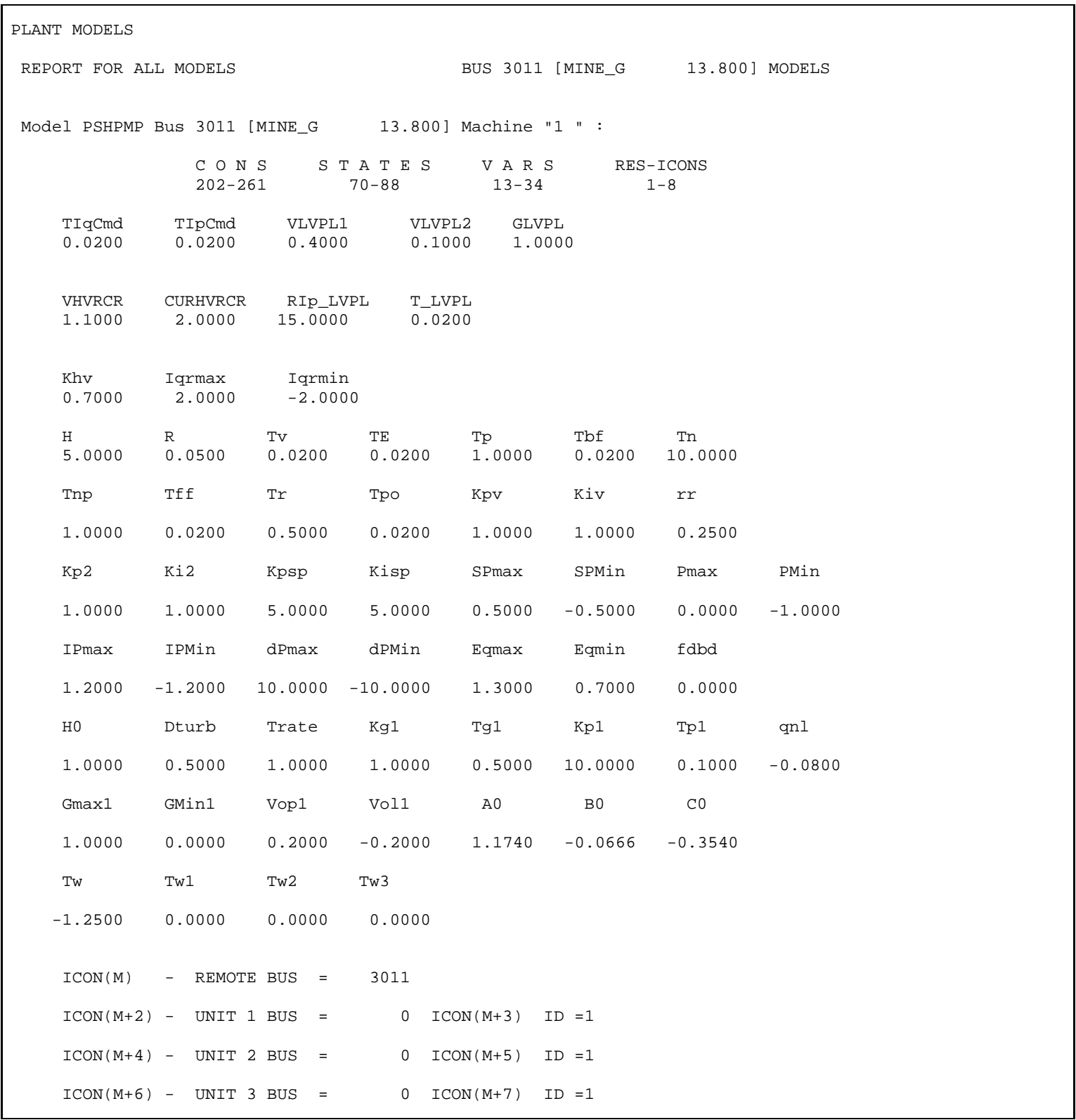

Figure 5-10 Dynamic Data for the AS PSH Pump 
The plots of Figure 5-11 allow comparison of the system frequency for the same disturbance: the trip of the ties to isolate area 5. With the conventional pump, frequency drops to $56.56 \mathrm{~Hz}$. Presence of the AS PSH pump makes the system frequency nadir much higher at $58.26 \mathrm{~Hz}$. However, with the characteristics of the load shedding protection discussed above, the AS pump could not improve the frequency response enough to prevent load shedding.

Note that these simulations are not meant to represent any particular system or events. However, they demonstrate the capabilities of the new PSH models and how these technologies could, in particular circumstances, make a significant impact on system performance following severe events.

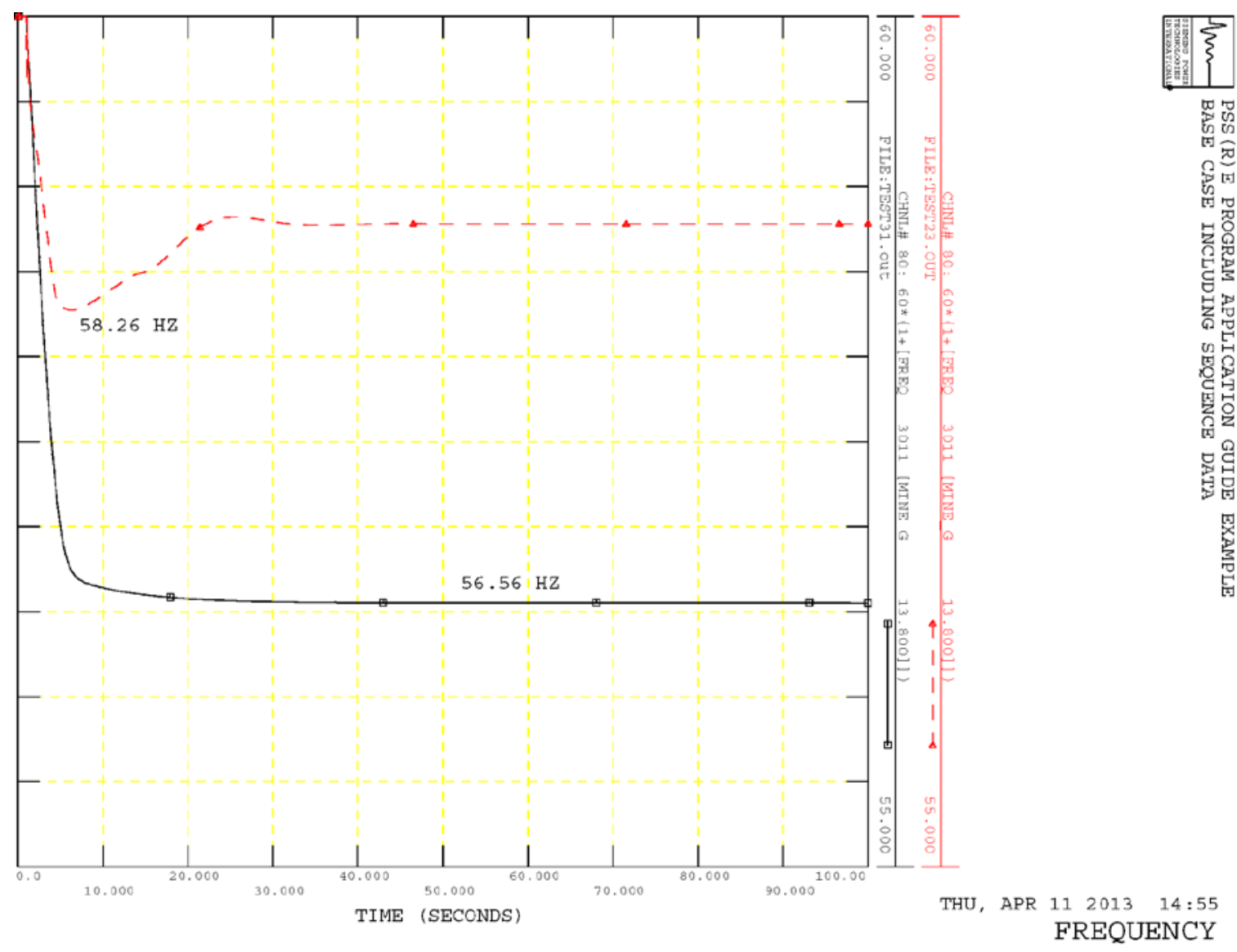

Figure 5-11 AS PSH Pump versus the Conventional Pump 
This page intentionally left blank. 


\section{Section 6}

\section{Testing the Models for the Western Interconnection}

An important task of this project is to develop dynamic simulation models of the advanced pumped storage hydro units for use in large-scale planning and interconnection studies. To demonstrate that the developed models meet this goal, tests were performed using the newly developed models applied to an actual power system, e.g., the Western Interconnection (WI).

The load flow and dynamic setup in PSS ${ }^{\circledR} \mathrm{E}$ format for the summer peak-load conditions for the year of 2017 was downloaded from the Western Electricity Coordinating Council (WECC) website. It includes the load flow case and dynamic data for all pertinent equipment. This model of the WI system comprises 19,212 buses, 24,401 branches (lines and transformers), 14,653 loads, and 3,837 machines with total generation of 189,542 MW.

The six existing PSH plants shown in Table 6-1 were selected to test the new models. The dispatch of these units was modified from that in the original WECC case, as shown in the table, by putting all of the units at the plant on-line and at a uniform output. ${ }^{1}$

Table 6-1 The Six Existing PSH Plants Selected for New Model Testing

\begin{tabular}{|c|c|c|c|c|c|}
\hline $\begin{array}{c}\text { Plant } \\
\text { Number }\end{array}$ & PSH Plant & $\begin{array}{l}\text { Number } \\
\text { of Units }\end{array}$ & $\begin{array}{l}\text { Unit } \\
\text { MVA }\end{array}$ & $\begin{array}{l}\text { Original Plant } \\
\text { Dispatch (MW) }\end{array}$ & $\begin{array}{c}\text { Plant } \\
\text { Re-dispatched } \\
\text { (MW) }\end{array}$ \\
\hline 1 & Castaic & 5 & 250 & $1 \times 232$ & $5 \times 212.5$ \\
\hline 2 & Helms & 3 & 390 & $2 \times 404$ & $3 \times 350$ \\
\hline 3 & Edward G. Hyatt & $\begin{array}{l}3 \\
3\end{array}$ & $\begin{array}{l}123 \\
115\end{array}$ & $5 \times 105$ & $6 \times 100$ \\
\hline 4 & Cabin Creek & 2 & 167 & $2 \times 60$ & $2 \times 150$ \\
\hline 5 & San Luis & 8 & 53 & $8 \times 17$ & $8 \times 45$ \\
\hline \multirow[t]{2}{*}{6} & Mount Elbert & 2 & 105 & $2 \times 90$ & $2 \times 90$ \\
\hline & & & Total & 1,926 & $3,372.5$ \\
\hline
\end{tabular}

1 The six PSH plants were assumed to be fully dispatchable in both the turbine and the pumping mode in this analysis. However, some of the PSH units presently have operating restrictions, so this may not be representative of actual operation. Also, there are PSH units in the WI in addition to the six $\mathrm{PSH}$ plants chosen for this analysis. 
One-line diagrams for all six plants are provided in Figure 6-1.

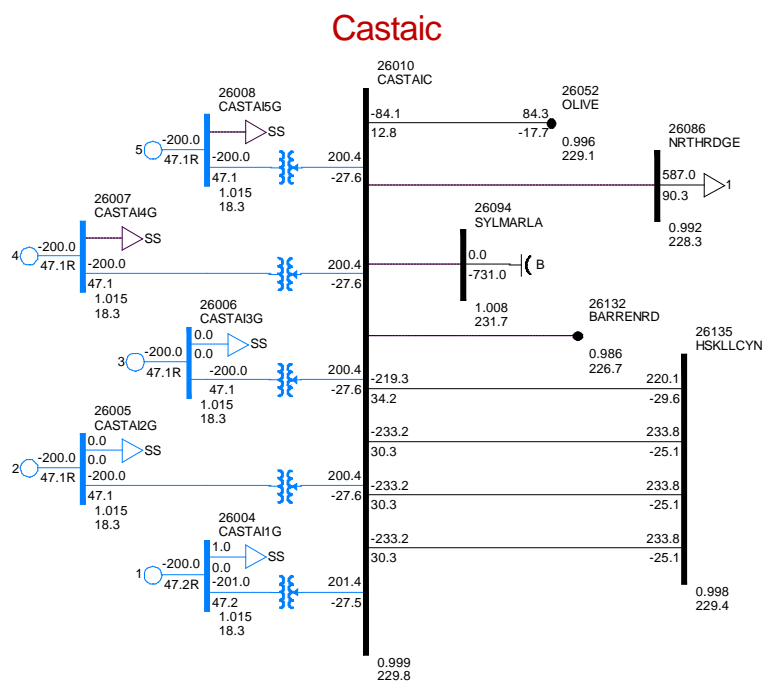

E. G. Hyatt
Helms

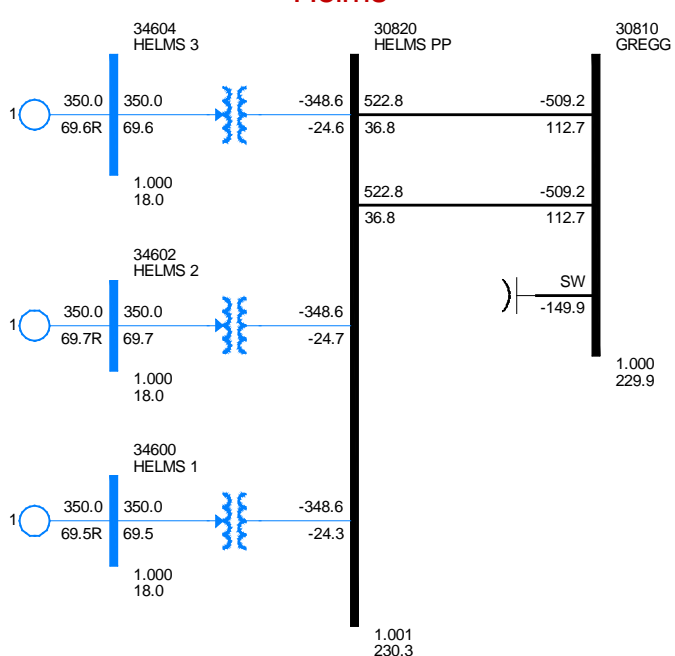

1.001
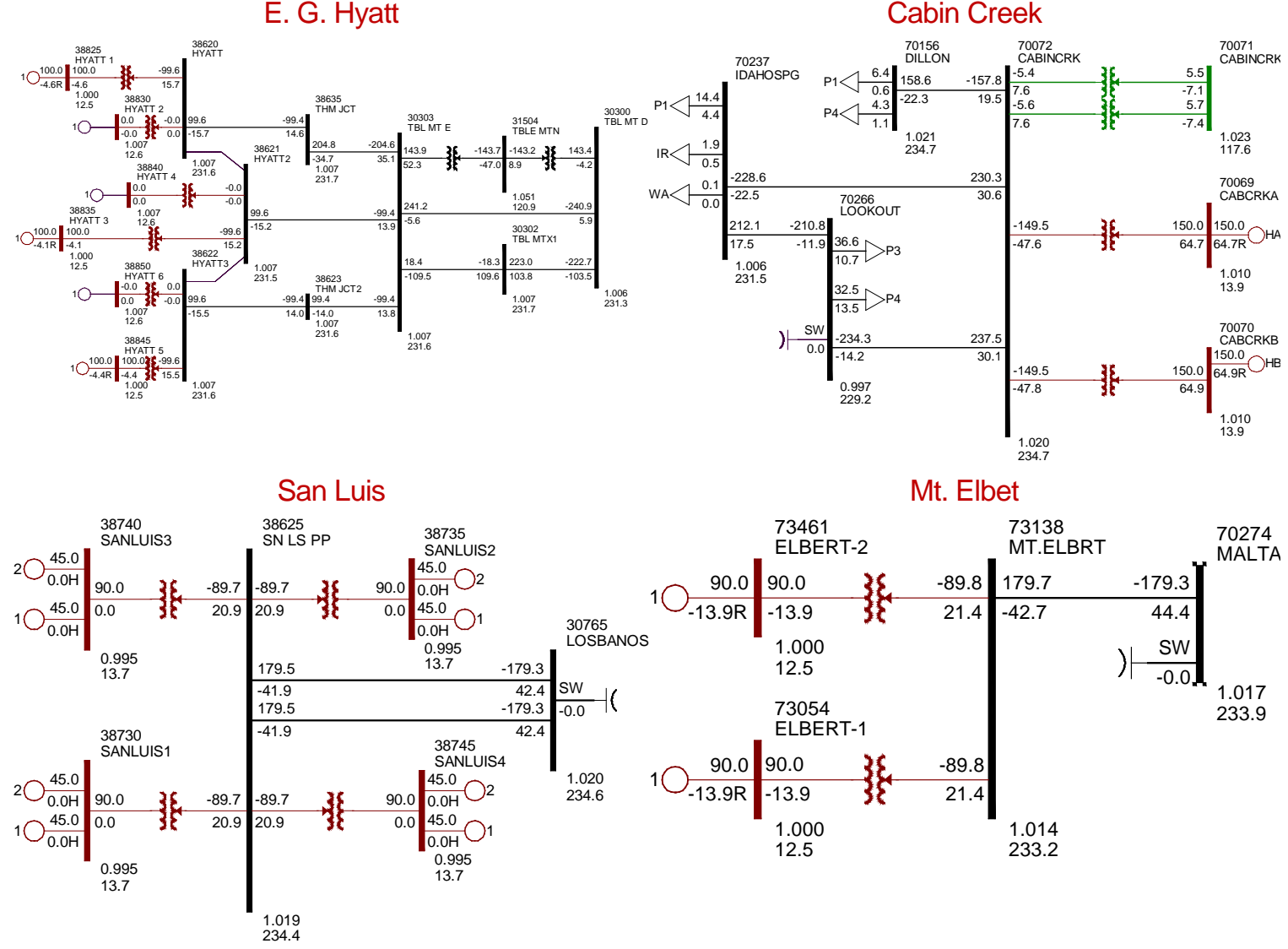

Figure 6-1 One-Line Diagrams of the Six PSH Plants

Dynamic data documentation for the conventional PSH units operating as turbines is provided in Appendix B, Sections B-8 through B-13, for one of the units of each of the six plants (as supplied in the WECC data). Dynamic data for other units at the same plant are identical to that for the unit shown. 
To study system performance with these six plants employing the AS PSH turbines, the dynamic data for the conventional units were replaced by the newly developed models. Dynamic data documentation for AS PSH units operating as turbines is provided in Appendix B, Sections B-14 through B-19, for each one of the units at each of the six plants. Dynamic data for other units at the same plant is identical to the unit shown.

Some key parameters of the dynamic models (e.g., the inertia constant of the rotating machine and the water time constant of the hydraulic system) were kept the same, as they represent the physical characteristics of the existing systems.

Tests were performed to see the response to both over-frequency and under-frequency events. As expected, the contribution of the six PSH plants with a total generation of about $3,372 \mathrm{MW}$ to frequency regulation for a system of about 190,000 MW is very small; hence, the difference between the responses of the system with conventional PSH turbines or with AS PSH turbines is very small.

Figure 6-2 shows the response to two events resulting in a drop in frequency. Both events simulate trip of generation, the loss of 2,150 MW due to trip of two large nuclear plants and the loss of $10,000 \mathrm{MW}$ of generation, which is not representative of any particular event, but just to show the impact of a very large loss of generation. The change in frequency is very small for both events; the frequency nadir is about $59.92 \mathrm{~Hz}$ for a loss of 2,150 MW and $59.55 \mathrm{~Hz}$ for a loss of $10,000 \mathrm{MW}$, respectively. However, these tests confirmed that the performance of the newly developed model was appropriate. Plots in Figure 6-3 through Figure 6-5 compare the response of active power in MW, mechanical power in MW, and rotor speed in $\mathrm{Hz}$ for the loss of 10,000 MW of generation with conventional PSH turbines (black traces) and AS PSH turbines (red traces). Note that the rotor speed for the conventional unit is locked to system frequency, whereas the rotor speed of the AS PSH units can be adjusted independently of system frequency; thus, the response of rotor speed is quite different and strongly dependent on the assumed characteristic of the speed optimizer. 


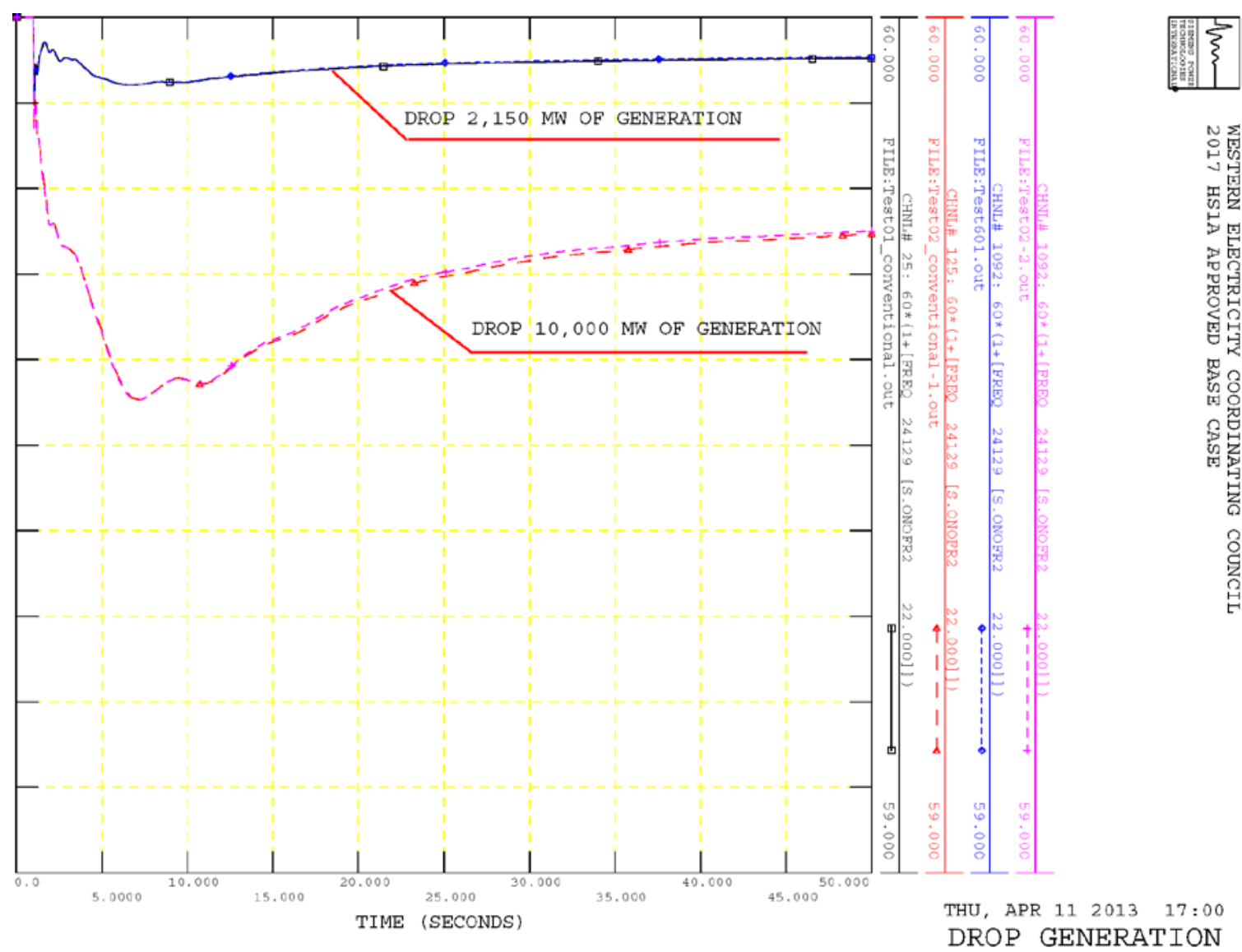

Figure 6-2 Response of System Frequency (in Hz) to a Drop in Generation of 2,150 MW and 10,000 MW 


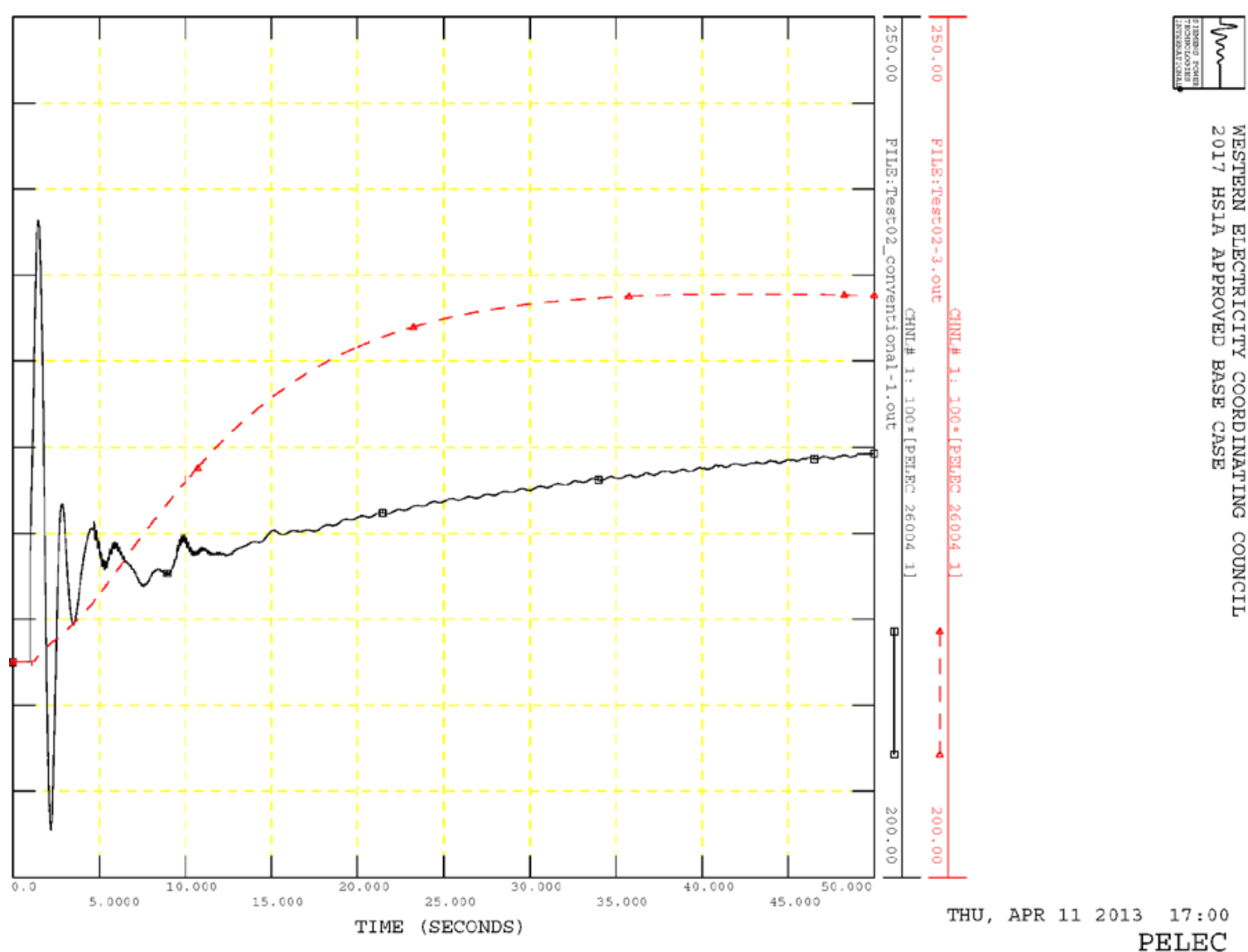

Figure 6-3 Comparison of the Active Power Response to a Drop of 10,000 MW of Generation: Conventional (Black) versus AS PSH (Red) 


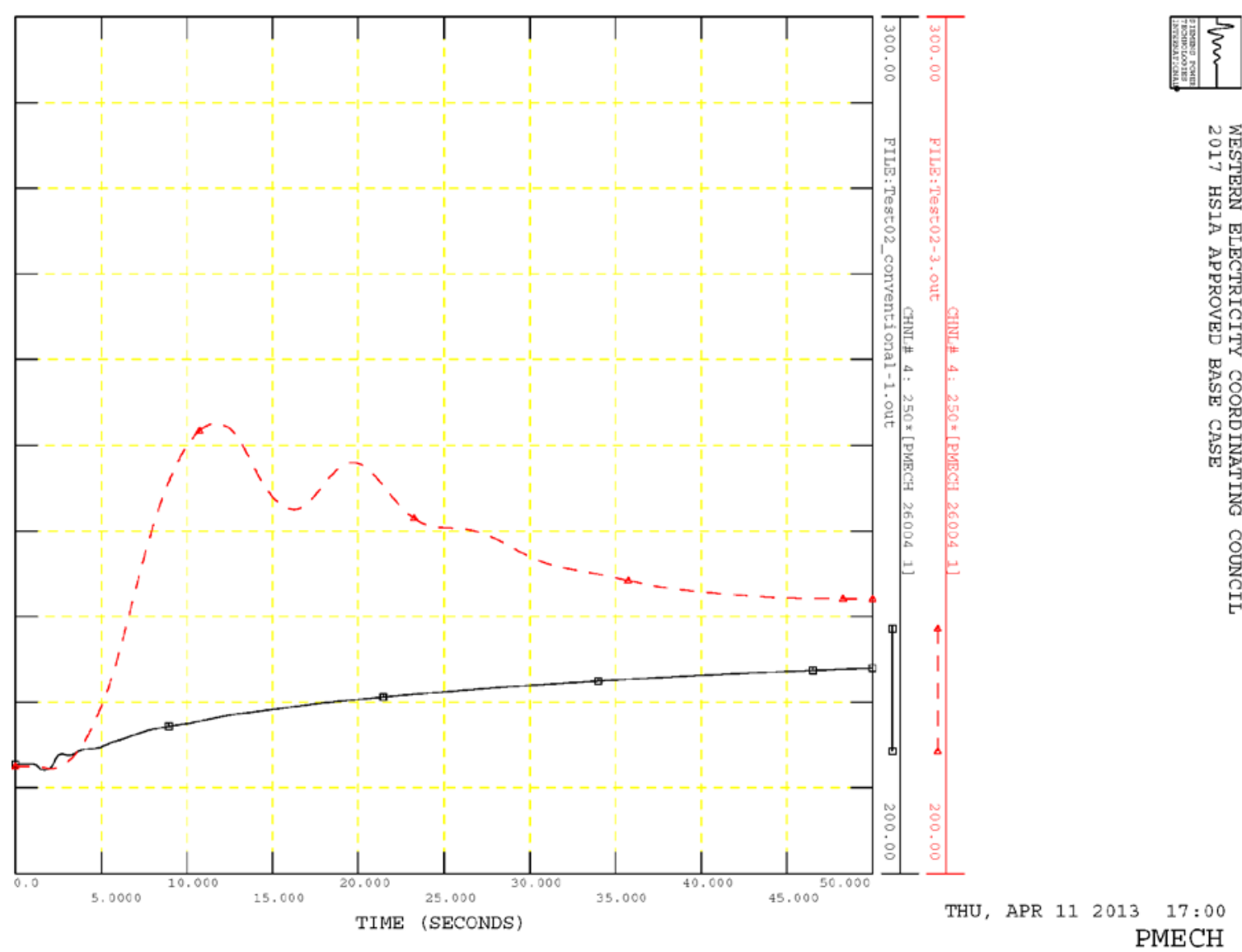

Figure 6-4 Comparison of the Mechanical Power Response to a Drop of 10,000 MW of Generation: Conventional (Black) versus AS PSH (Red) 


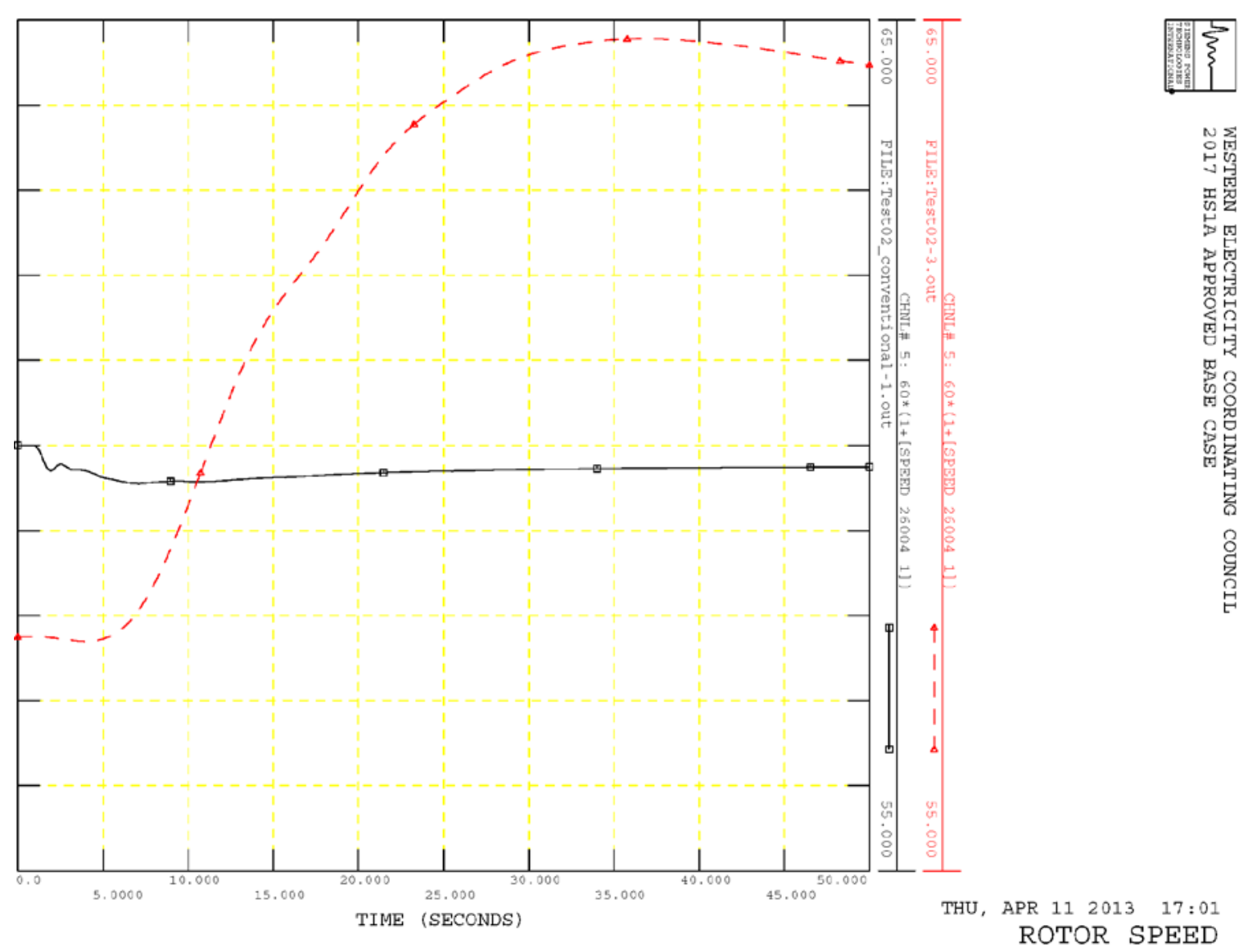

Figure 6-5 Comparison of the Response of Rotor Speed to a Drop of 10,000 MW of Generation: Conventional (Black) versus AS PSH (Red)

Conventional PSH turbine units have an excitation system that is responsible for the control of terminal voltage (or potentially the voltage at some other point). The converters of the AS $\mathrm{PSH}$ turbine units have an input from the reactive power controllers and will perform the same control action. This voltage control ability is confirmed by the plots of Figure 6-6 in which the terminal voltages of a PSH unit, a conventional turbine and an AS PSH turbine, are shown for the same disturbance as before, namely, the loss of 10,000 MW of generation. It is shown that the terminal voltage is controlled by the AS PSH turbine. Note that since the AS $\mathrm{PSH}$ turbine is not a synchronous machine, it does not have the oscillations due to intermachine angle swings. Since the purpose of these studies is to test model functionality, the control action of the AS PSH turbine has also not been optimized, and it may be possible to improve the speed of the voltage control. 


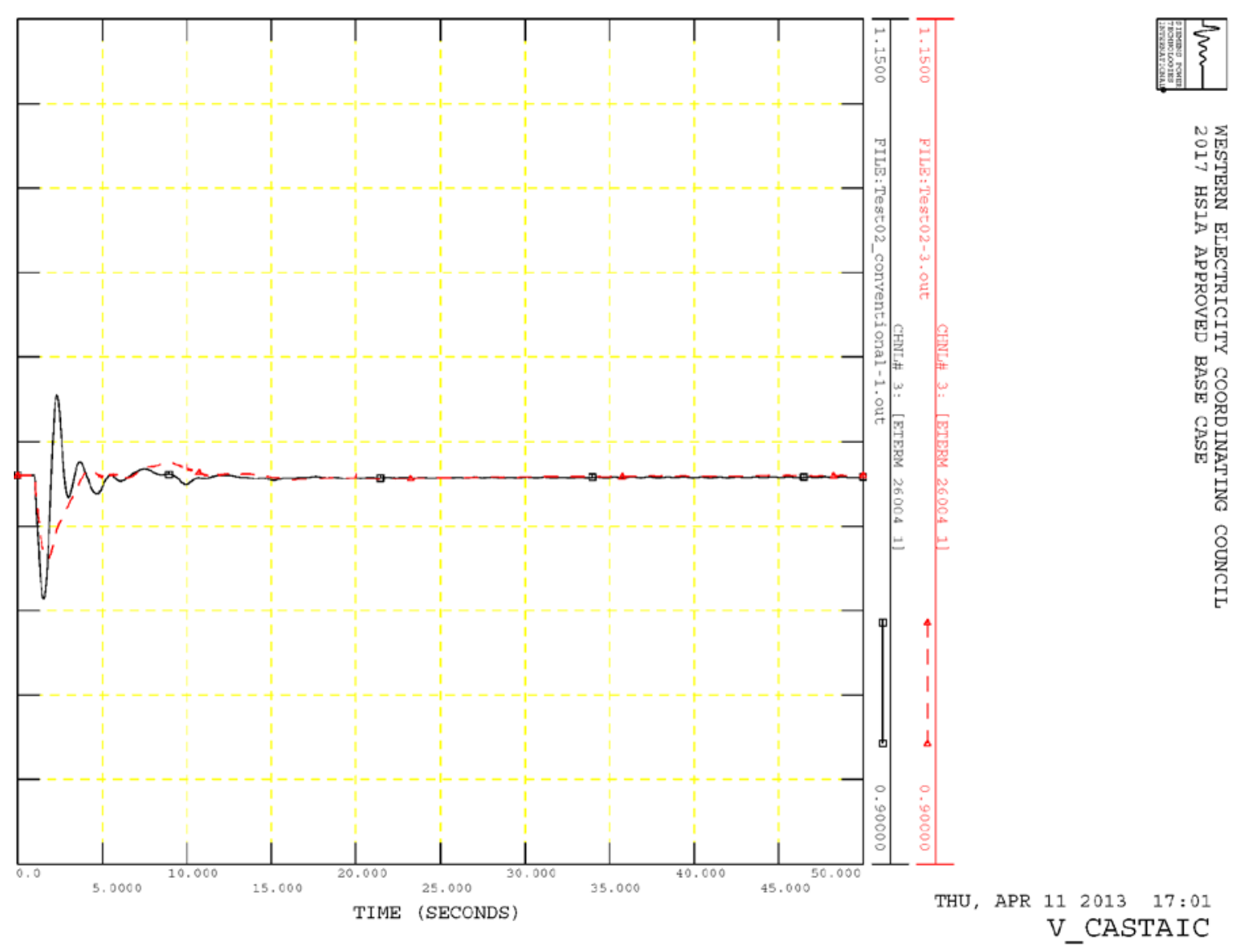

Figure 6-6 Terminal Voltage of a Castaic Unit Responding to the Loss of 10,000 MW of Generation: Conventional versus AS PSH Turbine Unit

A similar set of plots is given in Figure 6-7 through Figure 6-11 for an over-frequency event caused by a trip of $4,300 \mathrm{MW}$ of loads in the areas where the six candidate plants are located. For a large system like WECC, even the loss of such a large amount of load causes a relatively small change in frequency, and the peak frequency is only to $60.125 \mathrm{~Hz}$. Figure 6-7 shows the response of system frequency to the loss of load, and Figure 6-8 through Figure 6-5 compare the response of active power in MW, mechanical power in MW, and rotor speed in $\mathrm{Hz}$ for the loss of load with conventional PSH turbines (black traces) and AS PSH turbines (red traces). 


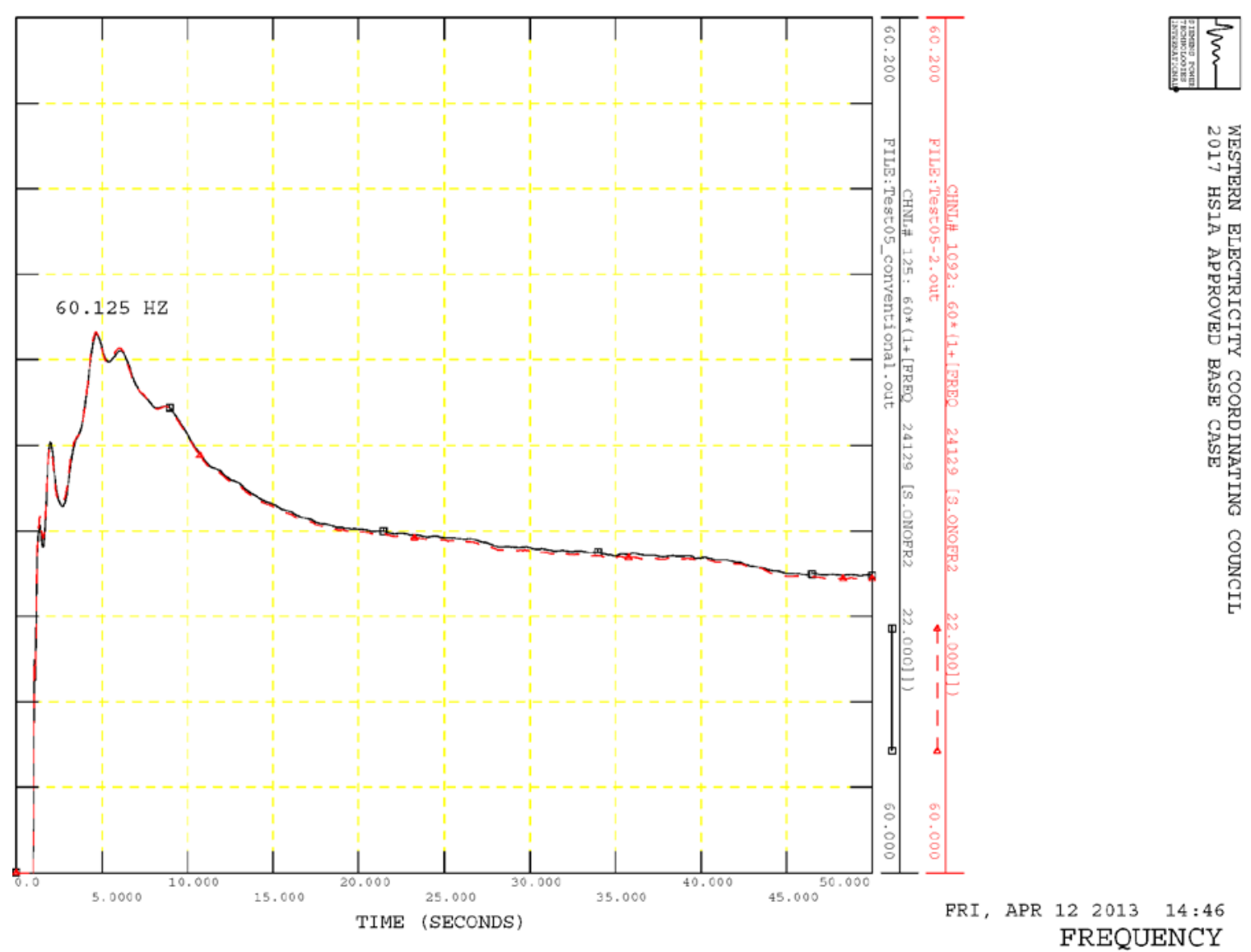

Figure 6-7 Response of System Frequency to Trip of 4,300 MW of Load: Conventional (Black) versus AS PSH (Red) 


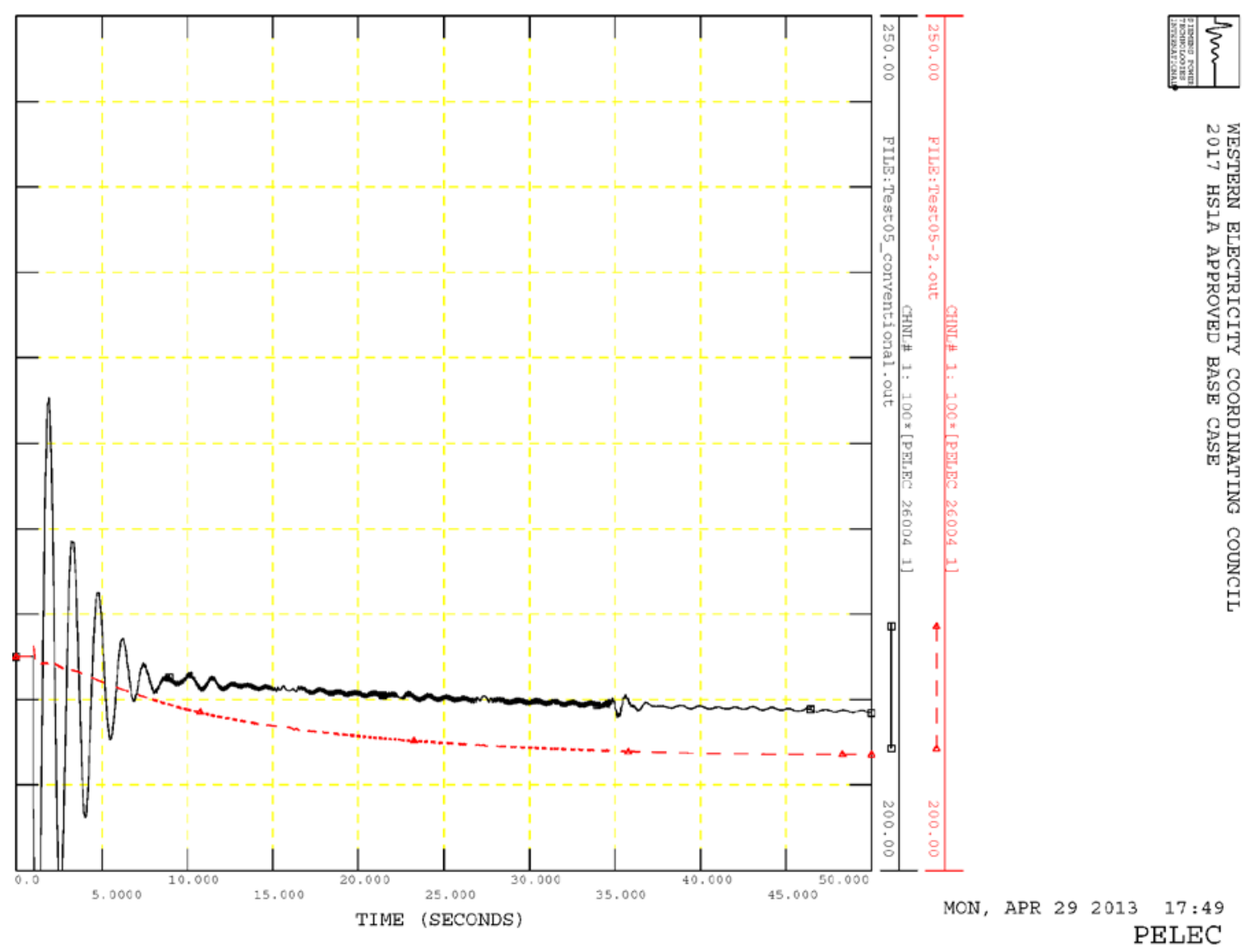

Figure 6-8 Comparison of the Response of Active Power to Trip of 4,300 MW of Load: Conventional (Black) versus AS PSH (Red) 


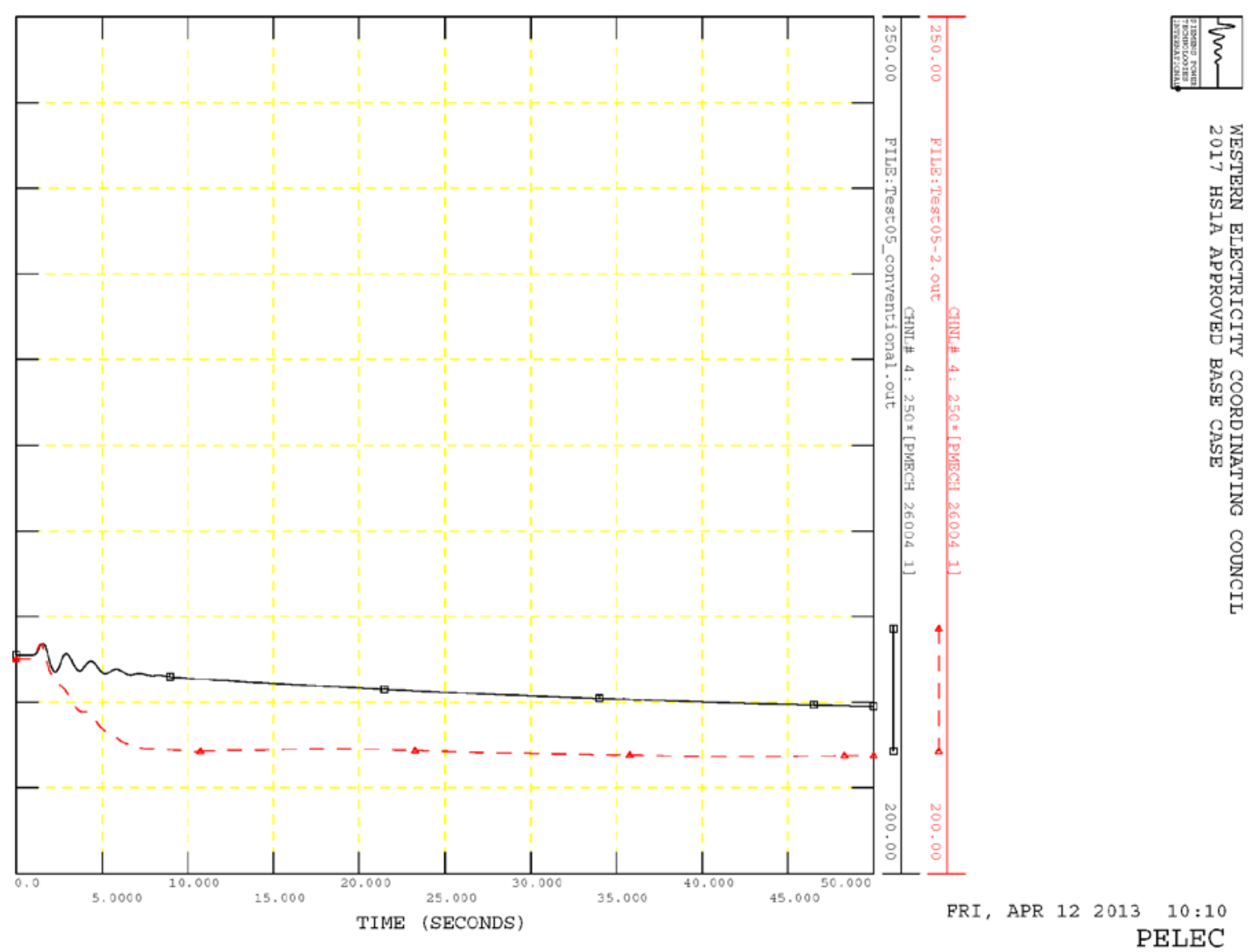

Figure 6-9 Comparison of the Response of Mechanical Power to Trip of 4,300 MW of Load: Conventional (Black) versus AS PSH (Red) 


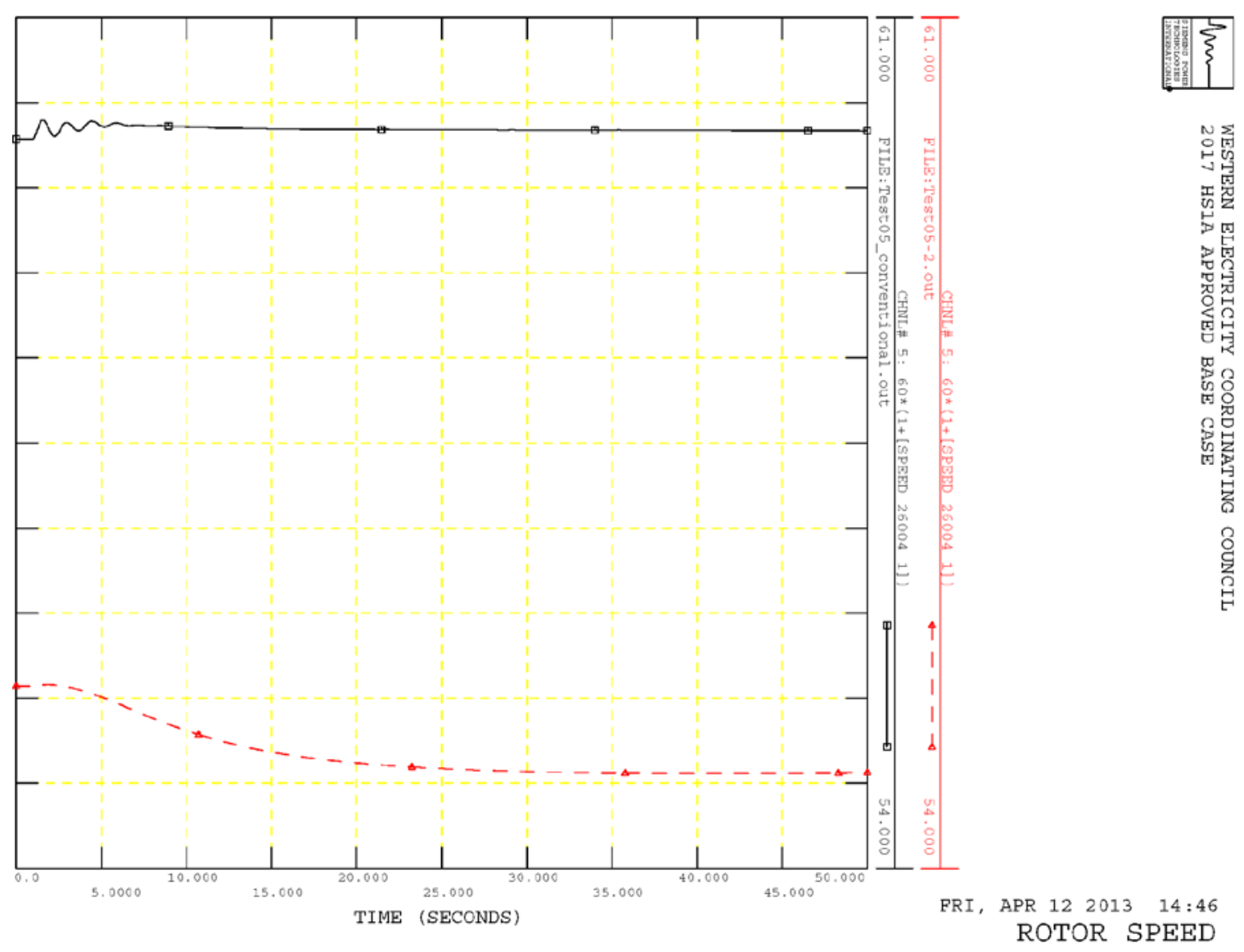

Figure 6-10 Comparison of the Response of Rotor Speed to Trip of 4,300 MW of Load: Conventional (Black) versus AS PSH (Red)

The voltage control capability of the AS PSH turbine is demonstrated again in Figure 6-11, where the terminal voltages of a PSH unit with a conventional turbine and an AS PSH turbine are shown for the loss of 4,300 MW of load. It can be seen that the voltage control by the AS $\mathrm{PSH}$ unit is comparable to the control with the conventional unit.

An essential part of power system planning and interconnection studies are transient stability studies performed to ensure that stability criteria are met. A dynamic simulation model must show adequate performance when "riding through" the different disturbances, including balanced and unbalanced faults. Disturbances were simulated similarly to those that would be routinely performed as part of such studies. Figure 6-11 shows the response to a threephase fault on the 230-kV Castaic bus, where one of the PSH plants is located. Figure 6-11 shows the faulted bus voltage and the relative rotor angle for the conventional and AS PSH turbines. Figure 6-12 shows the response to a single-line-to-ground (SLG) fault on the 230-kV Castaic bus. Both simulations show reasonable performance. 


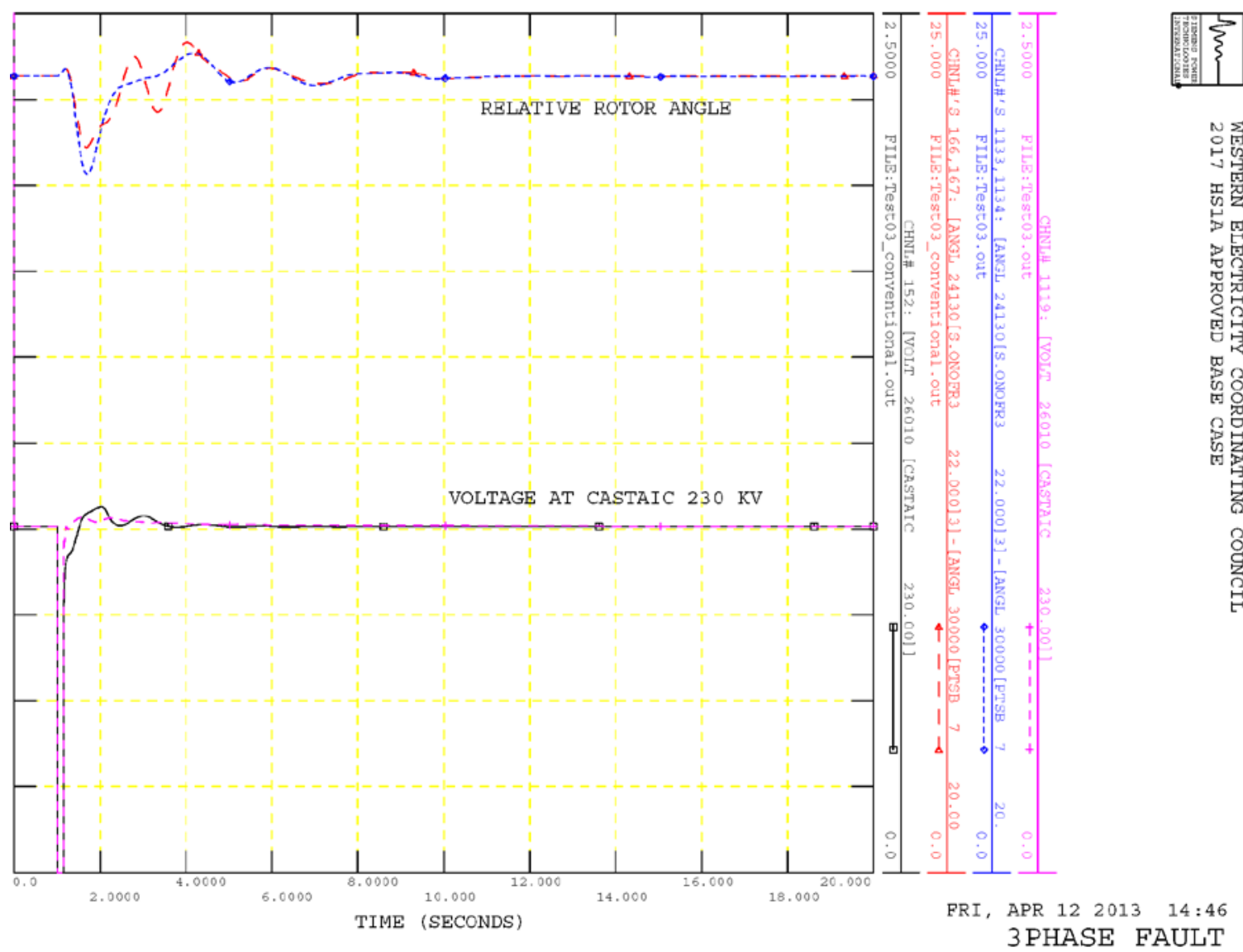

Figure 6-11 Comparison of the Response to a Three-Phase Fault on the 230-kV Castaic Bus: Faulted Bus Voltage and Relative Rotor Angle of the Castaic Unit with Conventional (Black and Red) and AS PSH (Blue and Pink) Turbines 


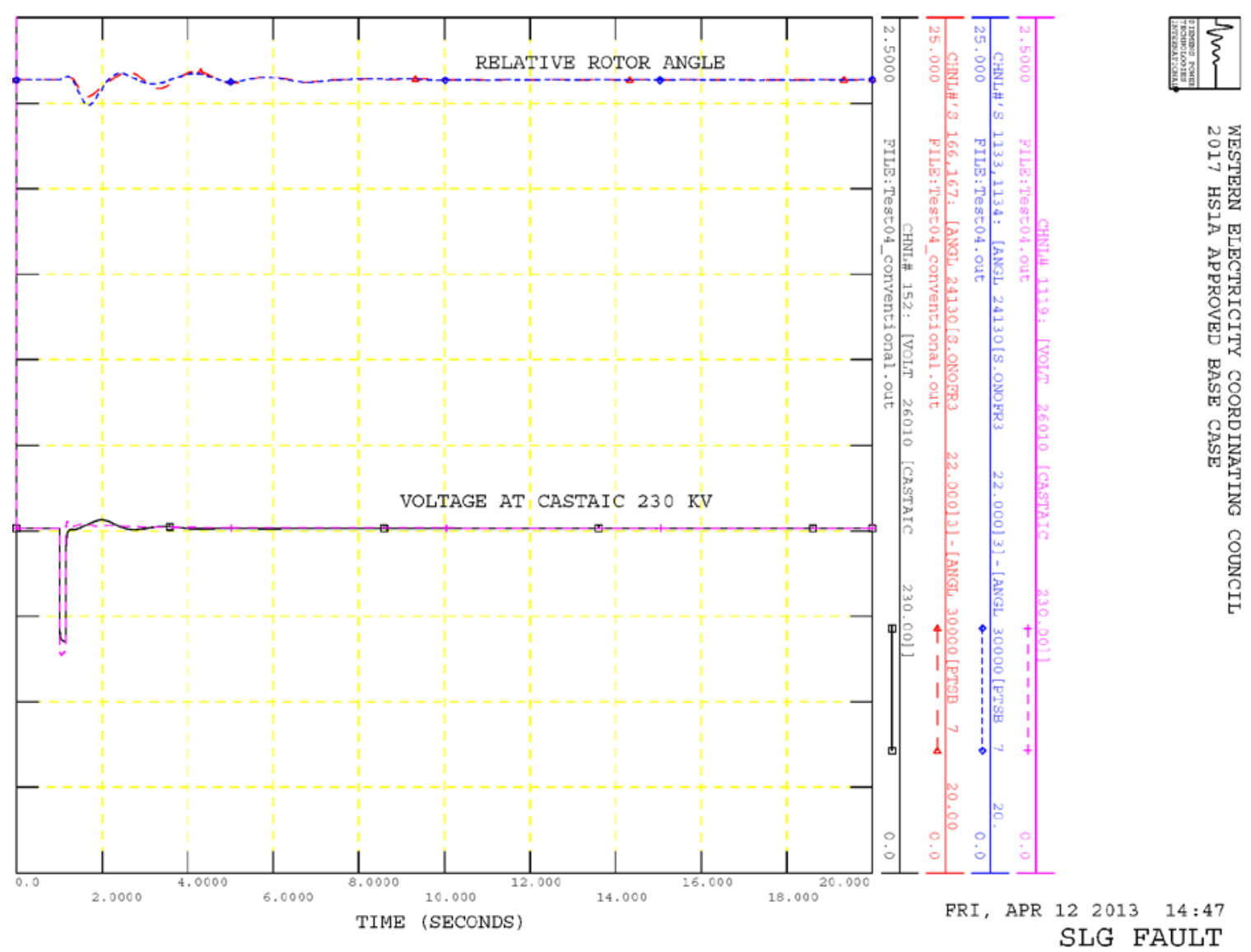

Figure 6-12 Comparison of the Response to a SLG Fault on the 230-kV Castaic Bus: Faulted Bus Voltage and Relative Rotor Angle of the Castaic Unit with Conventional (Black and Red) and AS PSH (Blue and Pink) Turbines

One of the most important anticipated contributions of an AS PSH plant is the ability to follow the large deviations of renewable sources of power (e.g., wind or solar power). For the very large WECC power system that covers a large geographical area, it is not realistic to expect very large deviations of total wind power in comparison to the total system power. Therefore, it is highly possible that customers (loads) will not see significant variation in the system frequency. From a large interconnected system standpoint, the contribution of the PSH plants and the differences among these contributions will be quite small, whether they are conventional or AS PSH plants. This is confirmed by the plots in Figure 6-13, which show the system frequency corresponding to ramping down of the total wind power of the system from an initial value of $1,127 \mathrm{MW}$ at a rate of $700 \mathrm{MW} / \mathrm{sec}$ for a period of one second. The frequency reduction is very small (down to $59.97 \mathrm{~Hz}$ ), and the difference between the frequency response for the conventional and AS PSH turbines is negligible. Note that this ramp in wind power is much faster than would be expected in an actual system and is meant to accentuate the control response.

Figure 6-14 Comparison of the Frequency Response to a Ramp Down of the Total Wind Power with Conventional (Black and Red) and AS PSH (Blue and Pink) Turbines depicts the active power response to the same event for conventional and AS PSH turbines. 


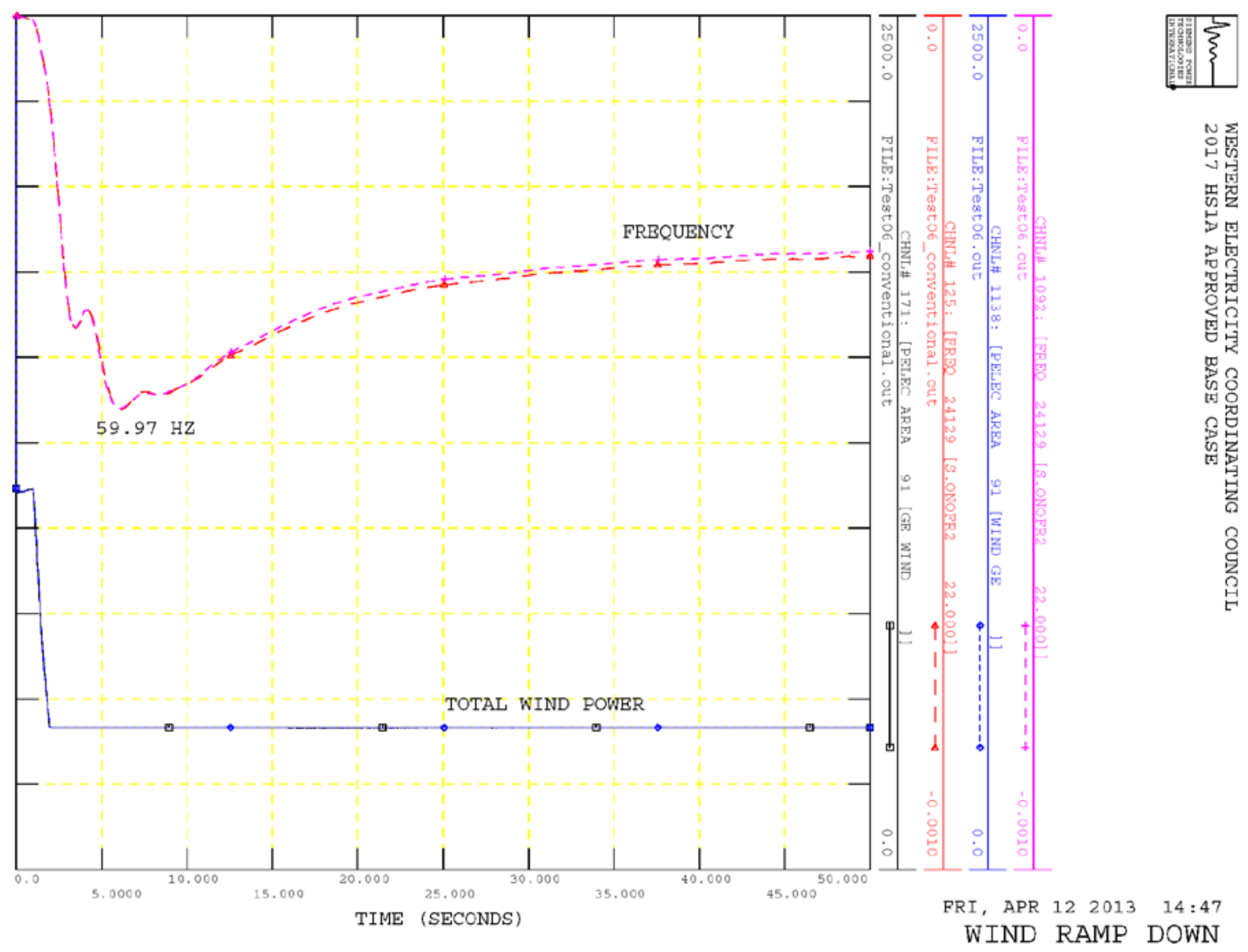

Figure 6-13 Comparison of the Frequency Response to a Ramp Down of the Total Wind Power with Conventional (Black and Red) and AS PSH (Blue and Pink) Turbines 


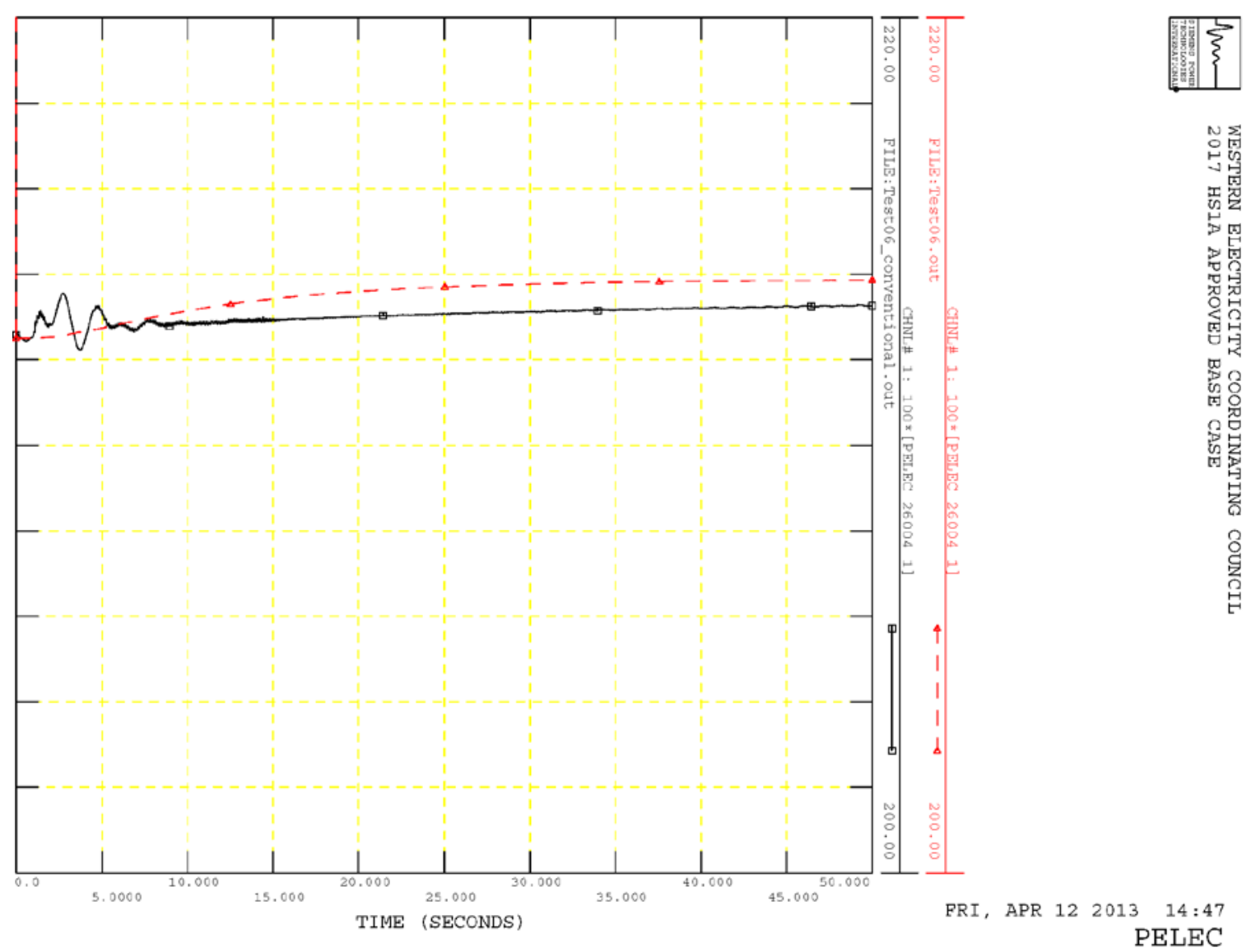

Figure 6-14 Comparison of the Frequency Response to a Ramp Down of the Total Wind Power with Conventional (Black and Red) and AS PSH (Blue and Pink) Turbines 
A conventional PSH unit in the pumping mode of operation does not participate in system frequency control, but operates with a constant value of its gate position as set by its operator. The AS PSH pump, due to controllability of the power converter, can control the rotor speed and affect the system frequency.

To make sure that the newly developed models are able to demonstrate the expected performance of AS PSH pumps, all of the PSH units of the Castaic plant have been converted to pumps with an output of $-200 \mathrm{MW}$, as shown in Figure 6-15.

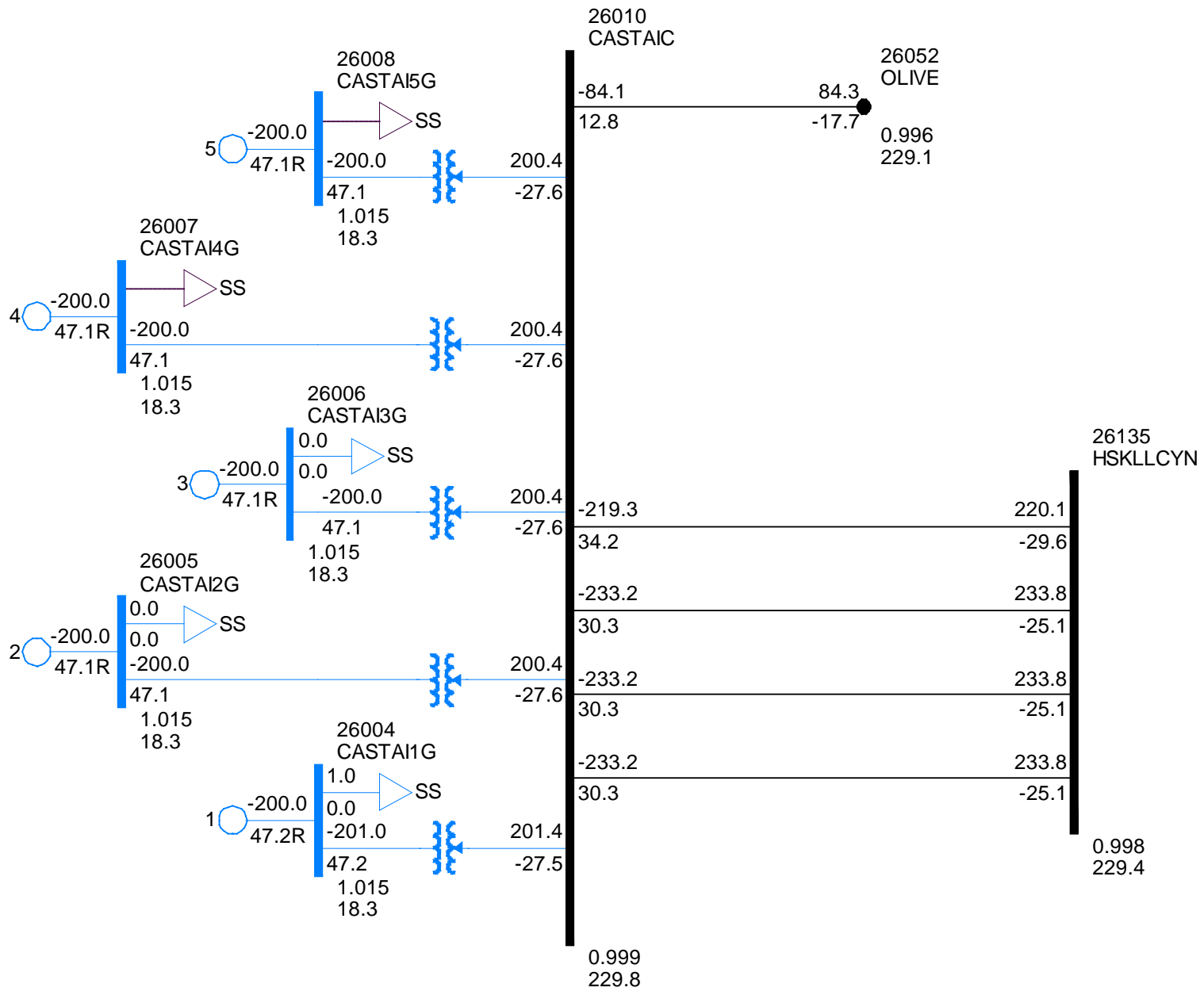

Figure 6-15 Castaic Units Operating as Pumps

The Castaic units were simulated as conventional pumps using the respective part of the new ternary unit model and as AS PSH units using the respective newly developed model. Both types of units were tested for 3-phase and SLG faults on the Castaic 230-kV bus. Figure 6-16 shows the terminal voltage of a Castaic unit and its reactive power for the SLG fault with both types of units. Although both the conventional pump and AS PSH pump can support the voltage during the remote or unbalanced fault, the reactive power supporting capability of an AS PSH unit is not as strong as that of the conventional unit with its excitation system. It is possible that this could be improved by parameter adjustment. 
Figure 617 shows the system frequency and active power response of a Castaic conventional and AS PSH unit for the loss of $10 \mathrm{GW}$ of generation. As we have seen above, taking a small share of the AS PSH units into account, they could not appreciably affect the response of system frequency, although one can clearly see the difference in the active power response. All five Castaic units completely unloaded (from -200 MW to $0 \mathrm{MW}$ ) responding to the frequency drop while trying to keep the rotor speed equal to the speed reference provided by the speed optimizer.

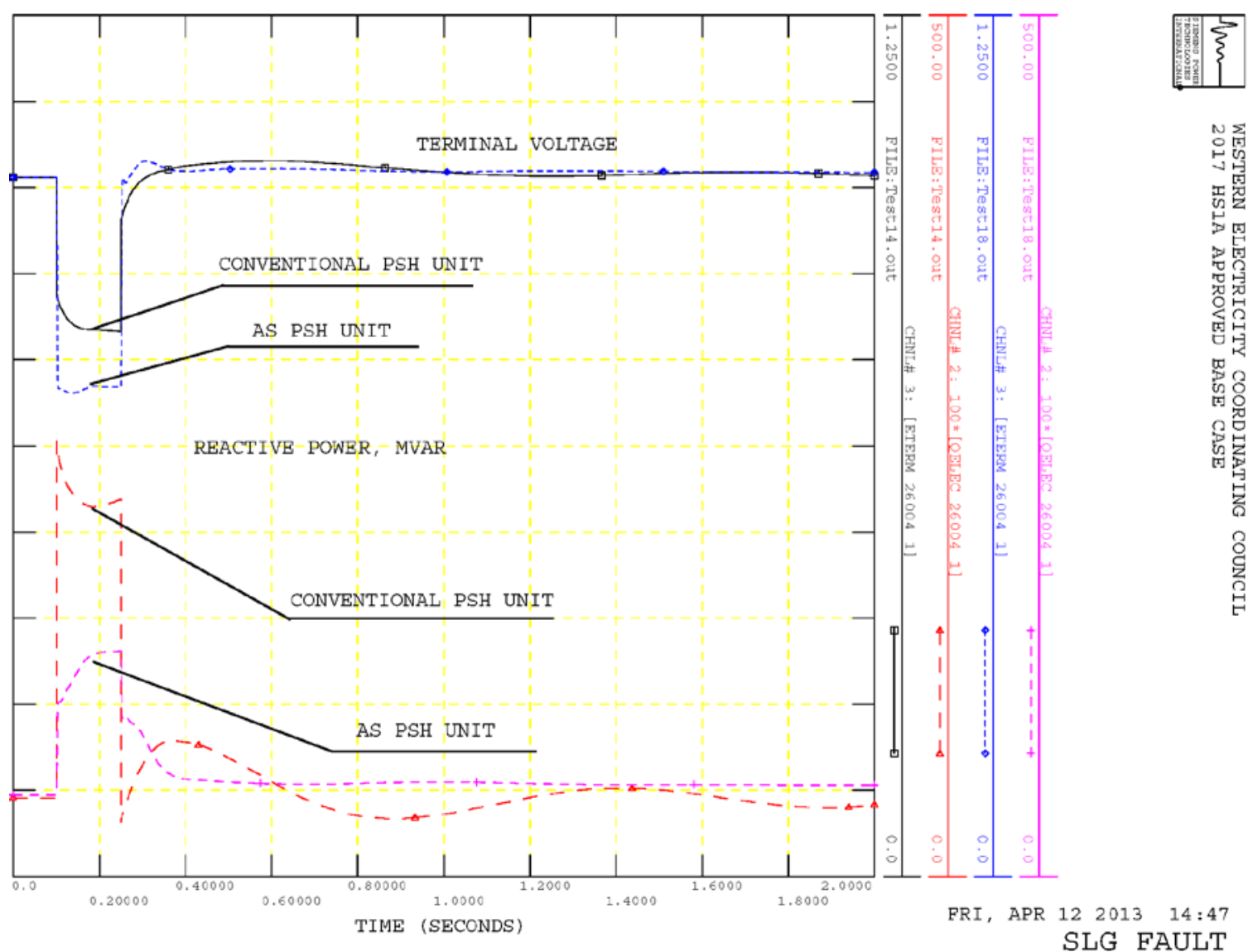

Figure 6-16 Comparison of the Voltage and Power Responses to a SLG Fault on the 230-kV Castaic Bus with Conventional or AS PSH Castaic Pumps 


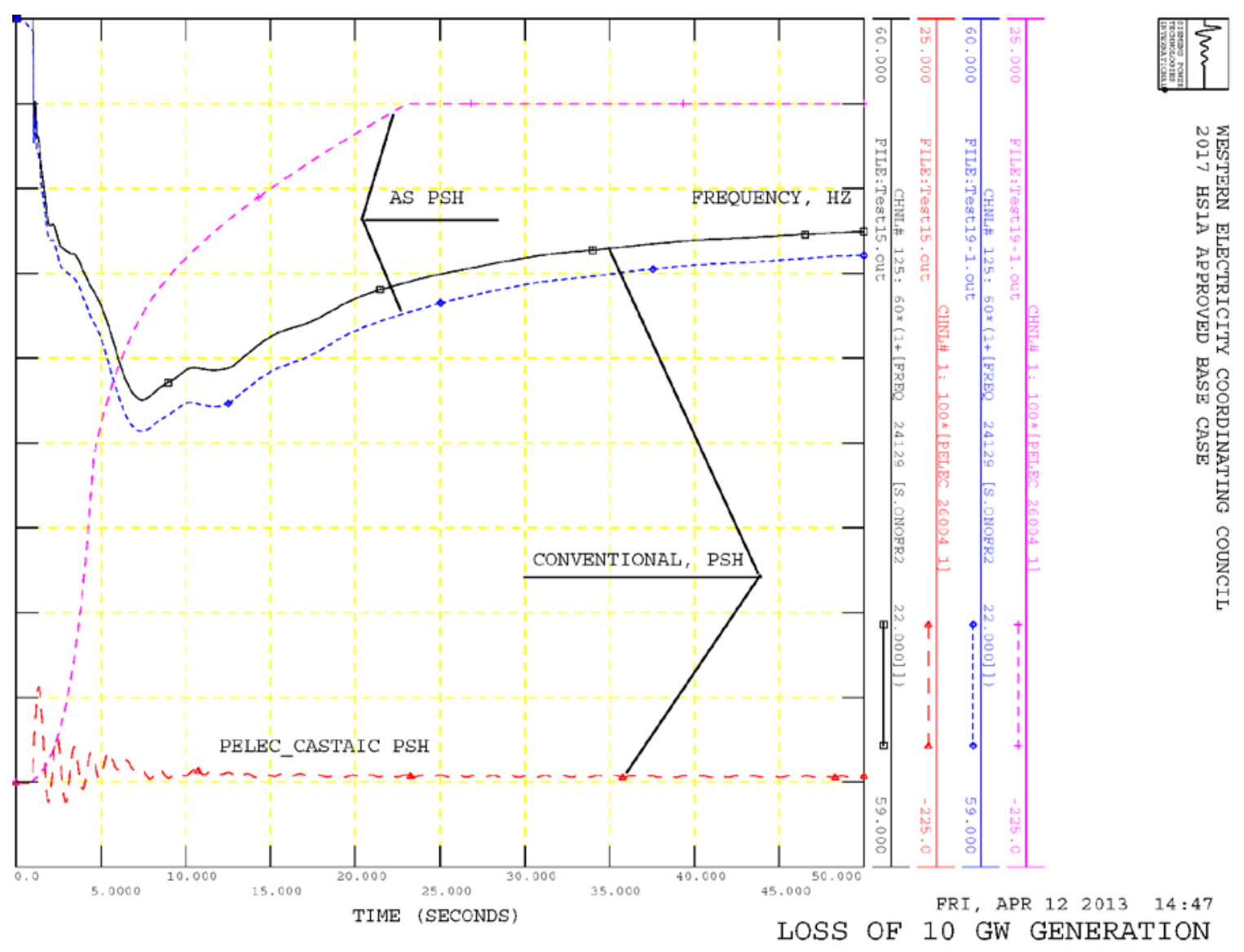

Figure 6-17 Comparison of the Frequency and Power Responses to a Loss of $10 \mathrm{GW}$ of Generation with Conventional or AS PSH Castaic Pumps

The last step in testing the newly developed models for the advanced PSH technologies using the WECC system assumed that all five Castaic units operated as ternary units in the hydraulic short-circuit mode. Each machine is modeled as a motor consuming $100 \mathrm{MW}$. The difference between the $100 \mathrm{MW}$ of mechanical power developed by the turbine and the -200 MW used by the pump is applied to the shaft of each unit, as illustrated in Figure 6-18. 


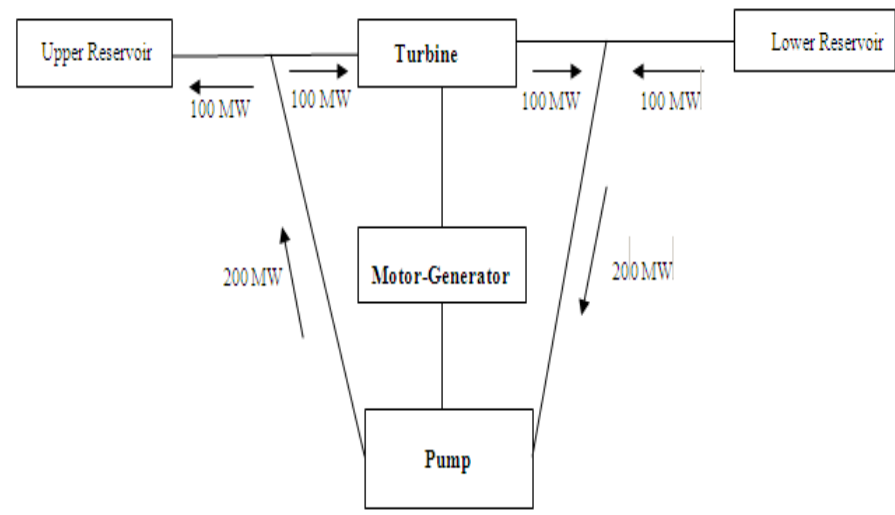

Figure 6-18 Mechanical Power Flow in the Short-Circuit Mode of Ternary Unit Operation

Plots in Figure 6-19 show the 230-kV Castaic bus voltage and terminal voltage of the Castaic unit, along with its reactive power in response to a 3-phase fault on the 230-kV Castaic bus. Figure 6-20 shows the mechanical power and rotor speed of the Castaic unit for this disturbance.

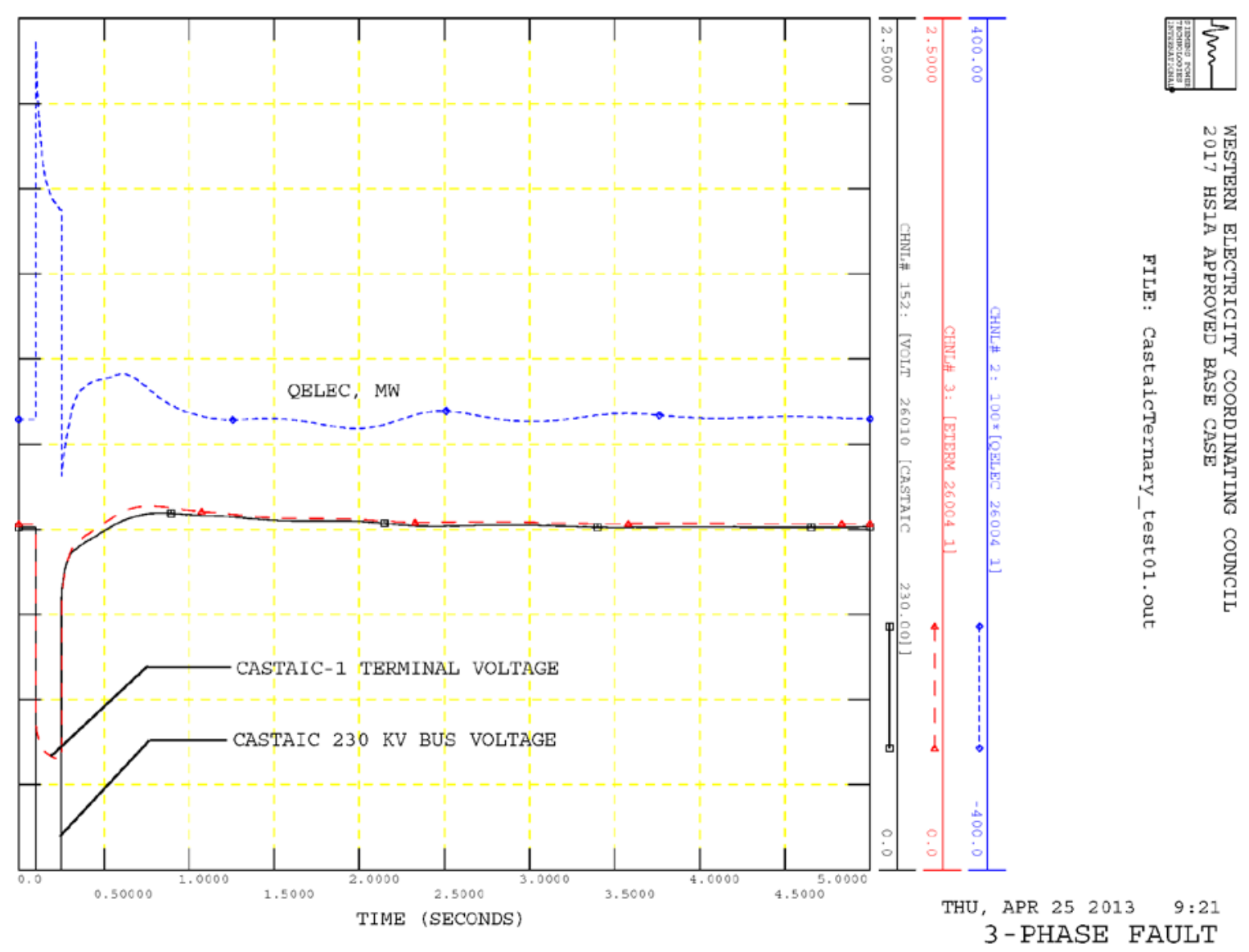

Figure 6-19 3-Phase Fault on the 230-kV Castaic Bus 


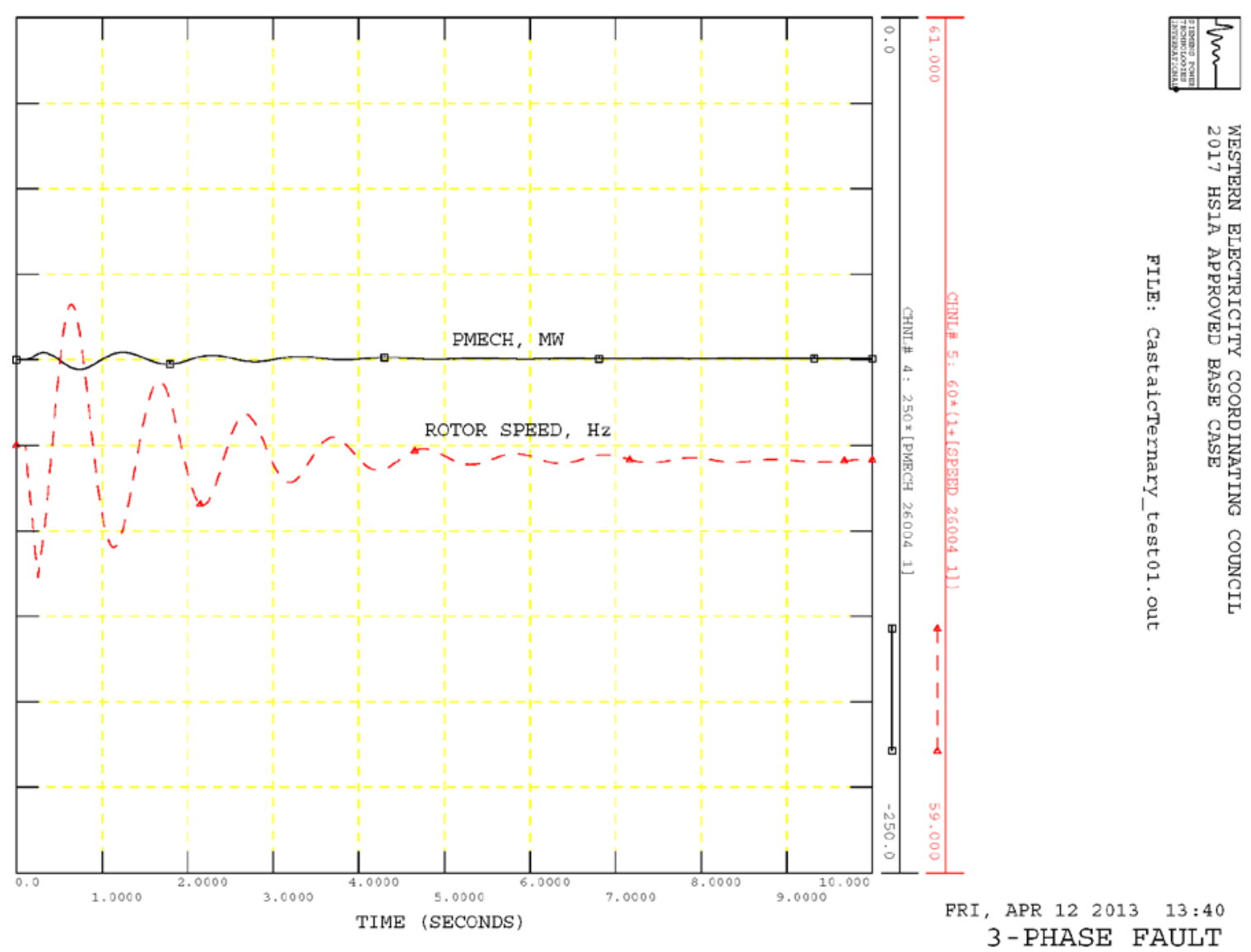

Figure 6-20 Mechanical Power and Rotor Speed in Response to a 3-Phase Fault on the 230-kV Castaic Bus

Figure 6-21 shows the system frequency and mechanical power of the Castaic unit for an under-frequency event caused by the loss of $10 \mathrm{GW}$ of generation. One can see that, in contrast to a conventional pump, the ternary unit in the hydraulic short-circuit mode of operation participates in frequency control. 


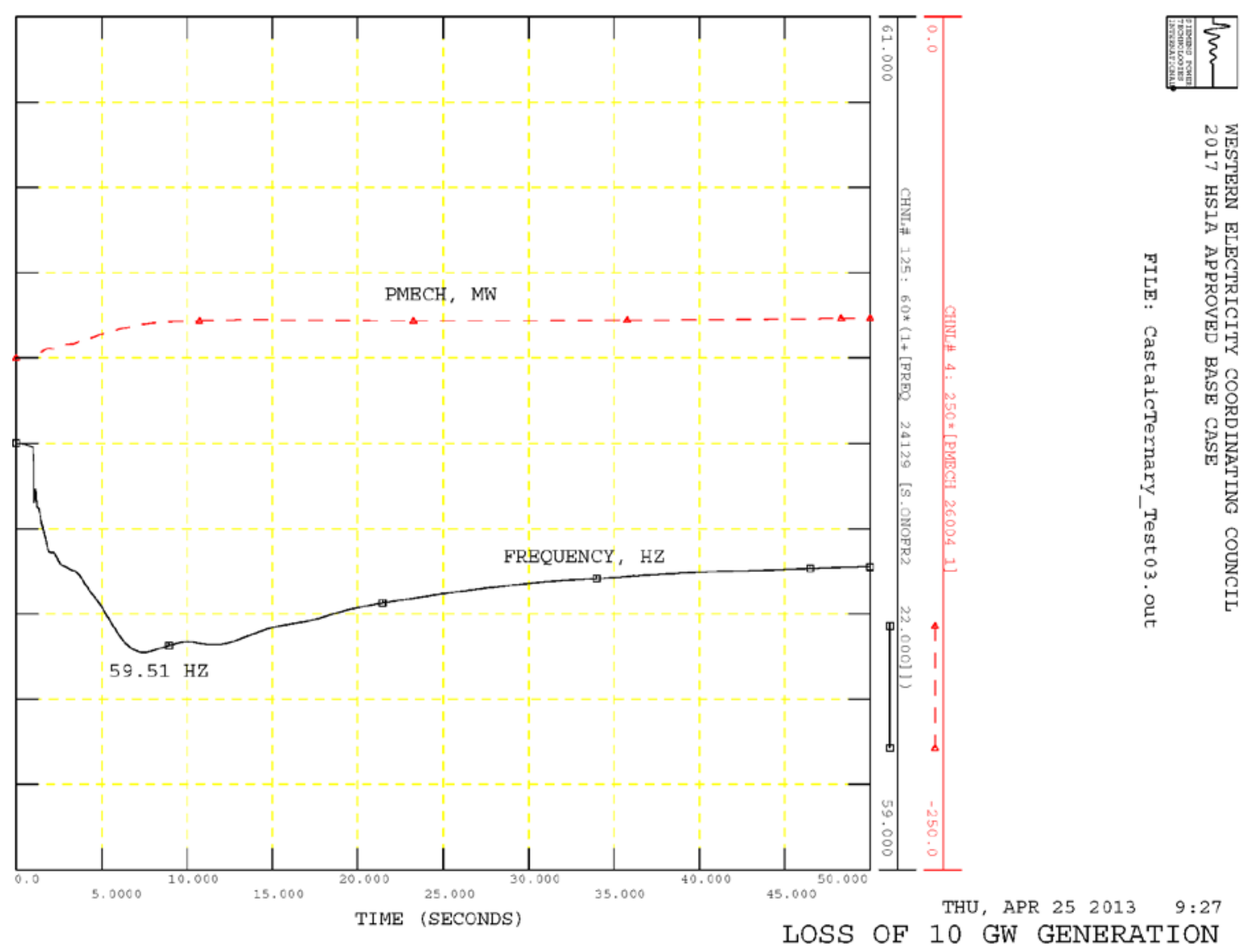

Figure 6-21 Mechanical Power and Frequency in Response to a Loss of $10 \mathrm{GW}$ of Generation 


\section{Section}

\section{Conclusions}

The following new dynamic simulation models have been developed and tested in the course of this project:

1. A model of an adjustable speed pumped storage hydro (AS PSH) unit operating as a turbine.

2. A model of an AS PSH unit operating as a pump.

3. A combined model of a ternary PSH unit that can be used for simulation of any of three modes of operation of this type of unit, namely:

- As a conventional hydro turbine

- As a conventional hydro pump

- As a ternary unit operating in the hydraulic short-circuit mode.

Earlier reports [2, 3] described the performance of these technologies, the approach to their modeling, and the details of the models' design.

Testing of newly developed models was reported on in this report. Tests were performed using three tests systems:

1. A small 12-bus sample test system was used to make sure that models showed adequate performance in responding to different disturbances, such as under- and over-frequency events caused by loss of generation or load, and three-phase and single-line-to-ground faults in the vicinity of the plant under study. This test system allowed variation in the level of penetration of the advanced technology.

2. Small sample test systems were used to demonstrate the potential benefit of the faster frequency control of the AS PSH technology. An example is shown in which this improved capability could be used to avoid or reduce the occurrence of load shedding following a sudden loss of generation or system separation.

3. The WI power system with about $190 \mathrm{GW}$ of generation was used to demonstrate the use of the models with an actual power system. The six existing PSH plants, totaling about 3,200 MW of installed capacity, were simulated using the newly developed models as well as with their original conventional PSH models. The response of these units (and of the system with these units) was simulated for a wide variety of 
disturbances, including the response to changes in the power generated by renewable energy sources. These tests ensured that the newly developed models could be used for practical analyses of real systems.

Thus, the tests demonstrated that the new models performed well and can be used for the typical dynamic simulation analyses required by planning and interconnection studies. The tests also demonstrated the new capabilities available in these models (e.g., the use of an adjustable speed pumped storage plant to provide regulation services in the pump mode). The tests showed the improved capabilities of the equipment such as the faster response to system events.

These new models fill a major need in the transmission system interconnection activity with regard to system dynamic performance studies for new pumped storage plants with adjustable speed or ternary pumped storage units. These models will be very useful in studies investigating how these technologies can be implemented to help address concerns related to the increasing integration of wind and solar photovoltaic renewable resources. 


\section{Section}

8

\section{References}

1. Review of Existing Hydroelectric Turbine-Governor Simulation Models, Task Report prepared for the study "Modeling and Analysis of Value of Advanced Pumped Storage Hydropower in the U.S.," Argonne National Laboratory, 2013.

2. Modeling Adjustable Speed Pumped Storage Hydro Units Employing Doubly-Fed Induction Machines, Task Report prepared for the study "Modeling and Analysis of Value of Advanced Pumped Storage Hydropower in the U.S.," Argonne National Laboratory, 2013.

3. Modeling Ternary Pumped Storage Units, Task Report prepared for the study "Modeling and Analysis of Value of Advanced Pumped Storage Hydropower in the U.S.," Argonne National Laboratory, 2013.

4. Hannett, L.N., B.P. Lam, F.S. Prabhakara, Q. Guofu, D. Mincheng, and B. Beilei, "Modeling of a Pumped Storage Hydro Plant for Power System Stability Studies," Proceedings of the International Conference on Power System Technology, POWERCON ‘98, 1998, Volume 2, pp. 1300-1304.

5. Kopf, E., S. Brausewetter, M. Giese, and F. Moser, "Optimized Control Strategies for Variable Speed Machines," 22nd IAHR Symposium on Hydraulic Machinery and Systems, June 29 - July 2, 2004, Stockholm, Sweden.

6. Hannett, L.N., J.W. Feltes, B. Fardanesh, and W. Crean, "Modeling and Control Tuning of a Hydro Station with Units Sharing a Common Penstock Section," IEEE Transactions on Power Systems, Volume 14, Issue 4, 1999, pp. 1407-1414.

7. "Hydraulic Turbine and Turbine Control Models for System Dynamic Studies," IEEE Transactions on Power Systems, Volume 7, Issue 1, 1992, pp. 167-179. 
This page intentionally left blank. 


\section{Appendix

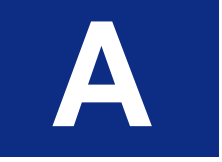

PSS $^{\circledR}$ E Load Flow Raw Data Files 


\title{
A.1 PSS ${ }^{\circledR} E$ Raw Data File for the Test System with the Single PSH Turbine
}

\author{
$0, \quad 100.00,33,0,1,60.00$
THREE MACHINES ISLAND SYSTEM \\ PSS(R)E-33.1 THU, DEC $272012 \quad 10: 38$
}

\begin{tabular}{|c|c|c|c|c|}
\hline & 0,1 & 1, & 1, 0.96302, & $-6.7991,1.10000,0.90000,1.1$ \\
\hline & & 1, & & $-5.9225,1$. \\
\hline & $.5000,1$, & 1, & 1,0 & \\
\hline & & 1, & & \\
\hline & 24 & 1, & & \\
\hline & 23 & 1, & & \\
\hline & & 1, & & \\
\hline & 23 & & & \\
\hline & 24.0 & & & . \\
\hline & & 1 , & 1.00000, & $\odot .2462,1.10000,0.90000,1.10000,0.900$ \\
\hline $\begin{array}{ll}1 & 1 \\
1 & 1\end{array}$ & $\begin{array}{l}0.000, \\
0.000,\end{array}$ & & 98.784 & 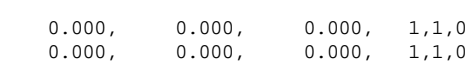 \\
\hline
\end{tabular}

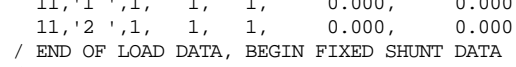
$10.267, \quad 15.000, \quad-15.000,1.00000$
8. $50.000,-50.000,1.00000$
๑, $\quad 28.900, \quad 0.00000 \mathrm{E}+\Theta, \quad 2.00000 \mathrm{E}-1,0.00000 \mathrm{E}+0,0.00000 \mathrm{E}+0,1.00000,1, \quad 100 . \odot, \quad 25.000, \quad 0.000, \quad 1,1.0000$

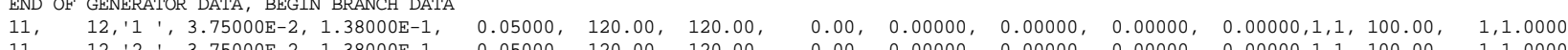

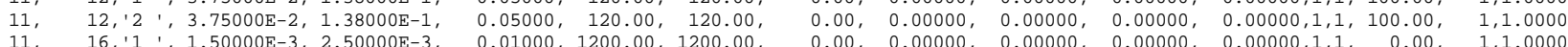

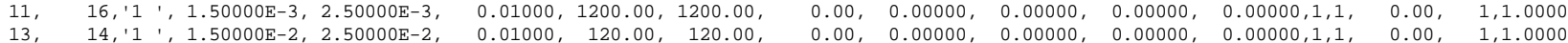

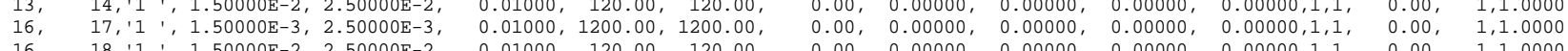

$16,18,11$ ', $1.50000 \mathrm{E}-2,2.50000 \mathrm{E}-2,0.01000,120.00,120.00$,

0 / END OF BRANCH DATA, BEGIN TRANSFORMER DATA

$12,13, \quad 0, \prime^{\prime} 1 \quad 1,1,1,0.00000 \mathrm{E}+0,0.00000 \mathrm{E}+0,2$,

$\begin{array}{ccc}0.00000 \mathrm{E}+\Theta, & 1.00000 \mathrm{E}-1, \quad 100.00 \\ 1.00000, \quad 0.000, \quad 0.000, \quad 120.00, \quad 120.00, & 0.00,0,\end{array}$

$1,0.00000 \mathrm{E}+0,0.00000 \mathrm{E}+0,1$,

$15, \quad 14, \quad 0,,^{\prime} 1,1,1,1,0.00000 \mathrm{E}+0,0.00000 \mathrm{E}+0,1$,
$\begin{array}{ll}0.00000 \mathrm{E}+0,5.0000 \mathrm{E}-2, \\ 1.00000, \quad 0.000, \quad 0.000, \quad 0.00, \quad 0.00, \quad 0.00,0,\end{array}$

$17, \quad 19, \quad 0,{ }^{\prime} 1 L^{\prime}, 1,1,1,0.00000 \mathrm{E}+0,0.00000 \mathrm{E}+0,1$,

$1.00000, \quad 0.000, \quad 0.000, \quad 0.00, \quad 0.00, \quad 0.00,0$,

$1.00000, \quad 0.000$

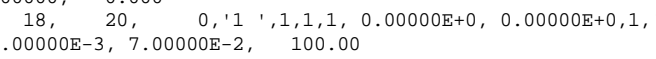

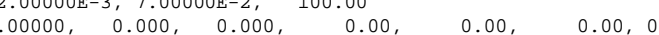

', $1, \quad 1,1.0000, \quad 0,1.0000, \quad 0,1.0000, \quad 0,1.0000$,

$0,1.10000,0.90000,1.10000,0.90000,33,0,0.00000,0.00000,0.000$

$1,1, \quad 1,1.0000, \quad 0,1.0000, \quad 0,1.0000, \quad 0,1.0000$,

$0,1.10000,0.90000,1.10000,0.90000,33,0,0.00000,0.00000,0.000$

', $1, \quad 1,1.0000, \quad 0,1.0000, \quad 0,1.0000, \quad 0,1.0000$,

$0,1.10000,0.90000,1.10000,0.90000,33,0,0.00000,0.00000,0.000$

', $1, \quad 1,1.0000, \quad 0,1.0000, \quad 0,1.0000, \quad 0,1.0000$,

$0,1.10000,0.90000,1.10000,0.90000,33,0,0.00000,0.00000,0.000$

END OF TRANSFORMER DATA, BEGIN AREA DATA

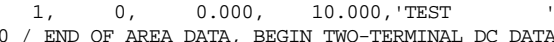

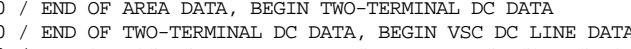

作

$\checkmark /$ END OF MULTI-TERMINAL DC DATA, BEGTN MULTI-SECTION LINE DATA

$\odot /$ END OF MULTI-SECTION LINE DATA, BEGIN ZONE DATA 

$\Theta /$ END OF INTER-AREA TRANSFER DATA, BEGIN OWNER DATA

1, 'TEST 0 INER ' '

- END OF OWNER DATA, BEGIN EACTS DEVICE

$13,0,0,1,1.10000,0.90000$,

0 / END OF SWITCHED SHUNT DATA, BEGIN GNE DATA

$\odot /$ END OF GNE DATA, BEGIN INDUCTION MACHINE DATA
$\odot /$ END OF INDUCTION MACHINE DATA 


\title{
A.2 PSS $^{\circledR}$ E Raw Data File for the Test System with the Single PSH Pump
}

Or, $100.00,33,0,1,60.00$
THREE MACHINES ISLAND SYSTEM

/ PSS(R)E-33.1

\author{
FRI, DEC $282012 \quad 11: 37$
}

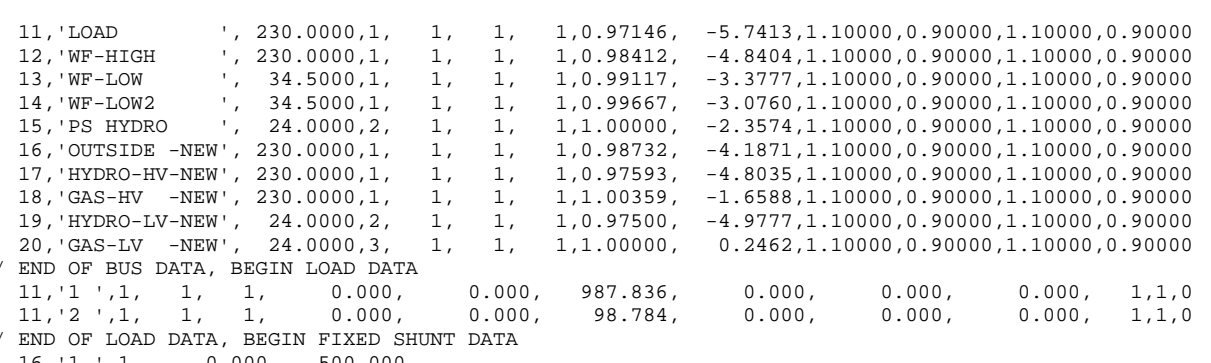

0 / END OF 'LOAD DATA, BEGIN FIXED SHUNT DATA

$16,{ }^{1} 1$ ' '1, 1 , 0.000 , 500.000
0 / END OF FIXED SHUNT DATA, BEGN GENERATOR DATA

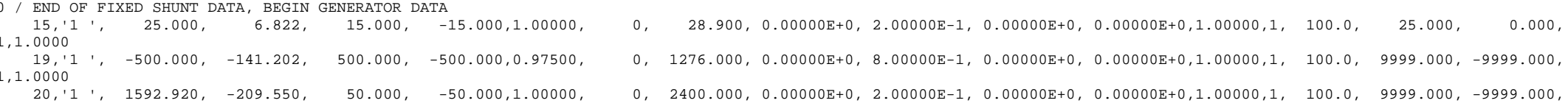

$1,1.0000$
$\Theta$

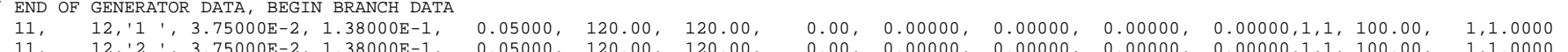

$11, \quad 12,1,3.75000 \mathrm{E}-2,1.38000 \mathrm{E}-1, \quad 0.05000,120.00,120.00, \quad 0.00, \quad 0.00000, \quad 0.00000, \quad 0.00000, \quad 0.00000,1,1,100.00, \quad 1,1.0000$

$\begin{array}{llllllllll}11, & 16, & 1\end{array}$

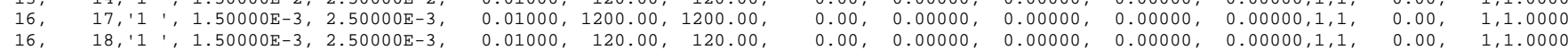

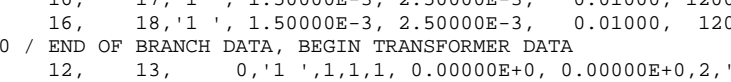

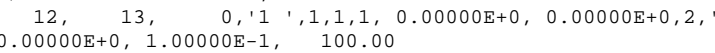

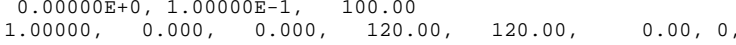

$1.00000, \quad 0.000 \quad 0,1^{\prime}, 1,1,1,0.00000 \mathrm{E}+0,0.00000 \mathrm{E}+0,1$,

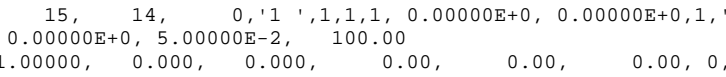

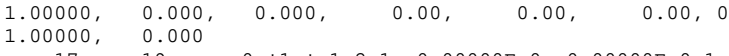

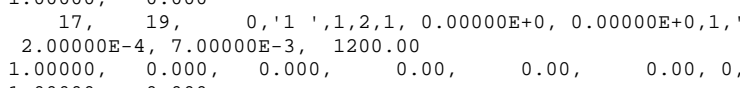

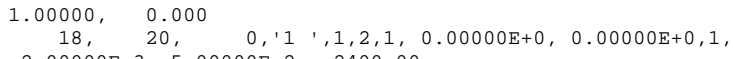

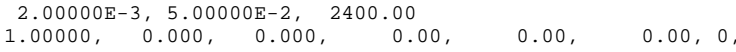

$\begin{array}{lll}1.00000, & 0.000 & \\ 1.00000 & & 0.000\end{array}$

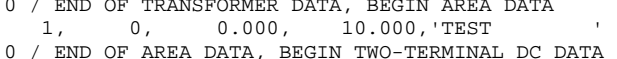

$\odot$ / END OF AREA DATA, BEGIN TWO-TERMINAL DC DATA
$0 /$ END OF TWO-TERMINAL DC DATA, BEGIN VSC DC LINE DATA

$\odot$ END OF TWO-TERMINAL DC DATA, BEGIN VSC DC LINE DATA
$\Theta /$ END OF VSC DC LINE DATA, BEGIN IMPEDANCE CORRECTION DATA

0 / END OF VSC DC LINE DATA, BEGIN IMPEDANCE CORRECTION DATA
$\Theta$ EN IMPEDANCE CORRECIION DATA, BEGIN MULTI-TERMINAL DC DATA

$\odot /$ END OF MULTI-TERMINAL DC DATA, BEGIN MULTI-SECTION LINE DATA

0 / END OF MULTI-SECTION LINE DATA, BEGIN ZONE DATA

1, 'TEST
$/$ END OF ZONE DATA, BEGIN INTER-AREA TRANSFER DATA

0 / END OF INTER-AREA TRANSFER DATA, BEGIN OWNER DATA

', $1, \quad 1,1.0000, \quad 0,1.0000, \quad 0,1.0000, \quad 0,1.0000, '$

$0,1.10000,0.90000,1.10000,0.90000,33,0,0.00000,0.00000,0.000$

', $1, \quad 1,1.0000, \quad 0,1.0000, \quad 0,1.0000, \quad 0,1.0000, '$

$0,1.10000,0.90000,1.10000,0.90000,33,0,0.00000,0.00000,0.000$

$1,1, \quad 1,1.0000, \quad 0,1.0000, \quad 0,1.0000, \quad 0,1.0000,{ }^{\prime}$

$0,1.10000,0.90000,1.10000,0.90000,33,0,0.00000,0.00000,0.000$

', $1, \quad 1,1.0000, \quad 0,1.0000, \quad 0,1.0000, \quad 0,1.0000,{ }^{\prime}$

$0,1.10000,0.90000,1.10000,0.90000,33,0,0.00000,0.00000,0.000$ 
PSS $^{\circledR}$ E Load Flow Raw Data Files

0 / END OF OWNER DATA, BEGIN FACTS DEVICE DATA

- / END OF FACTS DEVICE DATA, BEGIN SWITCHED SHUNT DATA

$13,0,0,0,1.10000,0.90000, \quad 0,100.0$,

$\odot$ / END OF SWITCHED SHUNT DATA, BEGIN GNE DATA

/ END OF GNE DATA, BEGIN INDUCTION MACHINE DATA

/ END OF INDUCTION MACHINE DATA 


\title{
A.3 $\quad$ PSS ${ }^{\circledR} E$ Raw Data File for the Test System with Four PSH Turbines
}

O, $100.00,33,0,1,60.00$
THREE MACHINES ISLAND SYSTEM

\author{
PSS(R)E-33.1 MON, MAR $182013 \quad 9: 28$
}

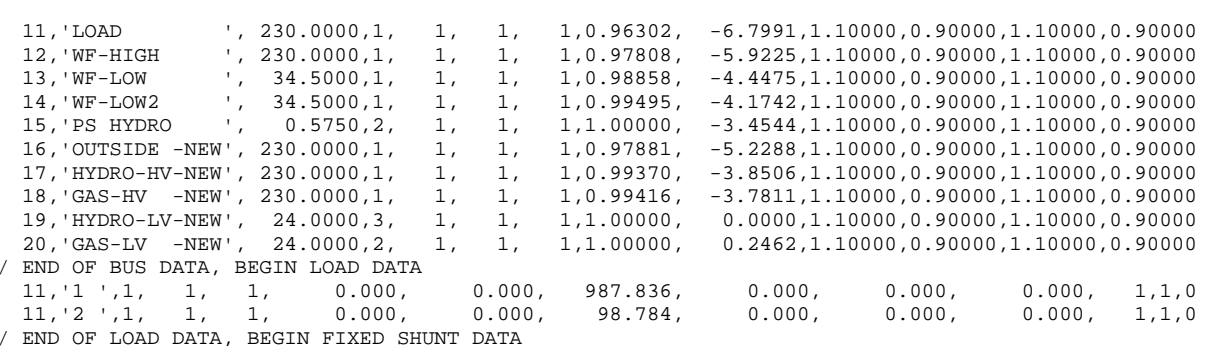

0 / END OF LOAD DATA, BEGIN FIXED SHUNT DATA

15, 1 25.000, 10.267, 15.000, -15.000, 1.00000,

$\begin{array}{llll}1,1.0000 & 19 \\ 11 & 1\end{array} \quad 239.003, \quad 23.691, \quad 125.000, \quad-125.000,1.00000$,

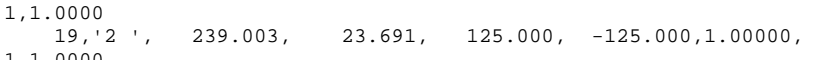

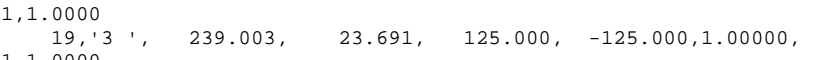

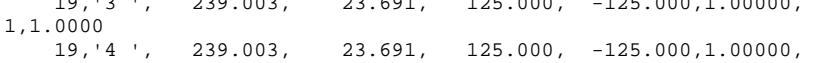

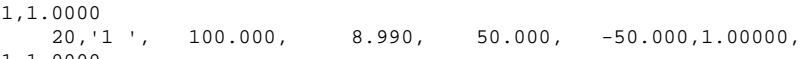

$0, \quad 28.900, \quad 0.00000 \mathrm{E}+0,2.00000 \mathrm{E}-1,0.00000 \mathrm{E}+0,0.00000 \mathrm{E}+0,1.00000,1, \quad 100.0, \quad 25.000, \quad 0.000$,

$0, \quad 294.000,0.00000 \mathrm{E}+0,8.00000 \mathrm{E}-1,0.00000 \mathrm{E}+0,0.00000 \mathrm{E}+0,1.00000,1, \quad 100.0, \quad 9999.000,-9999.000$,

$\odot ， 294.000,0.00000 \mathrm{E}+0,8.00000 \mathrm{E}-1,0.00000 \mathrm{E}+0,0.00000 \mathrm{E}+0,1.00000,1, \quad 100.0, \quad 9999.000, \quad-9999.000$,

$\odot, \quad 294.000,0.00000 \mathrm{E}+0,8.00000 \mathrm{E}-1,0.00000 \mathrm{E}+0,0.00000 \mathrm{E}+0,1.00000,1, \quad 100.0, \quad 9999.000, \quad-9999.000$,

$0, \quad 294.000,0.00000 \mathrm{E}+0,8.00000 \mathrm{E}-1,0.00000 \mathrm{E}+0,0.00000 \mathrm{E}+0,1.00000,1, \quad 100.0, \quad 9999.000,-9999.000$,

$\odot, \quad 200.000,0.00000 \mathrm{E}+0,2.00000 \mathrm{E}-1,0.00000 \mathrm{E}+0,0.00000 \mathrm{E}+0,1.00000,1, \quad 100.0, \quad 9999.000, \quad-9999.000$,

1, 1 / END OF GENERATOR DATA, BEGIN BRANCH DATA

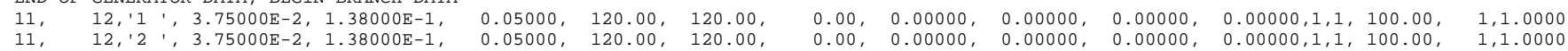

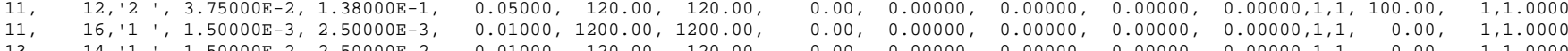

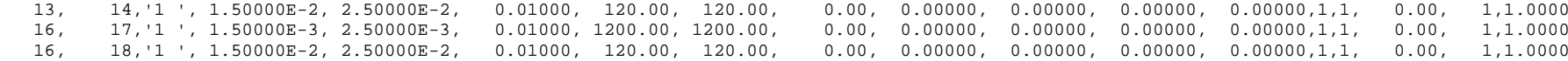

/ END OF BRANCH DATA, BEGIN TRANSFORMER DATA

$12, \quad 13, \quad 0,{ }^{2}, 1,1,1,1,0.00000 \mathrm{E}+0,0.00000 \mathrm{E}+0,2$,
$0.00000 \mathrm{E}+0,1.00000 \mathrm{E}-1,100.00$

$\begin{aligned} 0.00000 \mathrm{E}+0, & 1.00000 \mathrm{E}-1, \quad 100.00 \\ 1.00000, \quad 0.000, \quad 0.000, \quad 120.00, \quad 120.00, & 0.00,0,\end{aligned}$

$\begin{array}{lll}1.00000, & 0.000 & 0.0000\end{array}$

$\begin{array}{ccc}15, \quad 14, \quad 0,{ }^{\prime} 1{ }^{\prime}, 1,1,1,0.00000 \mathrm{E}+0,0.00000 \mathrm{E}+0,1, & \end{array}$

$1.00000, \quad 0.000, \quad 0.000, \quad 0.00, \quad 0.00, \quad 0.00,0$,

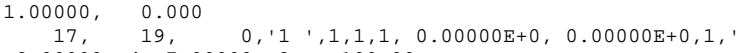

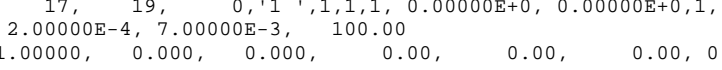

$\begin{array}{lll}1.00000, & 0.000, \\ 1.0000, & 0.000\end{array}$

$18, \quad 20, \quad 0,{ }^{\prime} 1,{ }^{2}, 1,1,1,0.00000 \mathrm{E}+0,0.00000 \mathrm{E}+0,1,{ }^{\prime}$
$2.00000 \mathrm{E}-3,7.00000 \mathrm{E}-2, \quad 100.00$

$1.00000, \quad 0.000, \quad 0.000, \quad 0.00, \quad 0.00, \quad 0.00,0$,

$\Theta /$ END' OF TRANSFORMER DATA, BEGIN AREA DATA

1, IND OF AREA DATA, BEGIN TWO-TERMINAL DC DATA
$0 / 1$ '

$\odot$ / END OF TWO-TERMINAL DC DATA, BEGIN VSC DC LINE DATA

/ END OF VSC DC LINE DATA, BEGIN IMPEDANCE CORRECTION DATA

0 / END OF MULTI-TERMINAL DC DATA, BEGIN MULTI-SECTION LINE DATA

$0,1.10000,0.90000,1.10000,0.90000,33,0,0.00000,0.00000,0.000$

', $1, \quad 1,1.0000, \quad 0,1.0000, \quad 0,1.0000, \quad 0,1.0000,{ }^{\prime}$

$0,1.10000,0.90000,1.10000,0.90000,33,0,0.00000,0.00000,0.000$

', $1, \quad 1,1.0000, \quad 0,1.0000, \quad 0,1.0000, \quad 0,1.0000,{ }^{\prime}$

$0,1.10000,0.90000,1.10000,0.90000,33,0,0.00000,0.00000,0.000$

', $1, \quad 1,1.0000, \quad 0,1.0000, \quad 0,1.0000, \quad 0,1.0000, '$

$0,1.10000,0.90000,1.10000,0.90000,33,0,0.00000,0.00000,0.000$ 
PSS $^{\circledR}$ E Load Flow Raw Data Files

0 / END OF MULTI-SECTION LINE DATA, BEGIN ZONE DATA

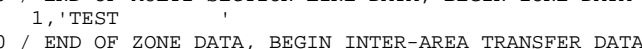

0 / END OF ZONE DATA, BEGIN INTER-AREA TRANSFER DATA
$0 /$ END OF INTER-AREA TRANSFER DATA, BEGIN OWNER DATA

1, 'TEST
0 / END OF OWNER DATA, BEGIN FACTS DEVICE DATA

1 END OF FACTS DEVICE DATA, BEGIN SWITCHED SHUNT DATA

$13,0,0,1,1.10000,0.90000, \quad 0,100.0$,
1

0 / END OF SWITCHED SHUNT DATA, BEGIN GNE DATA
0 , END OF GNE DATA, BEGIN INDUCTION MACHINE DATA

$0.00,1, \quad 1.00$

/ END OF INDUCTION MACHINE DATA 
This page intentionally left blank. 


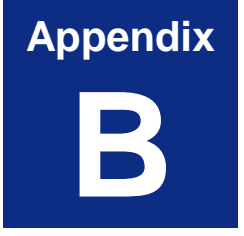

\section{PSS $^{\circledR}$ E Dynamic Data Documentation}




\section{B.1 Dynamic Data for the System with All Conventional Units}

1 PTI INTERACTIVE POWER SYSTEM SIMULATOR--PSS(R)E THU, DEC $27 \quad 2012$ 11:17 THREE MACHINES ISLAND SYSTEM

PLANT MODELS

REPORT FOR ALL MODELS AT ALL BUSES

BUS 15 [PS HYDRO

24.000] MODELS

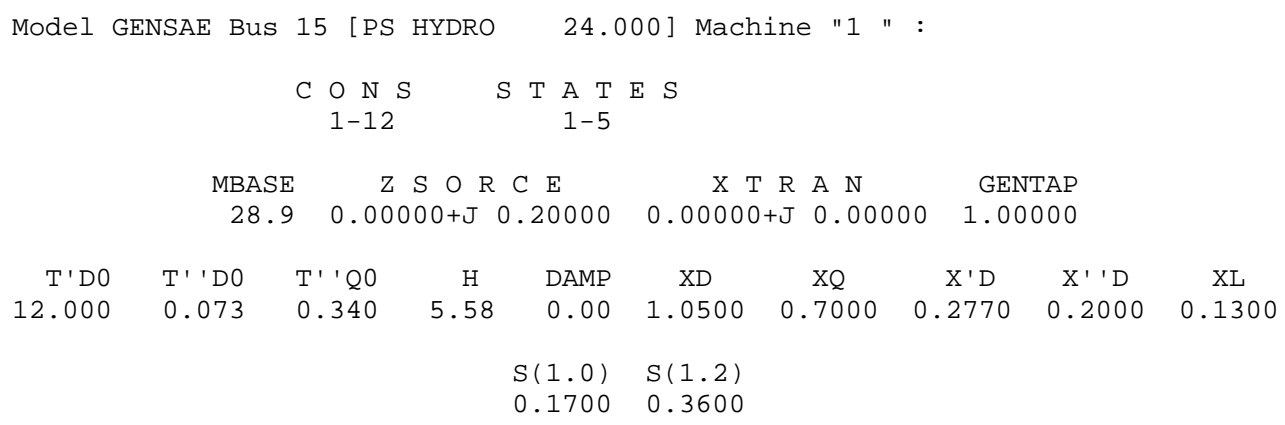

1 PTI INTERACTIVE POWER SYSTEM SIMULATOR--PSS(R)E THU, DEC $27 \quad 2012$ 11:17 THREE MACHINES ISLAND SYSTEM

PLANT MODELS

REPORT FOR ALL MODELS AT ALL BUSES

BUS 19 [HYDRO-LV-NEW24.000] MODELS

Model GENSAE Bus 19 [HYDRO-LV-NEW24.000] Machine "1 " :

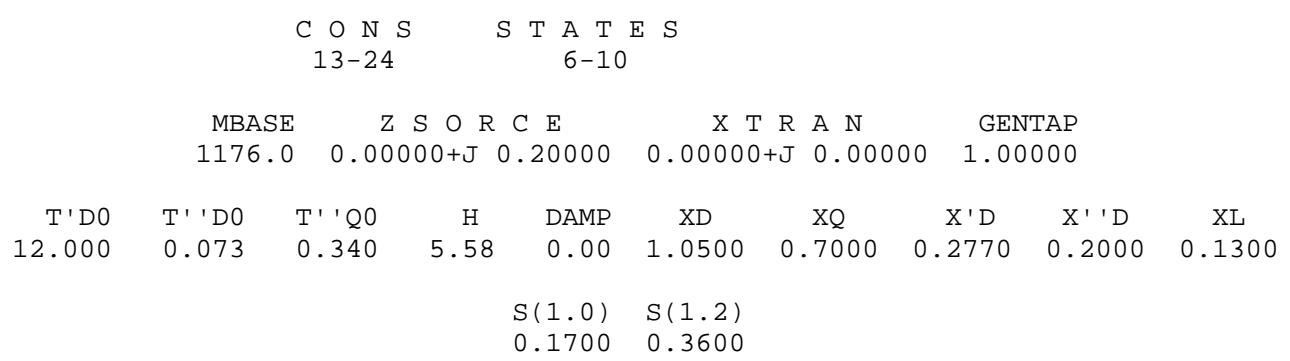


Model IEEEX1 Bus 19 [HYDRO-LV-NEW24.000] Machine "1 " :

C $0 \mathrm{NSS}$
$55-70$

$\begin{array}{ccccccccccc}\text { TR } & \text { KA } & \text { TA } & \text { TB } & \text { TC } & \text { VRMAX } & \text { VRMIN } & \text { KE } & \text { TE } & \text { KF } & \text { TF1 } \\ 0.05 \odot & 50.0 \odot & \odot .06 \odot & 1.00 & 1.500 & 1.000 & -0.4 \odot & 0.206 & 1.630 & 0.020 & 1.200\end{array}$

SWITCH E1 S(E1) E2 S(E2) KE VAR

$\begin{array}{llllll}0.0 & 2.5000 & 0.0200 & 3.6000 & 0.0400 & 0.0000\end{array}$

Model HYGOV Bus 19 [HYDRO-LV-NEW24.000] Machine "1 " :

$$
\begin{array}{ccc}
\text { C } 0 \text { NS S T A T E S } & \text { VA R S } \\
83-94 & 31-34 & 5-6
\end{array}
$$

R-PERM R-TEMP TR TF TG VELM GMAX GMIN TW AT DTURB QNL

$\begin{array}{llllllllllll}0.040 & 0.310 & 6.88 & 0.050 & 0.500 & 0.050 & 1.00 & 0.00 & 1.72 & 1.48 & 0.30 & 0.100\end{array}$

1 PTI INTERACTIVE POWER SYSTEM SIMULATOR--PSS(R)E

THU, DEC $272012 \quad 11: 17$

THREE MACHINES ISLAND SYSTEM

PLANT MODELS

REPORT FOR ALL MODELS AT ALL BUSES BUS 20 [GAS-LV -NEW24.000] MODELS

Model GENROU Bus 20 [GAS-LV -NEW24.000] Machine "1 " :

$$
\underset{25-38}{\text { C ONS S T A T E S }}
$$

MBASE Z S R C E X T R A N GENTAP

$200.0 \quad 0.00000+\mathrm{J} \quad 0.20000 \quad 0.00000+\mathrm{J} \quad 0.0000001 .00000$

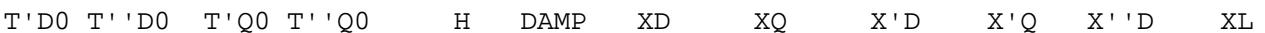

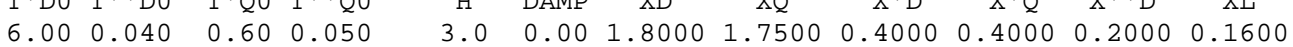

$S(1.0) \quad S(1.2)$

$\odot .1500 \quad 0.3000$ 


\section{B.2 Dynamic Data for the PSH Turbine}

1 PTI INTERACTIVE POWER SYSTEM SIMULATOR--PSS(R)E THU, JAN 10 2013 11:31 THREE MACHINES ISLAND SYSTEM

PLANT MODELS

REPORT FOR ALL MODELS AT ALL BUSES

BUS 19 [HYDRO-LV-NEW24.000] MODELS

Model PSHGEN Bus 19 [HYDRO-LV-NEW24.000] Machine "1 " :

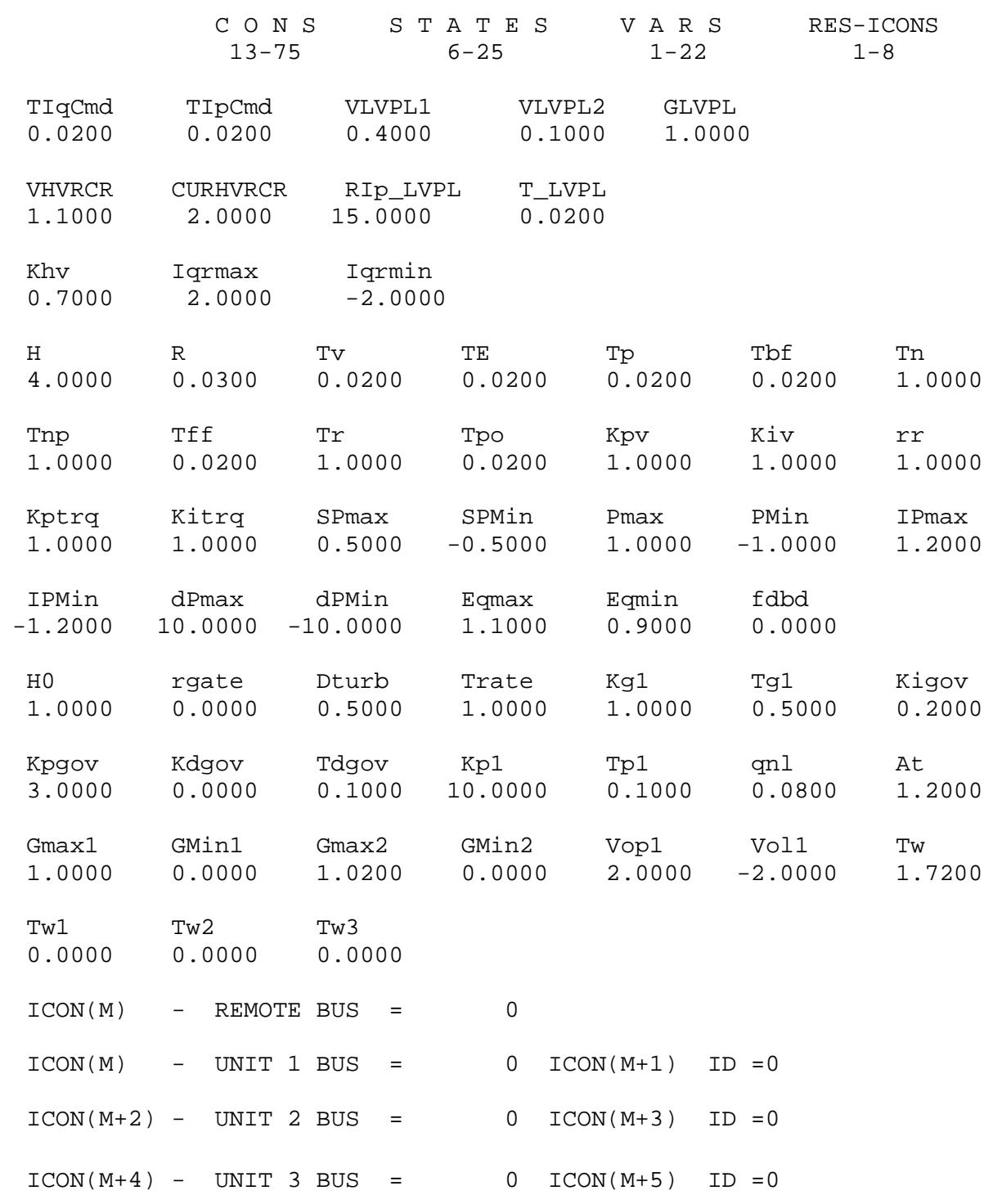


Table B.2.1 Parameters of the Rotor Speed Optimizer Read by the PSHGEN Model

\begin{tabular}{|c|c|c|c|c|c|c|c|}
\hline & \multicolumn{6}{|c|}{ Power (pu) } \\
\hline & & 0.80 & 0.84 & 0.88 & 0.92 & 0.96 & 1.00 \\
\hline \multirow{6}{*}{ 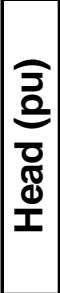 } & 0.80 & -0.05 & 0.00 & 0.05 & 0.10 & 0.15 & 0.20 \\
\hline & 0.84 & -0.06 & -0.01 & 0.04 & 0.09 & 0.14 & 0.19 \\
\hline & 0.88 & -0.07 & -0.02 & 0.03 & 0.08 & 0.13 & 0.18 \\
\hline & 0.92 & -0.08 & -0.03 & 0.02 & 0.07 & 0.12 & 0.17 \\
\hline & 0.96 & -0.09 & -0.04 & 0.01 & 0.06 & 0.11 & 0.16 \\
\hline & 1.00 & -0.10 & -0.05 & 0.00 & 0.05 & 0.10 & 0.15 \\
\hline
\end{tabular}

Table B.2.2 Parameters of the Gate Position Optimizer Read by the PSHGEN Model

\begin{tabular}{|c|c|c|c|c|c|c|c|}
\hline & \multicolumn{6}{|c|}{ Power } \\
\hline & & 0.80 & 0.84 & 0.88 & 0.92 & 0.96 & 1.00 \\
\hline \multirow{6}{*}{$\begin{array}{l}\text { 어 } \\
\text { İ } \\
\text { I }\end{array}$} & 0.80 & 0.80 & 0.84 & 0.88 & 0.92 & 0.96 & 1.00 \\
\hline & 0.84 & 0.76 & 0.80 & 0.84 & 0.88 & 0.92 & 0.96 \\
\hline & 0.88 & 0.72 & 0.76 & 0.80 & 0.84 & 0.88 & 0.92 \\
\hline & 0.92 & 0.68 & 0.72 & 0.76 & 0.80 & 0.84 & 0.88 \\
\hline & 0.96 & 0.64 & 0.68 & 0.72 & 0.76 & 0.80 & 0.84 \\
\hline & 1.00 & 0.60 & 0.64 & 0.68 & 0.72 & 0.76 & 0.80 \\
\hline
\end{tabular}




\section{B.3 Dynamic Data for four PSH Turbines Sharing the Same Penstock}

1 PTI INTERACTIVE POWER SYSTEM SIMULATOR--PSS(R)E FRI， JAN 11 2013 10:57 THREE MACHINES ISLAND SYSTEM

PLANT MODELS

REPORT FOR ALL MODELS AT ALL BUSES

BUS 15 [PS HYDRO

$\odot .5750]$ MODELS

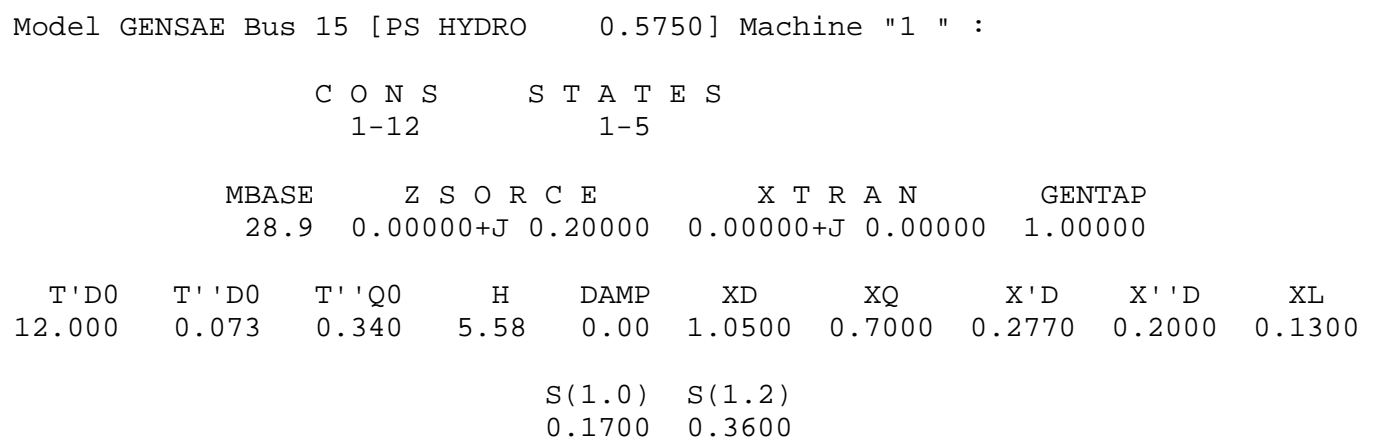

1 PTI INTERACTIVE POWER SYSTEM SIMULATOR--PSS(R)E FRI， JAN 11 2013 10:57 THREE MACHINES ISLAND SYSTEM

PLANT MODELS

REPORT FOR ALL MODELS AT ALL BUSES BUS 19 [HYDRO-LV-NEW24.000] MODELS

Model PSHGEN Bus 19 [HYDRO-LV-NEW24.000] Machine "1 " :

$\begin{array}{cccc}\text { C O N S } & \text { S T A T E S } & \text { V A R S } & \text { RES-ICONS } \\ 13-87 & 6-25 & 1-26 & 1-10\end{array}$

TIqCmd TIpCmd VLVPL1 VLVPL2 GLVPL

$\begin{array}{lllll}0.0200 & 0.0200 & 0.4000 & 0.1000 & 1.0000\end{array}$ 


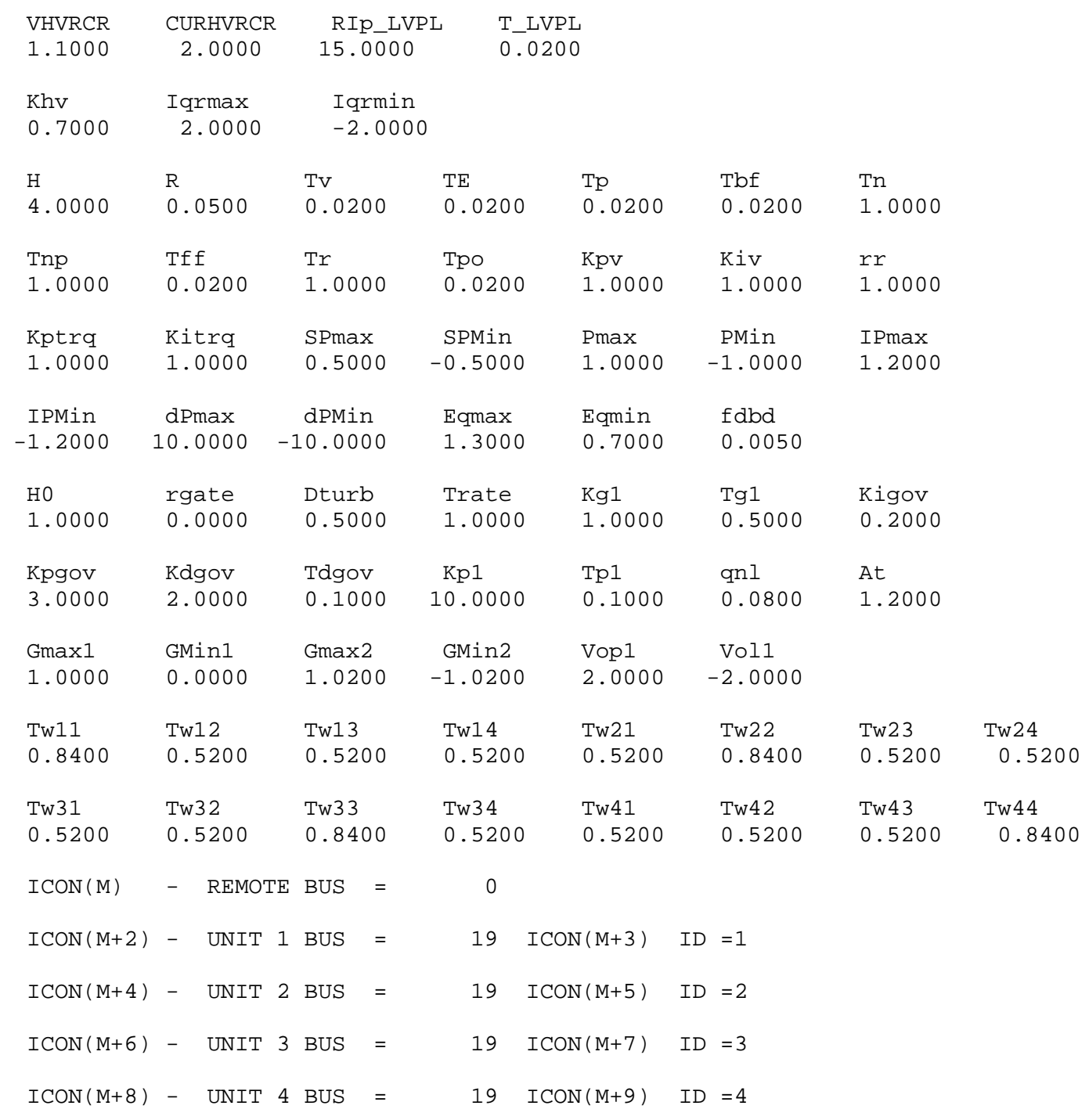

Model PSHGEN Bus 19 [HYDRO-LV-NEW24.000] Machine "2 " :

$$
\begin{array}{cccc}
\text { C O N S } & \text { S T A T E S } & \text { V A R S } & \text { RES-ICONS } \\
102-176 & 32-51 & 27-52 & 11-20
\end{array}
$$

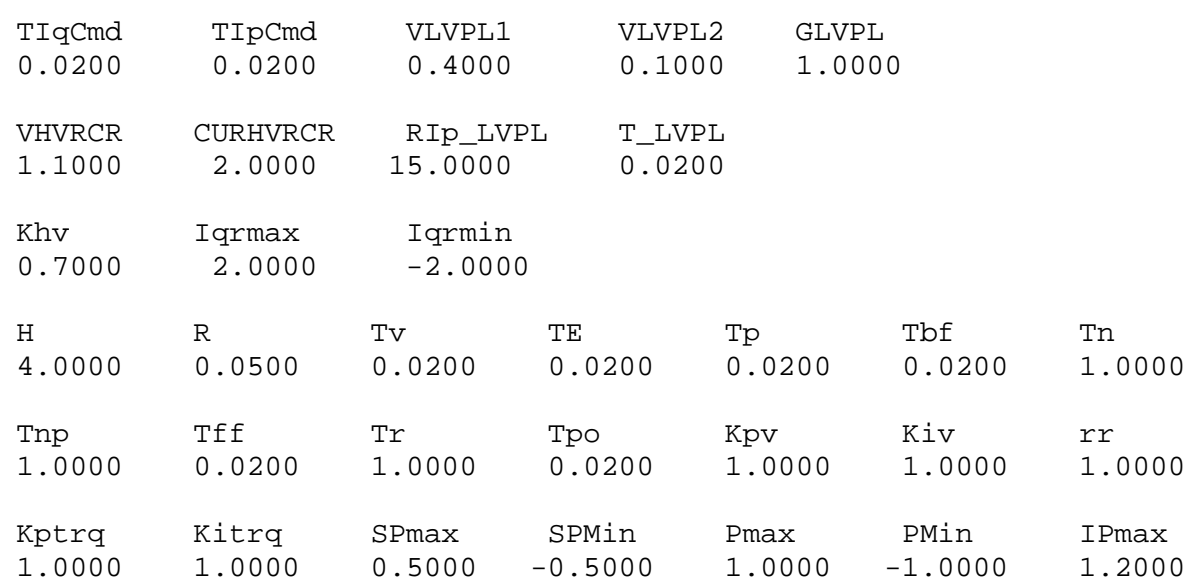




\begin{tabular}{|c|c|c|c|c|c|c|c|c|c|}
\hline $\begin{array}{l}\text { IPMin } \\
-1.200 \odot\end{array}$ & $\begin{array}{c}\text { dPmax } \\
10.0 \odot \odot \odot\end{array}$ & $\begin{array}{r}\text { dPMir } \\
-10.006\end{array}$ & & $\begin{array}{l}\text { Eqmax } \\
1.3006\end{array}$ & $\begin{array}{l}\text { Eqmin } \\
\odot .70 \odot \odot\end{array}$ & & $\begin{array}{l}\text { fdbd } \\
\odot . \odot \odot 5 \odot\end{array}$ & & \\
\hline $\begin{array}{l}\mathrm{H} \odot \\
1.000 \odot\end{array}$ & $\begin{array}{l}\text { rgate } \\
\odot .0 \odot \odot \odot\end{array}$ & $\begin{array}{l}\text { Dturk } \\
0.500\end{array}$ & & $\begin{array}{l}\text { Trate } \\
1.0006\end{array}$ & $\begin{array}{l}\mathrm{Kg} 1 \\
1.000 \odot\end{array}$ & & $\begin{array}{l}\operatorname{Tg} 1 \\
\odot .5 \odot \odot \odot\end{array}$ & $\begin{array}{l}\text { Kigov } \\
\odot .20 \odot \odot\end{array}$ & \\
\hline $\begin{array}{l}\text { Kpgov } \\
3.000 \odot\end{array}$ & $\begin{array}{l}\text { Kdgov } \\
2.0000\end{array}$ & $\begin{array}{l}\text { Tdgou } \\
0.100\end{array}$ & & $\begin{array}{c}\text { Kp1 } \\
10.0006\end{array}$ & $\begin{array}{l}\text { Tp1 } \\
0.1000\end{array}$ & & $\begin{array}{l}\text { qnl } \\
\odot . \odot 80 \odot\end{array}$ & $\begin{array}{l}\text { At } \\
1.2000\end{array}$ & \\
\hline $\begin{array}{l}\text { Gmax1 } \\
1.00 \odot \odot\end{array}$ & $\begin{array}{l}\text { GMin1 } \\
\odot .0 \odot \odot \odot\end{array}$ & $\begin{array}{l}\text { Gmax } \\
1.026\end{array}$ & & $\begin{array}{c}\text { GMin2 } \\
-1.0206\end{array}$ & $\begin{array}{l}\text { Vop1 } \\
2.00 \odot \odot\end{array}$ & & $\begin{array}{l}\text { Vol1 } \\
-2.00 \odot \odot\end{array}$ & & \\
\hline $\begin{array}{l}\text { Tw11 } \\
0.8400\end{array}$ & $\begin{array}{l}\text { Tw12 } \\
\odot .5200\end{array}$ & $\begin{array}{l}\text { Tw13 } \\
0.526\end{array}$ & & $\begin{array}{l}\text { Tw14 } \\
0.5206\end{array}$ & $\begin{array}{l}\text { Tw21 } \\
0.5200\end{array}$ & & $\begin{array}{l}\text { Tw22 } \\
\odot .840 \odot\end{array}$ & $\begin{array}{l}\text { Tw23 } \\
\odot .520 \odot\end{array}$ & $\begin{array}{l}\text { Tw24 } \\
0.5200\end{array}$ \\
\hline $\begin{array}{l}\text { Tw31 } \\
0.5200\end{array}$ & $\begin{array}{l}\text { Tw32 } \\
\odot .5200\end{array}$ & $\begin{array}{l}\text { Tw33 } \\
0.846\end{array}$ & & $\begin{array}{l}\text { TW34 } \\
0.5206\end{array}$ & $\begin{array}{l}\text { Tw41 } \\
0.5200\end{array}$ & & $\begin{array}{l}\text { Tw42 } \\
0.5200\end{array}$ & $\begin{array}{l}\text { Tw43 } \\
0.5200\end{array}$ & $\begin{array}{l}\text { Tw44 } \\
0.8400\end{array}$ \\
\hline $\operatorname{ICON}(M)$ & REMOTE & E BUS & $=$ & $\odot$ & & & & & \\
\hline $\operatorname{ICON}(M+2)$ & - UNIT & 1 BUS & $=$ & 19 & $\operatorname{ICON}(M+3)$ & ID & $=1$ & & \\
\hline $\operatorname{ICON}(M+4)$ & - UNIT & 2 BUS & $=$ & 19 & $\operatorname{ICON}(M+5)$ & ID & $=2$ & & \\
\hline $\operatorname{ICON}(M+6)$ & - UNIT & 3 BUS & $=$ & 19 & $\operatorname{ICON}(M+7)$ & ID & $=3$ & & \\
\hline $\operatorname{ICON}(M+8)$ & UNIT & 4 BUS & $=$ & 19 & $\operatorname{ICON}(M+9)$ & ID & $=4$ & & \\
\hline
\end{tabular}

Model PSHGEN Bus 19 [HYDRO-LV-NEW24.000] Machine "3 " :

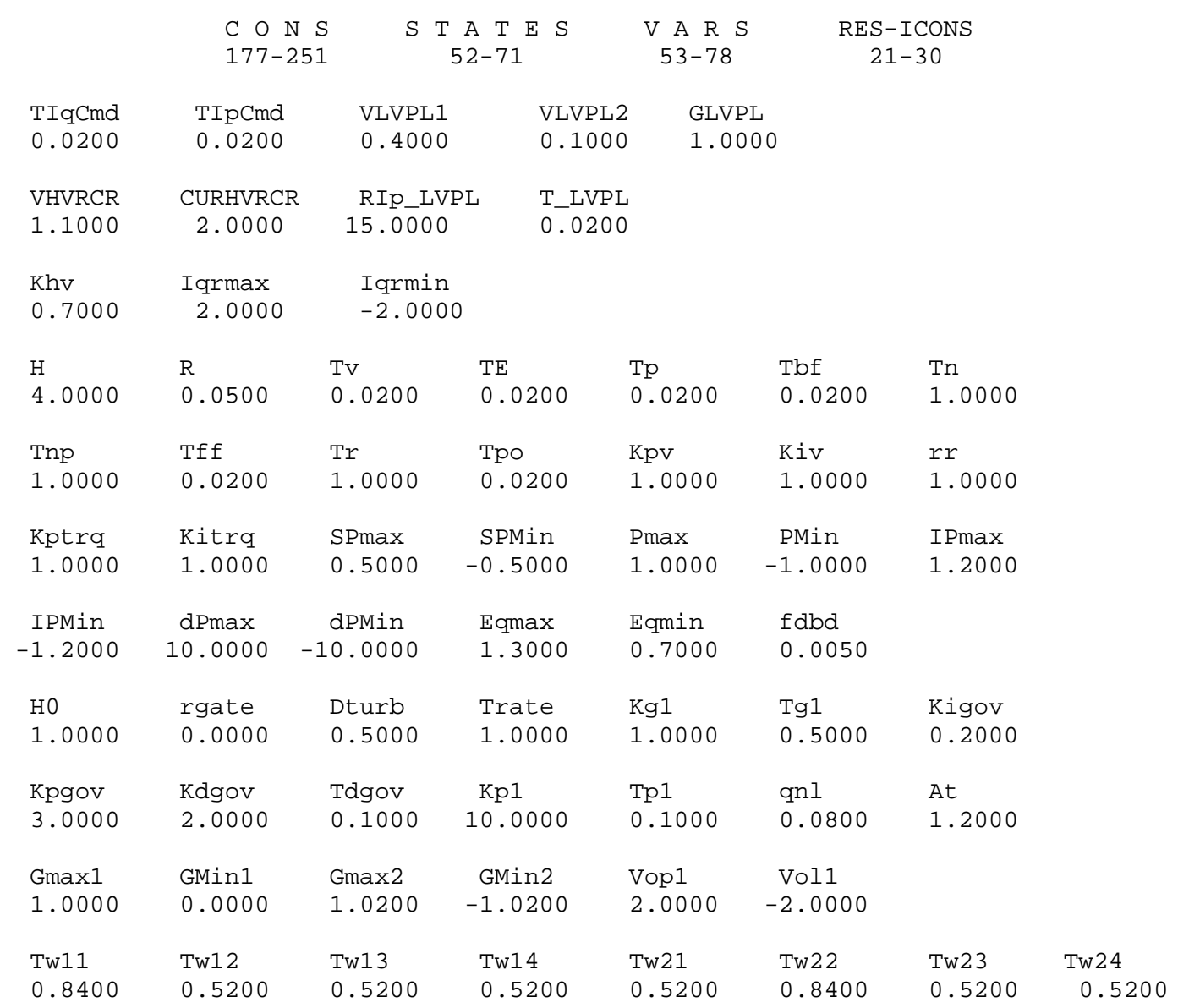




\begin{tabular}{|c|c|c|c|c|c|c|c|c|c|}
\hline $\begin{array}{l}\text { Tw31 } \\
\odot .5200\end{array}$ & $\begin{array}{l}\text { Tw32 } \\
\odot .5200\end{array}$ & $\begin{array}{l}\text { TW33 } \\
\odot .84\end{array}$ & & $\begin{array}{l}\text { Tw34 } \\
0.5200\end{array}$ & $\begin{array}{l}\text { Tw41 } \\
\odot .5200\end{array}$ & & $\begin{array}{l}\text { Tw42 } \\
\odot .5200\end{array}$ & $\begin{array}{l}\text { Tw43 } \\
0.5200\end{array}$ & $\begin{array}{l}\text { Tw44 } \\
0.8400\end{array}$ \\
\hline $\operatorname{ICON}(M)$ & REMOTE & $E$ BUS & $=$ & $\odot$ & & & & & \\
\hline $\operatorname{ICON}(M+2)$ & UNIT 1 & 1 BUS & $=$ & 19 & $\operatorname{ICON}(M+3)$ & ID & $=1$ & & \\
\hline $\operatorname{ICON}(M+4)$ & UNIT 2 & 2 BUS & $=$ & 19 & $\operatorname{ICON}(M+5)$ & ID & $=2$ & & \\
\hline $\operatorname{ICON}(M+6)$ & UNIT 3 & 3 BUS & $=$ & 19 & $\operatorname{ICON}(M+7)$ & ID & $=3$ & & \\
\hline $\operatorname{ICON}(M+8)$ & UNIT 4 & 4 BUS & $=$ & 19 & $\operatorname{ICON}(M+9)$ & ID & $=4$ & & \\
\hline
\end{tabular}

Model PSHGEN Bus 19 [HYDRO-LV-NEW24.000] Machine "4 " :

$\begin{array}{cccc}\text { C O N S } & \text { S T A T E S } & \text { V A R S } & \text { RES-ICONS } \\ 252-326 & 72-91 & 79-104 & 31-40\end{array}$

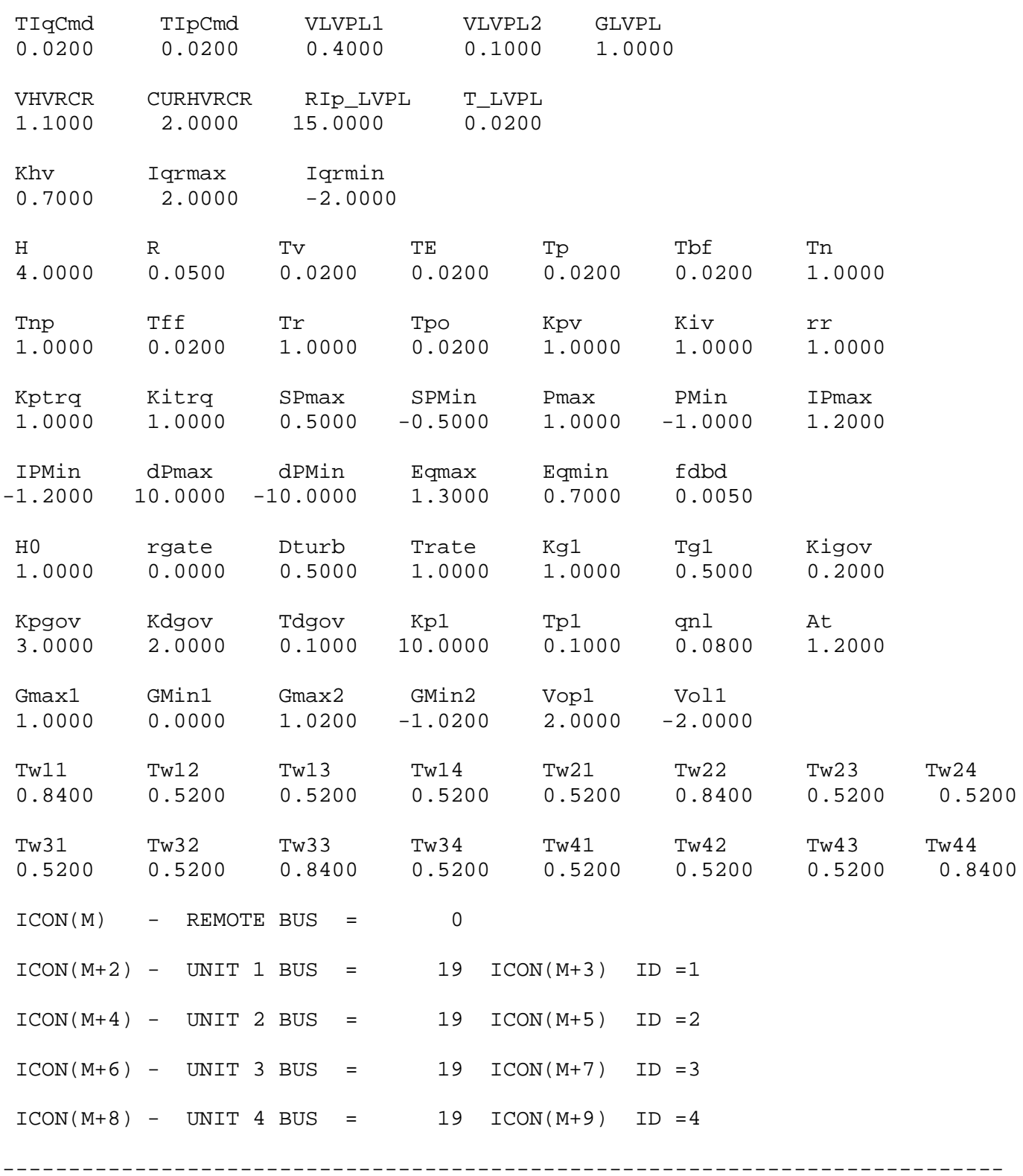




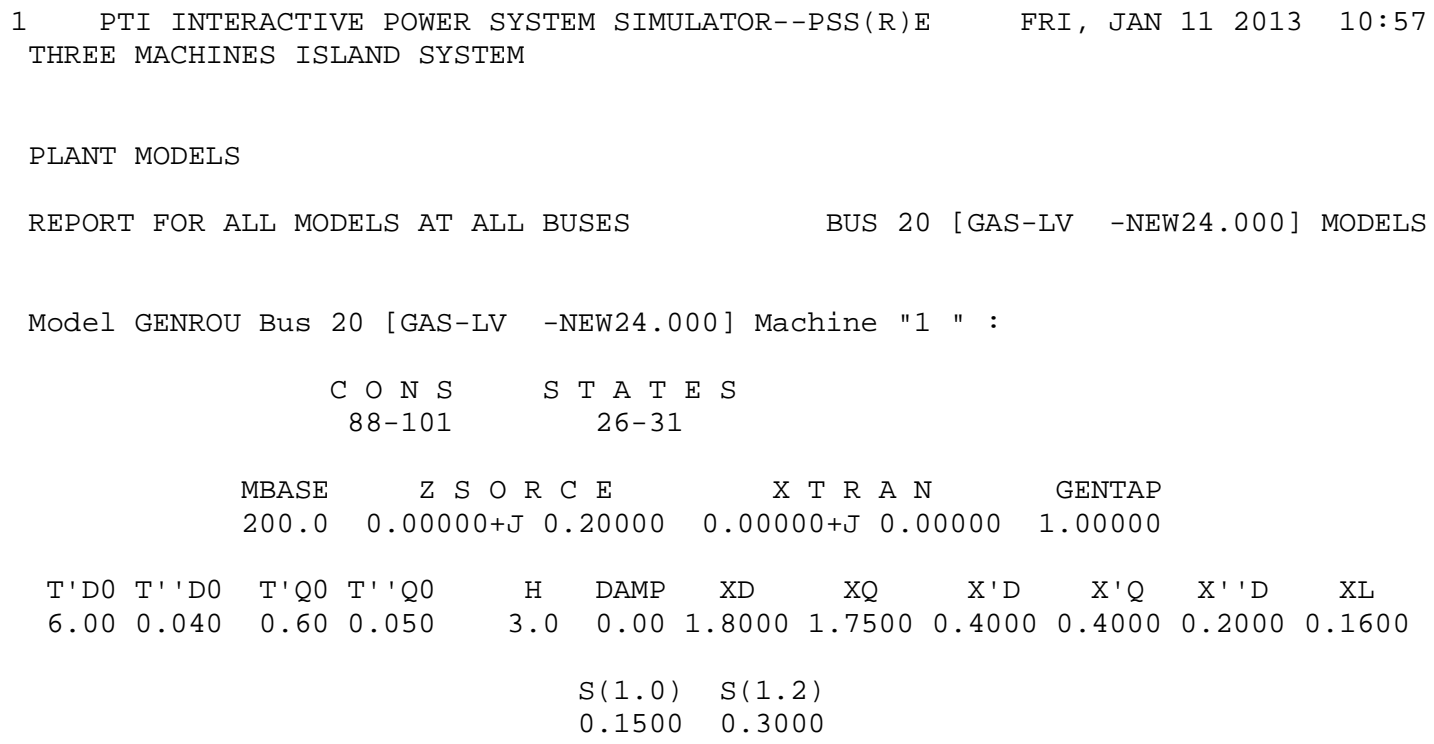




\section{B.4 Dynamic Data for the System with the PSH Pump}

1 PTI INTERACTIVE POWER SYSTEM SIMULATOR--PSS(R)E FRI， JAN 112013 8:39 THREE MACHINES ISLAND SYSTEM

PLANT MODELS

REPORT FOR ALL MODELS AT ALL BUSES BUS 15 [PS HYDRO 0.5750 ] MODELS

Model GENSAE Bus 15 [PS HYDRO 0.5750 ] Machine "1 " :

$$
\begin{array}{lrl}
C \underset{1-12}{0} \mathrm{NS} & \mathrm{S} \text { A T E S } \\
1-5 &
\end{array}
$$

MBASE Z S O R C E X T R A N GENTAP

\begin{tabular}{|c|c|c|c|c|c|c|c|c|c|}
\hline T'DO & $T^{\prime}$ 'DO & $T^{\prime}{ }^{\prime} Q \odot$ & $\mathrm{H}$ & DAMP & $X D$ & XQ & X'D & X' 'D & $X \mathrm{~L}$ \\
\hline 12.000 & $\odot .073$ & 0.340 & 5.58 & 0.00 & 1.0500 & 0.7000 & 0.2770 & 0.2000 & 0.1300 \\
\hline & & & & $\begin{array}{l}(1.0) \\
.1700\end{array}$ & $\begin{array}{l}S(1.2) \\
\Theta .3600\end{array}$ & & & & \\
\hline
\end{tabular}

$28.90 .00000+\mathrm{J} \quad 0.20000 \quad 0.00000+\mathrm{J} \quad 0.000001 .00000$

\begin{tabular}{|c|c|c|c|c|c|c|c|c|c|c|}
\hline \multirow{3}{*}{$\begin{array}{c}\text { TR } \\
\odot .050\end{array}$} & \multicolumn{3}{|c|}{$\begin{array}{r}C 0 \mathrm{~N} \mathrm{~S} \\
87-102\end{array}$} & \multicolumn{2}{|c|}{$\begin{array}{c}S T A \\
31-35\end{array}$} & \multicolumn{2}{|l|}{$\begin{array}{r}V A R \\
24\end{array}$} & \multirow[b]{2}{*}{ TE } & \multirow[b]{2}{*}{$\mathrm{KF}$} & \multirow{3}{*}{$\begin{array}{r}\text { TF1 } \\
1.206\end{array}$} \\
\hline & KA & TA & TB & TC & VRMAX & VRMIN & KE & & & \\
\hline & $50.0 \odot$ & $\odot .060$ & 1.00 & 1.500 & 1.000 & $-0.4 \odot$ & 0.206 & 1.630 & $\odot .020$ & \\
\hline & $\begin{array}{r}\text { SWITCH } \\
0.0\end{array}$ & & $\begin{array}{c}E 1 \\
2.5000\end{array}$ & $\begin{array}{r}S(E 1) \\
0.0200\end{array}$ & $\begin{array}{c}E 2 \\
3.6000\end{array}$ & $\begin{array}{r}S(E 2) \\
0.0400\end{array}$ & & $\begin{array}{l}\text { KE VAR } \\
\odot .0 \odot \odot \odot\end{array}$ & & \\
\hline
\end{tabular}

Model IEEEX1 Bus 15 [PS HYDRO 0.5750 ] Machine "1 " :

\begin{tabular}{|c|c|c|c|c|c|c|c|c|c|c|}
\hline & & $\begin{array}{l}\text { C } 0 \\
103\end{array}$ & $\begin{array}{l}\text { N S } \\
-114\end{array}$ & $\mathrm{ST}$ & $\begin{array}{c}T E S \\
-39\end{array}$ & & 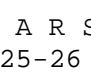 & & & \\
\hline R-PERM & R-TEMP & TR & $\begin{array}{c}\text { TF } \\
0.958\end{array}$ & TG & VELM & GMAX & GMIN & TW & AT DTURB & QNL \\
\hline
\end{tabular}

Model HYGOV Bus 15 [PS HYDRO 0.5750 ] Machine "1 " :

1 PTI INTERACTIVE POWER SYSTEM SIMULATOR--PSS(R)E THREE MACHINES ISLAND SYSTEM

FRI， JAN $112013 \quad 8: 39$

PLANT MODELS

REPORT FOR ALL MODELS AT ALL BUSES BUS 19 [HYDRO-LV-NEW24.000] MODELS

Model PSHPMP Bus 19 [HYDRO-LV-NEW24.000] Machine "1 " :
C $0 \mathrm{~N} \mathrm{~S}$
S T A T E S
V A R S
1-22
RES-ICONS
$13-72$
6-24
1-8

$\begin{array}{ccccl}\text { TIqCmd } & \text { TIpCmd } & \text { VLVPL1 } & \text { VLVPL2 } & \text { GLVPL } \\ 0.0200 & 0.0200 & 0.4000 & 0.1000 & 1.0000 \\ & & & & \\ \text { VHVRCR } & \text { CURHVRCR } & \text { RIp_LVPL } & \text { T_LLPL } & \\ 1.1000 & 2.0000 & 15.0000 & 0.0200 & \end{array}$

Khv Iqrmax Iqrmin 


\begin{tabular}{|c|c|c|c|c|c|c|c|c|}
\hline$\odot .7000$ & $2.000 \odot$ & \multicolumn{3}{|c|}{-2.0000} & & & & \\
\hline $\mathrm{H}$ & $\mathrm{R}$ & \multicolumn{2}{|l|}{ TV } & TE & $\mathrm{Tp}$ & Tbf & Tn & \\
\hline $4.0 \odot \odot \odot$ & $\odot . \odot \odot \odot \odot$ & \multicolumn{2}{|c|}{0.0200} & $\odot .020 \odot$ & $\odot .0200$ & $\odot .0200$ & $1.000 \odot$ & \\
\hline Tnp & \multirow{2}{*}{$\begin{array}{l}\text { Tff } \\
\odot . \odot 2 \odot \odot\end{array}$} & \multirow{2}{*}{\multicolumn{2}{|c|}{$\begin{array}{l}\operatorname{Tr} \\
0.5000\end{array}$}} & \multirow{2}{*}{$\begin{array}{l}\text { Tpo } \\
\odot .0200\end{array}$} & $\mathrm{Kpv}$ & Kiv & \multicolumn{2}{|l|}{$r r$} \\
\hline $1.000 \odot$ & & & & & 1.0000 & 1.0000 & 0.2500 & \\
\hline Kp2 & Ki2 & \multicolumn{2}{|c|}{ Kpsp } & & SPmax & SPMin & Pmax & \multirow{2}{*}{$\begin{array}{l}\text { PMin } \\
-1.0000\end{array}$} \\
\hline 1.0000 & 1.0000 & \multicolumn{2}{|c|}{5.0000} & 5.0000 & 0.5000 & -0.5000 & $\odot .00 \odot \odot$ & \\
\hline IPmax & \multirow{2}{*}{$\begin{array}{l}\text { IPMin } \\
-1.2000\end{array}$} & \multicolumn{2}{|c|}{ dPmax } & dPMin & Eqmax & Eqmin & fdbd & \\
\hline 1.2000 & & 10.000 & & -10.0000 & 1.3000 & 0.7000 & 0.0050 & \\
\hline $\mathrm{HO}$ & \multirow{2}{*}{$\begin{array}{l}\text { Dturb } \\
\odot .50 \odot \odot\end{array}$} & \multicolumn{2}{|c|}{ Trate } & \multirow{2}{*}{$\begin{array}{l}\mathrm{Kg} 1 \\
1.000 \odot\end{array}$} & Tg1 & Kp1 & Tp1 & qnl \\
\hline 1.0000 & & 1.000 & & & 0.5000 & 10.0000 & 0.1000 & -0.0800 \\
\hline Gmax1 & \multirow{2}{*}{$\begin{array}{l}\text { GMin1 } \\
\odot . \odot \odot \odot \odot\end{array}$} & \multirow{2}{*}{\multicolumn{2}{|c|}{$\begin{array}{l}\text { Vop1 } \\
2.00 \odot \odot\end{array}$}} & \multirow{2}{*}{$\begin{array}{l}\text { Vol1 } \\
-2.0 \odot \odot \odot\end{array}$} & $\mathrm{A} \Theta$ & BO & CO & \\
\hline $1 . \odot \odot \odot \odot$ & & & & & 1.1740 & -0.0666 & -0.3540 & \\
\hline Tw & \multirow{2}{*}{$\begin{array}{l}\text { TW1 } \\
\odot .0 \odot \odot \odot\end{array}$} & \multirow{2}{*}{\multicolumn{2}{|c|}{$\begin{array}{l}\text { Tw2 } \\
\odot .0000\end{array}$}} & \multirow{2}{*}{$\begin{array}{l}\text { TW3 } \\
\odot .0000\end{array}$} & & & & \\
\hline-1.1700 & & & & & & & & \\
\hline $\operatorname{ICON}(M)$ & - REMOTE & E BUS & $=$ & 12 & & & & \\
\hline $\operatorname{ICON}(M+2)$ & ) - UNIT = & 1 BUS & $=$ & $\odot$ & $\operatorname{ICON}(M+3)$ & ID $=\odot$ & & \\
\hline $\operatorname{ICON}(M+4)$ & - UNIT & 2 BUS & $=$ & $\odot$ & $\operatorname{ICON}(M+5)$ & ID $=\odot$ & & \\
\hline $\operatorname{ICON}(M+6)$ & - UNIT & 3 BUS & $=$ & 0 & $\operatorname{ICON}(M+7)$ & ID $=0$ & & \\
\hline
\end{tabular}

1 PTI INTERACTIVE POWER SYSTEM SIMULATOR--PSS(R)E THREE MACHINES ISLAND SYSTEM

FRI， JAN $112013 \quad 8: 39$

PLANT MODELS

REPORT FOR ALL MODELS AT ALL BUSES BUS 20 [GAS-LV -NEW24.000] MODELS

Model GENROU Bus 20 [GAS-LV -NEW24.000] Machine "1 " :

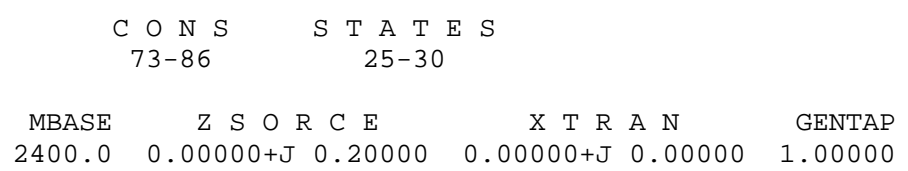

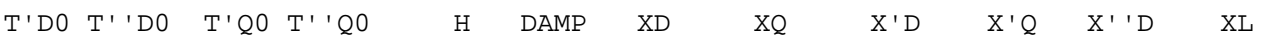

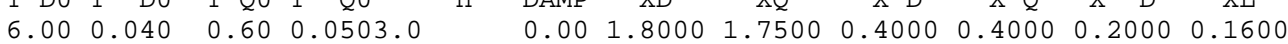

$S(1.0) \quad S(1.2)$

$0.1500 \quad 0.3000$ 


\section{B.5 Dynamic Data for the System with the Ternary Turbine}

1 PTI INTERACTIVE POWER SYSTEM SIMULATOR--PSS(R)E

THREE MACHINES ISLAND SYSTEM

PLANT MODELS

REPORT FOR ALL MODELS AT ALL BUSES

BUS 19 [HYDRO-LV-NEW24.000] MODELS

Model GENSAE Bus 19 [HYDRO-LV-NEW24.000] Machine "1 " :

$$
\begin{aligned}
& \text { C } 0 \text { N S S T A T E S } \\
& \text { 13-24 6-10 } \\
& \text { MBASE Z S O R C E X T R A N GENTAP } \\
& \text { 1176.๑ } \quad 0.00000+\mathrm{J} \quad 0.20000 \quad 0.00000+\mathrm{J} \quad 0.00000 \quad 1.00000 \\
& \begin{array}{llllllllll}
\text { T'DO } & T^{\prime} ' D \odot & T^{\prime} ' Q \odot & H & \text { DAMP } & X D & X Q & X^{\prime} D & X^{\prime} ' D & X L
\end{array} \\
& \begin{array}{llllllllll}
12.000 & 0.073 & 0.340 & 5.58 & 0.00 & 1.0500 & 0.7000 & 0.2770 & 0.200 \odot & 0.1300
\end{array} \\
& S(1.0) \quad S(1.2) \\
& \odot .1700 \quad 0.3600
\end{aligned}
$$

\begin{tabular}{|c|c|c|c|c|c|c|c|c|c|c|}
\hline \multirow[b]{2}{*}{$\begin{array}{c}\text { TR } \\
\odot .050\end{array}$} & \multicolumn{3}{|c|}{$\begin{array}{c}C 0 N S \\
55-70\end{array}$} & \multicolumn{2}{|c|}{$\begin{array}{c}\mathrm{S} T \underset{22-26}{A} \mathrm{~T} E \mathrm{~S} \\
22-2\end{array}$} & \multicolumn{2}{|l|}{$\begin{array}{rl}V A & R \\
& 2\end{array}$} & \multirow[b]{2}{*}{ TE } & \multirow[b]{2}{*}{$\begin{array}{cc} & \mathrm{KF} \\
\Theta & \odot 20\end{array}$} & \multirow[b]{2}{*}{$\begin{array}{r}\text { TF1 } \\
1.200\end{array}$} \\
\hline & $\begin{array}{c}\text { KA } \\
5 \odot, 0 \odot\end{array}$ & $\begin{array}{ll} & \text { TA } \\
\odot . & 06 \odot\end{array}$ & TB & $\begin{array}{l}\text { TC } \\
5 \odot \odot\end{array}$ & VRMAX & VRMIN & KE & & & \\
\hline & $\begin{array}{r}\text { SWITCH } \\
0.0\end{array}$ & & $\begin{array}{l}E 1 \\
5000\end{array}$ & $\begin{array}{r}S(E 1) \\
\odot .0200\end{array}$ & $\begin{array}{c}E 2 \\
3.6000\end{array}$ & $\begin{array}{r}S(E 2) \\
\odot .0400\end{array}$ & & $\begin{array}{l}\text { KE VAR } \\
0.2060\end{array}$ & & \\
\hline
\end{tabular}

\begin{tabular}{|c|c|c|c|c|c|c|}
\hline & $\begin{array}{r}C 0 \mathrm{~N} \mathrm{~S} \\
83-142\end{array}$ & $\begin{array}{l}S T A \\
31-3\end{array}$ & ${ }_{39} \mathrm{ES}$ & $\begin{array}{l}\text { A R S } \\
5-15\end{array}$ & $\begin{array}{c}\text { RES-ICONS } \\
1-4\end{array}$ & \\
\hline HO_t & rgate_t & Dturb_t & Trate_t & rpe_t & Tpe_t & \\
\hline $1 . \overline{0} \odot \odot \odot$ & 0.0000 & $0.500 \overline{0}$ & $1000 . \overline{0} 0$ & 0.0500 & $1 . \overline{0} 000$ & \\
\hline $\begin{array}{l}\text { Kigov_t } \\
\odot .200 \odot\end{array}$ & $\begin{array}{r}\text { Kpgov_t } \\
3.00 \odot \odot\end{array}$ & $\begin{array}{l}\text { Kdgov_t } \\
\odot . \odot \odot \odot \odot\end{array}$ & $\begin{array}{r}\text { Tdgov_t } \\
0.100 \odot\end{array}$ & & & \\
\hline $\mathrm{kp} \_t$ & Tp_t & qnl_t & At_t & & & \\
\hline 1.0000 & 0.5000 & 0.0800 & 1.2000 & & & \\
\hline Gmax1_t & Gmin1_t & Gmax2_t & Gmin2_t & & & \\
\hline $1.000 \odot$ & $\odot . \odot \odot \odot \odot$ & $1.020 \odot$ & $\odot . ๑ \odot \odot \odot$ & & & \\
\hline Vop_t & Vol_t & DB_spd1_t & DB_spd2_t & & & \\
\hline 2.0000 & -2.0000 & -0.0010 & 0.0010 & & & \\
\hline Gate1_t & Pg1_t & Gate2_t & Pg2_t & Gate3_t & Pg3_t & \\
\hline$\odot .0 \odot \odot \odot$ & $\odot . \odot \odot \odot \odot$ & $\odot .4000$ & 0.4000 & $\odot .600 \odot$ & 0.6000 & \\
\hline Gate4_t & Pg4_t & Gate5_t & Pg5_t & & & \\
\hline $0.800 \overline{0}$ & $0 . \overline{8} 000$ & $1.000 \overline{0}$ & $1 . \overline{0} 000$ & & & \\
\hline Dturb_p & Trate_p & Kp_p & Tp_p & qnl_p & At_p & \\
\hline 0.5000 & 15.0000 & 10.0000 & 0.1000 & 0.0800 & 1.2000 & \\
\hline Gmax1_p & GMin1_p & Vop_p & Vol_p & AQ_p & BO_p & co_p \\
\hline 1.0000 & 0.0000 & 2.0000 & -2.0000 & 1.1740 & -0.6660 & -0.3540 \\
\hline
\end{tabular}

Model IEEEX1 Bus 19 [HYDRO-LV-NEW24.000] Machine "1 " :

Model PSHTNY Bus 19 [HYDRO-LV-NEW24.000] Machine "1 " : 


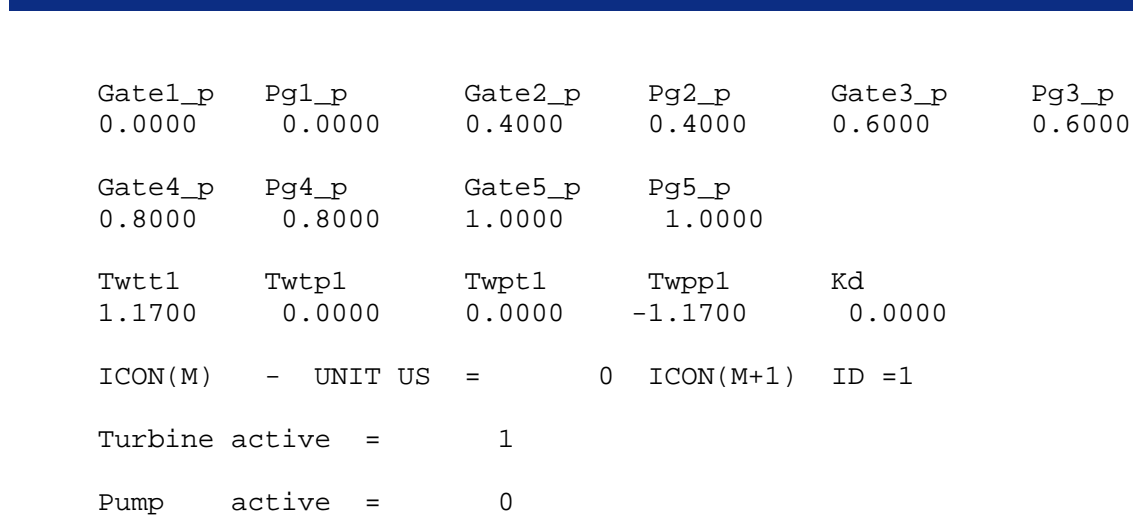




\section{B.6 Dynamic Data for the System with the Ternary Pump}

1 PTI INTERACTIVE POWER SYSTEM SIMULATOR--PSS(R)E FRI， JAN 112013 9:26 THREE MACHINES ISLAND SYSTEM

PLANT MODELS

REPORT FOR ALL MODELS AT ALL BUSES

BUS 15 [PS HYDRO

$\odot .5750]$ MODELS

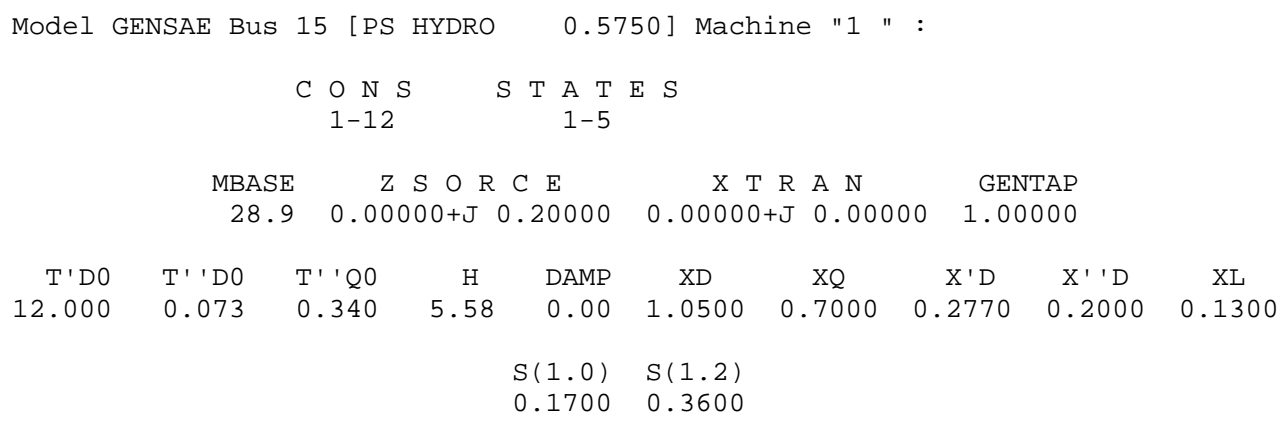

1 PTI INTERACTIVE POWER SYSTEM SIMULATOR--PSS(R)E FRI, JAN 112013 9:26 THREE MACHINES ISLAND SYSTEM

PLANT MODELS

REPORT FOR ALL MODELS AT ALL BUSES

BUS 19 [HYDRO-LV-NEW24.000] MODELS

Model GENSAE Bus 19 [HYDRO-LV-NEW24.000] Machine "1 " :

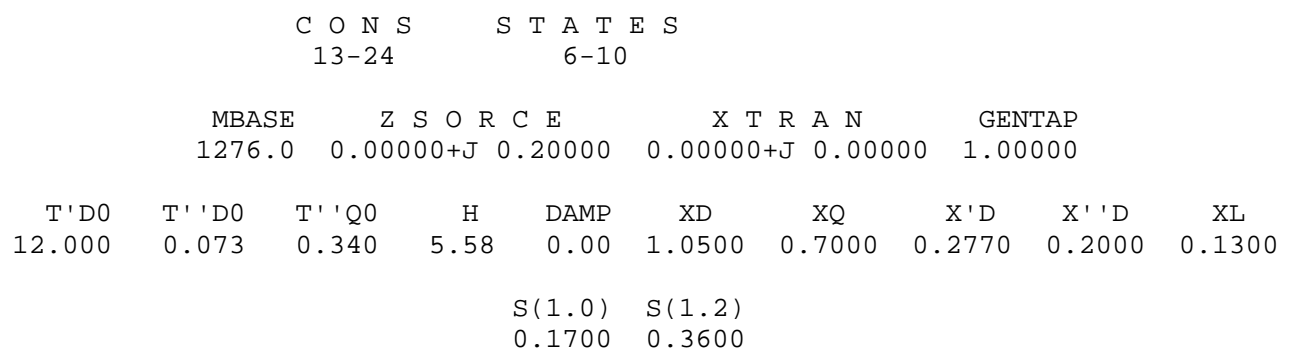


Model IEEEX1 Bus 19 [HYDRO-LV-NEW24.000] Machine "1 " :

\begin{tabular}{ccccccccccr}
\multicolumn{1}{c}{ C O N S } & S T A T E S & V A R & & & & \\
TR & KA & TA & TB & TC & TRMAX & VRMIN & KE & TE & KF & TF1 \\
0.050 & 50.00 & 0.060 & 1.00 & 1.500 & 1.000 & -0.40 & 0.206 & 1.630 & 0.020 & 1.200 \\
& & & & & & & & & & \\
& SWITCH & & E1 & S(E1) & E2 & S(E2) & & KE VAR & & \\
& 0.0 & 2.5000 & 0.0200 & 3.6000 & 0.0400 & & 0.0000 & &
\end{tabular}

Model PSHTNY Bus 19 [HYDRO-LV-NEW24.000] Machine "1 " :

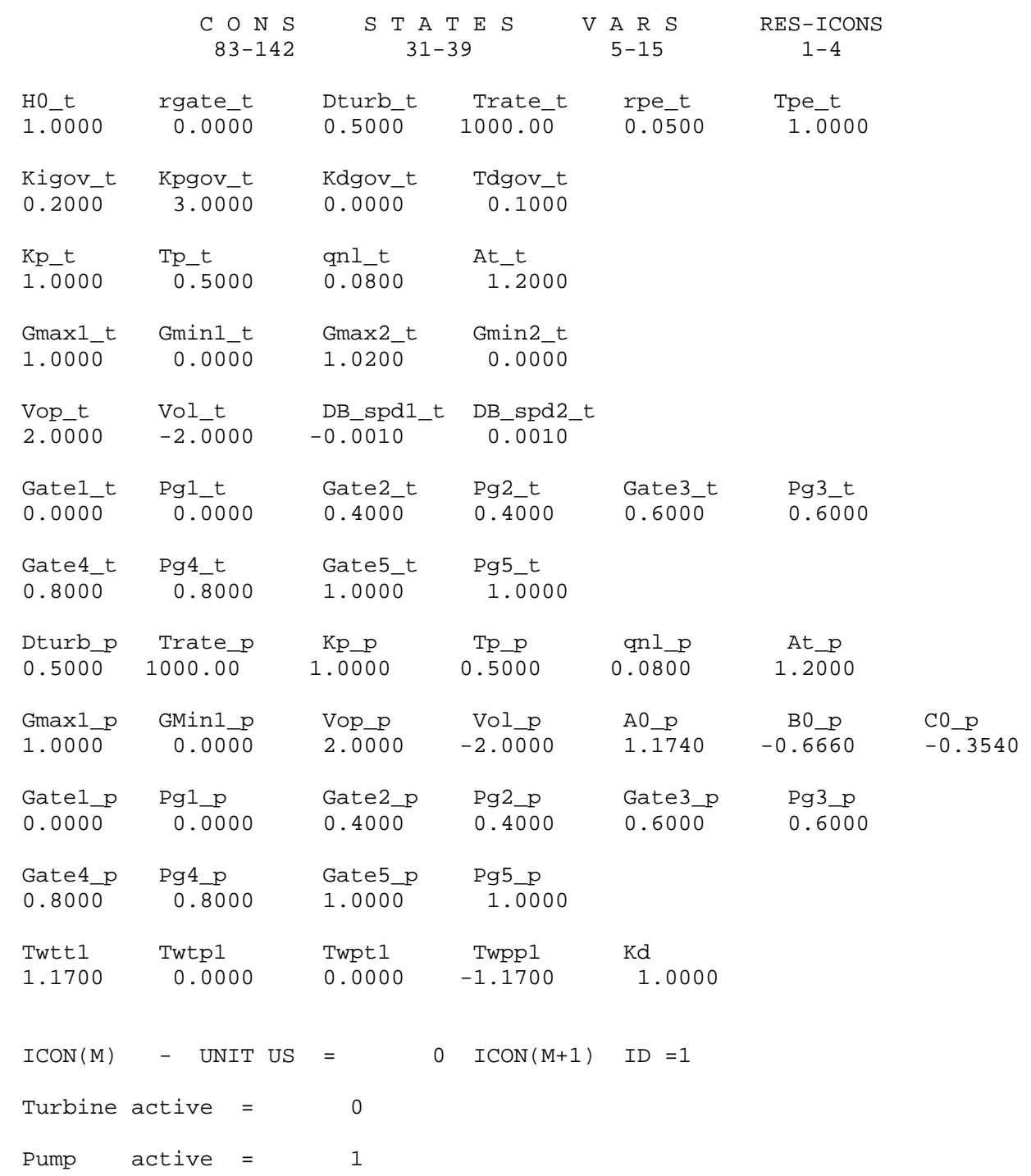




\section{B.7 Dynamic Data for the System with the Ternary Unit Operating in the Hydraulic Short-Circuit Mode}

1 PTI INTERACTIVE POWER SYSTEM SIMULATOR--PSS(R)E FRI, JAN 112013 9:33 THREE MACHINES ISLAND SYSTEM

PLANT MODELS

REPORT FOR ALL MODELS AT ALL BUSES

BUS 19 [HYDRO-LV-NEW24.000] MODELS

Model GENSAE Bus 19 [HYDRO-LV-NEW24.000] Machine "1 " :

$$
\begin{aligned}
& \text { C O N S S T A T E S } \\
& \text { 13-24 } 6-10 \\
& \text { MBASE Z S O R C E R A N GENTAP } \\
& \begin{array}{llllllll}
1276.0 & 0.00000+\mathrm{J} & 0.20000 & 0.00000+\mathrm{J} & 0.00000 & 1.00000
\end{array}
\end{aligned}
$$

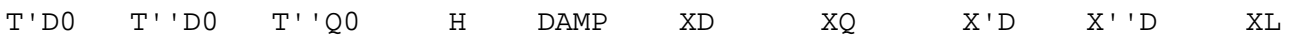

\begin{tabular}{|c|c|c|c|c|c|c|c|c|c|c|}
\hline \multirow{3}{*}{$\begin{array}{c}\text { TR } \\
\odot .05 \odot\end{array}$} & \multicolumn{3}{|c|}{$\begin{array}{c}\text { C } 0 \mathrm{~N} \mathrm{~S} \\
55-70\end{array}$} & \multicolumn{2}{|c|}{$\begin{array}{c}S T A T E S \\
22-26\end{array}$} & \multicolumn{2}{|l|}{$\begin{array}{rl}V & A \quad R \\
& 2\end{array}$} & \multirow[b]{2}{*}{ TE } & \multirow[b]{2}{*}{$\mathrm{KF}$} & \multirow{3}{*}{$\begin{array}{r}\text { TF1 } \\
1.200\end{array}$} \\
\hline & KA & TA & TB & TC & VRMAX & VRMIN & KE & & & \\
\hline & 50.00 & 0.060 & 1.00 & 1.500 & 1.000 & & & 1.630 & & \\
\hline & $\begin{array}{r}\text { SWITCH } \\
0.0\end{array}$ & & $\begin{array}{c}\mathrm{E1} \\
2.5000\end{array}$ & $\begin{array}{r}S(E 1) \\
\odot .0200\end{array}$ & $\begin{array}{c}E 2 \\
3.6000\end{array}$ & $\begin{array}{r}S(E 2) \\
0.0400\end{array}$ & & $\begin{array}{l}\text { KE VAR } \\
\odot .00 \odot \odot\end{array}$ & & \\
\hline
\end{tabular}

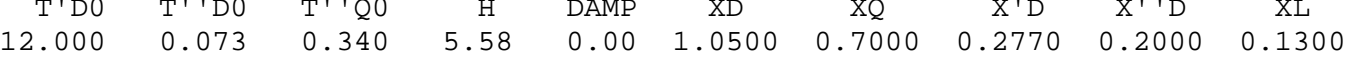

$$
\begin{aligned}
& S(1.0) \quad S(1.2) \\
& 0.1700 \quad 0.3600
\end{aligned}
$$

\begin{tabular}{|c|c|c|c|c|c|}
\hline & $\begin{array}{r}C 0 \mathrm{~N} \mathrm{~S} \\
83-142\end{array}$ & $\begin{array}{l}S \mathrm{~T} A \\
31-\end{array}$ & $9_{9}^{E S}$ & $\begin{array}{l}\text { A R S } \\
5-15\end{array}$ & $\begin{array}{c}\text { RES - ICONS } \\
1-4\end{array}$ \\
\hline $\begin{array}{l}\mathrm{H} \Theta_{-} \mathrm{t} \\
1.0 \odot \odot \odot\end{array}$ & $\begin{array}{r}\text { rgate_t } \\
0.000 \odot\end{array}$ & $\begin{array}{l}\text { Dturb_t } \\
\odot .5000\end{array}$ & $\begin{array}{l}\text { Trate_t } \\
1000.0 \odot\end{array}$ & $\begin{array}{l}\text { rpe_t } \\
0.0500\end{array}$ & $\begin{array}{l}\text { Tpe_t } \\
1.0000\end{array}$ \\
\hline $\begin{array}{l}\text { Kigov_t } \\
\odot .2000\end{array}$ & $\begin{array}{r}\text { Kpgov_t } \\
3.000 \odot\end{array}$ & $\begin{array}{l}\text { Kdgov_t } \\
\odot .0 \odot \odot \odot\end{array}$ & $\begin{array}{r}\text { Tdgov_t } \\
0.1000\end{array}$ & & \\
\hline $\begin{array}{l}\mathrm{Kp} \_\mathrm{t} \\
1.0000\end{array}$ & $\begin{array}{l}\text { Tp_t } \\
0.5000\end{array}$ & $\begin{array}{l}\text { qnl_t } \\
\odot .0800\end{array}$ & $\begin{array}{l}\text { At_t } \\
1.2000\end{array}$ & & \\
\hline $\begin{array}{l}\text { Gmax1_t } \\
1.0000\end{array}$ & $\begin{array}{r}\text { Gmin1_t } \\
\odot .0 \odot \odot \odot\end{array}$ & $\begin{array}{l}\mathrm{Gmax} 2{ }^{-} \mathrm{t} \\
1.0200\end{array}$ & $\begin{array}{r}\text { Gmin2_t } \\
\odot .00 \odot \odot\end{array}$ & & \\
\hline $\begin{array}{l}\text { Vop_t } \\
2.00 \odot \odot\end{array}$ & $\begin{array}{l}\text { Vol_t } \\
-2.000 \odot\end{array}$ & $\begin{array}{l}\text { DB_spd1_t } \\
-\odot .0010\end{array}$ & $\begin{array}{c}\text { DB_spd2_t } \\
0.0010\end{array}$ & & \\
\hline $\begin{array}{l}\text { Gate1_t } \\
\odot .00 \odot \odot\end{array}$ & $\begin{array}{l}\mathrm{Pg} 1 \_t \\
0.000 \odot\end{array}$ & $\begin{array}{l}\text { Gate2_t } \\
0.400 \odot\end{array}$ & $\begin{array}{l}\mathrm{Pg} 2 \_\mathrm{t} \\
\odot .4 \odot \odot \odot\end{array}$ & $\begin{array}{l}\text { Gate3_t } \\
0.6000\end{array}$ & $\begin{array}{l}\text { Pg3_t } \\
0.6000\end{array}$ \\
\hline $\begin{array}{l}\text { Gate4_t } \\
0.8000\end{array}$ & $\begin{array}{l}\mathrm{Pg} 4 \_\mathrm{t} \\
0.8000\end{array}$ & $\begin{array}{l}\text { Gate5_t } \\
1.0000\end{array}$ & $\begin{array}{l}\text { Pg5_t } \\
1.000 \odot\end{array}$ & & \\
\hline
\end{tabular}

Model IEEEX1 Bus 19 [HYDRO-LV-NEW24.000] Machine "1 " :

Model PSHTNY Bus 19 [HYDRO-LV-NEW24.000] Machine "1 " : 


\begin{tabular}{|c|c|c|c|c|c|c|c|}
\hline $\begin{array}{l}\text { Dturb_p } \\
0.5000\end{array}$ & $\begin{array}{l}\text { Trate_p } \\
1000.00\end{array}$ & $\begin{array}{l}\text { Kp_p } \\
1.00 \odot \odot\end{array}$ & & $\begin{array}{l}\text { Tp_p } \\
\odot .5000\end{array}$ & $\begin{array}{l}\text { qnl_p } \\
0.0800\end{array}$ & $\begin{array}{l}\text { At_p } \\
1.2000\end{array}$ & \\
\hline $\begin{array}{l}\text { Gmax1_p } \\
1.000 \odot\end{array}$ & $\begin{array}{r}\text { GMin1_p } \\
\odot . \odot \odot \odot \odot\end{array}$ & $\begin{array}{l}\text { Vop_p } \\
2 . \odot \odot \odot \odot\end{array}$ & & $\begin{array}{l}\text { Vol_p } \\
-2 . \odot \odot \odot \odot\end{array}$ & $\begin{array}{l}\text { A0_p } \\
1.1740\end{array}$ & $\begin{array}{c}\text { BO_p } \\
-0.6660\end{array}$ & $\begin{array}{l}\text { CO_p } \\
-0.3540\end{array}$ \\
\hline $\begin{array}{l}\text { Gate1_p } \\
\odot .0 \odot \odot \odot\end{array}$ & $\begin{array}{l}\mathrm{Pg}{ }_{1} \_\mathrm{p} \\
\odot .0 \odot \odot \odot\end{array}$ & $\begin{array}{l}\text { Gate2_p } \\
\odot .400 \odot\end{array}$ & & $\begin{array}{l}\text { Pg2_p } \\
\odot .40 \odot \odot\end{array}$ & $\begin{array}{l}\text { Gate3_p } \\
\odot .6000\end{array}$ & $\begin{array}{l}\text { Pg3_p } \\
\odot .600 \odot\end{array}$ & \\
\hline $\begin{array}{l}\text { Gate4_p } \\
\odot .800 \odot\end{array}$ & $\begin{array}{l}\text { Pg4_p } \\
0.8000\end{array}$ & $\begin{array}{l}\text { Gate5_p } \\
1.0000\end{array}$ & & $\begin{array}{l}\mathrm{Pg} 5 \_\mathrm{p} \\
1.0000\end{array}$ & & & \\
\hline $\begin{array}{l}\text { Twt t1 } \\
1.1700\end{array}$ & $\begin{array}{l}\text { Twtp1 } \\
\odot . \odot \odot \odot \odot\end{array}$ & $\begin{array}{l}\text { Twpt1 } \\
\odot .0 \odot \odot \odot\end{array}$ & & $\begin{array}{l}\text { Twpp1 } \\
-1.1700\end{array}$ & $\begin{array}{l}\mathrm{Kd} \\
2.000 \odot\end{array}$ & & \\
\hline $\operatorname{ICON}(M)$ & - UNIT US & $=$ & 0 & $\operatorname{ICON}(M+1)$ & ID $=1$ & & \\
\hline Turbine & active & 1 & & & & & \\
\hline Pump & active $=$ & 1 & & & & & \\
\hline
\end{tabular}




\section{B.9 Dynamic Data for Helms PSH Plant in WECC for Conventional Units}

PLANT MODELS

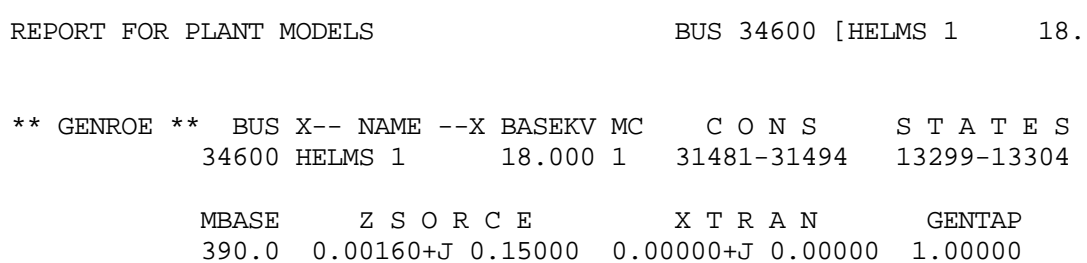

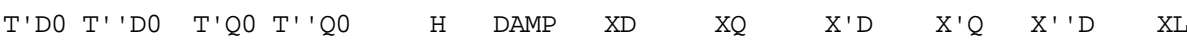

$\begin{array}{llllllllllll}9.00 & 0.060 & 0.75 & 0.121 & 5.17 & 0.00 & 1.1200 & 0.6530 & 0.2400 & 0.4000 & 0.1500 & 0.0990\end{array}$

$S(1.0) \quad S(1.2)$

$\odot .1186 \quad 0.4297$

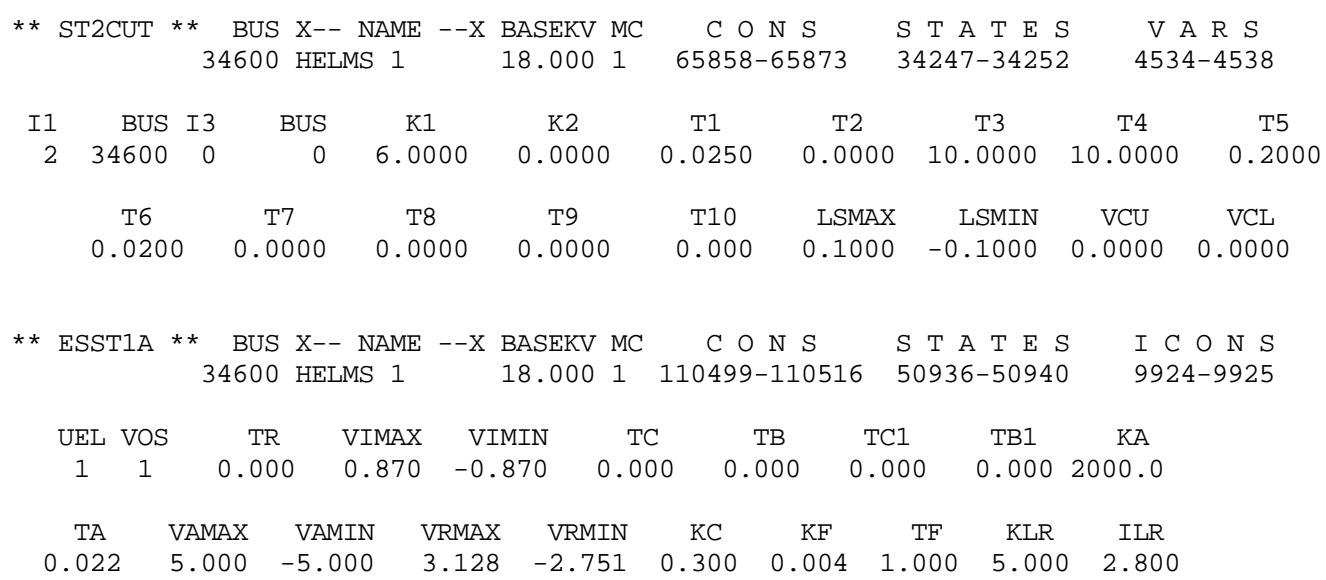

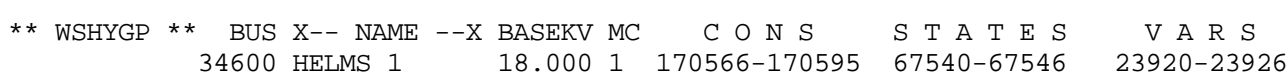

\begin{tabular}{|c|c|c|c|c|c|c|c|}
\hline $\begin{array}{c}\text { DB1 } \\
\odot . \odot \odot \odot\end{array}$ & $\begin{array}{c}\text { ERR } \\
\odot . \odot \odot \odot\end{array}$ & $\begin{array}{c}\text { TD } \\
\odot .05 \odot\end{array}$ & $\begin{array}{c}\mathrm{KI} \\
1.500\end{array}$ & $\begin{array}{c}\text { TF } \\
\odot .10 \odot\end{array}$ & $\begin{array}{c}K D \\
\odot .010\end{array}$ & $\begin{array}{l}\text { KP } \\
5.000\end{array}$ & $\begin{array}{c}R \\
\odot .0652\end{array}$ \\
\hline TT & KG & TP & VELOPE & VELCLO & PMAX & PMIN & DB2 \\
\hline 0.200 & 1.000 & 0.050 & 0.200 & 0.200 & 1.000 & $\odot .000$ & $\odot .00 \odot \odot$ \\
\hline GV1 & PGV1 & GV2 & PGV2 & GV3 & PGV3 & GV4 & PGV4 \\
\hline$\odot .000$ & 0.000 & 1.000 & 1.000 & $\odot .000$ & 0.000 & $\odot . \odot \odot \odot$ & 0.000 \\
\hline $\begin{array}{r}\text { GV5 } \\
\odot .0 \odot \odot\end{array}$ & $\begin{array}{r}\text { PGV5 } \\
\odot .0 \odot \odot\end{array}$ & $\begin{array}{l}\text { ATURB } \\
-1.000\end{array}$ & $\begin{array}{l}\text { BTURB } \\
\odot .50 \odot\end{array}$ & $\begin{array}{l}\text { TTURB } \\
1.673\end{array}$ & $\begin{array}{r}\text { TRATE } \\
405.000\end{array}$ & & \\
\hline
\end{tabular}




\section{B.10 Dynamic Data for Cabin Creek PSH Plant in WECC for Conventional Units}

PLANT MODELS

REPORT FOR PLANT MODELS

BUS 70069 [CABCRKA 13.800] MODELS

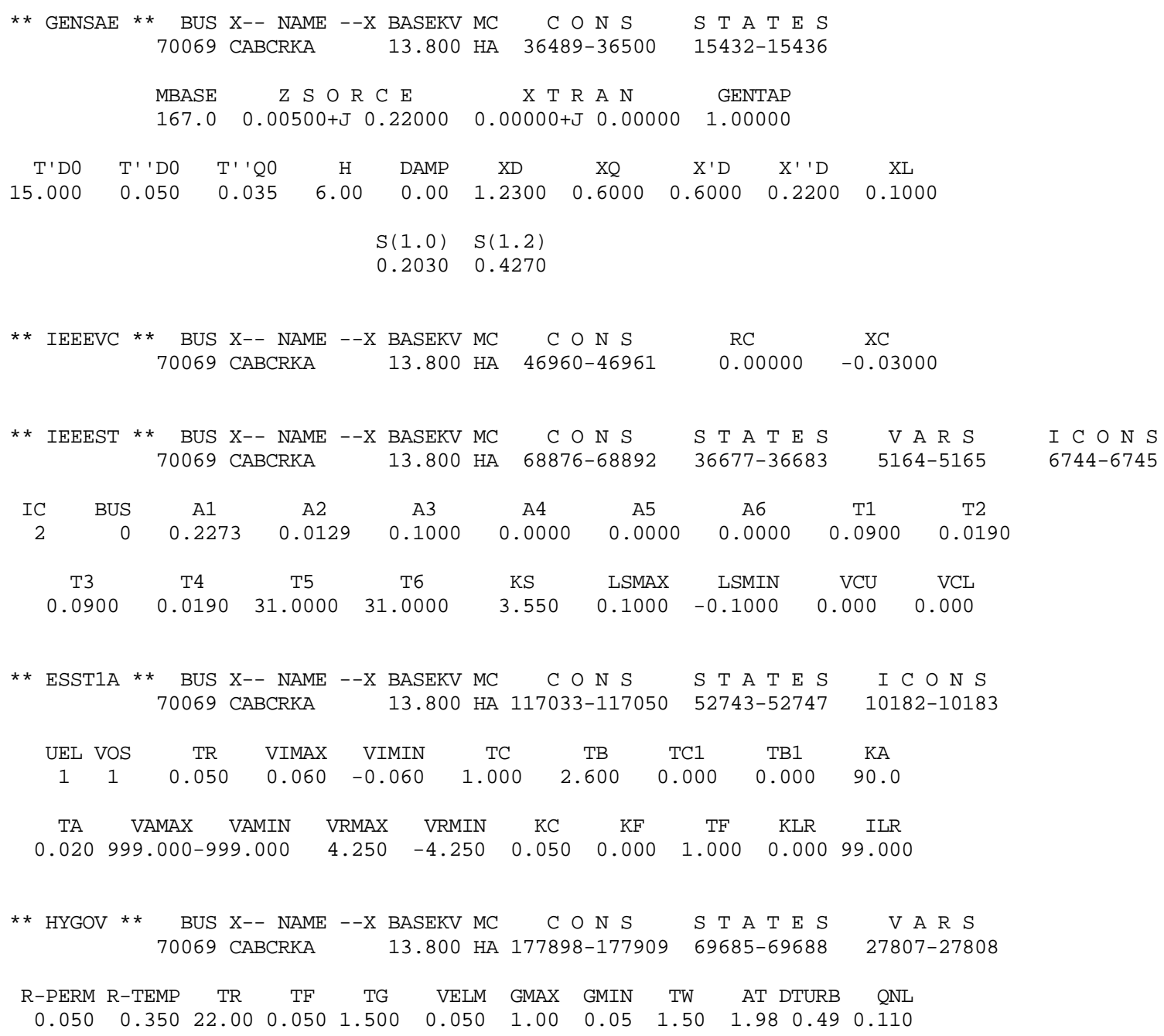




\section{B.11 Dynamic Data for San Luis PSH Plant in WECC for Conventional Units}

PLANT MODELS

REPORT FOR PLANT MODELS

BUS 38730 [SANLUIS1 13.800] MODELS

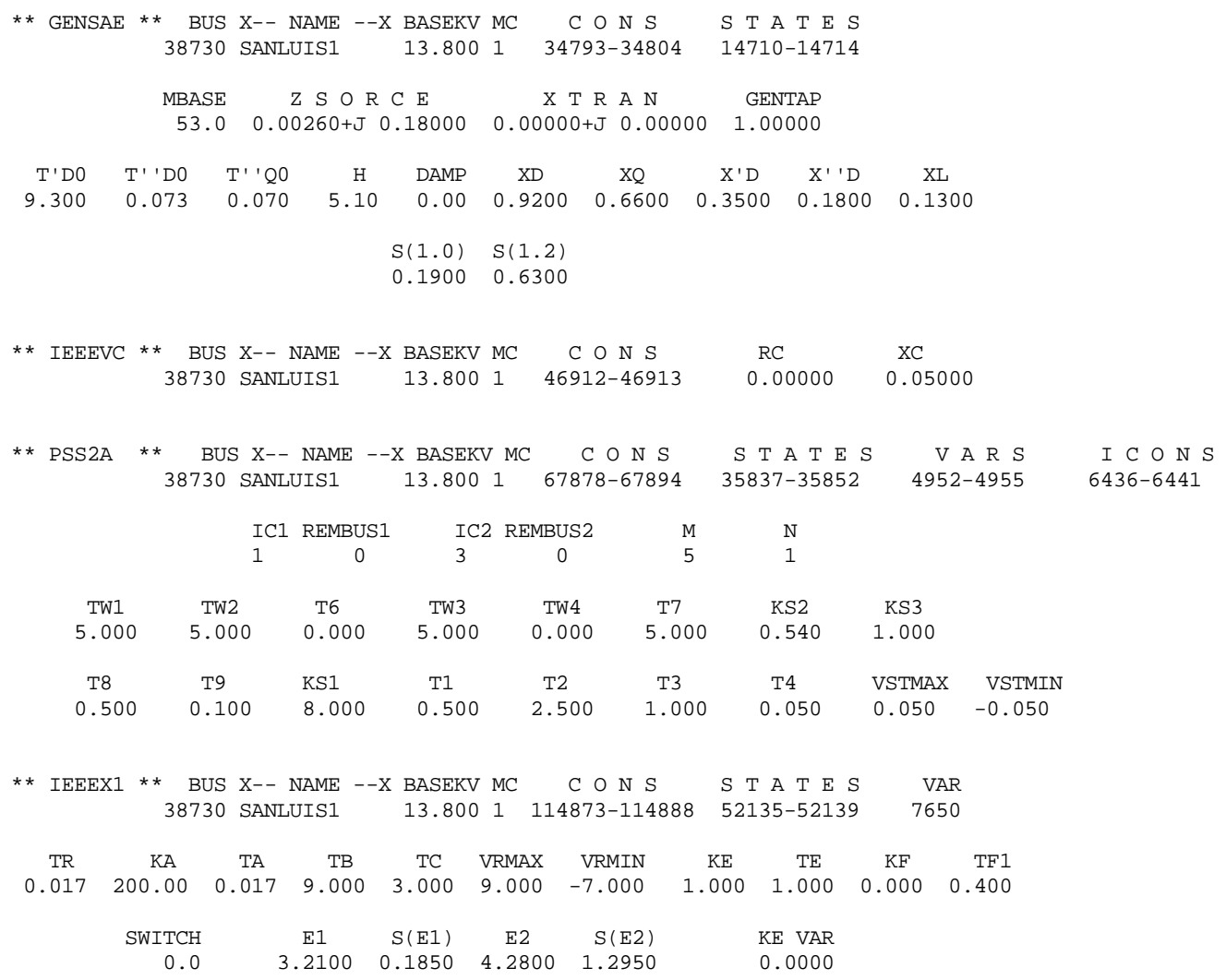




\section{B.12 Dynamic Data for E.G. Hyatt Conventional Units}

PLANT MODELS

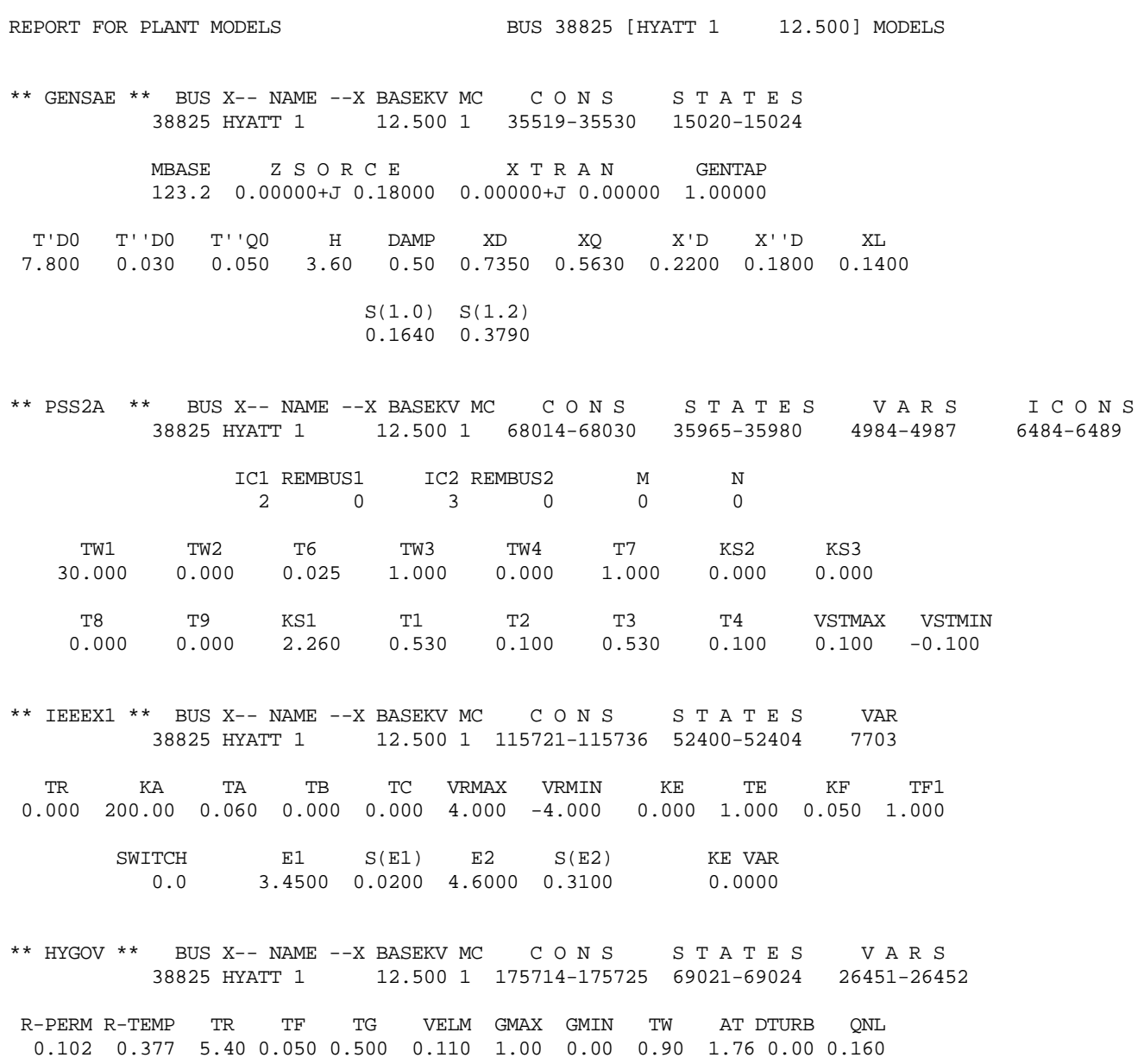




\section{B.13 Dynamic Data for Mt. Elbert Conventional Units}

PLANT MODELS

REPORT FOR PLANT MODELS

BUS 73054 [ELBERT-1

12.500] MODELS

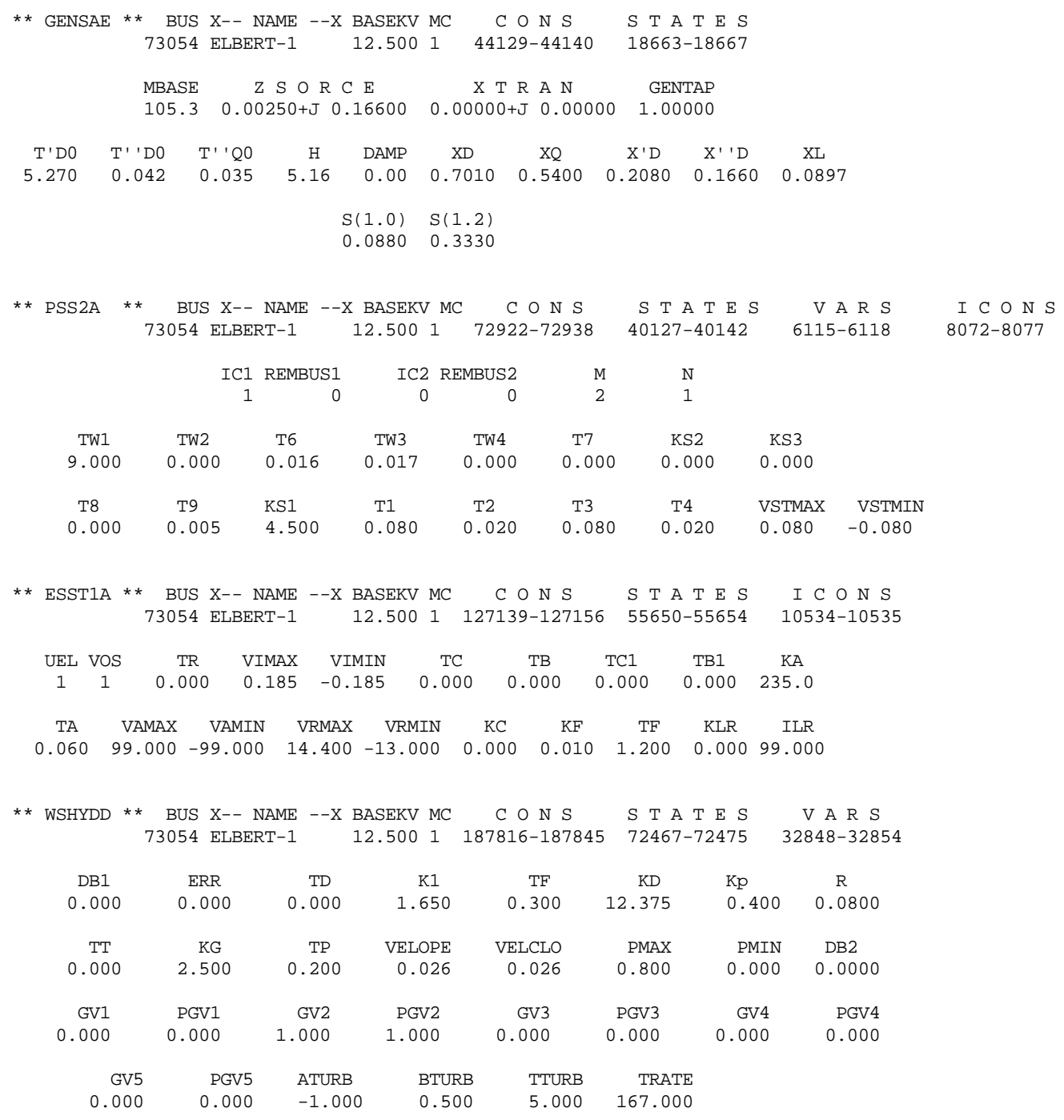




\section{B.14 Dynamic Data for Castaic AS PSH Turbine}

PLANT MODELS

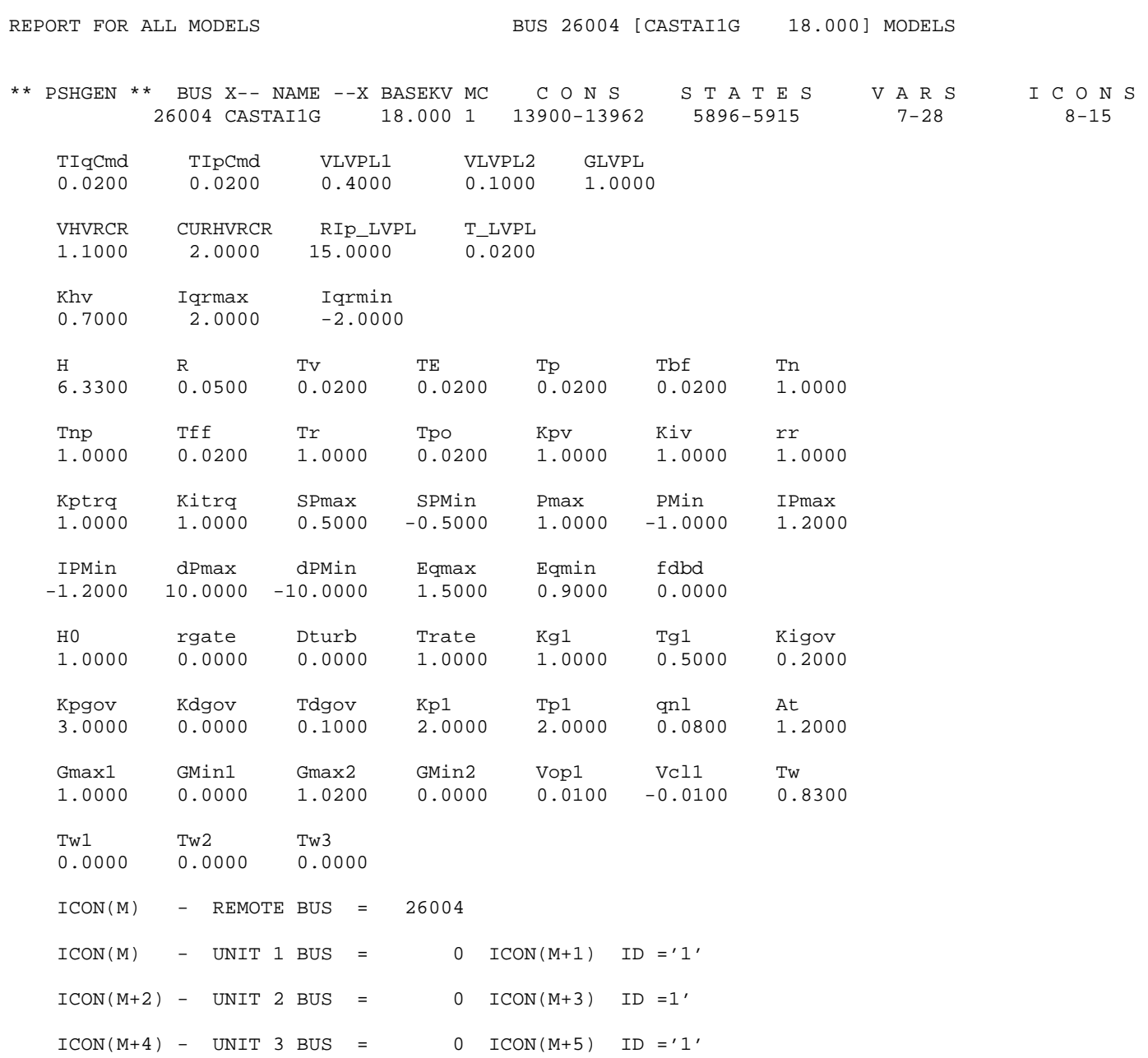




\title{
B.15 Dynamic Data for Helms AS PSH Turbine
}

\section{PLANT MODELS}

\author{
REPORT FOR ALL MODELS \\ BUS 34600 [HELMS 1 \\ 18. ๑0९] MODELS
}

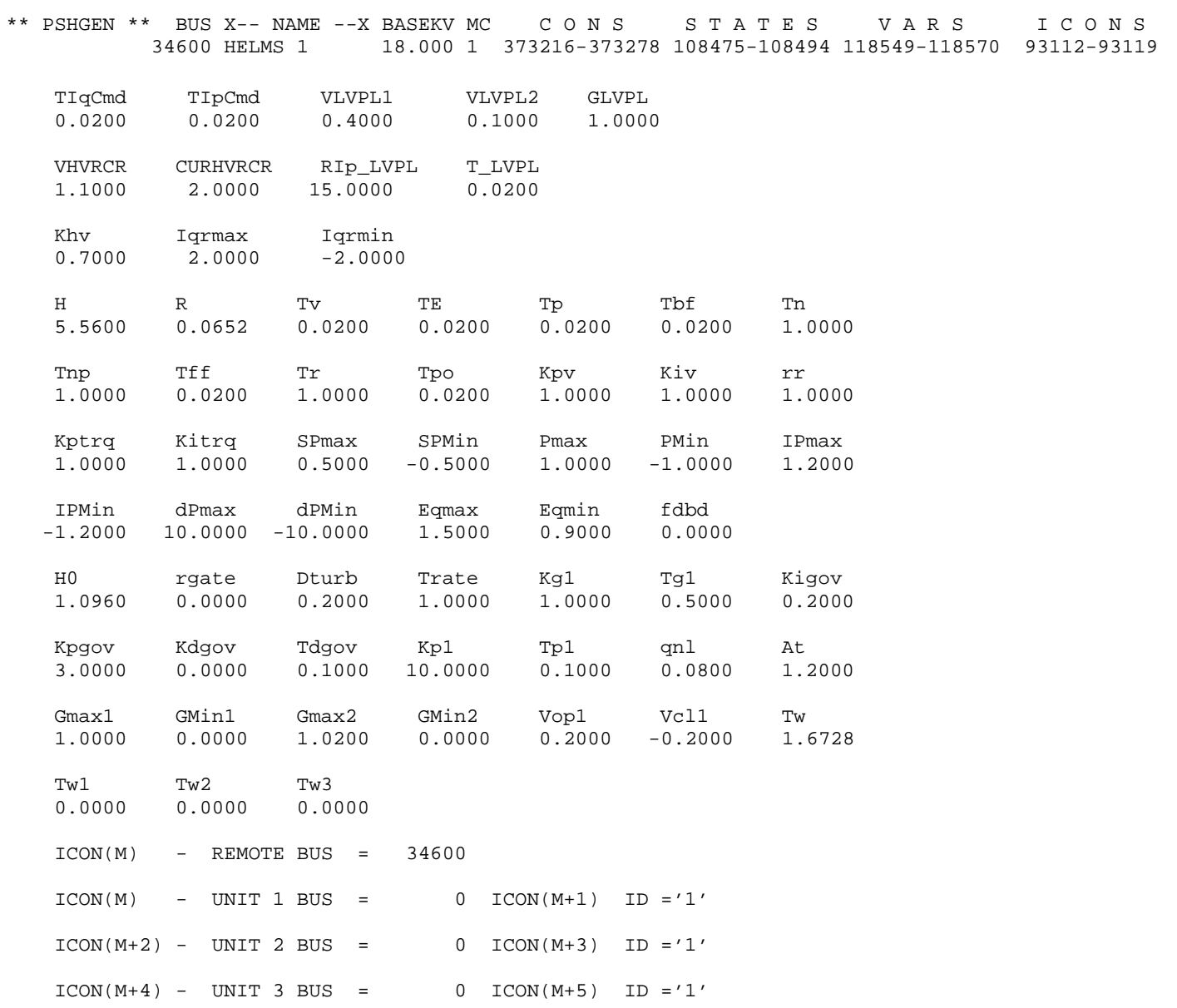




\section{B.16 Dynamic Data for Cabin Creek AS PSH Turbine}

PLANT MODELS

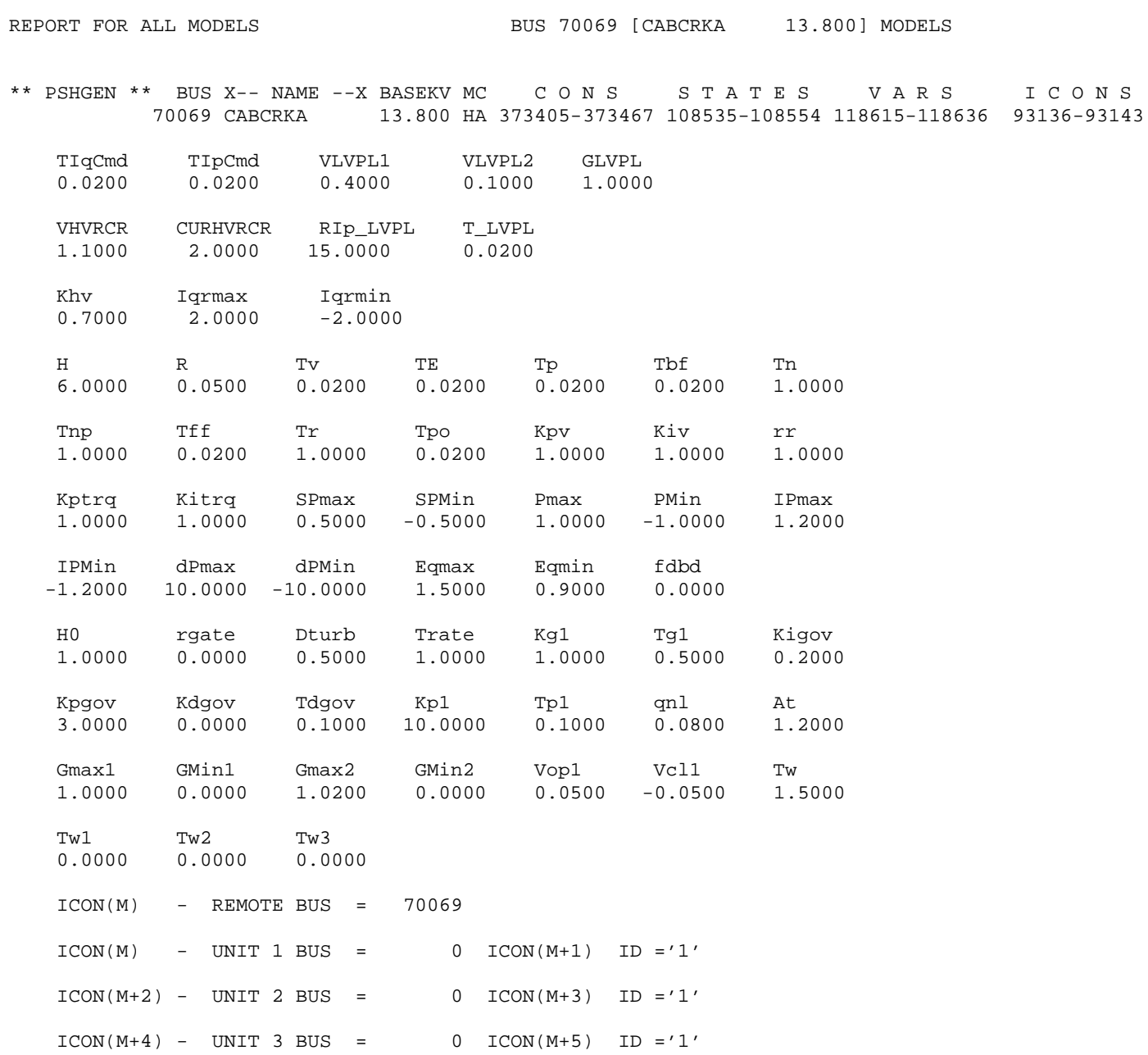




\section{B.17 Dynamic Data for San Luis AS PSH Turbine}

PLANT MODELS

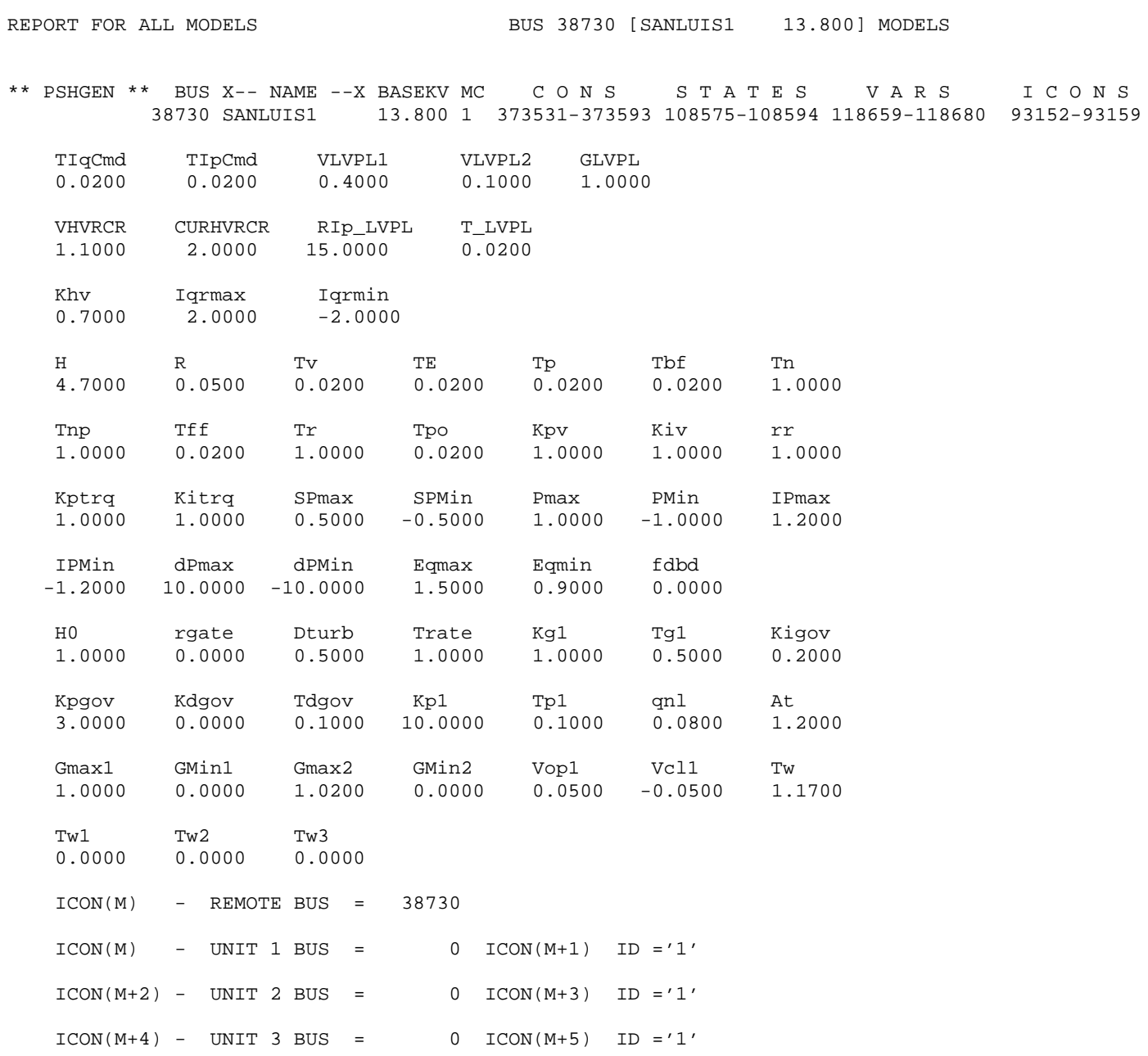




\section{B.18 Dynamic Data for Hyatt AS PSH Turbine}

PLANT MODELS

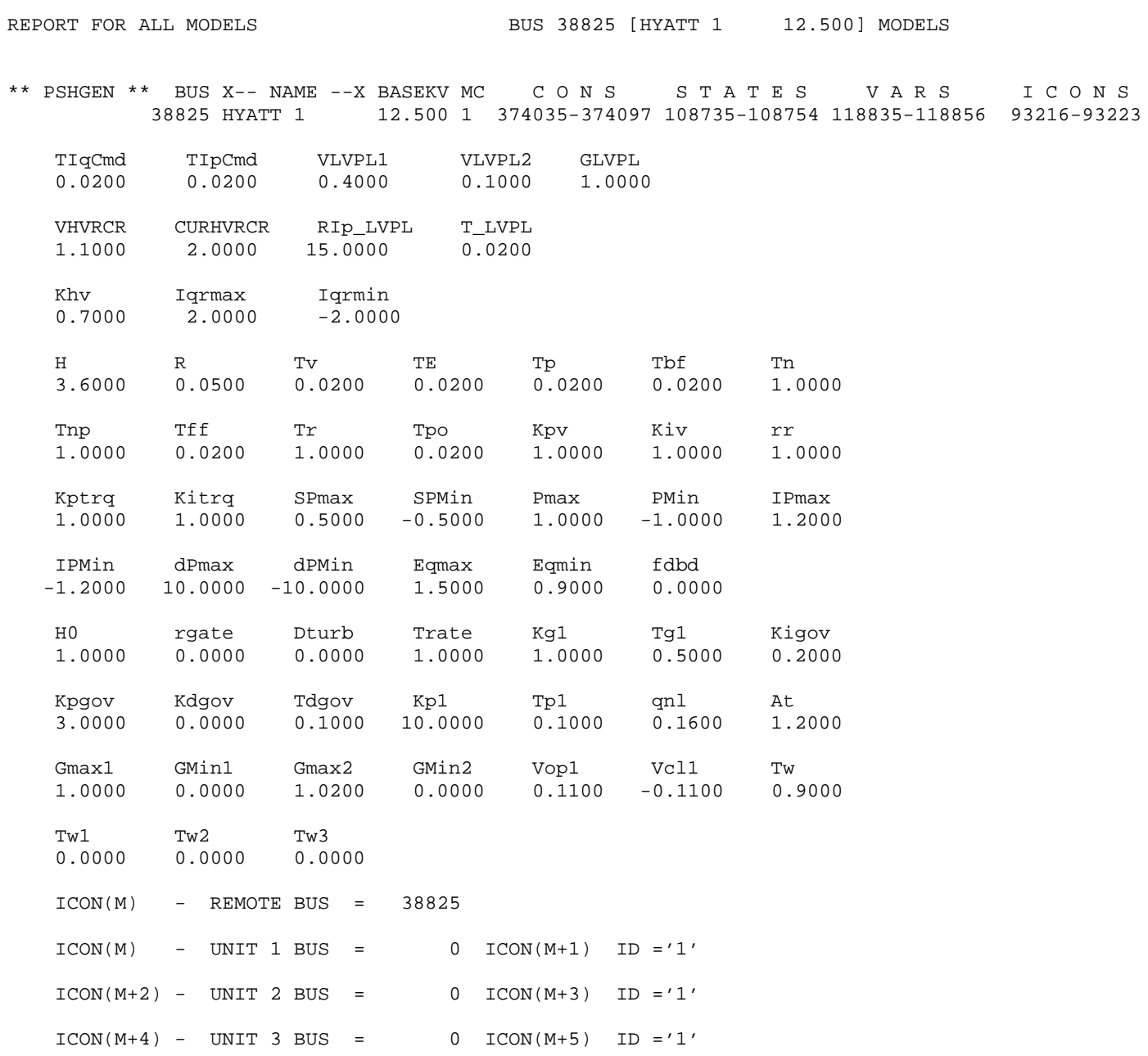




\section{B.19 Dynamic Data for Mt. Elbert AS PSH Turbine}

PLANT MODELS

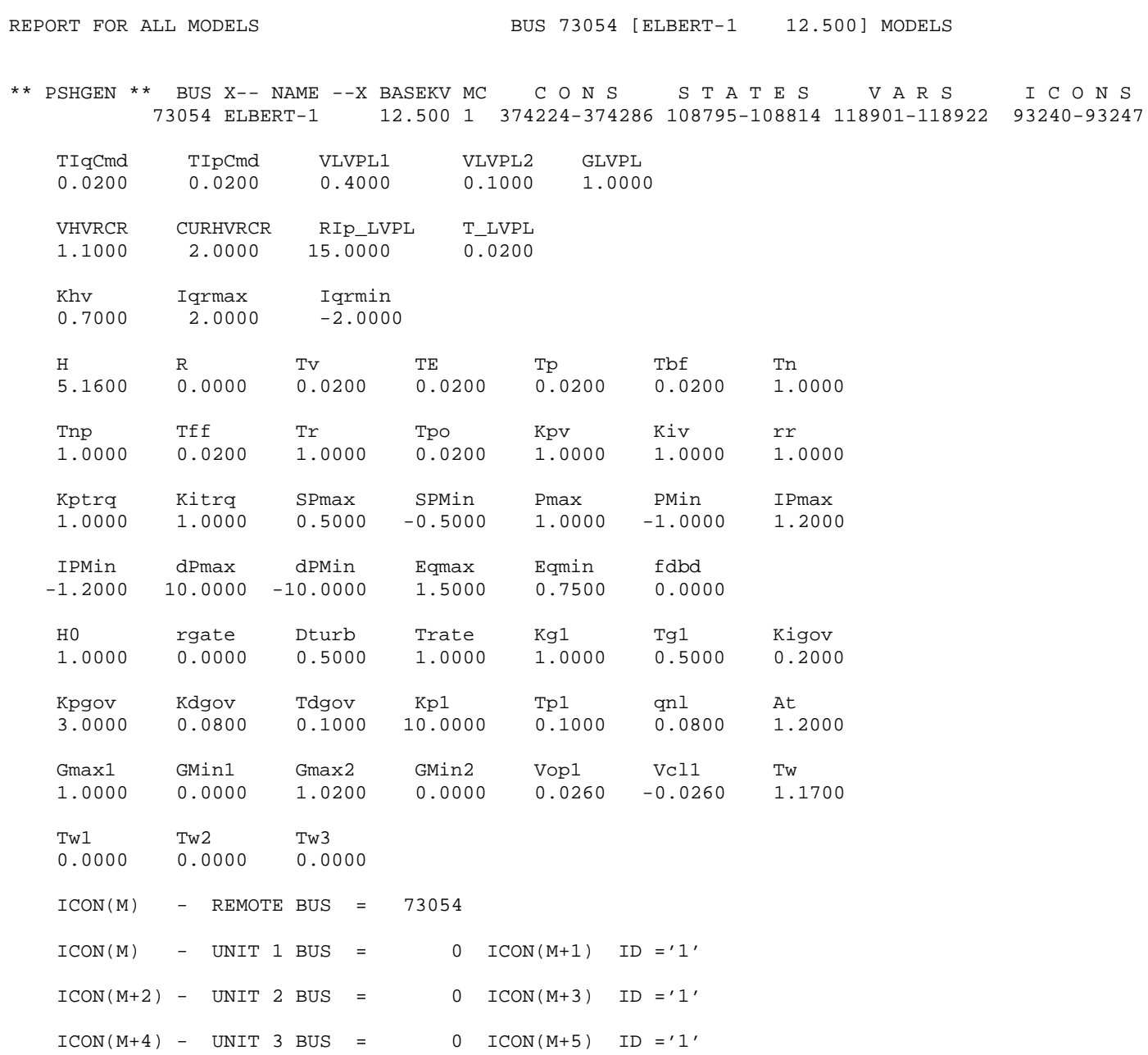




\section{Argonne}

\section{Decision and Information Sciences}

Argonne National Laboratory

9700 South Cass Avenue, Bldg. 221

Argonne, IL 60439-4844

www.anl.gov 